\title{
Vergleichende biochemische und strukturelle Untersuchung thermophiler $\alpha$-Amylasen
}

\author{
Dissertation \\ zur Erlangung des Doktorgrades \\ der Mathematisch-Naturwissenschaftlichen Fakultäten \\ der Georg-August-Universität zu Göttingen \\ vorgelegt von \\ Meike Ballschmiter \\ aus Göttingen
}

Göttingen 2005 
D 7

Referent:

Prof. Dr. W. Liebl

Korreferent:

Prof. Dr. G. Gottschalk

Tag der mündlichen Prüfung: 27. 4. 2005 


\section{Inhaltsverzeichnis}

I. EINLEITUNG.

1. Thermotoga maritima, Thermus thermophilus und Anaerobranca gottschalkii:

Bewohner heißer Standorte ................................................................1

2. Glykogenmetabolismus..................................................................................................... 5

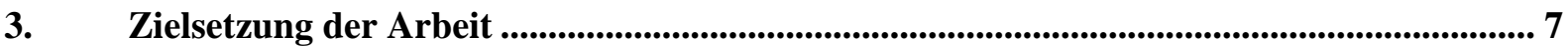

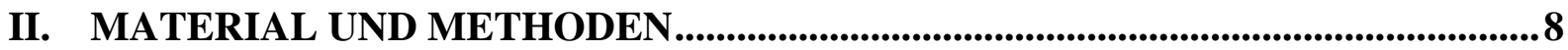

1. Organismen und Plasmide............................................................................................................ 8

2. Chemikalien und Enzyme ............................................................................................................... 10

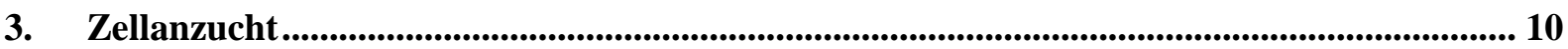

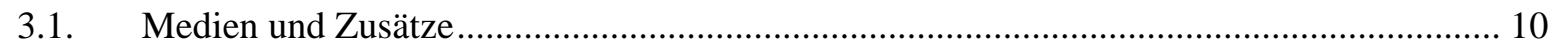

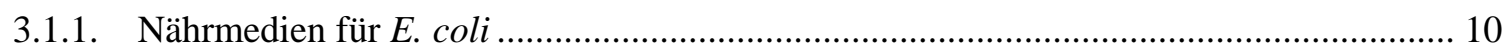

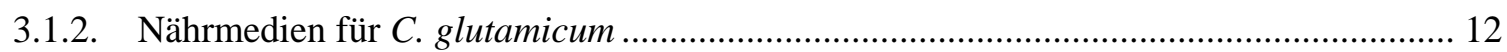

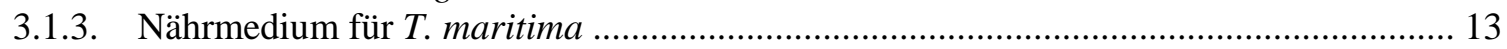

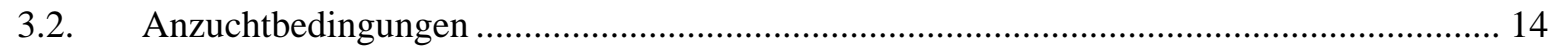

3.2.1. Anzucht von E. coli und C. glutamicum...................................................................... 14

3.2.2. Anzucht von E. coli B834 zur Inkorporation von Selenomethionin ................................ 15

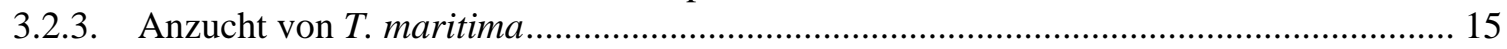

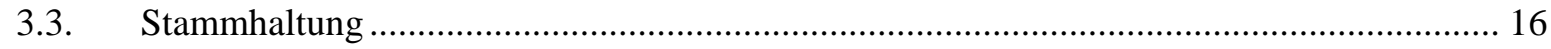

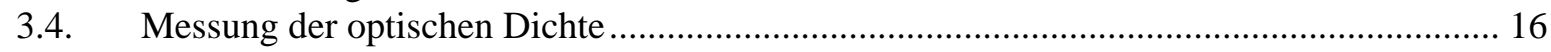

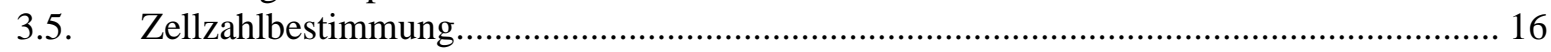

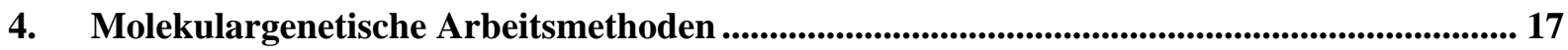

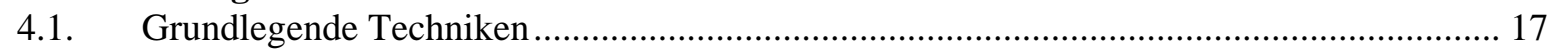

4.1.1. Behandlung von Materialien und Lösungen für das Arbeiten mit Nukleinsäuren ........... 17

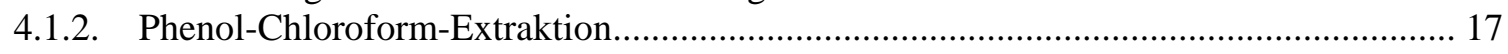

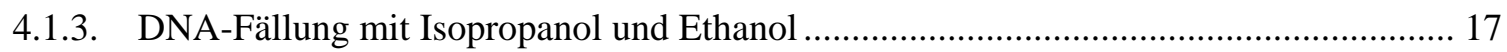

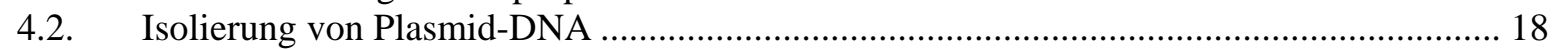

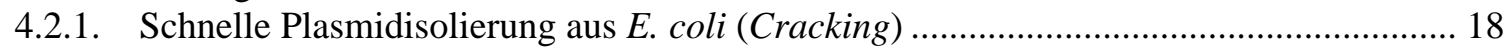

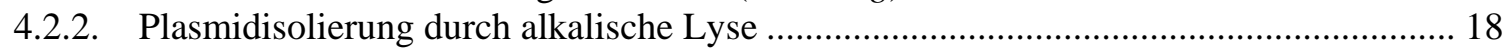

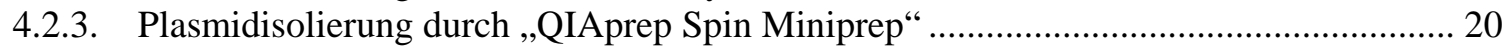

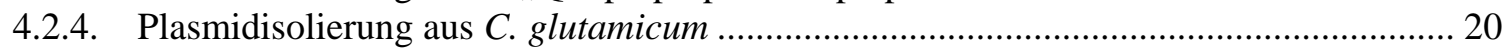

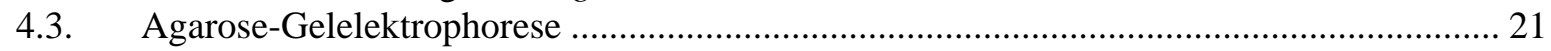

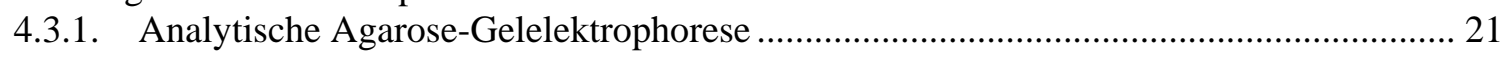

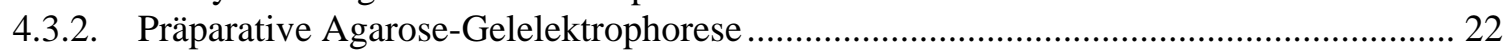

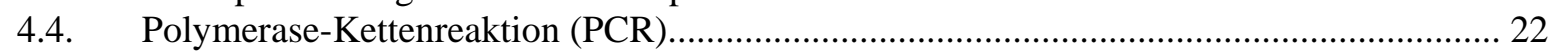

4.4.1. Amplifikation von DNA-Fragmenten mit Hilfe der PCR ........................................... 22

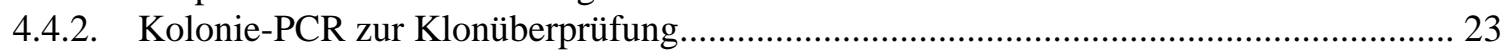

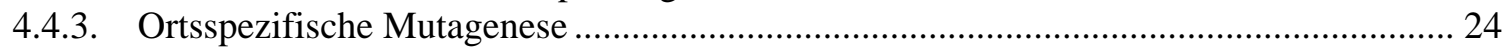

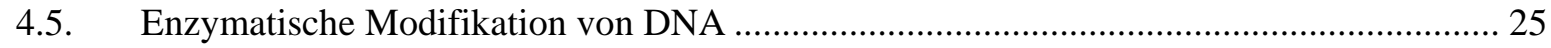

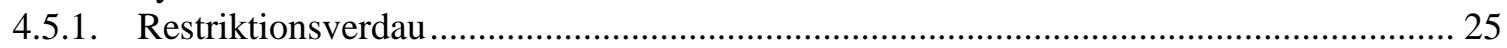

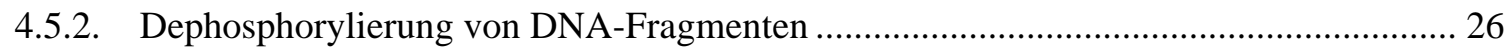

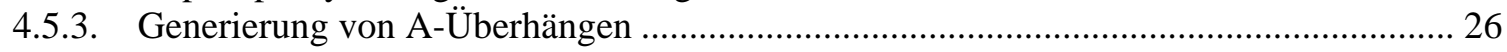

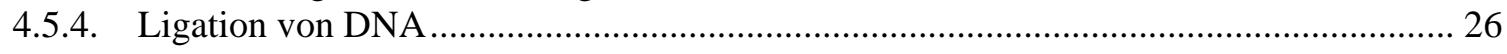




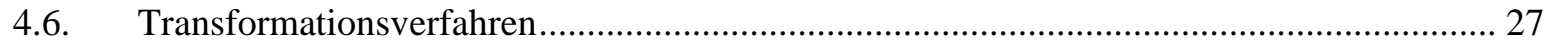

4.6.1. Herstellung kompetenter Zellen für die Transformation ................................................ 27

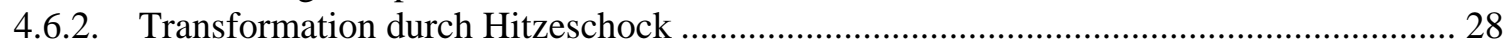

4.6.3. Herstellung kompetenter E. coli-Zellen für die Elektroporation ...................................... 28

4.6.4. Herstellung kompetenter C. glutamicum-Zellen für die Elektroporation

(nach Van der Rest et al., 1999) .................................................................................... 29

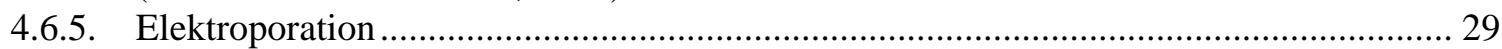

4.6.6. X-Gal Test zur Detektion rekombinater E. coli-Klone.................................................. 30

5. Proteinbiochemische Methoden ……......................................................................................... 31

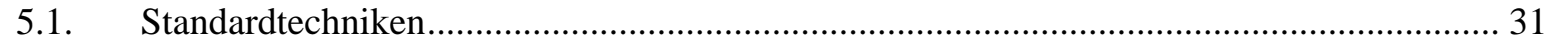

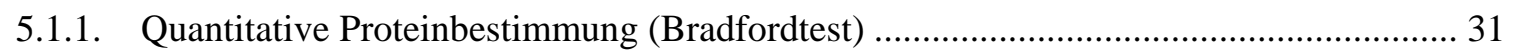

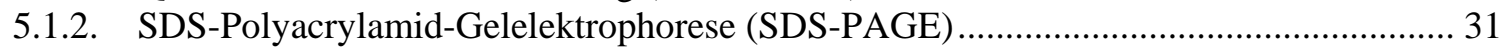

5.1.3. Nativ-Polyacrylamidgelelektrophorese (Nativ-PAGE) ..................................................... 33

5.1.4. Coomassie-Färbung von Proteinen in Polyacrylamid-Gelen ....................................... 34

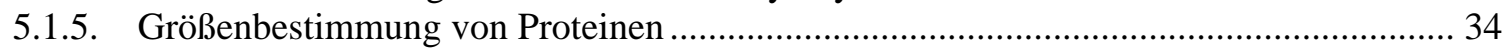

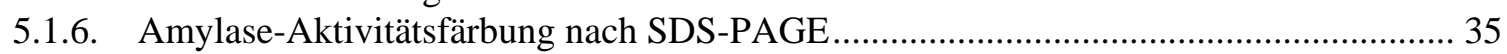

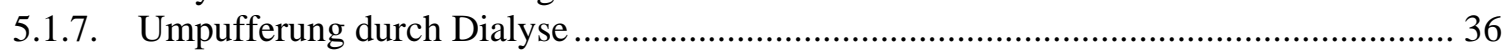

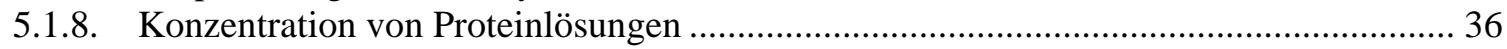

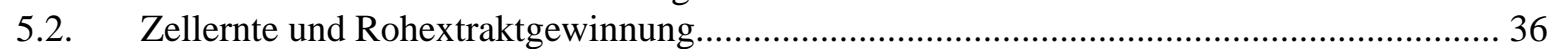

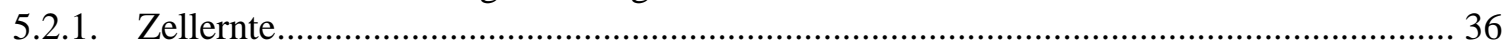

5.2.2. Zellaufschluß mit der „French Pressure Cell“................................................................... 37

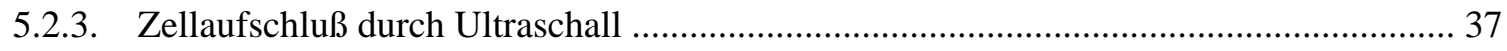

5.2.4. Abtrennung thermolabiler Proteine durch Hitzedenaturierung ....................................... 37

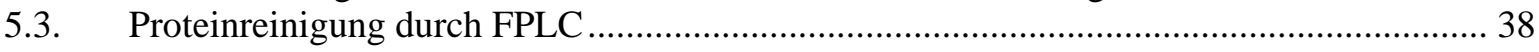

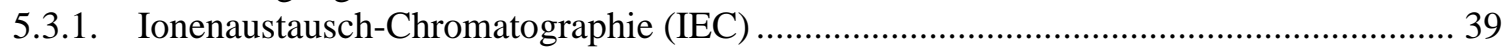

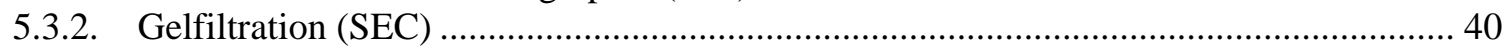

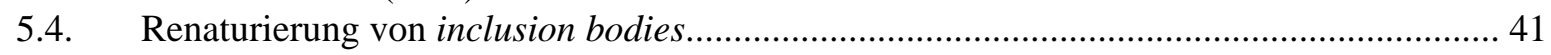

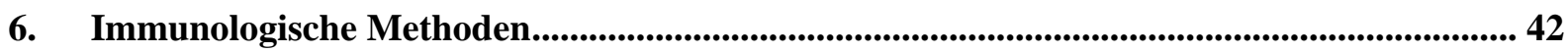

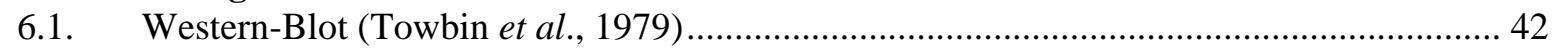

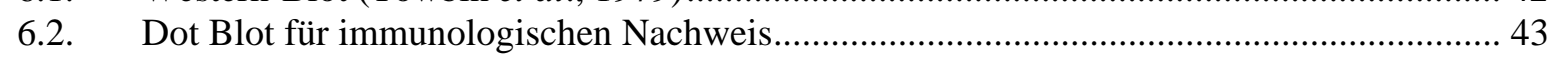

6.3. Immundetektion von Proteinen mit alkalische-Phosphatase-

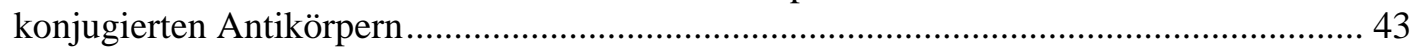

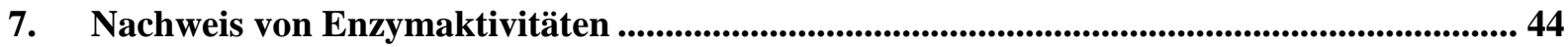

7.1. DNSA-Test zur Bestimmung der Menge reduzierender Zucker (Standard-Test) ............... 44

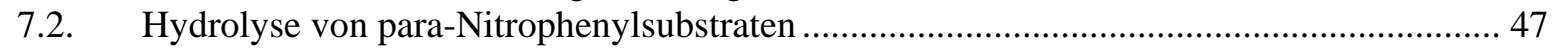

7.3. Produktanalyse durch Dünnschichtchromatographie (TLC) ............................................ 48

7.4. Quantitative Bestimmung von Nicht-Häm-Eisen ................................................................ 50

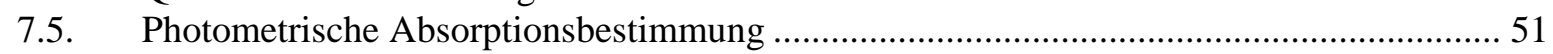

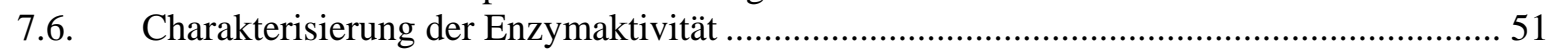

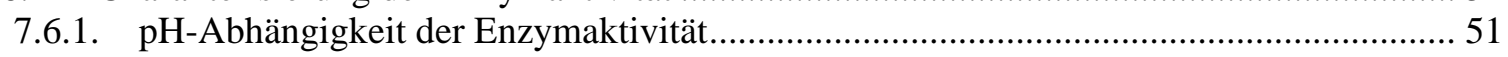

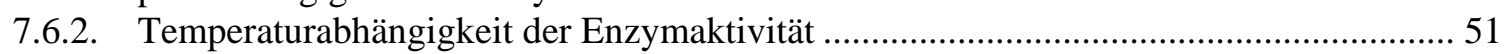

7.6.3. Einfluß von Metallionen und Chelatoren auf die Enzymaktivität ................................... 51

8. Charakterisierung glykosidischer Speicherstoffe ........................................................................... 52

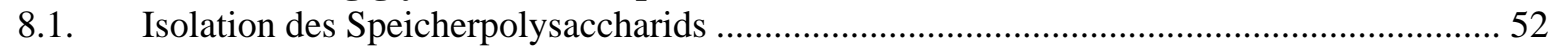

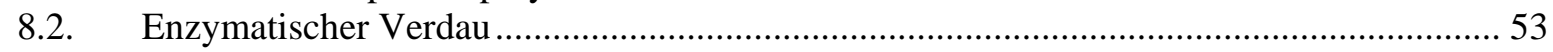

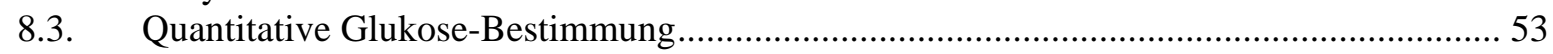

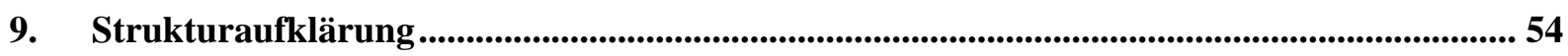

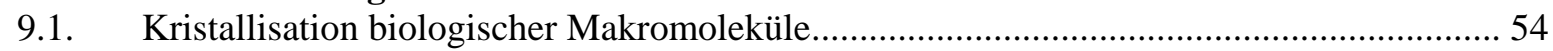

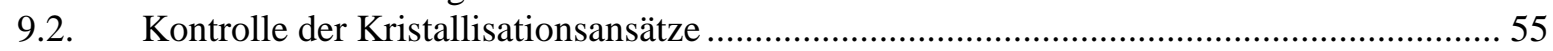

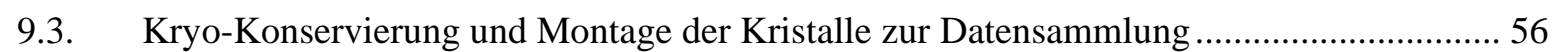

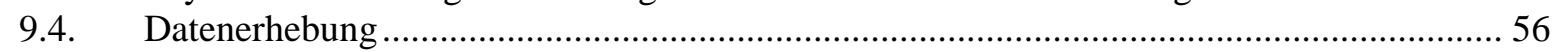


III. Experimente und Ergebnisse .58

1. Computergestützte Analysen der Sequenz des amyB-Tm-Gens und der Aminosäure- Sequenz von AmyB-Tm ........................................58

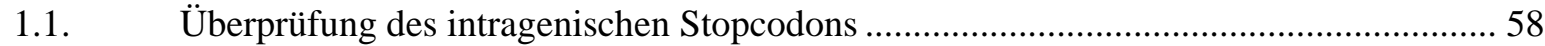

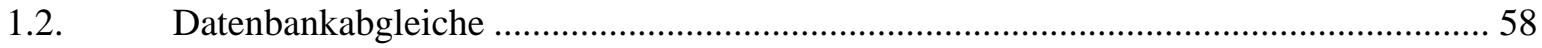

1.3. Analyse der AmyB-Tm-flankierenden Region............................................................... 61

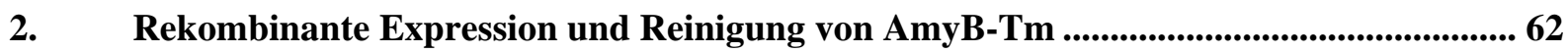

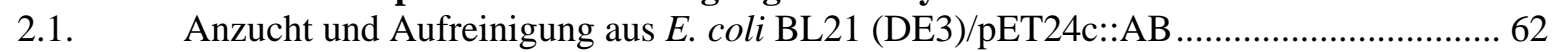

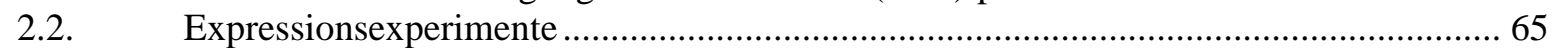

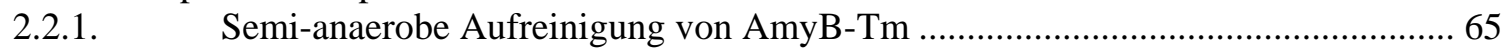

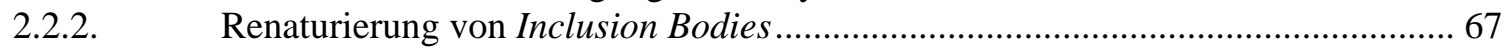

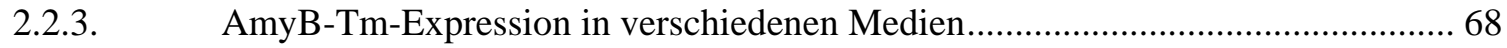

2.2.4. Abhängigkeit von AmyB-Tm-Aktivität und Expressionszeit..................................69 69

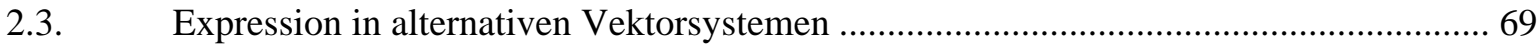

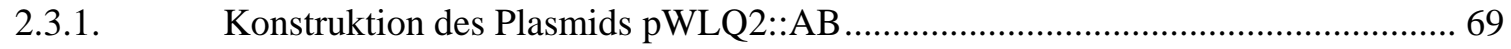

2.3.2. AmyB-Tm-Expression in pWLQ2::AB-transformierten E. coli-Kulturen .............. 70

2.3.3. AmyB-Tm-Expression in pTAA31 transformiertem E. coli JM83 …..................... 72

2.4. Expression in Corynebacterium glutamicum ............................................................... 74

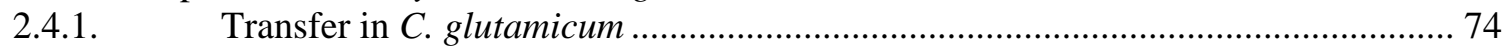

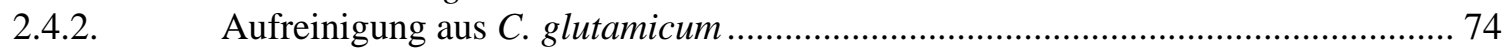

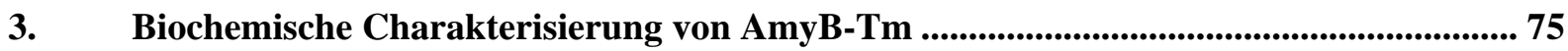

3.1. Allgemeine Untersuchungen zur enzymatischen Aktivität ............................................. 75

3.1.1. Aktivität von AmyB-Tm mit pNP-Substraten ......................................................... 75

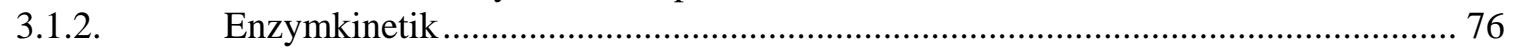

3.1.3. Untersuchungen zur Beteiligung von AmyB-Tm am Glykogenstoffwechsel ........ 77

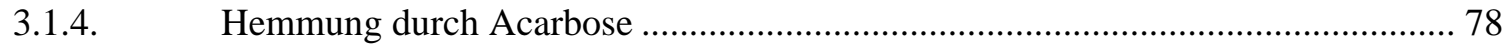

3.2. Einfluß von reduzierenden Agenzien .......................................................................... 78

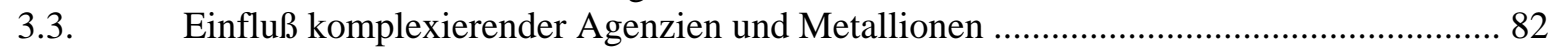

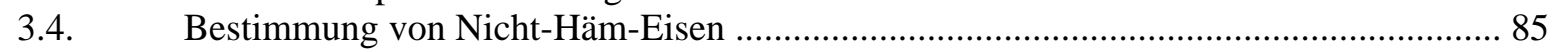

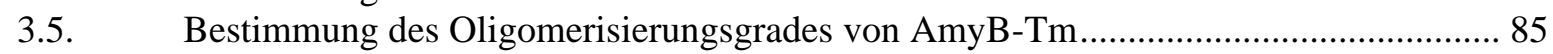

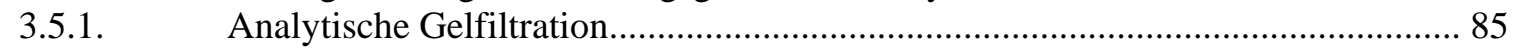

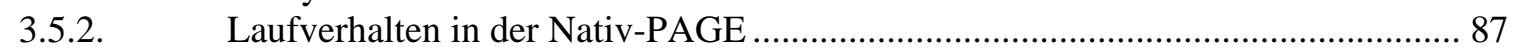

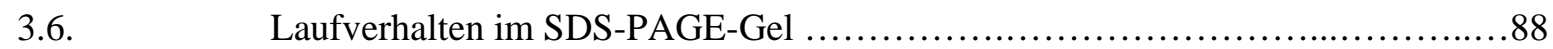

4. Untersuchung der AmyB-Expression in T. maritima ................................................................. 89

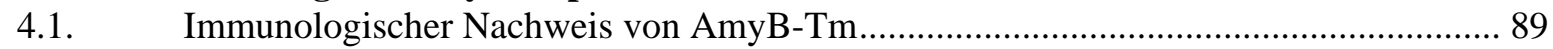

4.2. Wachstumsphasen-Abhängigkeit der AmyB-Expression in T. maritima......................... 90

5. Untersuchungen des Speicherpolysaccharids von T. maritima .......................................92 92

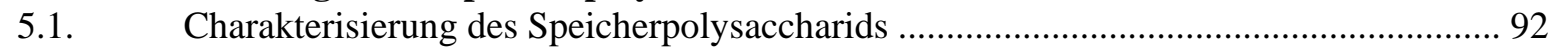

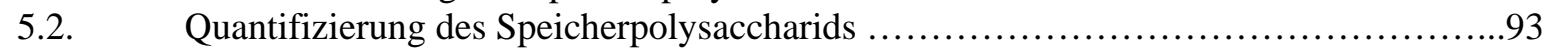

6. Aufklärung der Proteinstruktur von AmyB-Tm..........................................................94

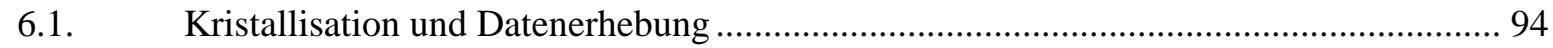

6.2. Aufreinigung von Selenomethionin-AmyB-Tm aus E. coli B834 (DE3) ...................... 95

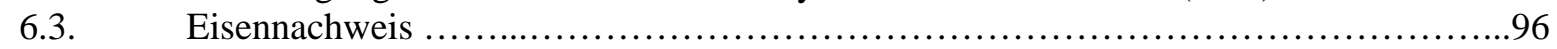

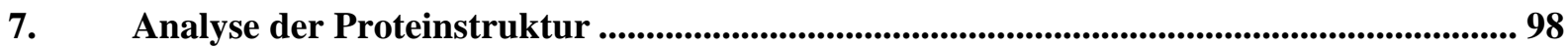

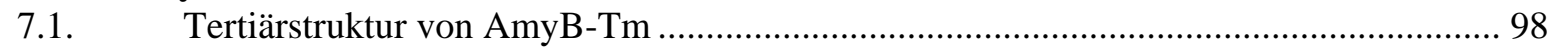

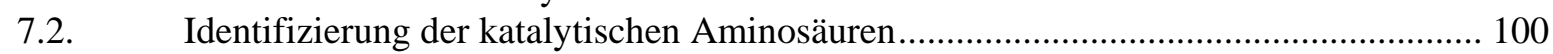

7.3. Identifizierung einer potentiellen Eisenbindestelle ................................................... 103 
8. Ortsspezifische Mutagenese von AmyB-Tm ...................................................................... 104

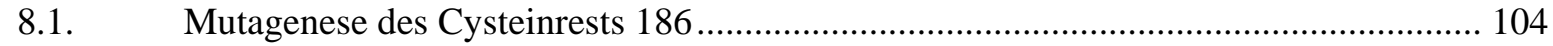

8.2. Expression und Aufreinigung der AmyBCys186-Mutante ........................................... 106

9. Klonierung von amyB-Tt aus T. thermophilus und teilweise Charakterisierung des

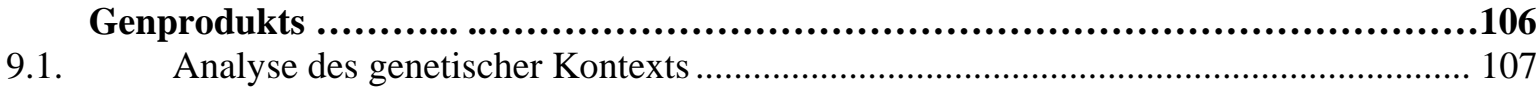

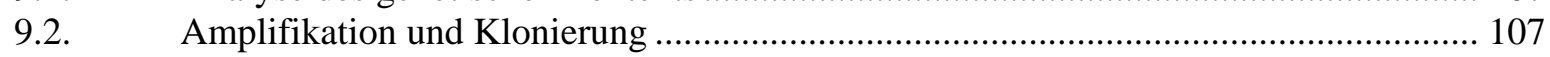

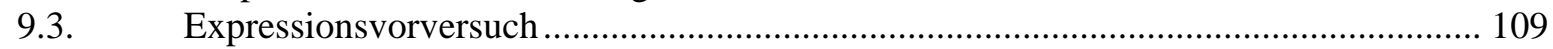

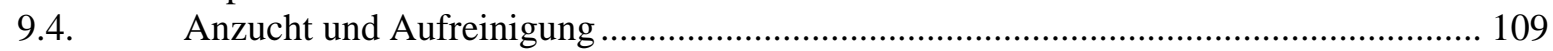

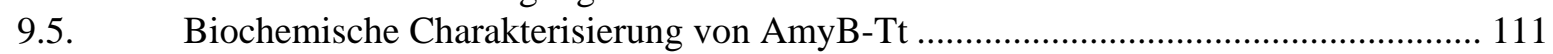

10. Untersuchungen der a-Amylasen AmyA und AmyB aus Anaerobranca gottschalkii 114

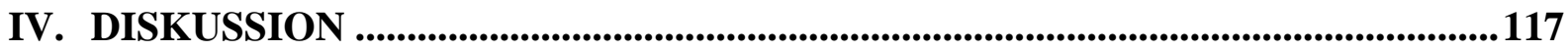

1. Die intrazelluläre $\alpha$-Amylase AmyB-Tm aus Thermotoga maritima................................ 117

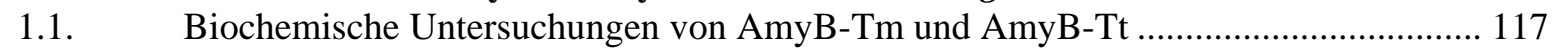

1.2. Abhängigkeit der AmyB-Tm-Aktivität von Metallionen .............................................. 120

1.3. Inhibitorischer Effekt von Nukleotiden auf AmyB-Tm ............................................. 122

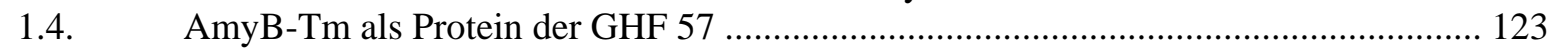

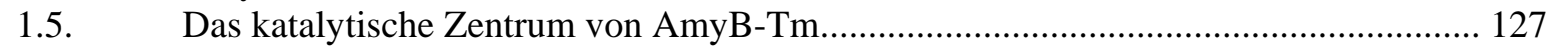

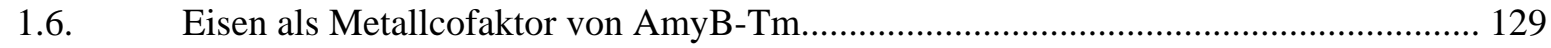

1.7. Die Rolle von AmyB-Tm im T. maritima Stoffwechsel .............................................. 131

2. Vergleich zweier $\alpha$-Amylasen aus Anaerobranca gottschalkii .............................................. 137

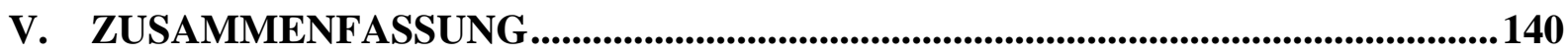

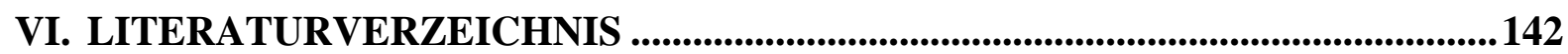

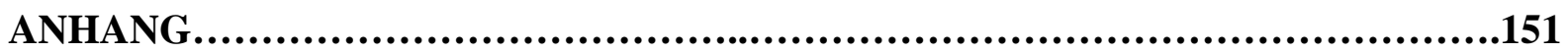

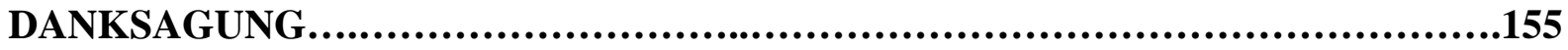




\section{Abkürzungsverzeichnis}

A

AA

Abb.

Amp

APS

BCIP

bidest.

bp

BSA

${ }^{\circ} \mathrm{C}$

COG

Da

DC

dest.

DMSO

DNA

DNase

DNSA

DTT

EDTA

et al.

Fa.

FPLC

g

$\mathrm{G} 1, \ldots ., \mathrm{G} 7$

h

HEPES

IPTG

$\mathrm{k}$

$\mathrm{kB}$

$\mathrm{kDa}$

l

LB

$\mathrm{m}$

M

$\mu$

MCS

$\min$

n

NBT

OD

ORF

$\mathrm{Pa}$

PAGE

PBS

PCR

Pfu-Polymerase

PEG

$\mathrm{pH}$
Ampere

Acrylamid

Abbildung

Ampicillin

Ammoniumpersulfat

5-Brom-4-Chlor-Indolyl-Phosphat

bidestilliert

Basenpaar

Bovines Serumalbumin

Grad Celsius

„Cluster of orthologous groups“

Dalton

Dünnschichtchromatographie

destilliert

Dimethylsulfoxid

Desoxyribonukleinsäure

Desoxyribonuklease

3,5-Dinitrosalicylsäure

Dithiothreitol

Ethylendiamintetraacetat

und weitere (et alii)

Firma

„Fast Protein Liquid Chromatography“

Gramm

Glucose,.....,Maltoheptaose (Maltooligosaccharide)

Stunde

N-2-Hydroxyethylpiperazin-N`-2-ethansulfonsäure

Isopropyl-1-thio- $\beta$-D-galactosid

Kilo- $\left(1 * 10^{3}\right)$

Kilobasen

Kilodalton

Liter

Luria-Bertani

milli- $\left(1 * 10^{-3}\right)$, Meter

Molar (mol/l), Mega- $\left(1 * 10^{6}\right)$

Mikro- $\left(1 * 10^{-6}\right)$

Multiklonierungsstelle (multiple cloning site)

Minute

Nano- $\left(1 * 10^{-9}\right)$

Nitrublue-Tetrazolium

Optische Dichte

offener Leserahmen (open reading frame)

Pascal

Polyacrylamid-Gel-Elektrophorese

Phosphat-NaCl-Puffer (phosphate buffered saline)

Polymerasekettenreaktion (polymerase chain reaction)

Polymerase aus Pyrococcus furiosus

Polyethylenglykol

negativer dekadischer Logarithmus der Protonenkonzentration 


$\begin{array}{ll}\text { PIPES } & \text { Piperazin-1,4-bis(2-ethansulfonsäure) } \\ \mathrm{r} & \text { resistent/Resistenz } \\ \text { RNA } & \text { Ribonukleinsäure } \\ \text { RNase } & \text { Ribonuklease } \\ \text { RT } & \text { Raumtemperatur } \\ \text { s } & \text { Sekunden } \\ \text { SDS } & \text { Natriumdodecylsulfat } \\ \text { ssDNA } & \text { einzelsträngige DNA } \\ \text { SV } & \text { Säulenvolumen } \\ \text { Tab. } & \text { Tabelle } \\ \text { TAE } & \text { Tris-Acetat-EDTA-Puffer } \\ \text { Taq-Polymerase } & \text { Polymerase aus Thermus aquaticus } \\ \text { TE } & \text { Tris-EDTA-Puffer } \\ \text { TEMED } & \text { N,N,N',N',- Tetramethylethylen-diamin } \\ \text { Tris } & \text { Tris-(hydroxymethyl)-aminomethan } \\ \text { U } & \text { Einheit der Enzymaktivität (unit) } \\ \text { ÜN } & \text { über Nacht } \\ \text { Upm } & \text { Umdrehungen pro Minute } \\ \text { UV } & \text { Ultraviolett } \\ \text { V } & \text { Volt } \\ \text { v/v } & \text { Volumen pro Volumen } \\ \text { Vol. } & \text { Volumen } \\ \text { w/v } & \text { Masse pro Volumen } \\ \text { x-Gal } & \text { 5-Brom-4-Chlor-3-indolyl- } \beta \text {-D-galactosid } \\ & \end{array}$




\section{Einleitung}

\section{Thermotoga maritima, Thermus thermophilus und Anaerobranca}

\section{gottschalkii: Bewohner heißer Standorte}

Eine nicht geringe Anzahl prokaryotischer Organismen existiert in Bereichen, die für den Menschen lebensfeindlich sind. In der anthropozentrisch geprägten Nomenklatur werden die Bewohner solcher Lebensräume als extremophil, das Äußerste liebend, bezeichnet. Darunter fallen in heißen und kalten Habitaten lebende Organismen (Thermophile, Psychrophile) genauso wie die Bewohner von Habitaten mit niedrigem oder hohem pH-Wert (Acidophile, Alkaliphile). Auch unter großem Druck (Piezophile) oder hohem Salzgehalt (Halophile) lebende Organismen werden als extremophil eingestuft.

Die Stellung der hyperthermophilen, d.h. außergewöhnlich hitzeliebenden, Organismen im Stammbaum, wo sie in den tiefsten und kürzesten Zweigen zu finden sind, ist ein Hinweis darauf, daß der gemeinsame Vorfahr der Archaeen und Bakterien ein hyperthermophiler Organismus gewesen ist. Es ist darüber hinaus wahrscheinlich, daß die Entstehung des Lebens auf unserem Planeten in einem heißen Milieu stattgefunden hat. Im Lichte dieser Erkenntnisse scheinen heiße Lebensräume nicht so sehr das Extrem darzustellen, sondern sind vielmehr ein sehr ursprüngliches Habitat. (Achenbach-Richter et al., 1987; Stetter, 1999; DeLong, 2001; Nisbet und Sleep, 2001; Di Giulio, 2003)

Die hitzeliebenden Organismen werden in drei Gruppen eingeteilt: Thermophile haben ein Wachstumsoptimum von $55{ }^{\circ} \mathrm{C}$ oder darüber, extrem thermophile wachsen optimal bei mindestens $70^{\circ} \mathrm{C}$ und hyperthermophile zeigen optimales Wachstum bei einer Temperatur von $80{ }^{\circ} \mathrm{C}$ und höher. Die Temperatur von $113^{\circ} \mathrm{C}$, bei der das Archaeon Pyrolobus fumarii sich gerade noch vermehren kann, stellt das bislang bekannte obere Limit des Lebens dar (Blöchl et al., 1997). Es ist aber es ist keinesfalls ausgeschlossen, daß bisher unentdeckte oder noch nicht kultivierte Organismen mit einer höheren Wachstumstemperatur existieren (Stetter, 1999). Anaerobranca gottschalkii und Thermus thermophilus, deren $\alpha$-Amylasen in dieser Arbeit untersucht wurden, werden aufgrund ihres Wachstumsoptimums den Thermophilen bzw. extrem Thermophilen zugeordnet. Das Bakterium Thermotoga maritima, auf dem das Hauptaugenmerk dieser Arbeit liegt, gehört zu den Hyperthermophilen.

Die große Mehrheit der bekannten hyperthermophilen Organismen sind Archaeen. Die Ordnungen der Thermotogales und der Aquificales stellen bis heute die einzigen hyperthermophilen Vertreter der Bakterien, was T. maritima zu einem hervorragenden Studienobjekt für die bakterielle Anpassung an das Leben unter hyperthermophilen Bedingungen macht. Während die Vertreter der Aquificales einen lithoautotrophen 
Stoffwechsel haben, leben die Vertreter der Thermotogales organoheterotroph. Beide Ordnungen stellen sehr tiefe Verzweigungen im Stammbaum der Bakterien dar und bilden gemeinsam mit den hyperthermophilen Archaeen ein Cluster um die gemeinsame Wurzel von Archaeen und Bakterien (Stetter, 1999; DeLong, 2001) (Abb. 1).

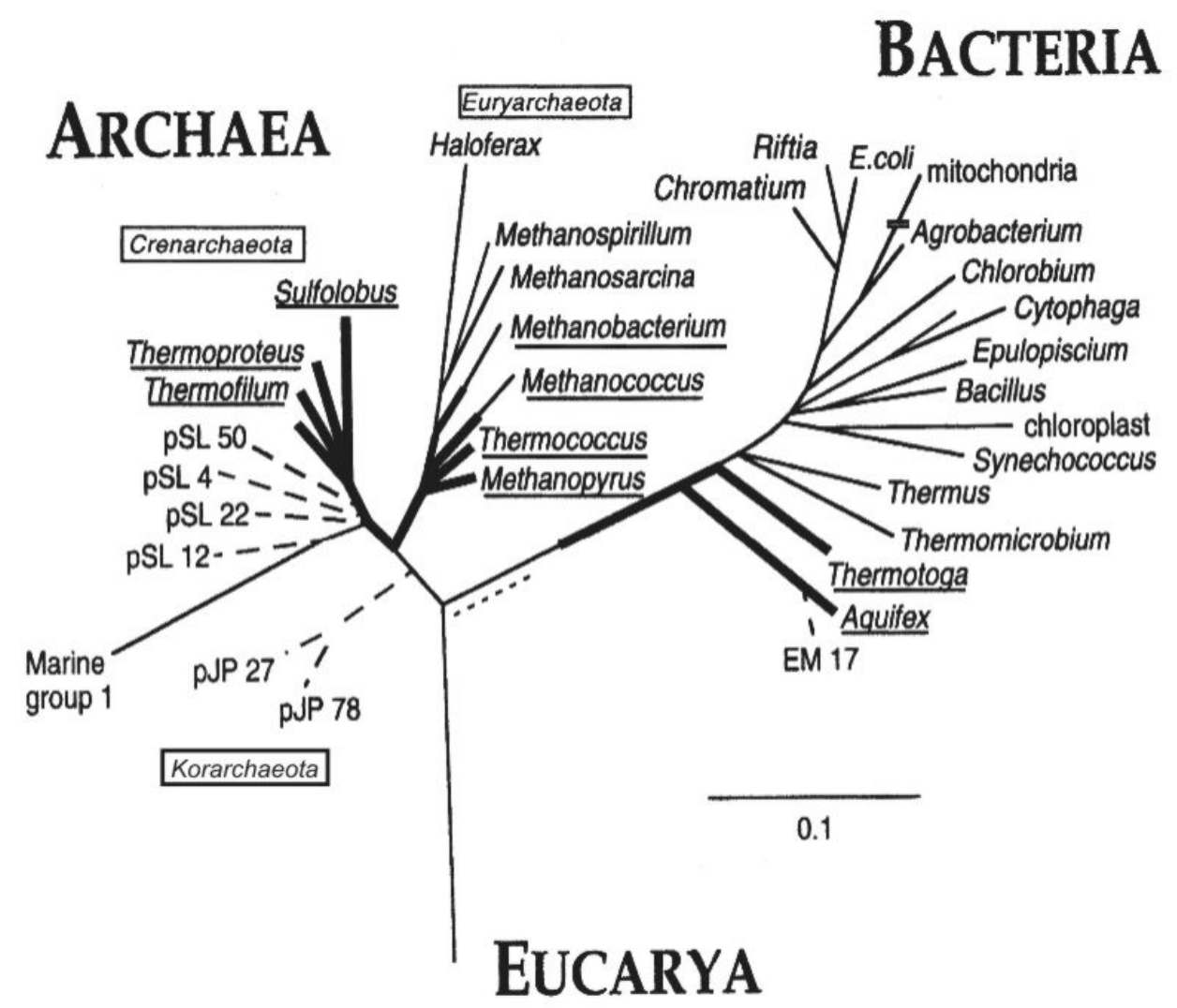

Abb. 1: Ribosomaler RNA-Stammbaum der Archaeen und Bakterien. Fettgedruckte Zweige und unterstrichene Gattungsnamen repräsentieren Hyperthermophile. Methanococcus und Methanobacterium beinhalten sowohl an hohe wie an niedrige Temperaturen angepaßte Spezies. Gestrichelte Linien stellen rRNA aus Umweltproben unkultivierter Organismen dar. Die gepunktete Linie repräsentiert die noch unsichere Position des gemeinsamen Vorfahren von Archaeen und Bakterien. (Aus DeLong, 2001, modifiziert.)

\section{Thermotoga maritima}

Das strikt anaerob lebende Bakterium Thermotoga maritima wurde aus dem Meeresboden vor der Insel Vulcano, Italien, isoliert und stellt mit seinem Wachstumsoptimum von $80{ }^{\circ} \mathrm{C}$ und seiner Fähigkeit, im Bereich von 55 bis $90{ }^{\circ} \mathrm{C}$ zu wachsen, zusammen mit dem nahe verwandten Thermotoga neapolitana das bisher thermophilste heterotroph lebende Bakterium dar (Huber et al., 1986; Belkin, et al., 1986). Inzwischen konnten T. maritima und seine nächsten Verwandten an vielen Orten mit geothermal erhitzen Meeressedimenten 
nachgewiesen werden, z. B. vor den Azoren, den Fidschi Inseln, vor der Küste Indonesiens und Japans, sowie an mehreren Tiefseestandorten (Huber et al., 1986; Huber und Stetter, 1992).

Charakteristisch für die Morphologie des Gram-negativen, stäbchenförmigen T. maritima ist die namensgebende ,Toga'. Diese an den Zellpolen auffällig abstehende äußere Hülle umgibt eine ballonartige Erweiterung des periplasmatischen Raums, deren Volumen das des Cytoplasmas übertreffen kann. Welche Vorteile T. maritima durch den so entstehenden zusätzlichen Reaktionsraum hat, ist noch nicht geklärt (Engel et al., 1992).

Wie die übrigen Vertreter der Thermotogales hat $T$. maritima einen chemoorganoheterotrophen Stoffwechsel und wächst auf vielen Mono- und Polysacchariden und anderen komplexen organischen Substraten, die zu 15 \% über den Entner-Douderoff-Weg und zu 85 \% über den Embden-Meyerhof-Parnas-Weg verwertet werden. Dabei benutzt T. maritima im Gegensatz zu vielen hyperthermophilen Archaeen die ,klassischen', nicht-modifzierten Varianten dieser Stoffwechselwege. Als Produkte der Fermentation entstehen Acetat, $\mathrm{CO}_{2}$ und $\mathrm{H}_{2}$, sowie in geringer Menge L-Laktat (Huber, et al., 1986; Huber und Stetter, 1992; Schröder et al., 1994; Selig et al., 1997).

Obwohl es sich bei T. maritima eindeutig um ein Eubakterium handelt, zeigte sich bei der Sequenzierung des Genoms, daß 24 \% der Gene hohe Ähnlichkeit zu archaeellen Genen haben. Außerdem wurden, obwohl T. maritima aufgrund der phylogenetischen Einordnung eher als primitiv gilt, überraschend viele Gene für am Zuckerstoffwechsel beteiligte Enzyme sowie für die hohe Anzahl von neun zuckerspezifischen Transportern gefunden. In Relation zu seiner Größe von 1,9 Mbp ist im T. maritima-Genom die höchste Anzahl von Kohlenhydrat-modifizierenden und -abbauenden Proteinen aller bislang bekannten prokaryotischen Genome kodiert. Allein der Anteil der für diese Arbeit relevanten GlykosidHydrolasen übersteigt den anderer Bakterien bei Weitem (Nelson et al., 1999) (Abb. 2). 


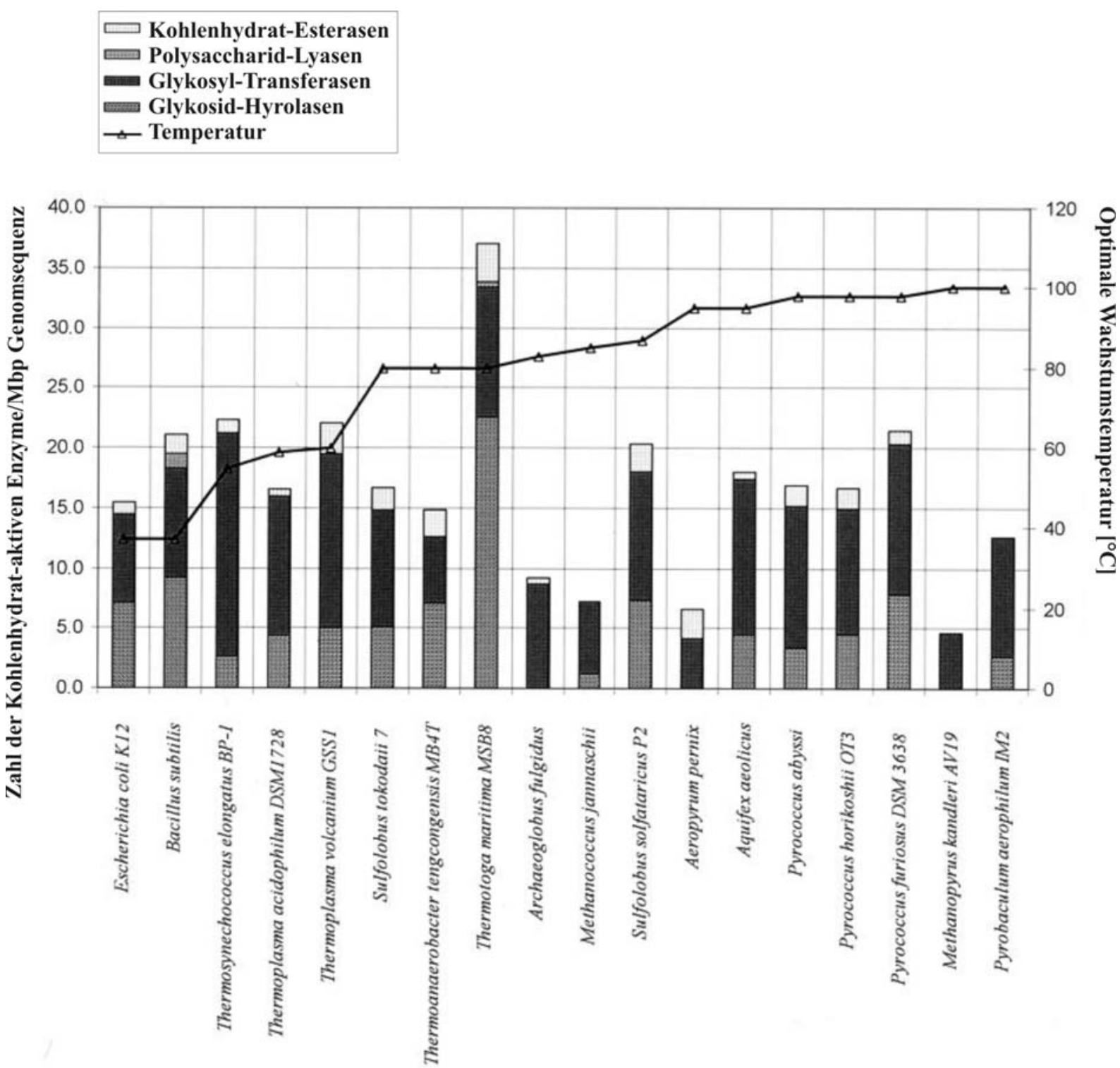

Organismus

Abb. 2: Zahl der Kohlenhydrat-modifizierenden und -abbauenden Enzyme, die in den Genomsequenzen thermophiler und hyperthermophiler Archaeen und Bakterien kodiert sind. $B$. subtilis and E. coli sind zum Vergleich gezeigt. Die zugrundeliegenden Daten wurden der CAZYDatenbank (http://afmb.cnrs-mrs.fr/CAZY) entnommen. (Aus Chhabra et al., 2003, modifiziert.)

\section{Thermus thermophilus}

Das Gram-negative Bakterium Thermus thermophilus wurde aus einer heißen Quelle in Japan isoliert. Sein Wachstumsoptimum liegt bei $75{ }^{\circ} \mathrm{C}$, aber der Organismus ist bis zu einer Temperatur von $85{ }^{\circ} \mathrm{C}$ zur Zellteilung fähig. T. thermophilus ist halotolerant und wächst unter aeroben Bedingungen obligat chemoorganoheterotroph (Oshima und Imahori, 1974). Neben dem 1,9 Mbp großen Chromosom liegt in T. thermophilus ein 230 kbp großes Megaplasmid vor. Der Guanin- und Cytosin-Anteil beträgt in beiden DNA-Molekülen durchschnittlich 
69,4\%, was der T. thermophilus-DNA einen ungewöhnlich hohen Schmelzpunkt verleiht (Henne et al., 2004). Als einziger der bisher isolierten thermophilen Organismen besitzt T. thermophilus eine natürliche Kompetenz zur Aufnahme von extrazellulärer DNA, was das Bakterium zu einem idealen Objekt für genetische Studien macht (Koyama et al., 1986).

\section{Anaerobranca gottschalkii}

Anaerobranca gottschalkii befindet sich als thermoalkaliphiles Bakterium mit einem pHOptimum von $\mathrm{pH}$ 8,5 und einem Temperaturoptimum von 50-55 ${ }^{\circ} \mathrm{C}$ gleich in zwei Grenzbereichen des Lebens. Neben seiner Einordnung unter den extrem thermophilen Organismen gehört es auch zur Gruppe der Alkaliphilen, die ein Wachstum bei pH 8,5 oder darüber auszeichnet. Obwohl aufgrund einer ungewöhnlich dünnen Zellwand die GramFärbung negativ ausfällt, gehört $A$. gottschalkii zu den Gram-positiven Bakterien (Prowe und Antranikian, 2001). Diese Klassifizierung wird interessanterweise von allen bisher isolierten Thermoalkaliphilen geteilt (Wiegel, 1998).

Das Bakterium wurde aus einem heißen Zulauf des alkalischen Bogoriasees (Kenia) isoliert, der zu einer Kette von Natron-Seen im Great Rift Valley in Ostafrika gehört. Es wächst unter obligat anaeroben Bedingungen und fermentiert ein breites Spektrum an Protein-Substraten sowie Mono- und Polysacchariden. Charakteristisch und namensgebend für A. gottschalkii ist die Y-förmige Verzweigung der Zellen (Prowe und Antranikian, 2001).

\section{Glykogenmetabolismus}

Bereits in früheren Studien konnten drei $\alpha$-Amylasen, eine extrazelluläre (AmyA-Tm) und zwei intrazelluläre (AmyB-Tm und AmyC-Tm), in T. maritima identifiziert werden (Liebl et al., 1996; Fütterer, 2001; Lim et al., 2003). A. gottschalkii besitzt vermutlich zwei $\alpha$ Amylasen, eine extrazelluläre (Amy-Ag) und eine intrazelluläre (AmyB-Ag), während im kürzlich sequenzierten Genom von T. thermophilus noch kein Gen mit Ähnlichkeit zu einer $\alpha$ Amylase gefunden werden konnte (Prowe, 1996; Henne et al., 2004).

Die Klasse der $\alpha$-Amylasen (EC: 3.2.1.1) ist ein verbreiteter Enzymtyp beim Stärkeabbau. Diese Enzyme spalten $\alpha$-1,4-glykosidische Bindungen hydrolytisch an beliebigen Stellen innerhalb des Polysaccharids, was zu einem Gemisch kleinerer Maltooligosaccharide als Abbauprodukte führt. Während die Funktion extrazellulärer Amylasen im möglichst schnellen Erschließen einer C-Quelle liegt, haben intrazelluläre andere Aufgaben. Ihnen dienen in der Zelle das bakterielle Speicherglykosid Glykogen und die nach extrazellulärem Stärkeabbau in die Zelle importierten, kurzkettigen Maltodextrine als Substrat. 
Glykogen wird von vielen Bakterien und Eukaryoten in der Zelle zur Energiespeicherung gebildet. Es stellt das tierische und prokaryotische Äquivalent zum pflanzlichen Speicherstoff Stärke dar. Als Grundbausteine dienen Glukoseeinheiten, die $\alpha$-1,4-glykosidisch bzw. $\alpha-1,6-$ glykosidisch verknüpft sind (Abb. 3). Glykogen unterscheidet sich von Amylopektin, dem verzweigten Bestandteil der aus Amylopektin und Amylose bestehenden Stärke, nur durch einen höheren Verzweigungsgrad, d.h. eine höhere Zahl von $\alpha$-1,6-Bindungen. Während Amylopektin eine durchschnittliche Kettenlänge von 18-24 Glukoseeinheiten hat, sind dies beim Glykogen 12-17 Glukoseeinheiten (Illingworth et al., 1952). In T. thermophilus, E. coli und thermophilen Archaeen wurden aber auch höher verzweigte Glykogene mit einer Kettenlänge von sieben oder elf Einheiten gefunden (Preiss et al., 1975; König et al., 1982; Boeck und Schinzel, 1998).

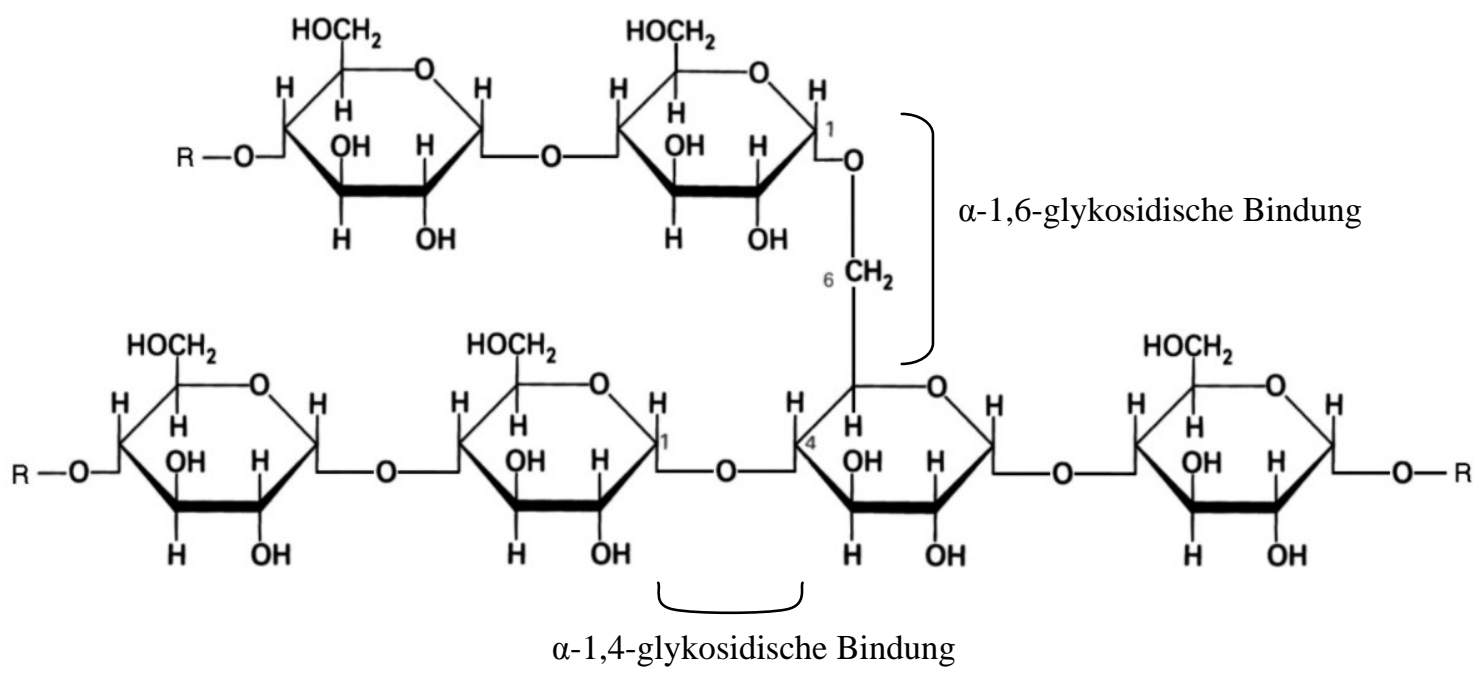

Abb. 3: Ausschnitt aus einem Glykogenmolekül. R steht für weitere Glykosylreste. (Nach Stryer, 1995, modifiziert.)

Glykogen wird in der Zelle gebildet, wenn eine C-Quelle in ausreichender Menge vorhanden ist. Bei Kohlenstoffmangel kann dieser Speicherstoff kontrolliert abgebaut und seine Komponenten in den Metabolismus eingeschleust werden. Der Auf- und Abbau von Glykogen erfolgt auf getrennten Stoffwechselwegen. In Bakterien dient ADP-Glukose als Ausgangspunkt beim Aufbau des Glykogens. Der aktivierte Zucker wird durch die ADPGlukose-Pyrophosphorylase in einer streng allosterisch regulierten Reaktion synthetisiert. Die Glykogensynthase katalysiert die Bildung einer glykosidische Bindung zwischen dem C1- 
Atom der aktivierten Glukose und dem nicht reduzierenden C4-Ende der wachsenden Glykogenkette, die als ,Primer' fungiert. Die Bildung der $\alpha-1,6$-Verzweigungen wird durch das sogenannte Verzweigungsenzym (branching enzyme), einer $(\alpha-1,4 \rightarrow \alpha-1,6)$ Transglukosylase, katalysiert, die $\alpha-1,4$-Bindungen im wachsenden Polysaccharid spaltet und die Oligosaccharidreste an einer anderen Stelle des Polymers $\alpha$-1,6-glykosidisch anknüpft (Lengler et al., 1999).

Der Abbau des Glykogens erfolgt vom nicht-reduzierenden Ende her durch die GlykogenPhosphorylase, die die $\alpha$-1,4-Bindung phosphorolytisch spaltet. Dabei wird im Gegensatz zur hydrolytischen Spaltung der Amylasen ein Glykosylrest auf ein Phosphat-Molekül statt eines $\mathrm{H}_{2} \mathrm{O}$-Moleküls übertragen. Es entsteht Glukose-1-Phosphat, welches durch die PhosphoGlukomutase zu Glukose-6-Phosphat isomerisiert und so in den Zuckerstoffwechsel eingeschleust wird. Die durch die Glykogen-Phosphorylase katalysierte Reaktion ist zwar reversibel, ist aber nicht am $\alpha$-Glukan Aufbau beteiligt. An den Verzweigungspunkten werden die $\alpha-1,6$-Bindungen durch eine $\alpha-1,6-G$-Gukosidase abgebaut. Der Unterschied zum extrazellulären Polysaccharidabbau besteht neben der Bildung von Glukose-1-Phosphat an Stelle von nicht-phosphorylierten Maltodextrinen darin, daß die Degradation des Glykogens streng kontrolliert wird und das angegriffene Polymer weitestgehend intakt bleibt (Lengler et al., 1999).

\section{Zielsetzung der Arbeit}

Die intrazelluläre $\alpha$-Amylase AmyB-Tm aus T. maritima sollte biochemisch untersucht, und mit dem ihr auf Aminosäuresequenz-Ebene ähnlichen Enzym AmyB-Tt aus T. thermophilus verglichen werden. Durch die Kristallisation und Aufklärung der dreidimensionalen Struktur von AmyB-Tm, in Zusammenarbeit mit der Abteilung Molekulare Strukturbiologie (Prof. Dr. R. Ficner) sollten Erkenntnisse über den Aufbau und das katalytische Zentrum dieser neuartigen $\alpha$-Amylase gewonnen werden.

Weiterhin sollten zwei $\alpha$-Amylasen aus A. gottschalkii hinsichtlich ihrer physikochemischen Eigenschaften und damit hinsichtlich ihrer Anpassung an ihre unterschiedliche Lokalisierung in der Zelle verglichen werden. 


\section{Material und Methoden}

\section{Organismen und Plasmide}

Die in der vorliegenden Arbeit verwendeten Bakterienstämme und Plasmide sind in Tabelle 1 bzw. 2 aufgeführt.

Tabelle 1: Verwendete E. coli-, T. maritima- und C. glutamicum- Stämme.

\begin{tabular}{|c|c|c|}
\hline Stamm & Beschreibung ${ }^{1)}$ & Referenz \\
\hline \multicolumn{3}{|l|}{ Escherichia coli } \\
\hline BL21(DE3) & $\mathrm{F}^{-}$ompT hsdS $S_{B}\left(r_{B}^{-} m_{B}^{-}\right) g a l d c m$ (DE3) & $\begin{array}{l}\text { Novagen, } \\
\text { Darmstadt }\end{array}$ \\
\hline B834(DE3) & $\mathrm{F}^{-}$ompT hsdSB $\left(r_{B}{ }^{-} m_{B}{ }^{-}\right)$gal dcm met (DE3) & $\begin{array}{l}\text { Novagen, } \\
\text { Darmstadt }\end{array}$ \\
\hline JM83 & ara $\Delta$ (lac-proAB) rpsL $\Phi 80 l a c Z \Delta \mathrm{M} 15$ & $\begin{array}{l}\text { Yanish-Perron } \\
\text { et al., } 1985\end{array}$ \\
\hline Rosetta 2 (DE3) & $\begin{array}{l}\text { F- ompT hsdS } S_{B}\left(\mathrm{r}_{\mathrm{B}^{-}} \mathrm{m}_{\mathrm{B}}-\right) \text { gal dcm lacY1 (DE3) } \\
\text { pRARE2 }\left(\mathrm{Cm}^{\mathrm{R}}\right)\end{array}$ & $\begin{array}{l}\text { Novagen, } \\
\text { Darmstadt }\end{array}$ \\
\hline XL1-Blue & $\begin{array}{l}\text { recA- thi hsdR1 supE44 relA1 lacF, } \\
\text { proAB lacI }{ }^{\mathrm{q}} \text { lacZ } \Delta \mathrm{M} 15 \text { Tn10[Tet] }\end{array}$ & $\begin{array}{l}\text { Bullock } \\
\text { et al., } 1987\end{array}$ \\
\hline \multicolumn{3}{|c|}{ Thermotoga maritima } \\
\hline MSB8 & Typstamm (=DSMZ 3109) & $\begin{array}{l}\text { DSMZ 3109, } \\
\text { Huber et al., } \\
1986\end{array}$ \\
\hline \multicolumn{3}{|l|}{$\begin{array}{l}\text { Corynebacterium } \\
\text { glutamicum }\end{array}$} \\
\hline DSMZ 20300 & Typstamm (=ATCC 13032) & DSMZ 20300 \\
\hline R163 & $\begin{array}{l}\text { C. glutamicum ASO19 restriktionsdefiziente } \\
\text { Mutante, } \text { tru }^{-}\end{array}$ & $\begin{array}{l}\text { Liebl et al., } \\
1989\end{array}$ \\
\hline
\end{tabular}

${ }^{1)}$ Geno- und Phänotypbezeichnungen: s. Bachmann (1987) 
Tabelle 2: Verwendete Plasmide.

\begin{tabular}{|c|c|c|c|}
\hline Stamm & Größe & Beschreibung ${ }^{1)}$ & Referenz \\
\hline$\overline{\text { pDRIVE }}$ & $3,85 \mathrm{~kb}$ & oriEc $(\mathrm{pUC}) P_{\text {lac }}$ lacZ $\mathrm{Kan}^{\mathrm{R}} \mathrm{Amp}^{\mathrm{R}}$ & Qiagen, Hilden \\
\hline pET21c & $5,44 \mathrm{~kb}$ & T7 Promotor lacI Amp ${ }^{\mathrm{R}}$ & $\begin{array}{l}\text { Novagen, San } \\
\text { Diego, CA, USA }\end{array}$ \\
\hline pET24c & $5,44 \mathrm{~kb}$ & T7 Promotor lacI Kan ${ }^{\mathrm{R}}$ & $\begin{array}{l}\text { Novagen, San } \\
\text { Diego, CA, USA }\end{array}$ \\
\hline pWLQ2 & $8,46 \mathrm{~kb}$ & $\begin{array}{l}\text { C. glutamicum/ E. coli Schaukelvektor, } \\
\text { lac } I^{\mathrm{q}} \mathrm{P}_{\text {tac }} \text { rrnB mob oriEc(colE1) } \\
\text { oriCg(pSR1) } \mathrm{Amp}^{\mathrm{R}} \operatorname{Kan}^{\mathrm{R}}\end{array}$ & Liebl et al., 1992 \\
\hline pTAA31 & $7,76 \mathrm{~kb}$ & $\begin{array}{l}\text { Amp }^{\mathrm{R}}, \text { Tet }^{\mathrm{R}}, c^{\prime} \text {, } \text { pUN121 Plasmid mit } \\
\text { BclI klonierter, chromosomaler } T \text {. } \\
\text { maritima DNA (inkl. amyB Gen) }\end{array}$ & $\begin{array}{l}\text { W. Liebl, pers. } \\
\text { Mitteilung, und } \\
\text { Fütterer, } 2001\end{array}$ \\
\hline tthi77 & $5,18 \mathrm{~kb}$ & $\begin{array}{l}\text { Amp }{ }^{\mathrm{R}} \text { pTZ19R Plasmid mit Hinc II } \\
\text { klonierter, chromosomaler Thermus } \\
\text { thermophilus HB27 DNA (inkl. amyB } \\
\text { Gen) }\end{array}$ & $\begin{array}{l}\text { Henne et al., } \\
2004\end{array}$ \\
\hline pET24c::AB & $7,00 \mathrm{~kb}$ & $\begin{array}{l}\text { pET24c Expressionsvektor mit dem } T \text {. } \\
\text { maritima amyB Gen, mittels BamH1, } \\
\text { NdeI kloniert }\end{array}$ & Fütterer, 2001 \\
\hline pET24c::ABCys186 & $7,00 \mathrm{~kb}$ & $\begin{array}{l}\text { pET24c Expressionsvektor mit dem } T \text {. } \\
\text { maritima amyB Gen mit Punktmutation } \\
\text { (As-Austausch C186 } \rightarrow \text { S186), mittels } \\
\text { BamH1, NdeI kloniert }\end{array}$ & diese Arbeit \\
\hline pET21c::TT-AB & $6,97 \mathrm{~kb}$ & $\begin{array}{l}\text { pET24c Expressionsvektor mit dem } T \text {. } \\
\text { thermophilus HB27 amyB Gen, mittels } \\
\text { NdeI und HindIII kloniert }\end{array}$ & diese Arbeit \\
\hline pWLQ2::AB & $\begin{array}{l}10,02 \\
\mathrm{~kb}\end{array}$ & $\begin{array}{l}\text { pWLQ2 Expressionsvektor mit dem } T \text {. } \\
\text { maritima amyB Gen, mittels SmaI und } \\
\text { SalI kloniert }\end{array}$ & diese Arbeit \\
\hline
\end{tabular}

\footnotetext{
${ }^{1)}$ Phänotypbezeichnungen: Amp ${ }^{\mathrm{R}}$, Ampicillin-Resistenz; Kan ${ }^{\mathrm{R}}$, Kanamycin-Resistenz; Tet ${ }^{\mathrm{R}}$, TetracyclinResistenz;

Genotypbezeichnungen: lacI, Repressor des Lactose Operons; lacPOZ', Promotor-Operator-Region des LactoseOperons und $\alpha$-Peptid der $\beta$-Galactosidase; $c l$ ', cl-Strukturgen; oriEc, origin of replication in E. coli; oriCg, origin of replication in C. glutamicum; mob, P-Typ spezifische recognition site für den konjunktionalen Transfer aus E. coli Donorstämmen wie z.B. S17-1; $\mathrm{P}_{\text {lac }}$, lac Promotor; $\mathrm{P}_{\text {tac }}$, fusionierter trp/ lacUV5 Promoter; rrnB, Terminations-Region der Replikation des rrnB Operons in E. coli.
} 


\section{Chemikalien und Enzyme}

Soweit nicht anders erwähnt, wurden Chemikalien der Firmen Merck (Darmstadt), Oxoid (Basingstoke, England), Roth (Karlsruhe), Biomol (Hamburg) und Sigma-Aldrich (Deisenhofen) mit den Reinheitsgraden „pro analysis“ und „reinst“ verwendet. Restriktionsenzyme wurden von der Firma MBI Fermentas (St. Leon-Rot) bezogen.

\section{Zellanzucht}

\subsection{Medien und Zusätze}

\subsubsection{Nährmedien für $E$. coli}

Standardmäßig wurden E. coli-Kulturen in Luria-Bertani (LB)-Vollmedium angezogen, welches durch 20 minütiges Autoklavieren bei $120^{\circ} \mathrm{C}$ sterilisiert wurde. Zur Herstellung von Festmedium wurden 12 g/l Agar zugefügt. Zu Platten, die der Selektion auf amylolytische Aktivität dienen sollten, wurde 0,5 \% (w/v) Stärke zugefügt.

\section{LB-Medium}

Trypton $10 \mathrm{~g}$

Hefeextrakt $\quad 5 \mathrm{~g}$

$\mathrm{NaCl} \quad 5 \mathrm{~g}$

$\mathrm{H}_{2} \mathrm{O}_{\text {bidest. }} \quad$ ad $1000 \mathrm{ml}$

Für die Produktion von Selenomethionin-haltigem AmyB-Protein wurde E. coli B834 in M9Flüssigmedium kultiviert.

\section{M9-Medium (vereinfacht):}

\begin{tabular}{lrllr}
$\mathrm{Na}_{2} \mathrm{HPO}_{4}$ & $6 \mathrm{~g}$ & \multicolumn{3}{l}{ nach dem Autoklavieren hinzufügen: } \\
$\mathrm{KH}_{2} \mathrm{PO}_{4}$ & $3 \mathrm{~g}$ & Glukose & {$[40 \%(\mathrm{w} / \mathrm{v})]$} & $10 \mathrm{ml}$ \\
$\mathrm{NH}_{4} \mathrm{Cl}$ & $1 \mathrm{~g}$ & $\mathrm{MgSO}_{4}$ & $(1 \mathrm{M})$ & $1 \mathrm{ml}$ \\
$\mathrm{NaCl}$ & $0,5 \mathrm{~g}$ & $\mathrm{CaCl}_{2}$ & $(0,1 \mathrm{M})$ & $1 \mathrm{ml}$ \\
$\mathrm{H}_{2} \mathrm{O}_{\text {bidest. }}$ & ad $980 \mathrm{ml}$ & Biotin & $(1 \mathrm{mg} / \mathrm{ml})$ & $2 \mathrm{ml}$ \\
& & Thiamin & $(1 \mathrm{mg} / \mathrm{ml})$ & $2 \mathrm{ml}$ \\
& & L-Methionin $(25 \mathrm{mg} / \mathrm{ml})$ & $2 \mathrm{ml}$
\end{tabular}

Alle Medienzusätze wurden getrennt angesetzt und sterilfiltriert. 
Semi-anaerobe E. coli-Kulturen wurden in M1-Flüssigmedium, einer Kombination von M9und LB-Medium, angezogen. Das zunächst aerobe Medium wurde mit E. coli inokuliert. Nach Erreichen der logarithmischen Wachstumsphase wurde das Kulturgefäß mit einem Gummistopfen verschlossen. Die Kulturen anaerobisierten sich im weiteren Verlauf des Wachstums durch ihre Stoffwechseltätigkeit. Die Ernte erfolgte nach einer Kultivierung von 1-2 Tagen.

\section{M1-Medium:}

Trypton

Hefeextrakt

$\mathrm{Na}_{2} \mathrm{HPO}_{4}$

$\mathrm{KH}_{2} \mathrm{PO}_{4}$

$\mathrm{NaCl}$

$\mathrm{H}_{2} \mathrm{O}_{\text {bidest. }}$

\section{$32 \mathrm{~g}$}

$20 \mathrm{~g}$

$6 \mathrm{~g}$

$3 \mathrm{~g}$

$0,5 \mathrm{~g}$

ad $1000 \mathrm{ml}$

nach dem Autoklavieren hinzufügen:

$\begin{array}{llr}\text { Glukose } & {[40 \%(\mathrm{w} / \mathrm{v})]} & 10 \mathrm{ml} \\ \mathrm{MgSO}_{4} & (1 \mathrm{M}) & 1 \mathrm{ml} \\ \mathrm{CaCl}_{2} & (0,1 \mathrm{M}) & 1 \mathrm{ml}\end{array}$

Alle Medienzusätze wurden getrennt angesetzt und sterilfiltriert.

Zur positiven Selektion plasmidhaltiger Mikroorganismen wurden den Mediem Antibiotika zugefügt. Zu Agarplatten, die der Selektion rekombinanter E. coli-Klone mit dem Plasmid pBlueskript $\mathrm{SK}^{+}$dienen sollten, wurden außerdem x-Gal und IPTG zugesetzt. Die Zugabe des Antibiotikums sowie der weiteren hitzelabilen Medienbestandteile in den in Tab. 3 aufgeführten Konzentrationen erfolgte nach dem Autoklavieren bei einer Temperatur von $55{ }^{\circ} \mathrm{C}$ oder darunter bzw. bei Flüssigmedien kurz vor dem Animpfen. Zur Vermeidung von Kontaminationen wurden alle Stammlösungen sterilfiltriert. 
Tab. 3: Konzentrationen der verwendeten Medienzusätze

\begin{tabular}{|c|c|c|c|}
\hline Substanz & Lösungsmittel & $\begin{array}{c}\text { Stammlösung } \\
{[\mathrm{mg} / \mathrm{ml}]}\end{array}$ & Endkonzentration $[\mu \mathrm{g} / \mathrm{ml}]$ \\
\hline Ampicillin & $\mathrm{H}_{2} \mathrm{O}_{\text {bidest. }}$ & 50 & 50 \\
\hline Kanamycin & $\mathrm{H}_{2} \mathrm{O}$ bidest. & 25 & 25 \\
\hline Chloramphenicol & Ethanol [50 \% (v/v)] & 34 & 34 \\
\hline IPTG & $\mathrm{H}_{2} \mathrm{O}$ bidest. & 24 & 24 \\
\hline x-Gal & Dimethylformamid & 20 & 64 \\
\hline
\end{tabular}

\subsubsection{Nährmedien für C. glutamicum}

Für die Kultur von C. glutamicum wurde standardmäßig LB-Fest- und Flüssigmedium mit Antibiotikazusatz verwendet. Nach der Elektroporation jedoch wurde für die Anzucht ein Spezialmedium nach Liebl et al. (1989) benutzt.

\section{BHIS-Medium}

2x BHI-Medium:

Brain-Heart-Infusion (Difco) 3,7 g

$\mathrm{H}_{2} \mathrm{O}_{\text {bidest. }} \quad$ ad $50 \mathrm{ml}$

2x Sorbitol-Lösung:

D-Sorbitol

$$
\text { 9,3 g }
$$

$\mathrm{H}_{2} \mathrm{O}_{\text {bidest. }}$

ad $50 \mathrm{ml}$

$\mathrm{MgSO}_{4}$

Alle Lösungen wurden separat autoklaviert. Nach dem Abkühlen wurden die BHI- und Sorbitol-Lösungen vereint und 2 ml MgSO4-Lösung wurde hinzugefügt. 


\section{LBHIS-Festmedium:}

2x BHI-Medium:

Brain-Heart-Infusion (Difco) 18,5 g

Trypton $5 \mathrm{~g}$

Hefeextrakt 2,5 g

$\mathrm{NaCl} 5 \mathrm{~g}$

Agar $14 \mathrm{~g}$

$\mathrm{H}_{2} \mathrm{O}_{\text {bidest. }} \quad$ ad $500 \mathrm{ml}$

2x Sorbitol:

D-Sorbitol $93 \mathrm{~g}$

$\mathrm{H}_{2} \mathrm{O}_{\text {bidest. }} \quad$ ad $500 \mathrm{ml}$

$\mathrm{MgSO}_{4} \quad 1 \mathrm{M}$

Alle Lösungen wurden separat autoklaviert. Nach dem Abkühlen wurden die BHI und Sorbitol-Lösungen vereint und $20 \mathrm{ml} \mathrm{MgSO} 4$ Lösung sowie die entsprechenden Antibiotika für die Selektion hinzugefügt.

\subsubsection{Nährmedium für T. maritima}

Zur anaeroben Anzucht von T. maritima diente ein sogenanntes „vereinfachtes Medium“ (VM, Winterhalter, 1995), ein Komplexmedium, dem gegebenenfalls 0,5 \% (w/v) Stärke oder 0,5 \% (w/v) Glukose als C-Quelle zugesetzt wurden. Als Redoxindikator wurde dem Medium vor dem Autoklavieren (20 min, $120^{\circ} \mathrm{C}$ ) Resazurin beigefügt, welches an der Luft blau ist und im vollständig reduzierten Medium farblos ist.

\section{VM:}

Caseinpepton $5 \mathrm{~g}$

Hefeextrakt $1 \mathrm{~g}$

„Instant Ocean“ Aquariensalz 25 g

Stammlösung Resazurin $\quad 1 \mathrm{ml}$

Stammlösung Titancitrat $\quad 200 \mu \mathrm{l}$

Leitungswasser ad $1000 \mathrm{ml}$

$\mathrm{pH} 7,6$ 


\section{Stammlösungen:}

Resazurin (0,1 \%): $\quad$ Resazurin $100 \mathrm{mg}$

$$
\mathrm{H}_{2} \mathrm{O}_{\text {bidest. }} \text { ad } 100 \mathrm{ml}
$$

Das Medium wurde vor dem Autoklavieren durch dreimaliges Ent- bzw. Begasen mit Stickstoff bei einem Druck von 1 bar anaerobisiert, wobei am Ende ein geringer Überdruck in den Flaschen belassen wurde. Unmittelbar vor dem Animpfen wurde das Reduktionsmittel Titancitrat sowie gegebenenfalls wäßrige Glukosestammlösung $[40 \%$ (w/v)] steril zugegeben, da Glukose im Gegensatz zu Stärke vom Medium getrennt autoklaviert und anaerobisiert werden muß. Der anfänglich eingestellte pH-Wert von 7,6 stellt sich nach Zugabe aller Medienbestandteile bei $80{ }^{\circ} \mathrm{C}$ auf $\mathrm{pH}$ 6,8- 7,3 ein. Titancitrat wurde statt des einfacher zu handhabenden Natriumsulfids als Reduktionsmittel verwendet, da Natriumsulfid mit dem Medium ausfällt und so eine optische Messung der Zelldichte in der Kultur erschwert.

Titan(III)citrat-Lösung (nach Zehnder und Wuhrmann, 1976):

Kaliumcitrat $(0,2 \mathrm{M}) \quad 50 \mathrm{ml}$

Titan(III)chlorid [15\% (w/v)] $5 \mathrm{ml}$

Lagerung im Dunkeln und bei RT in einer Serumflasche unter $\mathrm{N}_{2}$-Atmosphäre

Beide Stammlösungen wurden unter anaeroben Bedingungen hergestellt. Der pH-Wert der Kaliumcitrat-Lösung wurde mit gesättigter $\mathrm{K}_{2} \mathrm{CO}_{3}$-Lösung auf $\mathrm{pH}$ 7,0 eingestellt, wobei ständig mit $\mathrm{N}_{2}$ begast, nicht aber durchgast wurde, da der $\mathrm{pH}$-Wert sonst nicht stabil blieb. Nach Zugabe der Titan(III)chlorid-Lösung wurde der pH-Wert erneut auf 7,0 eingestellt.

\subsection{Anzuchtbedingungen}

\subsubsection{Anzucht von $E$. coli und C. glutamicum}

Alle E. coli- und C. glutamicum-Stämme wurden aerob bei $37^{\circ} \mathrm{C}$ bzw. $30^{\circ} \mathrm{C}$ schwenkend auf einem Rundschüttler (Infors HT, Bottmingen, $\mathrm{CH}$ ) in Flüssigkulturen unter Selektionsdruck angezogen. Dabei wurden Reagenzgläser oder Erlenmeyerkolben verwendet, deren Volumina dem Zehnfachen des Kulturvolumens entsprachen. Für die Großanzucht zur Gewinnung rekombinanter Proteine wurden 2 l LB-Flüssigmedium auf zwei 5 l Erlenmeyerkolben mit Schikanen verteilt und aus einer Vorkultur 1 \%ig (v/v) angeimpft. Bei einer OD $_{600}$ von 0,7 wurden die Kulturen mit 1 mM IPTG induziert. Geerntet wurden die Zellen durch 15minütige 
Zentrifugation bei 8000 Upm in einer Kühlzentrifuge bei $4{ }^{\circ} \mathrm{C}$ (Sorvall ${ }^{\circledR} \mathrm{RC}-5 \mathrm{~B}$, Dupont). Die Kultivierung von E. coli-Stämmen auf LB-Platten erfolgte bei $37{ }^{\circ} \mathrm{C}$ über Nacht, die Kultivierung von C. glutamicum-Stämmen ebenfalls auf LB-Platten bei $30{ }^{\circ} \mathrm{C}$. C. glutamicum R163 wurde aufgrund seines langsameren Wachstums über 2-3 Tage kultiviert.

Die Kulturen wurden regelmäßig mikroskopisch (Olympus BX41) auf ihre Homogenität untersucht, insbesondere um eine Kontamination der C. glutamicum-Kulturen mit E. coli auszuschließen.

\subsubsection{Anzucht von E. coli B834 zur Inkorporation von Selenomethionin}

Zur de novo Lösung der Struktur von AmyB wurden multiwavelength anomalous diffraction (MAD)-Experimente durchgeführt, für die Protein benötigt wird, bei dem alle MethioninReste durch Selenomethionin substituiert sind. Zu diesem Zweck wurde der Methioninauxotrophe Stamm E. coli B834 (DE3) mit dem Plasmid pET24c::AB transformiert und in Methionin-supplementierten M9-Medium kultiviert. Die Großanzucht zur rekombinanten Gewinnung Selenomethion-haltigen AmyB-Proteins erfolgte in 1 l M9-Flüssigmedium in einem 5 l-Erlenmeyerkolben mit Schikanen. Die Kultur wurde 2 \%ig aus einer $30 \mathrm{ml}$ Vorkultur angeimpft und bei $30^{\circ} \mathrm{C}$ auf einem Rundschüttler (Infors HT, Bottmingen, CH) bei 120 Upm inkubiert. Neben Kanamycin zur Selektion plasmidhaltiger Zellen wurde zunächst auch L-Methionin (50 mg/l) der Kultur zugefügt. Nach 3,5 h Wachstum wurde bei einer $\mathrm{OD}_{600}$ von $\sim 0,8$ die Inkubation unterbrochen und die Zellen durch Zentrifugation (7000 Upm, $20 \mathrm{~min}, 4{ }^{\circ} \mathrm{C}$ ) geerntet. Das Zellpellet wurde in $1 \mathrm{l}$ M9-Medium ohne L-Methionin aufgenommen und die Inkubation bei $30{ }^{\circ} \mathrm{C}$ fortgesetzt. Nach $1 \mathrm{~h}$, in der im Medium eventuell noch vorhandene L-Methionin-Reste verbraucht werden sollten, wurde $50 \mathrm{mg} / \mathrm{l} \mathrm{DL}$ Selenomethionin der Kultur zugesetzt, und nach weiteren 30 min Inkubation wurde die Überexpression von AmyB durch Zugabe von 1 mM IPTG induziert. Nach Wachstum über Nacht wurde die Kultur durch Zentrifugation (7000 Upm, 15 min, $4{ }^{\circ} \mathrm{C}$ ) geerntet, die Zellen in $20 \mathrm{mM}$ Tris-Puffer (pH 8,0, mit 5 mM DTT) gewaschen und in $6 \mathrm{ml}$ des gleichen Puffers aufgenommen.

\subsubsection{Anzucht von T. maritima}

Die Anzucht von T. maritima erfolgte in mit Gummistopfen verschlossenen Serumflaschen (bis $100 \mathrm{ml}$ ) und Müller-Krempel-Flaschen (bis $500 \mathrm{ml}$ ). Vor dem Animpfen wurde das Medium auf $80{ }^{\circ} \mathrm{C}$ vorgewärmt. Alle Inokulierungen, Probenahmen und Zusätze von 
Lösungen wurden mit sterilen Spritzen und Kanülen durchgeführt, wobei versucht wurde, den Sauerstoffeintrag in die Kultur so gering wie möglich zu halten. Die Gummistopfen wurden vor dem Durchstechen mit der Kanüle mit 70 \%igen Ethanol abgeflammt. Kulturen für die Stammhaltung und für Passagen in ein anders Medium wurden 5 \%ig angeimpft, Kulturen für die Aufnahme der Wachstumskurve wurden 7,5 \%ig angeimpft. Die Inkubation erfolgte auf einem Rundschüttler (Innova 440 Incubator Shaker, New Brunswick, Nürtingen) bei 100 Upm, um eine gleichmäßige Verteilung der Zellen im Medium zu gewährleisten. Die Zellernte erfolgte unter aeroben Bedingungen durch Zentrifugation bei $8000 \mathrm{Upm}$ in einer Kühlzentrifuge bei $4{ }^{\circ} \mathrm{C}$ (Sorvall ${ }^{\circledR} \mathrm{RC}-5 \mathrm{~B}$, Dupont).

\subsection{Stammhaltung}

E. coli- und C. glutamicum- Stämme wurden bis zu vier Wochen auf LB-Platten bei $4{ }^{\circ} \mathrm{C}$ gelagert. Für eine langfristige Konservierung wurden Glycerinkulturen angelegt. Dazu wurden frische Übernachtkulturen mit sterilem Glycerin (87 \%) im Verhältnis 1:1 gemischt und bei $-70^{\circ} \mathrm{C}$ eingefroren. Anaerobe Kulturen von T. maritima wurden bis zu einem Jahr in einer Serumflasche bei $4{ }^{\circ} \mathrm{C}$ aufbewahrt.

\subsection{Messung der optischen Dichte}

Die optische Dichte von Flüssigkulturen wurde in Einmalküvetten mit einer Schichtdicke von $1 \mathrm{~cm}$ photometrisch bei einer Wellenlänge von $600 \mathrm{~nm}$ bestimmt (Ultraspec 3300 pro, Pharmacia Biotec), wobei als Nullwert unbeimpftes Medium verwendet wurde.

\subsection{Zellzahlbestimmung}

Die Gesamtzellzahl in Flüssigkulturen wurde durch Auszählen der Bakterienzellen mit Hilfe einer Neubauer-Zählkammer (Fa. Neubauer, Hamburg) unter dem Lichtmikroskop (Olympus BX41, Objektiv Plan 40x/0.65 Ph2, Okular 10x) bestimmt. Hierbei wurde auch die Reinheit der Kultur kontrolliert und die Zellmorphologie beobachtet.

Die verwandte Zählkammer bestand aus 9 b-Feldern, die wiederum in 16 c-Felder mit einer Fläche A von je 0,0025 mm² unterteilt waren. Der Abstand d vom Objektträger zu Deckglas betrug 0,01 mm. Die Zellzahl pro ml errechnet sich durch:

$$
\text { Zellzahl/ml = durchschnittliche Zellzahl pro c-Feld } \times \frac{1}{V_{c}}
$$


Dabei gilt für das Volumen eines c-Feldes $\mathrm{V}_{\mathrm{c}}$ :

$$
\begin{aligned}
\mathrm{V}_{\mathrm{C}} & =\mathrm{A} * \mathrm{~d} \\
& =0,0025 \cdot 0,01 \mathrm{~mm}^{3} \\
& =2,5 \cdot 10^{-8} \mathrm{ml}
\end{aligned}
$$

Die Zellzahl jeder Probe wurde dreifach bestimmt, wobei pro Zellzahlbestimmung 10 bFelder ausgezählt wurden, um statistisch signifikante Werte zu erhalten.

\section{Molekulargenetische Arbeitsmethoden}

\subsection{Grundlegende Techniken}

\subsubsection{Behandlung von Materialien und Lösungen für das Arbeiten mit Nukleinsäuren}

Um eine Kontamination durch Nukleasen zu vermeiden, wurden alle thermostabilen Lösungen, Glaswaren und anderen Materialien, die für das Arbeiten mit Nukleinsäuren notwendig waren, autoklaviert oder gegebenenfalls abgeflammt. Thermolabile Medienzusätze wie Antibiotika wurden sterilfiltriert. Des weiteren wurde die Arbeitsfläche regelmäßig mit 70 \%igem (v/v) Ethanol gesäubert.

\subsubsection{Phenol-Chloroform-Extraktion}

Zur Entfernung von Proteinen und anderen Verunreinigungen aus DNA-Lösungen wurden diese 1:1 mit einem Phenol/Chloroform/Isoamylalkohol-Gemisch [25:24:1 (v/v/v)] versetzt und kräftig gemischt. Zur Phasentrennung wurden die Proben 10 min bei 13000 Upm zentrifugiert (Minispin plus, Eppendorf, Hamburg) und die wäßrige, DNA-haltige Phase vorsichtig abgehoben. Zur Entfernung von Phenolresten wurde anschließend die Extraktion mit Chloroform/Isoamylalkohol [24:1 (v/v)] wiederholt.

\subsubsection{DNA-Fällung mit Isopropanol und Ethanol}

Die DNA-Lösungen wurden mit 0,1 Vol. einer $3 \mathrm{M}$ Natrium-Acetat-Lösung ( $\mathrm{pH} \mathrm{5,2)} \mathrm{und}$ 0,7 Vol. Isopropanol oder 3,5 Vol. eiskaltem, unvergälltem Ethanol (96 \% (v/v)) versetzt. Die DNA wurde dann mit Isopropanol 15 min bei RT bzw. mit Ethanol 30 min bis $12 \mathrm{~h}$ bei $-20{ }^{\circ} \mathrm{C}$ gefällt. Die gefällte DNA wurde durch 30 minütige Zentrifugation bei $13000 \mathrm{Upm}$ und $4{ }^{\circ} \mathrm{C}$ pelletiert (Biofuge fresco, Kendro, Osterode). Das Pellet wurde anschließend mit 70 \%igem $(\mathrm{v} / \mathrm{v})$ Ethanol (mind. $500 \mu \mathrm{l})$ gewaschen, in der Vakuumzentrifuge (Speed Vac ${ }^{\circledR}$ Plus

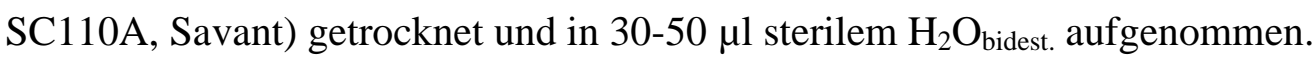




\subsection{Isolierung von Plasmid-DNA}

\subsubsection{Schnelle Plasmidisolierung aus E. coli (Cracking)}

Diese Methode dient ausschließlich der schnellen Analyse von E. coli-Transformanten, deren high-copy Plasmide durch Agarose-Gelelektrophorese (II.4.3.1) hinsichtlich ihrer Größe charakterisiert werden sollen. Der Vorteil dieser Methode liegt darin, daß als Ausgangsmaterial keine ÜN-Flüssigkultur benötigt wird, sondern daß die Plasmid-DNA direkt aus einer Kolonie von einer Agarplatte gewonnen wird.

\section{Durchführung:}

Eine frische Kolonie ausreichender Größe wurde mit einem Zahnstocher von der Agarplatte abgenommen und in $20 \mu \mathrm{l} 10 \mathrm{mM}$ EDTA (pH 8) resuspendiert. Es folgte die Zugabe von $20 \mu \mathrm{l}$ frisch angesetztem Aufschluß-Puffer (aus Stammlösungen) und eine fünfminütige Inkubation bei $70{ }^{\circ} \mathrm{C}$. Nach der Abkühlung auf Raumtemperatur wurden 1,5 $\mu \mathrm{l} 4 \mathrm{M} \mathrm{KCl}$ und 1,0 $\mu$ l DNA-Auftragspuffer (II.4.3.1) zugegeben. Alternativ konnte statt des DNAAuftragspuffers auch 1 \%ige (w/v) Bromphenolblau-Lösung verwendet werden. Der Ansatz wurde 5 min auf Eis inkubiert und anschließend 5 min bei $13000 \mathrm{Upm}\left(4^{\circ} \mathrm{C}\right)$ zentrifugiert. Zur Agarose-Gelelektrophorese (II.4.3.1) wurden $20 \mu \mathrm{l}$ des Überstandes direkt eingesetzt.

\section{Aufschluß-Puffer:}

$\begin{array}{rll}250 \mu \mathrm{l} & \mathrm{NaOH} & \text { (Stammlösung 4 M) } \\ 2,5 \mathrm{ml} & \text { Saccharoselösung } & \text { (Stammlösung 40\%) } \\ 500 \mu \mathrm{l} & \text { SDS } & \text { (Stammlösung 5\%) } \\ \text { ad } 5 \mathrm{ml} & \mathrm{H}_{2} \mathrm{O}_{\text {bidest. }} & \end{array}$

\subsubsection{Plasmidisolierung durch alkalische Lyse}

Grundlegend für diese Methode der Plasmidisolierung (nach Birnboim und Doly, 1979, mod.) ist, daß chromosomale DNA in einem pH-Bereich zwischen 12 und 12,5 denaturiert, während die als ccc-Form vorliegende Plasmid-DNA weitestgehend erhalten bleibt. Unter Einwirkung von SDS und $\mathrm{NaOH}$ (Puffer 2) erfolgt bei niedrigen Temperaturen eine Lyse der Bakterienzellwand und Denaturierung der hochmolekularen chromosomalen DNA. DNaseAktivität wird durch den hohen $\mathrm{pH}$-Wert sowie durch das EDTA in Puffer 1 verhindert. Durch Zugabe von Puffer 3 erfolgt eine Neutralisierung, welche eine Aggregation der chromosomalen DNA bewirkt. Weiterhin kommt es zur Präzipitation von Protein-SDSKomplexen und hochmolekularer RNA. Durch Zentrifugation sedimentieren die 
Makromoleküle und hochmolekularen Komplexe, während die Plasmid-DNA im Überstand bleibt, aus dem sie mit Hilfe von Isopropanol gefällt werden kann (II.4.1.3).

\section{Durchführung:}

Eine $5 \mathrm{ml}$ Kultur wurde unter Selektionsdruck bei $37{ }^{\circ} \mathrm{C}$ über Nacht angezogen. Anschließend wurden die Zellen in einem Eppendorf-Cup durch Zentrifugation (13000 Upm, 30 s) (Minispin plus, Eppendorf, Hamburg) geerntet. Das Pellet wurde in $200 \mu \mathrm{l}$ P1 (mit RNase) vollständig resuspendiert. Durch Zugabe von $200 \mu$ l P2 und 2x Schwenken wurden die Zellen lysiert. Es erfolgte gegebenenfalls eine 2 minütige Inkubation bei RT, bis die Lösung klar wurde. Zur Fällung von Proteinen und chromosomaler DNA wurde der Ansatz mit $200 \mu$ l P3 neutralisiert und nach 2x Schwenken für 5 min auf Eis inkubiert. Im Anschluß wurde die Probe bei $13000 \mathrm{Upm}\left(4{ }^{\circ} \mathrm{C}, 30 \mathrm{~min}\right.$ ) zentrifugiert. Der Überstand wurde in ein neues Eppendorf-Cup überführt, bei Bedarf mit Phenol extrahiert (II.4.1.2), und anschließend mit Isopropanol gefällt (II.4.1.3).

\section{Lösungen:}

\section{P1 (TE-Puffer):}

Tris- $\mathrm{HCl} \quad 50 \mathrm{mM}$

EDTA $10 \mathrm{mM}$

RNase A $200 \mu \mathrm{g} / \mathrm{ml} \quad$ (Stammlösung $10 \mathrm{mg} / \mathrm{ml}$ )

$\mathrm{pH} 8,0$

Zugabe der RNase-Lösung nach dem Autoklavieren, Lagerung bei $4{ }^{\circ} \mathrm{C}$.

\section{P2 (Lysis-Puffer):}

$\mathrm{NaOH} \quad 0,2 \mathrm{M}$

SDS $\quad 1 \%(\mathrm{w} / \mathrm{v})$

\section{P3 (Neutralisationspuffer):}

Kaliumacetat $3 \mathrm{M}$

pH 5,5 


\section{RNase Stammlösung (50x):}

RNase A $10 \mathrm{mg} / \mathrm{ml}$ gelöst in

$\begin{array}{ll}\text { Tris-HCl } & 50 \mathrm{mM} \\ \text { EDTA } & 10 \mathrm{mM} \\ \text { pH 8,0 } & \end{array}$

Die RNase Stammlösung wurde 15 min im Wassserbad gekocht. Nach dem Abkühlen erfolgte die Lagerung bei $-20^{\circ} \mathrm{C}$.

\subsubsection{Plasmidisolierung durch „QIAprep Spin Miniprep“}

Das Plasmidisolierungskit der Firma Qiagen (Hilden) ermöglicht die Präparation von etwa $20 \mu \mathrm{g}$ hochreiner DNA. Diese Methode basiert ebenfalls auf der alkalischen Lyse, verbunden mit der Verwendung einer Säule, an welche während der Aufreinigung die Plasmid-DNA selektiv bindet. Die Durchführung dieser Plasmid-Isolierung erfolgte gemäß der vom Hersteller mitgelieferten Versuchsvorschrift.

\subsubsection{Plasmidisolierung aus $C$. glutamicum}

Die dicke Zellwand der Gram-positiven C. glutamicum-Zellen erforderte einen Abbau der Zellwand vor der alkalischen Lyse. Dafür wurde das geerntete Zellpellet in $80 \mu \mathrm{T}$ TE-Puffer gelöst (II.4.2.2). Es wurden $10 \mu \mathrm{l}$ einer wäßrigen Lysozymlösung (100 mg/ml) zugesetzt und der Ansatz $1 \mathrm{~h}$ bei $37^{\circ} \mathrm{C}$ inkubiert. Um die Reaktion abzustoppen, wurden $10 \mu \mathrm{l}$ 0,5 M EDTA-Lösung hinzugegeben. Nach der Zugabe von weiteren $100 \mu$ l TE-Puffer wurde die alkalische Lyse wie unter II.4.2.2 und II.4.2.3 fortgeführt.

0,5 M EDTA:

$\begin{array}{ll}\text { EDTA } & 18.61 \mathrm{~g} \\ \mathrm{H}_{2} \mathrm{O}_{\text {bidest. }} & 100 \mathrm{ml} \\ \text { pH 8,0 } & \end{array}$




\subsection{Agarose-Gelelektrophorese}

\subsubsection{Analytische Agarose-Gelelektrophorese}

Bei der Agarose-Gelelektrophorese wandern die negativ geladenen Nukleinsäuren im elektrischen Feld zur Anode, wobei die Migrationsgeschwindigkeit der DNA-Fragmente von mehreren Faktoren abhängt, z.B. der Größe der Gelporen (bestimmt durch die Agarosekonzentration), der angelegten Spannung und der Salzkonzentration des Puffers. Die Auftrennung der DNA-Fragmente erfolgt entsprechend ihrer Größe, da die Laufgeschwindigkeit der Fragmente umgekehrt proportional zu ihrer Molekularmasse ist.

\section{Durchführung:}

Für die gelelektrophoretische Auftrennungen von Nukleinsäuren wurden horizontale Elektrophoresekammern (Hoefer $^{\circledR}$ HE33 Mini Horizontal Submarine Unit; Pharmacia Biotech) verwendet. Die Agarose-Gele bestanden aus 0,8 \% (w/v) Agarose in $1 \mathrm{x}$ TAEPuffer, welcher auch als Elektrophoresepuffer benutzt wurde. Die DNA-Proben wurden 5:1 mit DNA-Auftragspuffer gemischt, der sowohl zur Beschwerung der Proben als auch zur Markierung der Lauffront bei 500 bp diente. Die Auftrennung erfolgte bei einer konstanten Spannung von 70-100 V. Nach Beendigung der Gelelektrophorese wurden die Nukleinsäuren im Gel in einer wäßrigen Ethidiumbromid-Lösung $(1 \mu \mathrm{g} / \mathrm{ml})$ 10-20 min gefärbt und anschließend im Wasserbad kurz entfärbt. In der Gel-Dokumentationsanlage (BioRad ${ }^{\circledR}$ GelDoc 1000) wurde die DNA bei UV-Licht durch das eingelagerte Ethidiumbromid sichtbar gemacht, fotografisch dokumentiert und eventuell nachträglich bearbeitet (Multi-AnalystV.1.1.1.-Dokumentationsprogramm). Die Bestimmung der Größe von DNA-Fragmenten erfolgte nach an Hand der Laufstrecken eines mitaufgetrennten internen Standards. Als Größenstandard diente dabei eine 1 kB-Leiter (Gene Ruler ${ }^{\mathrm{TM}} 1 \mathrm{kB}$ DNA Ladder, MBI Fermentas), welche in einer Konzentration von 0,05 $\mu \mathrm{g} / \mu \mathrm{l}$ eingesetzt wurde.

\section{Lösungen:}

\section{Ethidiumbromid-Färbebad:}

$250 \mu \mathrm{l}$ einer $2 \mathrm{mg} / \mathrm{ml}$ Ethidiumbromidlösung in $500 \mathrm{ml} \mathrm{H} \mathrm{H}_{2} \mathrm{O}_{\text {bidest. }}$ 


\section{0x TAE-Puffer:}

Tris-HCl $242 \mathrm{~g}$

Eisessig $57,1 \mathrm{ml}$

$\mathrm{Na}_{2}$ EDTA* $2 \mathrm{H}_{2} \mathrm{O}$ $37,2 \mathrm{~g}$

$\mathrm{H}_{2} \mathrm{O}_{\text {bidest. }}$ ad $1000 \mathrm{ml}$

$\mathrm{pH} \mathrm{8,5}$

\section{0x DNA-Auftragspuffer (Beschwerlösung):}

Ficoll $400 \quad 7,5 \mathrm{~g}$

Bromphenolblau $50 \mathrm{mg}$

EDTA $(0,5 \mathrm{M}) \quad 10 \mathrm{ml}$

$\mathrm{H}_{2} \mathrm{O}_{\text {bidest. }} \quad$ ad $50 \mathrm{ml}$

\subsubsection{Präparative Agarose-Gelelektrophorese}

Prinzipiell wurde bei der präparativen Gelelektrophorese wie bei dem unter II.4.3.1 beschriebenen analytischen Verfahren vorgegangen. Um Interkalations- und UV-induzierte Schäden zu minimieren, wurden der Färbeschritt und die anschließende UV-Exposition möglichst kurz gehalten. Nach der Elektrophorese wurden definierte Banden mit einem Skalpell aus dem Gel herausgeschnitten. Zur Präparation der DNA aus dem Gelstück wurde das „QIAQuick Gel Extraction Kit“ (QIAGEN, Hilden) verwendet. Alle benötigten Protokolle und Reagenzien lagen dem Kit bei.

\subsection{Polymerase-Kettenreaktion (PCR)}

\subsubsection{Amplifikation von DNA-Fragmenten mit Hilfe der PCR}

Bei der PCR wird ein DNA-Molekül in vitro vervielfältigt. Falls erforderlich, werden die zu amplifizierenden DNA-Bereiche mit neuen Restriktionsschnittstellen versehen, weshalb die Primer entsprechend der neuen Schnittsequenzen Fehlpaarungen zum DNA-Matrizenstrang aufweisen können. Die Hybridisierungs (annealing)-Temperatur bei der PCR-Reaktion ist abhängig von der Länge und Zusammensetzung der Oligonukleotid-Primer. Je größer der G+C-Gehalt ist, desto höher liegt die Hybridisierungstemperatur. Es gilt die Näherung

$$
\mathrm{T}_{\mathrm{D}}\left({ }^{\circ} \mathrm{C}\right)=(2 \times[\mathrm{A}+\mathrm{T}]+4 \mathrm{x}[\mathrm{C}+\mathrm{G}]),
$$

wobei A, T, C und G Platzhalter für die Anzahl der jeweiligen Basen sind. Zur Durchführung der PCR-Läufe wurden programmierbare Thermoblöcke (Primus 25, MWG-Biotech, 
Ebersberg, oder MJ Research PTC-200 Gradient Cycler, Biozym, Hess. Oldendorf) verwendet. Die Primer wurden bei der MWG-Biotech AG (Ebersberg) in Auftrag gegeben.

Die Polymerase-Kettenreaktion wurde zur Amplifikation der zu klonierenden DNA und zur späteren Überprüfung der Klone eingesetzt. Für die Amplifikation der zu klonierenden Gene wurde Pfu-Polymerase (Promega, Mannheim) verwendet, da diese die Fähigkeit zum proofreading hat und somit eine geringere Fehlerrate als die Taq-Polymerase besitzt. Zur Überprüfung von rekombinanten Klonen wurde die PCR mit Taq-Polymerase (Eigenherstellung) durchgeführt. Dabei wurden entweder spezifische Primer oder T7-Primer verwendet, die für Regionen vor und nach der MCS des pET21/24c Vektors spezifisch sind. Die Sequenzen der Primer-Paare sind in Tab. 4 aufgeführt.

Die Reinigung der PCR-Amplifikate, die zur Klonierung eingesetzt werden sollten, von Primern, Polymerase und evtl. Nebenprodukten erfolgte durch präparative AgaroseGelelektrophorese und Aufreinigung mit Hilfe eines Kits (II.4.3.2).

Tab. 4: Für die PCR verwendete Primer. Bei der Amplifikation eingefügte Schnittstellen zur Klonierung sind unterstrichen.

\begin{tabular}{lll}
\hline Bezeichnung & Sequenz & $\begin{array}{c}\text { Schnitt- } \\
\text { stelle }\end{array}$ \\
\hline T7_fwd & TAATACGACTCACTATAGG & \\
T7_rev & CTAGTTATTGCTCAGCGG & \\
amyB_ctrl_fwd (=APM V) & CCAGAGGTGGTGAACG & \\
amyB_ctrl_rev (=APM R) & GAAAACACCACTTGGCGTC & \\
amyB_pWLQ2_fwd & GGCCCGGGATTGTGAGCGGATAACAATTCC & SmaI \\
amyB_pWLQ2_rev & GCTTGTCGACGGAGCTCGAAT & SalI \\
pWLQ2_ctrl_fwd & TGCGCCGACATCATAACGGTTCTGG & \\
pWLQ2_ctrl_rev & TGATGCCTGGCAGTTCCCTACTCTC & \\
Tt_amyB_fwd & ACCGTGGTACGCTAGGCATATGGCGCGCTTCG & NdeI \\
Tt_amyB_rev & GAACTGAAGCTTGGCGTGGCGCACCTCGG & HindIII \\
\hline
\end{tabular}

\subsubsection{Kolonie-PCR zur Klonüberprüfung}

Als schnelle Alternative zur herkömmlichen PCR, bei der als template isolierte DNA eingesetzt wurde, erfolgte die PCR-Überprüfung großer Zahlen rekombinanter E. coli-Klone durch Kolonie-PCR. Dabei wurden PCR-Ansätze im $35 \mu$ l Maßstab vorbereitet. Die gut gewachsenen Kolonien der zu testenden Klone wurden mit einem Zahnstocher von der 
Agarplatte abgenommen und in die PCR-Reaktionsgefäße überführt. Dabei genügte ein leichtes Abstreifen der Zahnstocherspitze an der Wand, um genügend Zellmaterial für die PCR in den Ansatz zu bringen.

\section{Mastermix für die Kolonie-PCR}

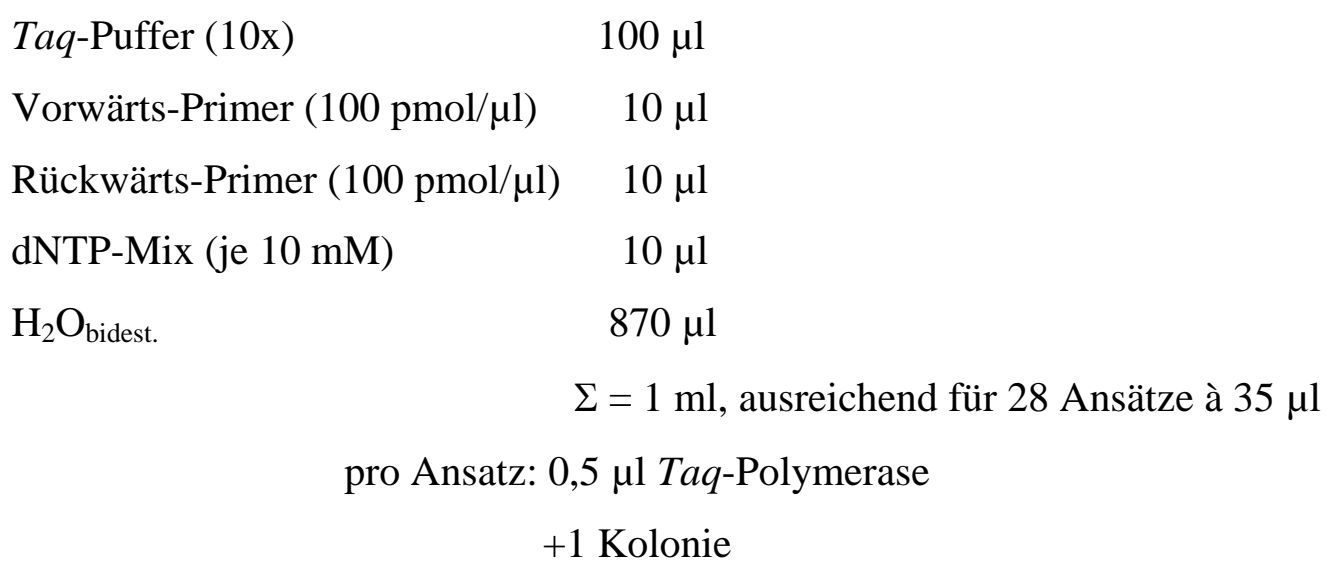

\subsubsection{Ortsspezifische Mutagenese}

Zur Einführung von Punktmutationen und damit zum gezielten Aminosäureaustausch wurde der QuikChangẹSite-Directed Mutagenesis Kit (Stratagene, Heidelberg) verwendet. Dem Kit liegt folgendes Prinzip zugrunde: Zwei synthetische Primer (mit der gewünschten Mutation in der Mitte) sind jeweils komplementär zu den antiparallelen DNA-Strängen des Vektors mit dem Zielinsert und werden mittels der PfuTurbo-DNA-Polymerase (Stratagene) verlängert (Tab. 5). Der Einbau der Oligonukleotid-Primer erzeugt ein mutiertes Plasmid mit Strangbrüchen. Nach der PCR wird das parentale DNA-Template mittels der DpnIEndonuklease, die spezifisch für (halb-) methylierte DNA ist, abgedaut. Die DNA aus fast allen E. coli-Stämmen ist Dam-methyliert und dem Angriff durch die Nuklease ausgesetzt, so daß letztlich eine Selektion für mutierte, nichtmethylierte, weil synthetisch entstandene, DNA erfolgt. Die verbleibende neue (mutierte) zirkuläre DNA wird in E. coli XL1-Blue transformiert und in den Zellen dann die Strangbrüche des mutierten Plasmides repariert. Die eigentliche Durchführung erfolgte nach dem vom Hersteller beigefügten Protokoll. 
PCR-Bedingungen:

$20 x\left[\begin{array}{lr}95^{\circ} \mathrm{C} & 30 \mathrm{~s} \\ 94^{\circ} \mathrm{C} & 30 \mathrm{~s} \\ 60^{\circ} \mathrm{C} & 1 \mathrm{~min} \\ 68^{\circ} \mathrm{C} & 10 \mathrm{~min} \\ 68^{\circ} \mathrm{C} & 2 \mathrm{~min}\end{array}\right.$
PCR Ansatz:

$\begin{array}{lc}\text { Pfu-Turbo Puffer (10x) } & 5 \mu \mathrm{l} \\ \text { template DNA (pET24c::AB) } & 1 \mu \mathrm{l}(100 \mathrm{ng}) \\ \text { Primer }(100 \mathrm{pmol} / \mu \mathrm{l}) & \text { je } 0,1 \mu \mathrm{l} \\ \text { dNTP-Mix }(10 \mathrm{mM}) & 1 \mu \mathrm{l} \\ \mathrm{H}_{2} 0_{\text {bidest. }} & \text { ad } 50 \mu \mathrm{l} \\ \text { Pfu-Turbo Polymerase } & 0,5 \mu \mathrm{l}\end{array}$

Tab. 5: Für die Cystein 186-Mutagenese verwendete Primer. Die eingefügte BglII Schnittstelle ist unterstrichen, das zum C186/S186 Austausch führende Codon ist fett gedruckt.

\begin{tabular}{ll}
\hline Bezeichnung & Primer-Sequenz \\
\hline AmyB_C186Mut_fwd & TTTGGCTTGCGGAAAGCGGATACTATCAGGGGCT_AGATCT \\
AmyB_C186Mut_rev & AGATCTAGCCCCTGATAGTATCCGCTTTCCGCAAGCCAAA \\
\hline
\end{tabular}

\subsection{Enzymatische Modifikation von DNA}

\subsubsection{Restriktionsverdau}

Diese Methode des Schneidens von DNA beruht auf der hohen Spezifität der aus Prokaryoten isolierten Restriktionsendonukleasen (Typ II) gegenüber ihrer meist palindromischen Erkennungssequenz im DNA-Doppelstrang. Die Enzyme hydrolysieren an definierten Stellen die Phosphodiester-Bindungen zwischen zwei Basen in beiden Strängen, woraus überhängende oder glatte Enden resultieren können.

\section{Durchführung:}

Die DNA-Lösungen wurden mit 1/10 Volumen des vom Hersteller empfohlenen 10fach

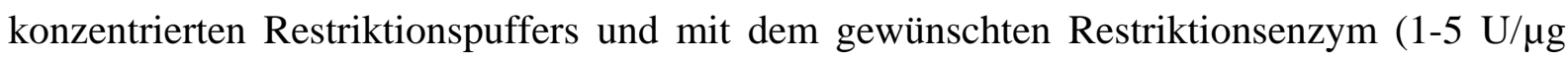
DNA) versetzt und für 1-2 h inkubiert. Bei Doppelverdauansätzen wurde ein Puffer verwendet, in dem beide Enzyme gut schneiden. Die Inkubationstemperatur lag bei $37^{\circ} \mathrm{C}$.

\section{Standard- Restriktionsansatz:}

$\begin{array}{lc}\text { DNA-Lösung } & \mathrm{x} \mu \mathrm{l} \\ \text { Restriktionspuffer (10x) } & 2 \mu \mathrm{l} \\ \mathrm{H}_{2} \mathrm{O}_{\text {bidest. }} & 18-\mathrm{x} \mu \mathrm{l} \\ + & 1-5 \mathrm{U} \text { Restriktionsenzym } / \mu \mathrm{g} \text { DNA }\end{array}$




\subsubsection{Dephosphorylierung von DNA-Fragmenten}

Zur Vermeidung von Selbstligationen restriktionsverdauter Vektor-DNA konnten gegebenenfalls die 5'-Phosphatgruppen enzymatisch mit alkalischer shrimp oder antarctic Phosphatase (Boehringer Mannheim, bzw. New England Biolabs, Frankfurt) abgespalten werden. Hierzu wurden direkt zum Restriktionsverdau-Ansatz (II.4.5.1) $2 \mu$ l PhosphatasePuffer (10x) (Boehringer Mannheim) und 1,5 $\mu$ l Phosphatase gegeben. Nach einer 30minütigen Inkubation bei $37^{\circ} \mathrm{C}$ wurde nochmals $1 \mu \mathrm{l}$ Phosphatase zugegeben. Eine weitere Inkubation von 30 min schloß sich an. Nach einer Hitzeinaktivierung für 10 min bei $75{ }^{\circ} \mathrm{C}$ und einer Phenol/Chloroform/Isoamylalkohol-Extraktion mit anschließender Ethanolfällung (II.4.1.2, 4.1.3) konnte der Ansatz zur Ligation verwendet werden.

\subsubsection{Generierung von A-Überhängen}

Zur Ligation in den pDrive Vektor war es nötig, an die Produkte der PCR mit PfuPolymerase, die glatte Enden hatten, A-Überhänge am 3'-Terminus anzufügen. Dazu wurde das PCR-Produkt gereinigt (II.4.3.2) und einer Verlängerungsreaktion mit Taq-Polymerase bei $72{ }^{\circ} \mathrm{C}$ für $20 \mathrm{~min}$ in einem Thermocycler (MWG, Ebersberg) unterworfen. Die Ligation des aufgereinigten PCR-Produkts in den Vektor pDrive erfolgte nach Anleitung des Herstellers (Novagen).

Reaktionsansatz:

aufgereinigtes Pfu-PCR Produkt $\quad 15 \mu \mathrm{l}$

Taq-Puffer $\quad 5 \mu \mathrm{l}$

dNTPs $(2 \mathrm{mM}) \quad 4 \mu \mathrm{l}$

dATP $(2 \mathrm{mM}) \quad 2 \mu \mathrm{l}$

Taq-Polymerase $\quad 0,5 \mu \mathrm{l}$

$\mathrm{H}_{2} \mathrm{O}_{\text {bidest. }} \quad$ ad $50 \mu \mathrm{l}$

\subsubsection{Ligation von DNA}

Die T4-Ligase katalysiert unter ATP-Verbrauch die Bildung von Phosphodiester-Bindungen zwischen 5‘-Phosphat- und 3‘-Hydroxyl-Enden von DNA. Das Verhältnis von Insert-DNA zu Vektor-DNA sollte dabei idealerweise 5:1 betragen. Vor der Ligation wurden die Restriktionsenzyme in den DNA-haltigen Lösungen durch eine Hitzebehandlung (10 min, $70^{\circ} \mathrm{C}$ ) inaktiviert, oder es wurden Fragmente verwendet, die in einem präparativen Agarosegel aufgereinigt worden waren (II.4.3.2) Dem Ligationsansatz (20 $\mu$ l) wurden 
1/10 Vol. eines zehnfach konzentrierten ATP-haltigen Ligationspuffers und 0,5 $\mu$ l (1 Unit) T4-DNA-Ligase (beides Promega) zugesetzt. Ligationen von DNA-Fragmenten mit kohäsiven Enden erfolgten bei $16{ }^{\circ} \mathrm{C}$ und von Fragmenten mit glatten Enden (Zugabe von 0,1 Vol. 50 \%igem (v/v) Polyethylenglykol (PEG) zur Erhöhung der Viskosität) bei Raumtemperatur jeweils über Nacht.

\subsection{Transformationsverfahren}

\subsubsection{Herstellung kompetenter Zellen für die Transformation}

Eine Hauptkultur (250 ml SOB-Medium, in $1 \mathrm{l}$ Schikanekolben) wurde mit $1 \mathrm{ml}$ einer exponentiell wachsenden E. coli-LB-Vorkultur angeimpft und bei $18{ }^{\circ} \mathrm{C}$ im Schüttelwasserbad (Gyrotory, Modell G76, New Brunswick Scientific, Edison, NY, USA) bis zu einer OD $_{600}$ von 0,6-0,7 etwa 24 h angezogen. Nach 10minütiger Abkühlung auf Eis wurden die Zellen durch Zentrifugation (10 min, $5000 \mathrm{Upm}, 4{ }^{\circ} \mathrm{C}$, GSA-Rotor) geerntet, in $80 \mathrm{ml}$ eiskaltem TB-Puffer vorsichtig resuspendiert, weitere $10 \mathrm{~min}$ auf Eis gestellt und nochmals abzentrifugiert. Das Pellet wurde in $20 \mathrm{ml}$ kaltem TB-Puffer aufgenommen, mit 1,4 ml DMSO (Endkonzentration: $7 \%(\mathrm{v} / \mathrm{v})$ ) versetzt, sorgfältig gemischt, erneut $10 \mathrm{~min}$ auf Eis gestellt und in Aliquots à $200 \mu \mathrm{l}$ auf vorgekühlte Eppendorf-Cups aufgeteilt. Die Zellen wurden sofort in flüssigem Stickstoff eingefroren und bei $-70^{\circ} \mathrm{C}$ gelagert.

\section{Lösungen:}

SOB-Medium (nach Hanahan, 1983):

$\begin{array}{lc}\text { Trypton } & 2,0 \%(\mathrm{w} / \mathrm{v}) \\ \text { Hefeextrakt } & 0,5 \%(\mathrm{w} / \mathrm{v}) \\ \mathrm{NaCl} & 10 \mathrm{mM} \\ \mathrm{KCl} & 2,5 \mathrm{mM} \\ \mathrm{MgCl}_{2} & 10 \mathrm{mM} \\ \mathrm{MgSO}_{4} & 10 \mathrm{mM}\end{array}$

Die Magnesiumsalze wurden aus getrennt autoklavierten Stammlösungen (1 $\mathrm{M} \mathrm{MgCl}_{2} / 1 \mathrm{M}$ $\mathrm{MgSO}_{4}$ ) zugegeben. 


\section{TB-Puffer:}

Pipes-Puffer

$10 \mathrm{mM}$

$\mathrm{MnCl}_{2}$

$55 \mathrm{mM}$ (getrennt autoklaviert)

$\mathrm{CaCl}_{2}$

$15 \mathrm{mM}$

$\mathrm{KCl}$

$250 \mathrm{mM}$

$\mathrm{pH} 6,7$

\subsubsection{Transformation durch Hitzeschock}

Die kompetenten Zellen (E. coli XL1-blue oder DH5 $\alpha$ ) wurden 5 min auf Eis aufgetaut, mit $5 \mu$ Ligationsansatz (10-150 ng DNA) pro $100 \mu$ l Zellen gemischt und für 30 min auf Eis inkubiert. Bei einem Hitzeschock von 90 s bei $42{ }^{\circ} \mathrm{C}$ erfolgte dann die Aufnahme der DNA. Im Anschluß wurden die Zellen nochmals 3 min auf Eis inkubiert, bevor $800 \mu$ l LB-Medium dazugegeben wurden. Der Ansatz wurde $1 \mathrm{~h}$ bei $37^{\circ} \mathrm{C}$ zur Ausprägung der Selektivmarker inkubiert, auf Agarplatten unter Selektivbedingungen ausplattiert $(100 \mu \mathrm{l})$ und bei $37^{\circ} \mathrm{C}$ über Nacht inkubiert.

\subsubsection{Herstellung kompetenter $E$. coli-Zellen für die Elektroporation}

Vornehmliches Ziel der Zellpräparation ist die Beseitigung von Salzen aus der Zellsuspension, da diese die Elektroporation stören. Aus einer gut angewachsenen E. coliVorkultur wurden 500 ml LB-Medium 1 \%ig angeimpft und auf dem Rundschüttler bis zu einer $\mathrm{OD}_{600}$ von 0,5-0,6 inkubiert. Nach dem Abkühlen des Mediums in Eiswasser (ca. 10 min) wurden die Zellen in sterilen GSA-Zentrifugenbechern geerntet (5000 Upm, 20 min, $4{ }^{\circ} \mathrm{C}$ ). Das Pellet wurde in der verbliebenen Flüssigkeit resuspendiert und mit eiskaltem, sterilem $\mathrm{H}_{2} \mathrm{O}_{\text {bidest. }}$ gewaschen. Nach einer weiteren Zentrifugation (5000 Upm, 20 min, $4{ }^{\circ} \mathrm{C}$ ) wurde das Pellet in $40 \mathrm{ml}$ eiskaltem, $10 \%$ igem (v/v) Glycerin aufgenommen. Im Anschluß an eine erneute Zentrifugation (5000 Upm, $10 \mathrm{~min}, 4{ }^{\circ} \mathrm{C}$ ) wurde das Volumen des Pellets abgeschätzt, und die Zellen mit dem gleichen Volumen 10 \%igen (v/v) Glycerin versetzt. Die Zellen wurden aliquotiert $(60 \mu \mathrm{l})$ und entweder sofort für eine Transformation genutzt oder bei $-70^{\circ} \mathrm{C}$ gelagert. 


\subsubsection{Herstellung kompetenter C. glutamicum-Zellen für die Elektroporation (nach Van der Rest et al., 1999)}

Eine 10 ml LB-Vorkultur mit 2 \% Glukose wurde mit einer Einzelkolonie C. glutamicum angeimipft und über Nacht bei $30{ }^{\circ} \mathrm{C}$ inkubiert. Die Hauptkultur erfolgte in einem 1lErlenmeyerkolben in $100 \mathrm{ml}$ LB-Medium unter Zusatz von $20 \mathrm{ml}$ frisch angesetzter EpoAdditiv-Lösung, wobei die Hauptkultur mit der gesamten 10 ml-Vorkultur inokuliert wurde. Die Inkubation erfolgte bei $18{ }^{\circ} \mathrm{C}$ und $120 \mathrm{Upm}$ auf einem Rundschüttler. Die suboptimale Wachstumstemperatur und die Anwesenheit von Isoniazid, einem Inhibitor der MycolsäureSynthese, behindern das Wachstum derart, daß die finale $\mathrm{OD}_{600}$ der Kultur 0,6 nicht überschreitet. Nach 28 h Inkubation wurde die Kultur 20 min auf Eis gekühlt und die Zellen anschließend durch Zentrifugation (500 Upm, $10 \mathrm{~min}, 4^{\circ} \mathrm{C}$ ) geerntet. Das Zellpellet wurde viermal in $50 \mathrm{ml}$ eiskaltem, 10 \%igem (v/v) Glycerin gewaschen. Nach erneuter Zentrifugation (500 Upm, $10 \mathrm{~min}, 4^{\circ} \mathrm{C}$ ) wurde das Volumen des Pellets abgeschätzt, und die Zellen mit dem gleichen Volumen 10 \%igen (v/v) Glycerin versetzt. Die Zellen wurden aliquotiert $(100 \mu \mathrm{l})$ und entweder sofort für eine Transformation genutzt oder bei $-70{ }^{\circ} \mathrm{C}$ gelagert.

\section{Epo-Additiv-Lösung:}

$\begin{array}{lc}\text { Isoniazid } & 400 \mathrm{mg} \\ \text { Glycin } & 2,5 \mathrm{~g} \\ \text { Tween } 80 & 100 \mu \mathrm{l} \\ \mathrm{H}_{2} \mathrm{O}_{\text {bidest. }} & \text { ad } 20 \mathrm{ml}\end{array}$

Unmittelbar vor der Inokulation frisch ansetzen.

\subsubsection{Elektroporation}

Setzt man biologische Membranen einem starken elektrischen Feld aus, werden sie porös. DNA, die sich außerhalb der Zellmembran befindet, kann während eines elektrischen Impulses durch die entstehenden Poren in die Zellen eindringen. Die Elektroporation ist empfindlich gegenüber Salz-Ionen. Falls DNA-Lösung aus einem Ligationsansatz direkt für die Elektroporation eingesetzt wird, muß diese vorher in einer Mikrodialyse mit Hilfe von auf $\mathrm{H}_{2} \mathrm{O}_{\text {bidest. }}$ schwimmenden Membranfiltern (0,025 $\mu \mathrm{m}$, VSWP01300, Millipore, Eschborn) 20 min dialysiert werden. Die Elektroporation erfolgte bei E. coli und C. glutamicum nach 
demselben Protokoll, wobei die C. glutamicum-Zellen in einem speziellen Regenerationsmedium aufgenommen wurden.

\section{Durchführung:}

Die eingefrorenen Zellen (II.4.6.3, 4.6.4) wurden schonend auf Eis aufgetaut. Nach Zugabe von 0,1-1 $\mu$ g DNA-Lösung (2-5 $\mu \mathrm{l})$ wurde der Ansatz in vorgekühlte, sterile Elektroporationsküvetten pipettiert und für 2 min auf Eis inkubiert. Die Zellen wurden dann in einem Elektroporationsgerät (Gene-Pulser ${ }^{\circledR}$ II, Bio-Rad GmbH, München) unter den folgenden Bedingungen elektroporiert:

Kapazität: $\quad 25 \mu \mathrm{Fd}$

Spannung: $\quad 2,5 \mathrm{kV}$

Widerstand: $200 \Omega$

Die sich ergebenden Entladungszeiten sollten zwischen 4,5 und 5 ms liegen. Sofort nach erfolgter Elektroporation wurde bei E. coli-Zellen $1 \mathrm{ml} \mathrm{LB-Medium} \mathrm{und} \mathrm{bei} \mathrm{C.} \mathrm{glutamicum-}$ Zellen $1 \mathrm{ml}$ auf $30{ }^{\circ} \mathrm{C}$ vorgewärmtes BHIS-Medium zugesetzt. Die Zellen wurden für eine Stunde bei $37{ }^{\circ} \mathrm{C}$ bzw. $30{ }^{\circ} \mathrm{C}$ zur Expression der Selektionsmarker und zur allgemeinen Regeneration inkubiert. Danach erfolgte das Ausplattieren $(20-100 \mu \mathrm{l})$ auf Selektivnährböden (LB bzw. LBHIS).

\subsubsection{X-Gal Test zur Detektion rekombinater $E$. coli-Klone}

Dieser Test wurde neben den plasmidkodierten Antibiotikaresistenzen zur Selektion rekombinanter Klone verwendet und basiert auf der Grundlage, daß die $\beta$-Galaktosidase $\mathrm{x}$-Gal enzymatisch spaltet, und daß das Reaktionsprodukt durch Luftoxidation zu einem blauen Indigofarbstoff (5-Brom-4-chlor-indigo) umgewandelt wird. Das Plasmid pDrive beinhaltet das 5'-Ende des lacZ-Gens, welches für das $\alpha$-Peptid der $\beta$-Galaktosidase kodiert. Die Plasmide der pBluescript-Reihe enthalten zusätzlich dazu auch den Promotor- und Operatorbereich des lac-Operons. Das lacZ-Genprodukt kann die durch Deletion verkürzte, inaktive $\beta$-Galaktosidase diverser $\quad E$. coli-Klonierungsstämmen (DH5 $\alpha, \quad$ XL1-Blue) komplementieren. IPTG wird dabei als künstlicher Induktor der $\beta$-Galaktosidase-Gene in den Zellen verwendet. Für diesen Test wurden $100 \mu$ l einer transformierten E. coli-Suspension auf selektiven Nährböden ausplattiert, die IPTG und x-Gal enthielten. Nach dem Wachstum konnten die Kolonien anhand ihrer Färbung unterschieden werden. Blaue Kolonien enthielten das religierte Plasmid, während bei weißen Klonen mit hoher Wahrscheinlichkeit eine 
Insertion in der Multiklonierungsstelle (MCS) des lacZ-Gens stattgefunden hatte, so daß entweder kein vollständiges Transkript mehr gebildet wird (wenn die integrierte DNA einen Transkriptionsterminator trug) oder es zur Bildung eines Hybridproteins kommt, welches keine funktionelle $\alpha$-Komplementation im Wirtsorganismus ermöglicht.

\section{Proteinbiochemische Methoden}

\subsection{Standardtechniken}

\subsubsection{Quantitative Proteinbestimmung (Bradfordtest)}

Für eine quantitative Proteinbestimmung wurde der „Protein Assay Kit“ von der Firma BioRad (München) verwendet, der auf der colorimetrischen Methode von Bradford (1976, mod.) basiert. Der anionisch vorliegende Farbstoff Coomassie Brilliant Blue G250 bindet dabei an positiv geladene Aminosäuren der Proteine. Maximal können Proteinmengen von 10 $\mu \mathrm{g}$ bestimmt werden. Die untere Nachweisgrenze liegt bei $1 \mu \mathrm{g}$.

\section{Durchführung:}

Die Proteinlösung wurde mit $1 \mathrm{ml}$ der nach Angaben des Herstellers (Konzentrat-Verdünnung 1:5 mit $\mathrm{H}_{2} \mathrm{O}$ ) angefertigten Färbelösung versetzt, der Ansatz gut gemischt und für 10 min bei RT im Dunkeln inkubiert. Nach nochmaligem Durchmischen erfolgte die Messung der OD bei 595 nm gegen eine Nullprobe ohne Protein. Die Quantifizierung erfolgte mit Hilfe einer Eichergeraden, die mit BSA im Bereich von 0-20 $\mu$ g Protein/Ansatz erstellt wurde.

\subsubsection{SDS-Polyacrylamid-Gelelektrophorese (SDS-PAGE)}

Mit Hilfe der SDS-PAGE (nach Laemmli, 1970, mod.) lassen sich Proteine entsprechend ihrer molaren Massen auftrennen, wobei Dimere bzw. Multimere in ihre Untereinheiten zerteilt werden. Die meisten Proteine binden SDS in einem konstanten Verhältnis. Dodecylsulfat überträgt auf die Proteine eine sehr hohe negative Ladung, wodurch die eigentliche Ladung des Proteins maskiert wird. SDS-beladene Proteine liegen somit in einem konstanten Ladungs-Masse-Verhältnis vor. Für die Trennleistung in einem bestimmten Molekularmassenbereich ist der Vernetzungsgrad des Acrylamid/Bisacrylamid-Gels entscheidend. Zur Auftrennung von Proteinen mit Molekularmassen im Bereich von 10180 kDa wurde ein 10 \%iges Gel verwendet. 


\section{Lösungen:}

Acrylamid-Stammlösung (AA):

Acrylamid/Bisacrylamid-Lösung (24:1) 40 \% (w/v)

\section{Trenngel-Stammlösung (TG):}

Tris

SDS

$\mathrm{H}_{2} \mathrm{O}_{\text {bidest. }}$

pH 8,8

10 x Elektrophorese-Puffer :

Tris

Glycin

SDS

$\mathrm{H}_{2} \mathrm{O}_{\text {bidest. }}$

$\mathrm{pH} 8,4$

Ammoniumpersulfat (APS):

$10 \%$ APS (w/v) in $\mathrm{H}_{2} \mathrm{O}_{\text {bidest. }}$
Sammelgel-Stammlösung (SG):

Tris

$6,1 \mathrm{~g}$

$0,4 \mathrm{~g} \quad$ SDS

$0,4 \mathrm{~g}$

ad $100 \mathrm{ml}$

$\mathrm{H}_{2} \mathrm{O}_{\text {bidest. }}$

ad $100 \mathrm{ml}$

pH 6,8

\section{4 x Probenpuffer:}

$\begin{array}{rlr}30,3 \mathrm{~g} & \text { Glycerin [87\% w/v)] } & 7,5 \mathrm{ml} \\ 144,1 \mathrm{~g} & \beta \text {-Mercaptoethanol } & 2,5 \mathrm{ml} \\ 10,0 \mathrm{~g} & \text { SDS } & 1,2 \mathrm{~g} \\ \text { ad } 1000 \mathrm{ml} & \text { Bromphenolblau } & \\ & {[2 \%(\mathrm{w} / \mathrm{v})]} & 0,5 \mathrm{ml} \\ & \text { Tris-HCl } & 0,4 \mathrm{~g} \\ & \mathrm{H}_{2} \mathrm{O}_{\text {bidest. }} & \text { ad } 50 \mathrm{ml}\end{array}$

Durchführung:

Herstellung der Gele:

Zunächst wurden die Glasplatten und Spacer gründlich mit 70 \%igem (v/v) EtOH gereinigt und in den Gießstand eingespannt. Das Trenngel wurde nach dem unten aufgeführten Pipettierschema ohne APS und TEMED zusammenpipettiert und gründlich durchmischt. Nach Zugabe von APS und TEMED und wiederholtem Mischen wurde der Ansatz bis $2 \mathrm{~cm}$ unter den oberen Rand der Glasplatten gegossen. Um einen luftblasenfreien Abschluß des Trenngels zu erhalten, wurde es bis zum Rand der Glasplatten mit EtOH (70\% (v/v)) oder $\mathrm{H}_{2} \mathrm{O}_{\text {bidest. }}$ überschichtet. Nach der Polymerisation des Trenngels wurde das Sammelgel ebenfalls nach dem unten aufgeführten Pipettierschema vorbereitet und auf das Trenngel gegossen. Danach wurde der Kamm möglichst ohne Luftblasen eingesetzt. 


\section{Pipettierschema (für ein Gel):}

\section{Lösung}

AA (40 \%ig (w/v))

TG

SG

$\mathrm{H}_{2} \mathrm{O}_{\text {bidest. }}$

TEMED

APS

\section{Trenngel $10 \%$}

$1 \mathrm{ml}$

$1 \mathrm{ml}$

$--$

$2 \mathrm{ml}$

$3 \mu \mathrm{l}$

$30 \mu \mathrm{l}$

\section{Sammelgel $3 \%$}

$0,2 \mathrm{ml}$

$0,48 \mathrm{ml}$

$1,32 \mathrm{ml}$

$2 \mu \mathrm{l}$

$15 \mu \mathrm{l}$

Probenvorbereitung:

Die Proteinproben wurden mit Probenpuffer gemischt (1:4) und anschließend mindestens 5 min bei $95{ }^{\circ} \mathrm{C}$ denaturiert. Danach erfolgte eine kurze Zentrifugation mit $13000 \mathrm{Upm}$, um das Kondenswasser aus dem Deckel des Eppendorf-Cups zu entfernen.

Elektrophorese:

Das Gel wurde in der Elektrophoresekammer fixiert (BioRad Mini-PROTEAN II Cell 10/0,75 $\mathrm{cm}$ ). Sowohl Anoden- als auch Kathodenraum wurden mit $1 \mathrm{x}$ Elektrophoresepuffer befüllt. Die Geltaschen konnten nach vorsichtigem Herausziehen des Kamms mit bis zu $20 \mu$ Probe beladen werden. Die Elektrophorese wurde bei einer konstanten Stromstärke von zunächst 15 mA, später $30 \mathrm{~mA}$ pro Gel in der Kammer durchgeführt, bis die blaue Lauffront das untere Ende des Gels erreicht hatte (etwa 45-60 min).

\subsubsection{Nativ-Polyacrylamidgelelektrophorese (Nativ-PAGE)}

Bei dieser Methode erfolgt die Auftrennung von Proteinen im elektrischen Feld in Abhängigkeit ihrer Ladung und Größe bei gegebenem pH-Wert des Elektrophoresepuffers und gegebenem Vernetzungsgrad des Polyacrylamids. Die nativen Proteingele wurden auf dieselbe Weise wie die SDS-Gele (II.5.1.2) angefertigt und bestehen ebenfalls aus einem Trenn- und einem Sammelgel. Anstelle von SDS-haltigen Lösungen wurden die unter II.5.1.2 aufgeführten Lösungen ohne SDS eingesetzt.

\section{Durchführung:}

Die Proteinproben wurden 4:1 mit Probenpuffer versetzt und ohne vorherige Denaturierung in die Geltaschen gefüllt. Nach einem Vorlauf von $15 \mathrm{~min}$ bei $50 \mathrm{~V}$ erfolgte die elektrophoretische Auftrennung der Proteine bei $100 \mathrm{~V}$. 


\section{4 x Probenpuffer für native Gele:}

$\begin{array}{lc}\text { Glycerin [87 \% (v/v)] } & 7,5 \mathrm{ml} \\ \text { Bromphenolblau [2 \% (w/v)] } & 0,5 \mathrm{ml} \\ \text { Tris-HCl } & 0,4 \mathrm{~g} \\ \mathrm{H}_{2} \mathrm{O}_{\text {bidest. }} & \text { ad } 25 \mathrm{ml} \\ \text { pH 6,8 } & \end{array}$

\subsubsection{Coomassie-Färbung von Proteinen in Polyacrylamid-Gelen}

Die SDS-Gele wurden nach Beendigung der Elektrophorese kurz mit $\mathrm{H}_{2} \mathrm{O}$ gespült und dann für 30 min in der Färbelösung unter Schwenken gefärbt. Nach Spülen mit Wasser wurde das Gel in Entfärbelösung, welche mehrmals erneuert wurde, geschwenkt, bis der Hintergrund des Gels farblos war. Die fertigen SDS-Gele konnten danach zur dauerhaften Konservierung luftblasenfrei zwischen zwei Lagen Cellophanfolie im Gel-Air-Dryer (BioRad, München) für eine Stunde getrocknet werden.

\section{Lösungen:}

\section{Coomassie-Färbelösung:}

Coomassie-Brilliant-Blue R $250 \quad 1,5 \mathrm{~g}$

Methanol $455 \mathrm{ml}$

Eisessig $\quad 80 \mathrm{ml}$

$\mathrm{H}_{2} \mathrm{O}_{\text {bidest. }} \quad$ ad $1000 \mathrm{ml}$

mehrfach verwendbar

\section{Entfärbelösung:}

Methanol

$250 \mathrm{ml}$

Eisessig

$350 \mathrm{ml}$

$\mathrm{H}_{2} \mathrm{O}_{\text {bidest. }}$

ad $1000 \mathrm{ml}$

\subsubsection{Größenbestimmung von Proteinen}

Die Bestimmung von Proteingrößen erfolgte nach Auftrennung in der SDS-PAGE (II.5.1.2) im Vergleich zur Laufstrecke eines im gleichen Gel aufgetrennten internen Standards. Als Größenstandard diente dabei der „High Molecular Weight Standard“ (Sigma), welcher aus folgenden sechs Proteinen besteht: 


\section{Markerproteine:}

Myosin, Kaninchenmuskel

$\beta$-Galactosidase, E. coli

Phosphorylase b, Kaninchenmuskel

Albumin, Rind

Albumin, Hühnerei

Carboanhydrase, Rinder- Erythrocyten 29000

\section{Molekularmasse [Da]}

205000

116000

97400

66000

45000

\subsubsection{Amylase-Aktivitätsfärbung nach SDS-PAGE}

Die Aktivitätsfärbung im SDS-PAGE-Gel beruht auf der Möglichkeit der Renaturierung der in der SDS-PAGE (II.5.1.2) aufgetrennten Proteine und der dadurch möglichen Rekonstitution der enzymatischen Aktivität. So können mit geeigneten Detektionsverfahren die Positionen der enzymatisch aktiven Proteinbanden im SDS-Gel bestimmt werden und Rückschlüsse auf deren Molekularmasse gezogen werden.

\section{Durchführung:}

Nach der Elektrophorese wurde das SDS-PAGE-Gel in kurz gewässert und anschließend in 200-400 ml Puffer I überführt. Nach 45 min Inkubation bei RT wurde das Gel in über Nacht in 200-400 ml Puffer II inkubiert. Im gleichen Puffer wurde das Gel dann je nach Enzymaktivität für 15 min - 3 h bei der für das jeweilige Enzym optimalen Temperatur inkubiert. Für AmyA-Ag und AmyB-Ag waren dies 15 min bei $75^{\circ} \mathrm{C}$. Das Gel wurde kurz gewässert und die Aktivitätsbanden dann durch Zugabe von Lugol'scher Lösung in Form von hellen Höfen sichtbar gemacht.

\section{Lösungen:}

\section{Puffer I:}

Phosphatpuffer (pH 7,0) (abhängig vom Enzym) 0,2 M

\section{Puffer II:}

Phosphatpuffer (pH 7,0) (abhängig vom Enzym) 0,2 M

lösliche Stärke $1 \%(\mathrm{w} / \mathrm{v})$ 


\section{Lugol'sche Lösung:}

$\begin{array}{ll}\mathrm{I}_{2} & 1 \mathrm{~g} \\ \mathrm{KI} & 2 \mathrm{~g} \\ \mathrm{H}_{2} 0_{\text {dest. }} & \text { ad } 300 \mathrm{ml}\end{array}$

\subsubsection{Umpufferung durch Dialyse}

Entsalzung und Umpufferung von Proteinlösungen wurden durch Dialyse in Dialyseschläuchen durchgeführt (VISKING ${ }^{\circledR}$ Dialysis Tubing, Serva, Heidelberg). Zunächst wurde ein angemessen großes Schlauchstück abgeschnitten, wobei $1 \mathrm{~cm}$ Dialyseschlauch ca.

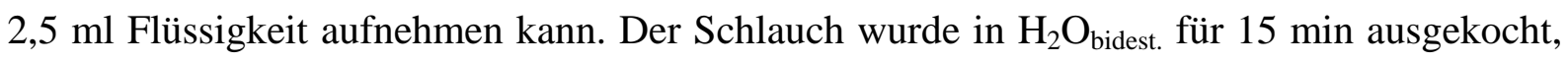
anschließend mit der Proteinlösung befüllt und an beiden Enden mit Dialyseklammern abgedichtet. Die Dialyse erfolgte über Nacht unter leichtem Rühren gegen 2-5 1 Puffer bei $4{ }^{\circ} \mathrm{C}$ im Kühlraum.

\subsubsection{Konzentration von Proteinlösungen}

Um Proteinlösungen einzuengen, wurden Mikrokonzentratoren (Amicon Ultra, Millipore, Cork, Irland) mit einem Ausschlußgröße von 10 kDa bzw. 30 kDa verwendet. Dabei konnten Proteinlösungen von $14 \mathrm{ml}$ auf $200 \mu \mathrm{l}$ eingeengt werden. Die Zentrifugation erfolgte in einer Kühlzentrifuge (Centrifuge 5804, Eppendorf, Hamburg) bei 3000 Upm.

\subsection{Zellernte und Rohextraktgewinnung}

\subsubsection{Zellernte}

Zur Gewinnung von Rohextrakten wurden E. coli-, C. glutamicum- und T. maritima-Zellen in Flüssigkultur angezogen und, wie unter II.3.2 beschrieben, geerntet. Das Pellet wurde entsprechend den weitern Erfordernissen in Puffer aufgenommen, i.d. R. 20 mM Tris-Puffer (pH 8,0). Dieser Puffer diente auch als Waschpuffer. Nach gegebenenfalls mehrmaligem Waschen durch Resuspendieren und Abzentrifugieren (15 min, $7000 \mathrm{Upm}, 4^{\circ} \mathrm{C}$ ) wurde das Naßgewicht des Pellets bestimmt und die Zellen in 2-3 ml Puffer pro g Naßgewicht gründlich resuspendiert. Da C. glutamicum als Gram-positives Bakterium eine gegenüber mechanischer Belastung sehr widerstandsfähige Zellwand besitzt, wurde vor dem Aufschluß von C. glutamicum der Zellsuspension Lysozym (Endkonzentration $10 \mathrm{mg} / \mathrm{ml}$ ) zugesetzt und die Suspension $1 \mathrm{~h}$ bei $37^{\circ} \mathrm{C}$ inkubiert. 


\subsubsection{Zellaufschluß mit der „French Pressure Cell“}

Der Aufschluß von Zellen in der „French Pressure Cell“ (American Instrument Company, Silver Spring, USA) erfolgt dadurch, daß die Zellsuspension zunächst einem Druck von 6,9 MPa ausgesetzt wird, der absinkt, wenn ein kleines Ventil geöffnet wird, und die Zellen hindurchgepreßt werden. Der plötzliche Druckabfall bewirkt das Platzen und somit die Lyse der Zellen. Das zähflüssige Lysat wird aufgefangen und zentrifugiert, wobei Zelltrümmer sedimentieren und von dem cytoplasmatischen Überstand getrennt werden. Der Überstand mit löslichen, intrazellulären Proteinen wird als Rohextrakt bezeichnet. Diese Methode wurde ausschließlich bei größeren Kulturvolumina eingesetzt.

\section{Durchführung:}

Die Zellsuspension wurde durch zweimalige Passage durch die „French Pressure Cell“ aufgeschlossen. Das zähflüssige Lysat wurde in SS34-Röhrchen aufgefangen und 20 min zentrifugiert (SS34-Rotor, $15000 \mathrm{Upm}, 4^{\circ} \mathrm{C}$ ).

\subsubsection{Zellaufschluß durch Ultraschall}

Kulturvolumina von $\leq 5 \mathrm{ml}$ wurden durch Ultraschallaufschluß unter Verwendung einer Ultraschall-Sonde (Ultraschallprozessor UP 200S, 24 kHz, 200 W, Fa. Dr. Hielscher GmbH, Teltow; Sonotrode S2, $2 \mathrm{~mm}$ ) lysiert. Diese Methode wurde nur angewendet, um kleine Mengen Proteinextrakt zu gewinnen, so daß rasch variable Parameter überprüft und optimiert werden konnten. Die Zellsuspension wurde in einem Eppendorf-Cup $5 \mathrm{~min}$ beschallt (35 \%ige Amplitude, Cycle 0,5). Obwohl mit thermostabilen Enzymen gearbeitet wurde, wurden die Zellen beim Aufschluß mit Eis gekühlt. Das Abzentrifugieren der Zelltrümmer erfolgte bei $13000 \mathrm{Upm}$ für $15 \mathrm{~min}$ in einer Tischzentrifuge (Biofuge fresco, Kendro, Osterode). Der Überstand wurde in ein neues Eppendorf-Cup überführt.

\subsubsection{Abtrennung thermolabiler Proteine durch Hitzedenaturierung}

Zur ersten Anreicherung eines thermophilen Enzyms aus dem Rohextrakt eines mesophilen Wirtes eignet sich besonders die Denaturierung der thermolabilen Wirtsproteine durch einen Hitzeschritt. Dazu wurde der aus dem Zellaufschluß gewonnene klare Überstand in einem SS34-Röhrchen im Wasserbad für $20 \mathrm{~min}$ bei dem rekombinanten Protein angemessener Temperatur inkubiert. Die durch die Hitze denaturierten und präzipitierten Wirtsproteine wurden abzentrifugiert (13000 Upm, 15 min, $4{ }^{\circ} \mathrm{C}$ ). Anschließend wurde der Überstand abgenommen. 


\subsection{Proteinreinigung durch FPLC}

Bei einer säulenchromatographischen Proteinreinigung mittels FPLC (Fast Protein Liquid Chromatography) wird das zu trennende Substanzgemisch in Lösung (mobile Phase) über eine Säule aus einer festen, porösen Matrix (stationäre Phase) geschickt. Die Wechselwirkungen der gelösten Bestandteile mit der stationären Phase verzögern die Wanderungsgeschwindigkeit durch die Matrix in substanzspezifischer Weise. Auf diesem Wege wird im Idealfall z.B. der hitzegefällte Rohextrakt in separate Fraktionen reiner Proteine aufgetrennt.

\section{Durchführung:}

Alle Puffer und Proben wurden vor dem Auftragen filtriert, um eine Verunreinigung des Säulenmaterials mit Staubpartikeln zu vermeiden. Die Filtration der Proben erfolgte durch Einweg-Sterilfilter (Minisart 0,2 $\mu \mathrm{m}$, Sartorius). Die Puffer wurden mit $\mathrm{H}_{2} \mathrm{O}_{\text {bidest. }}$ hergestellt und anschließend mit einer Vakuumpumpe (Savant) durch Cellulosenitrat-Filter (0,45 $\mu \mathrm{m}$, Schleicher \& Schuell, Dassel) filtriert. Um das Eindringen von Luftblasen in das Säulenmaterial zu verhindern, wurden alle Anschlüsse drop to drop verbunden. Die Säulen werden in 20 \%igem (v/v) Ethanol gelagert. Direkte Umpufferung der Säulen von Ethanol zu einem salzhaltigen Puffer oder umgekehrt sollte durch Spülen mit MilliQ-Wasser vermieden werden.

Die verwendete ÄKTA-FPLC-Anlage besteht aus folgenden Komponenten (alle Amersham Biosciences, Freiburg):

Geräte: Monitor UPC-900

Pumpe P-920

In-line Mixer M-925

Motor Valve INV-907

Fraction Collector Frac-900

$10 \mathrm{ml}$ und $50 \mathrm{ml}$ Superloop, $1 \mathrm{ml}$ und $250 \mu$ Probenschleifen

Säulen: SOURCE 30Q HR10/10

Superdex 200 prep grade XK 16/60 


\subsubsection{Ionenaustausch-Chromatographie (IEC)}

Das Trennprinzip der Ionenaustausch-Chromatographie beruht auf elektrostatischen Wechselwirkungen zwischen den Proteinen und den funktionellen Gruppen des Gelmaterials. Dabei treten geladene Gruppen auf der Oberfläche der Proteine mit entgegengesetzt geladenen Gruppen auf der Austauschermatrix in Interaktion und führen so zu einer Bindung an die Säule, wobei die Stärke dieser Bindung von den individuellen Ladungseigenschaften der einzelnen Polypeptide abhängt. Entscheidende Parameter sind die Ionenstärke (Salzkonzentration) und der pH-Wert. Die Elution erfolgt durch eine Erhöhung der Ionenstärke, wodurch die elektrostatische Wechselwirkung zwischen Protein und Gelmaterial geschwächt wird.

Für die IEC wurde in dieser Arbeit der starke Anionenaustauscher SOURCE 30Q in einer selbstgepackten HR10/10 Säule (8,25 ml Säulenvolumen) verwendet. Das Material besteht aus monodispersen Partikeln mit $30 \mu \mathrm{m}$ Durchmesser und einer kontrollierten Porenstruktur, die hohe Stabilität und geringen Rückdruck gewährleisten. Die funktionelle Gruppe der SOURCE 30Q ist ein quartäres Amin, das über einen hydrophilen Spacer an die Säulenmatrix gebunden ist. Die Proteinbindungskapazität beträgt bis zu 25 mg Protein pro ml Gelbett. Die empfohlene Flußrate wird mit 300-990 cm/h (4-13 ml/ min) bei einem maximalen Rückdruck von $5 \mathrm{MPa}$ angegeben.

\section{Durchführung:}

Die Säule wurde zur Vorbereitung zunächst mit 1 Säulenvolumen (SV) Puffer A (= Niedrigsalzpuffer) und anschließend mit 2 Säulenvolumina Puffer B (= Hochsalzpuffer) gespült, um die funktionellen Gruppen mit Gegenionen abzusättigen. Dann wurde das Medium mit mindestens 8 SV Auftragungspuffer A auf die Startbedingungen äquilibriert. Die Probe (in Puffer A) wurde unter Niedrigsalzbedingungen auf die Säule aufgetragen und in einem ansteigenden Salzgradienten eluiert.

Puffer A: 20 mM Tris-HCl pH 8,0

Puffer B : 20 mM Tris-HCl pH 8,0 + 1000 mM NaCl 


\subsubsection{Gelfiltration (SEC)}

Im Gegensatz zur Anionenaustausch-Chromatographie und zur hydrophoben InteraktionsChromatographie handelt es sich bei der Gelfiltration um eine nicht-adsorbtive Methode, bei der die Trennung der Proteine aufgrund ihrer Größe erfolgt. Die inerte, poröse Matrix bietet den Proteinen in Abhängigkeit von ihrer Größe ein mehr oder weniger großes Verteilungsvolumen, mit dem Resultat, daß größere Proteine, denen ein kleineres Verteilungsvolumen zur Verfügung steht, früher eluieren als kleine Proteine; daher der englische Name Size Exclusion Chromatography (SEC). Im Rahmen dieser Arbeit wurde die Gelfiltration zur Ermittlung des Polymerisationsgrades von AmyB-Tm genutzt.

Es wurde dabei eine Superdex High Load 16/60-Säule verwendet. Die Matrix dieser Säule besteht aus in makroporöse, hochvernetzte Agarose-Partikel (mittlerer Durchmesser $34 \mu \mathrm{m}$ ) kovalent eingebundenen Dextranen. Nichtspezifische Interaktionen mit den Proteinen sind bei diesem Gelmaterial minimalisiert. Empfohlen wird eine Flußrate von 10-50 cm/h bei einem maximalen Rückdruck von 0,3 MPa.

\section{Durchführung:}

Damit die Gelfiltration zur Molekularmassenbestimmung von Enzymen verwendet werde konnte, mußten folgende Säulenparameter bekannt sein:

A) das gesamte Säulenvolumen $\mathrm{V}_{\mathrm{t}}$

B) das Ausschlußvolumen der Säule $V_{0}$

C) das Elutionsvolumen des Proteins $\mathrm{V}_{\mathrm{e}}$

Anhand dieser Größen konnte der Verteilungskoeffizient $\mathrm{K}_{\mathrm{AV}}$ eines Proteins ermittelt werden, der folgendermaßen definiert ist:

$$
K_{A V}=\frac{V_{e}-V_{0}}{V_{t}-V_{0}}
$$

Durch Kalibrierung der Gelfiltrationssäule mit Eichproteinen, Bestimmung des Säulenausschluß-Volumens, Ermittlung des jeweiligen Verteilungskoeffizienten und Auftragung des dekadischen Logarithmus der Molekularmasse gegen den $\mathrm{K}_{\mathrm{AV}}$-Wert wurde eine Eichgerade erstellt, aus der sich die Molekularmasse eines Proteins anhand seines Verteilungskoeffizienten berechnen ließ.

\section{Auftragspuffer:}

$50 \mathrm{mM}$ Tris- $\mathrm{HCl}(\mathrm{pH} 8,0)+150 \mathrm{mM} \mathrm{NaCl}$ 


\subsection{Renaturierung von inclusion bodies}

Bei der Expression, insbesondere der Überexpression, von rekombinanten Proteinen kann es zur Bildung größerer Mengen mißgefalteten Proteins kommen. Dieses formt in E. coli sogenannten inclusion bodies, d.h. unlöslichen Proteinagglomerate, die einen Großteil der Zellmasse ausmachen können. Die Renaturierung solcher mißgefalteten Proteine ist oft schwierig. In den meisten Renaturierungsprotokollen wird zunächst das unlösliche Protein durch Zugabe von Harnstoff oder chaotropen Salzen entfaltet, um dann in einem großen Volumen bei geringer Proteinkonzentration die Zusätze zu entfernen und so die spontane Faltung der Polypeptidkette in eine native Konformation zu veranlassen. Gelegentlich wird auch versucht, den Faltungsschritt durch Chaperone zu beeinflussen. Die hier verwendete Methode beruht ausschließlich auf der Zugabe und langsamen Entfernung einer hohen Harnstoff-Konzentration.

\section{Durchführung:}

Nach einer Überexpression des AmyB-Tm-Proteins in E. coli BL21 (DE3)/pET24c::AB wurden die Zellen geerntet, im Renaturierungspuffer aufgenommen und mit der French Pressure Cell aufgeschlossen (II.3.2.1, 5.2.1 und 5.2.2). Um nicht aufgeschlossene Zellen zu entfernen, wurde der Rohextrakt bei $4000 \mathrm{Upm}$ und $4{ }^{\circ} \mathrm{C} 10 \mathrm{~min}$ zentrifugiert. Das Pellet wurde verworfen und der Überstand erneut zentrifugiert (13000 Upm, $30 \mathrm{~min}, 4{ }^{\circ} \mathrm{C}$ ). Das nun entstandene Pellet aus unlöslichen Zellbestandteilen wurde in $10 \mathrm{ml}$ Puffer B resupendiert. Nach 30 min Inkubation bei Raumtemperatur unter Schwenken wurde die Suspension 30 min bei $13000 \mathrm{Upm}\left(4^{\circ} \mathrm{C}\right)$ abzentrifugiert. Das Pellet wurde erneut in $10 \mathrm{ml}$ Puffer B aufgenommen und der Inkubationsschritt und die folgende Zentrifugation wiederholt. Das Pellet wurde nun in 5-20 ml Renaturierungspuffer mit 8 M Harnstoff sorgfältig gelöst. Nach 10 minütiger Inkubation bei Raumtemperatur wurde die Lösung 30 min bei 13000 Upm $\left(4^{\circ} \mathrm{C}\right)$ zentrifugiert. Der Überstand wurde in ein neues SS-34 Röhrchen überführt und der Zentrifugationsschritt wiederholt. Der Überstand wurde dann 3 h bei Raumtemperatur gegen 0,5 1 Renaturierungspuffer mit $1 \mathrm{M}$ Harnstoff dialysiert. In einem zweiten Dialyseschritt wurde der Überstand über Nacht gegen 11 Renaturierungspuffer ohne Zusatz von Harnstoff dialysiert. Das Dialysat wurde bei $13000 \mathrm{Upm}$ und $4{ }^{\circ} \mathrm{C}$ für 20 min zentrifugiert. Der Erfolg wurde gelelektrophoretisch überprüft. 


\section{Renaturierungspuffer:}

Tris $20 \mathrm{mM}$

K-Glutamat $\quad 125 \mathrm{mM}$

Glycerin $\quad 5 \%(\mathrm{v} / \mathrm{v})$

DTT $2 \mathrm{mM}$

$\mathrm{H}_{2} \mathrm{O}_{\text {bidest. }} \quad$ ad $1000 \mathrm{ml}$

Vor Zugabe von DTT pH-Wert mit KOH auf pH 8,0 einstellen und Puffer filtrieren.

\section{Puffer B:}

Lysozym (50 mg/ml Stammlösung) $\quad 126 \mu \mathrm{l}$

Deoxycholat (100 mg/ml Stammlösung) $\quad 300 \mu \mathrm{l}$

EDTA (0,5 M Stammlösung) $\quad 60 \mu \mathrm{l}$

Renaturierungspuffer ad $30 \mathrm{ml}$

Frisch ansetzen.

\section{Immunologische Methoden}

\subsection{Western-Blot (Towbin et al., 1979)}

Nach der Auftrennung durch Polyacrylamid-Gelelektrophorese konnten Proteine für immunologische Tests aus dem Gel auf eine Nitrocellulosemembran transferiert werden. Die Übertragung erfolgte dabei elektrophoretisch unter Verwendung einer Western-Blot-Kammer (Eigenbau) nach dem Semi-Dry-Verfahren. Das Whatmanpapier und eine Nitrocellulosemembran (Protran BA83, Schleicher \& Schuell, Dassel) wurden, nachdem sie auf Gelgröße zurechtgeschnitten waren, zusammen mit dem Gel in Transferpuffer gelegt. Anschließend wurden auf die Anodenplatte in folgender Reihenfolge drei Lagen Whatmanpapier, die Nitrocellulosemembran, das Gel und wiederum drei Lagen Whatmanpapier, jeweils unter Vermeidung von Luftblasen, aufgelegt. Nach der Entfernung überschüssigen Transferpuffers mittels saugfähigen Papiers legte man die Kathodenplatte auf und beschwerte die Apparatur. Die Proteine wurden bei konstanter Stromstärke mit $5 \mathrm{~mA} / \mathrm{cm}^{2}$ Membranfläche für 30-45 min übertragen. 


\section{Transferpuffer:}

Tris $(125 \mathrm{mM})$

$15,14 \mathrm{~g}$

Glycin (192 mM)

$14,40 \mathrm{~g}$

Methanol, $100 \%(\mathrm{v} / \mathrm{v})$

$200 \mathrm{ml}$

$\mathrm{H}_{2} \mathrm{O}$ dest.

ad $1000 \mathrm{ml}$

$\mathrm{pH}$ 8,6; Lagerung bei $4{ }^{\circ} \mathrm{C}$

\subsection{Dot Blot für immunologischen Nachweis}

Zur schnellen Überprüfung der Spezifität der verwendeten polyklonalen anti-AmyB-TmAntikörper (aus mit rekombinantem AmyB-Tm immunisiertem Kaninchen, Fütterer, 2001) wurden 0,1-2 $\mu \mathrm{g}$ aufgereinigtes AmyB-Tm-Protein direkt auf eine Nitrocellulosemembran pipettiert und getrocknet. Die weitere Behandlung der Membran erfolgte wie unter II.6.3 beschrieben.

\subsection{Immundetektion von Proteinen mit alkalische-Phosphatase- konjugierten Antikörpern}

Die Sichtbarmachung der auf einer Nitrocellulosemembran transferierten Proteine (II.6.1) mit den für sie spezifischen Antikörpern erfolgte mit Hilfe einer gekoppelten alkalischen Phosphatase-Reaktion. Die Membran wurde dabei zur Vermeidung unspezifischer Bindungen für 2 h bei RT mit einer wiederverwendbaren Blockierungslösung (TBST mit $3 \%$ (w/v) BSA) abgesättigt. Dann erfolgte die Bindung der polyklonalen Antikörper an ihr Substrat (TBST + 1. Antikörper (Endblutung), Verhältnis 1:2500; Inkubation 1 h). Es folgten drei Waschschritte zu je 5 min in TBST zur Entfernung ungebundener Antikörper. Im nächsten Schritt wurde der sekundäre Antikörper (Anti-Kaninchen-Antikörper, IgG, mit alkalischer Phosphatase (SigmaAldrich Chemie GmbH); Verhältnis 1:5000 in TBST) an die bereits gebundenen primären Anti-AmyB-Tm-Antikörper durch eine 30minütige Inkubation gekoppelt. Die Nitrocellulosemembran wurde $3 \mathrm{x}$ in TBST (je $5 \mathrm{~min}$ ) und $2 \mathrm{x}$ in TBS (je $3 \mathrm{~min}$ ) gewaschen. Anschließend erfolgte die Sichtbarmachung der Proteine durch Zugabe der Färbelösung. Die Farbreaktion wurde mittels $\mathrm{H}_{2} \mathrm{O}_{\text {demin. }}$ abgestoppt und die Membran im Dunkeln gelagert. 
TBS:

Tris-HCl 2,42 g

$\mathrm{NaCl} \quad 8,7 \mathrm{~g}$

$\mathrm{H}_{2} \mathrm{O}_{\text {demin. }}$ ad $1000 \mathrm{ml}$

$\mathrm{pH} 7,5$
TBST:

TBS mit 0,05 \% (v/v) Tween 20

\section{Färbelösung:}

Detektionspuffer $\quad 10 \mathrm{ml}$

NBT/BCIP stock solution $\quad 200 \mu \mathrm{l}$

(Roche Diagnostics, Mannheim)

Lösung vor Gebrauch frisch ansetzen.

\section{Detektionspuffer:}

$\begin{array}{lr}\mathrm{NaCl}(100 \mathrm{mM}) & 5,84 \mathrm{~g} \\ \mathrm{MgCl}_{2}(5 \mathrm{mM}) & 1,02 \mathrm{~g} \\ \text { Tris (100 mM) } & 12,11 \mathrm{~g} \\ \mathrm{H}_{2} \mathrm{O}_{\text {demin. }} & \text { ad } 1000 \mathrm{ml}\end{array}$

$\mathrm{pH}$ 9,5; Lagerung des Puffers bei $4{ }^{\circ} \mathrm{C}$

\section{Nachweis von Enzymaktivitäten}

\subsection{DNSA-Test zur Bestimmung der Menge reduzierender Zucker (Standard-Test)}

Bei der Hydrolyse von polymeren Zuckern werden Oligomere bzw. Monomere gebildet, wodurch sich die Zahl der reduzierenden Enden vervielfacht. Eine Quantifizierung der reduzierenden Aldehydgruppen, bzw. $\alpha$-Hydroxysubstituenten bei Ketosen, wird durch den Einsatz von 3,5-Dinitrosalicylsäure ermöglicht. Wie in Abb. 4 dargestellt ist, wird in Gegenwart von Phenol und Natriumsulfit 3,5-Dinitrosalicylsäure durch die reduzierenden Enden zu 3-Amino-5-nitrosalicylsäure reduziert. Diese Reaktion verursacht bei $100{ }^{\circ} \mathrm{C}$ einen Farbumschlag von gelb nach braun. Die bräunliche Färbung des Testansatzes, die bei einer Wellenlänge von $575 \mathrm{~nm}$ photometrisch quantifiziert werden kann, ist proportional zur Bildung von 3-Amino-5-nitrosalicylsäure, deren Menge wiederum äquimolar zu der Anzahl der reduzierenden Enden ist. 
reduzierender Zucker +

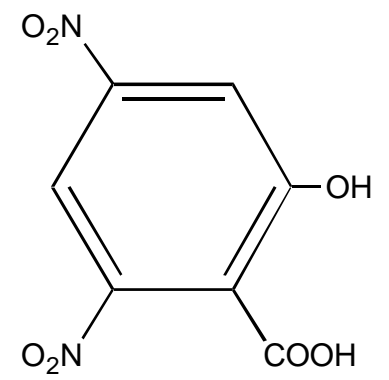

(3,5- Dinitrosalicylsäure)

(gelb)

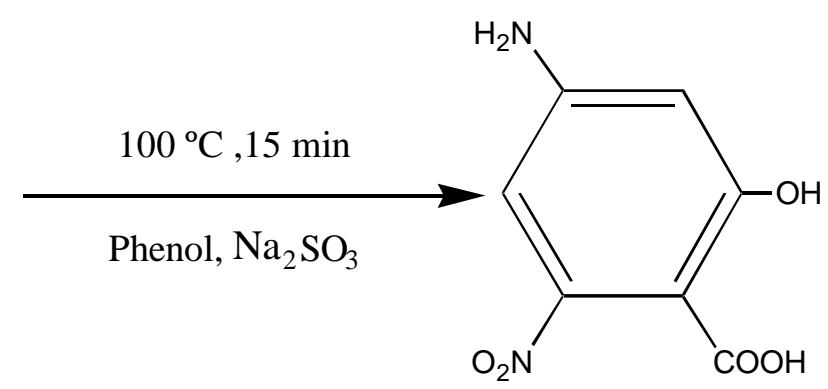

(3-Amino-5-nitrosalicylsäure)

(braun)

+ Zuckersäure

Abb. 4: Reaktionsmechanismus der 3,5- Dinitrosalicylsäure mit reduzierenden Zuckern.

\section{Durchführung:}

Der Reaktionsansatz wurde ohne Enzym bei der gewählten Inkubationstemperatur 5 min im Heizblock präinkubiert. Im Abstand von 20 s wurde dann das Enzym zugegeben, der Ansatz kurz gevortext und so schnell wie möglich wieder in den Heizblock zurückgestellt. Die Inkubation erfolgte für eine enzymabhängige Inkubationstemperatur und -zeit. Die Reaktion wurde durch Zugabe von $750 \mu \mathrm{l}$ DNSA-Reagenz gestoppt, wobei wieder 20 s Abstand zwischen den E-Cups eingehalten wurden, um eine gleich lange Inkubation zu gewährleisten. Nach kurzem Mischen wurden die Deckel der Eppendorf-Cups mit einer Nadel durchstochen. Die Ansätze wurden dann 15 min bei $98{ }^{\circ} \mathrm{C}$ im Heizblock inkubiert und anschließend auf Eis abgekühlt. Durch Messung der OD bei 575 nm (gegen einen Ansatz ohne Enzym) konnte mit einer aus definierten Maltosekonzentrationen hergestellten Eichgerade die Anzahl der reduzierenden Enden und somit auch die hydrolytische Aktivität des Enzyms bestimmt werden. Dabei entsprach 1 Unit der Enzymaktivität, die in 1 min zur Freisetzung von $1 \mu \mathrm{mol}$ reduzierenden Enden führte. Alle Messungen erfolgten als Doppelbestimmungen. 


\section{Enzymassay:}

für AmyB-Tm

für AmyB-Tt

250 mM Tris-Puffer, $\mathrm{pH} 8,0^{\left(90^{\circ} \mathrm{C}\right)}$

$100 \mu \mathrm{l} 250 \mathrm{mM}$ PIPES-Puffer, pH 6,5 $\left(^{\left(70^{\circ} \mathrm{C}\right)}\right.$

$100 \mu \mathrm{l}$

Substrat (1\%)

$250 \mu \mathrm{l}$ Substrat (1\%)

$250 \mu \mathrm{l}$

DTT (1 M)

$5 \mu \mathrm{l} \operatorname{DTT}(0,1 \mathrm{M})$

$5 \mu \mathrm{l}$

$\mathrm{H}_{2} \mathrm{O}_{\text {bidest. }}$

150-x $\mu \mathrm{l} \quad \mathrm{H}_{2} \mathrm{O}_{\text {bidest. }}$

150-x $\mu \mathrm{l}$

Enzym

$\mathrm{x} \mu \mathrm{l}$ Enzym

$\mathrm{x} \mu \mathrm{l}$

$\Sigma=500 \mu \mathrm{l}$

$\Sigma=500 \mu \mathrm{l}$

Inkubation $1 \mathrm{~h}$ bei $90{ }^{\circ} \mathrm{C}$

Inkubation $45 \mathrm{~min}$ bei $70^{\circ} \mathrm{C}$

für AmyA-Ag

für AmyB-Ag

$200 \mathrm{mM}$ McIlvaine-Puffer, 200 mM McIlvaine-Puffer,

$\mathrm{pH} 8,0^{\left(60^{\circ} \mathrm{C}\right)}$

$100 \mu \mathrm{l} \mathrm{pH} \mathrm{6,0}\left(^{\left(50^{\circ} \mathrm{C}\right)}\right.$

$100 \mu \mathrm{l}$

Substrat (1\%)

$250 \mu \mathrm{l}$ Substrat (1\%)

$250 \mu \mathrm{l}$

$\mathrm{H}_{2} \mathrm{O}_{\text {bidest. }}$

150-x $\mu \mathrm{l} \quad \mathrm{H}_{2} \mathrm{O}_{\text {bidest. }}$

150-x $\mu \mathrm{l}$

Enzym

$\mathrm{x} \mu \mathrm{l}$ Enzym

$\mathrm{x} \mu \mathrm{l}$

$\Sigma=500 \mu \mathrm{l}$

$\Sigma=500 \mu \mathrm{l}$

Inkubation $20 \mathrm{~min}$ bei $60^{\circ} \mathrm{C}$

Inkubation $15 \min$ bei $50{ }^{\circ} \mathrm{C}$

\section{Lösungen:}

DNSA- Reagenz:

Dinitrosalicylsäure

Phenol

$\mathrm{Na}_{2} \mathrm{SO}_{3}$

K-Na-Tartrat

$\mathrm{NaOH}$

$\mathrm{H}_{2} \mathrm{O}_{\text {bidest. }}$

Vor Licht schützen und bei $4{ }^{\circ} \mathrm{C}$ lagern.

Substrat:

Stärke in $\mathrm{H}_{2} \mathrm{O}_{\text {bidest. }}$

(potato starch, soluble, Sigma)
$10 \mathrm{~g}$

$2 \mathrm{ml}$

$0,5 \mathrm{~g}$

$200 \mathrm{~g}$

$10 \mathrm{~g}$

ad $1000 \mathrm{ml}$

$1 \%$

$2,42 \mathrm{~g}$

ad $1000 \mathrm{ml}$ 
250 mM PIPES-Puffer: PIPES

$$
\mathrm{H}_{2} \mathrm{O}_{\text {bidest. }}
$$

MacIlvaine-Puffer:

$$
\begin{aligned}
& \mathrm{Na}_{2} \mathrm{HPO}_{4} \\
& \text { Zitronensäure } \\
& \mathrm{H}_{2} \mathrm{O}_{\text {bidest. }}
\end{aligned}
$$

$$
75,6 \mathrm{~g}
$$

ad $1000 \mathrm{ml}$

$200 \mathrm{mM}$

$100 \mathrm{mM}$

ad $1000 \mathrm{ml}$

Maltose-Stammlösung: Maltose $(10 \mathrm{mg} / \mathrm{ml})$ in $\mathrm{H}_{2} \mathrm{O}_{\text {bidest. }}$ zur Erstellung einer Eichgerade im Bereich von 0,3 - $2 \mu \mathrm{mol}$

\subsection{Hydrolyse von para-Nitrophenylsubstraten}

Para-Nitrophenyl (pNP)-Glykoside sind synthetische Testsubstrate für hydrolytische Enzyme. Durch die enzymatische Spaltung der arylglykosidischen Bindung wird p-Nitrophenol freigesetzt, das sich durch seine gelbe Färbung photometrisch bei $420 \mathrm{~nm}$ bestimmen läßt.

$$
\text { p-Nitrophenyl-Glykosid } \rightarrow \text { p-Nitrophenol + Zucker }
$$

(farblos)

(gelb)

\section{Testansatz:}

Probe $\mathrm{x} \mu \mathrm{l}$

$250 \mathrm{mM}$ Tris-Puffer, $\mathrm{pH} 8,0^{\left(90^{\circ} \mathrm{C}\right)} \quad 60 \mu \mathrm{l}$

$1 \mathrm{M}$ Dithiothreitiol (DTT) $\quad 3 \mu \mathrm{l}$

$\mathrm{H}_{2} \mathrm{O}_{\text {bidest. }} \quad 227-\mathrm{x} \mu \mathrm{l}$

nach 3 min Präinkubation bei $90{ }^{\circ} \mathrm{C}$ Zugabe von

pNP-Glykosid (0,1 M in DMSO) $\quad 10 \mu \mathrm{l}$

\section{Durchführung:}

Die Reaktion wurde nach Präinkubation durch Zugabe des Substrats gestartet. Nach 25 min wurde die Reaktion auf Eis durch Zufügen von $500 \mu \mathrm{Na}_{2} \mathrm{CO}_{3}(1 \mathrm{M})$ abgestoppt. Die Alkalisierung dient auch der Verstärkung der Gelbfärbung, deren Intensität bei 420 nm gegen eine Negativkontrolle ohne Enzym gemessen wurde. Mit p-Nitrophenol in Konzentrationen von 0 bis 150 nmol wurde eine Eichgerade unter Testbedingungen erstellt. Durch Multiplikation des erhaltenen Extinktionswerts der Testansätze mit dem reziproken Wert des 
ermittelten Steigungsfaktors der Eichgeraden wurde die Menge an p-Nitrophenol (in $\mu$ mol) bestimmt, die im Test freigesetzt wurde. Eine Unit entspricht der Enzymaktivität, die $1 \mu \mathrm{mol}$ p-Nitrophenol in 1 min freisetzt.

\subsection{Produktanalyse durch Dünnschichtchromatographie (TLC)}

Die Dünnschichtchromatographie ist eine Form der Verteilungschromatographie zwischen einer hydrophilen (stationären) und einer hydrophoben (mobilen) Phase und dient zur Analyse von Stoffgemischen verschiedener organischer Verbindungen wie Zuckern, Aminosäuren und Nukleotiden. Auf einer mit Sorptionsmittel (Kieselgel, Cellulose) beschichteten Dünnschichtfolie werden wenige $\mu \mathrm{l}$ des zu analysierenden Stoffgemisches aufgetragen. In einer geschlossenen Kammer bewirken Kapillarkräfte das Aufsteigen eines Lösungsmittelgemisches aus einer wäßrigen und einer organischen Komponenten (aufsteigende Chromatographie). Die wäßrige Komponente bildet mit dem Sorbtionsmittel eine gelartige stationäre Phase, während die organische Komponente als mobile Phase eine Auftrennung der Moleküle im Substanzgemisch gemäß ihrer Polarität bewirkt. Die Wanderungsgeschwindigkeiten der zu trennenden Substanzen erfolgt in Abhängigkeit von ihrer relativen Löslichkeit in der stationären und der mobilen Phase, wobei unpolare Moleküle schneller wandern als polare. Aufgetrennte Substanzen werden durch Besprühen des Chromatogramms mit Reagenzlösungen detektiert, welche mit den Molekülen gefärbte Produkte bilden. Im Rahmen dieser Arbeit wurde die Dünnschichtchromatographie zur Auftrennung von Mono- und Oligosacchariden genutzt, wie sie bei hydrolytischer Spaltung auftreten. Anhand eines Maltooligosaccharid-Standards (G1-G7) wurden die Produkte identifiziert. Als stationäre Phase dienten mit Kieselgel beschichtete Aluminium-Folien (Kieselgel 60, $\mathrm{F}_{254}$, Merck, Darmstadt). Als mobile Phase wurden folgende Laufmittel verwendet:

Laufmittel 1:

1- Propanol

$60 \%$

Ethylacetat $\quad 10 \%$

$\mathrm{H}_{2} \mathrm{O}_{\text {bidest. }} \quad 30 \%$

Laufzeit 2x 3 h
Laufmittel 2:

1- Propanol $50 \%$

Nitromethan $\quad 30 \%$

$\mathrm{H}_{2} \mathrm{O}_{\text {bidest. }}$

$20 \%$

Laufzeit 1x 2 h

\section{Laufmittel 3:}

D/L-Laktat $(85 \%(\mathrm{w} / \mathrm{v})) \quad 2,1 \mathrm{ml}$ Isopropanol $\quad 40 \mathrm{ml}$

Aceton $\quad 40 \mathrm{ml}$ $\mathrm{H}_{2} \mathrm{O}_{\text {bidest. }} \quad 17,9 \mathrm{ml}$

\section{Laufzeit 1x 3 h}


Weitere Lösungen:

Substratlösungen:

$1 \%(\mathrm{w} / \mathrm{v})$ bzw. Maltooligosaccharide 0,1 M

Maltooligosaccharid-Standard: $\quad 0,1 \%(\mathrm{w} / \mathrm{v})$

Stammlösung der

Entwicklunsreagenz:

$\begin{array}{lc}\text { Anilin } & 1 \mathrm{ml} \\ \text { Diphenylamin } & 1 \mathrm{~g} \\ \text { Aceton } & 100 \mathrm{ml}\end{array}$

Lagerung lichtgeschützt bei $4^{\circ} \mathrm{C}$.

Entwicklungsreagenz:

$$
\begin{aligned}
& \text { Stammlösung der Entwicklunsreagenz } 5 \mathrm{ml} \\
& 85 \text { \% (v/v) Ortho-Phosphorsäure } \quad 0,5 \mathrm{ml}
\end{aligned}
$$

Die Herstellung erfolgt kurz vor der Anwendung. Das Volumen ist ausreichend für die Entwicklung einer DC-Platte.

Durchführung:

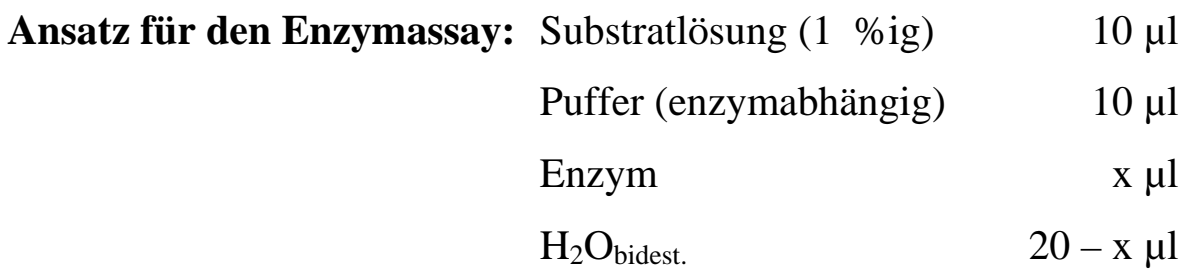

Der Testansatz wurde bei $90{ }^{\circ} \mathrm{C}$ für eine angemessene Zeit (meist $1 \mathrm{~h}$ ) inkubiert und anschließend auf Eis gestellt. In der Zwischenzeit wurden die Dünnschichtplatten und die Kammer für den Lauf vorbereitet. Aliquots der Testansätze von $2 \mu \mathrm{l}$ wurden entlang einer Linie $1 \mathrm{~cm}$ vom unteren Rand der DC-Platte strichförmig aufgetragen (Abstand der einzelnen Proben mindestens 0,7 cm; Abstand zum Seitenrand der DC-Platte mindestens 1,5 cm). Wurden Proben in einem Umfang von mehr als $2 \mu$ l aufgetragen, mußten die Probenauftragsstriche zwischen den einzelnen Aufträgen 10 min bei RT oder mit einem Fön gut getrocknet werden.

Die Chromatographiekammer wurde mit Whatmanpapier ausgekleidet und die Schliffränder von Deckel und Kammer mit Vaseline gefettet. Anschließend wurden $100 \mathrm{ml}$ des jeweiligen Laufmittels über das Whatmanpapier in die Kammer gefüllt. Die trockene DC-Platte wurde in die gut äquilibrierte Dünnschicht-Kammer eingesetzt, wobei sie, um eine gerade Lauffront zu bekommen, die Seitenstreben nicht berühren durfte. 
Nachdem die Lauffront $2 \mathrm{~cm}$ unter dem oberen Plattenrand angekommen war, wurde die DCPlatte getrocknet (Lagerung bei $-20{ }^{\circ} \mathrm{C}$ in Alufolie möglich) und mit frisch hergestellter Sprühlösung (Entwicklungsreagenz $+1 / 10$ Vol. Phosphorsäure) besprüht. Die besprühte Platte wurde in Alufolie eingewickelt und für 12 min bei $140{ }^{\circ} \mathrm{C}$ inkubiert. Zur Aufbewahrung wurde die Platte anschließend in Schlauchfolie eingeschweißt. Eine eventuelle Dokumentation durch Einscannen der DC-Platten mußte sofort erfolgen, da diese nach einigen Wochen einen blauen Hintergrund entwickeln.

\subsection{Quantitative Bestimmung von Nicht-Häm-Eisen}

Der Nicht-Häm-Eisen-Gehalt wurde colorimetrisch durch Bildung eines Ferrozin-Komplexes nachgewiesen (Fish, 1988). Mit saurer Kaliumpermanganat-Lösung wurde $\mathrm{Fe}^{3+}$ aus dem Protein gelöst und mit Ascorbinsäure $\mathrm{zu} \mathrm{Fe}^{2+}$ reduziert, um anschließend komplexiert werden zu können.

\section{Durchführung:}

Es wurden $200 \mu$ l Lösung A mit $400 \mu$ l Probe oder Standardlösung $\left(\mathrm{FeCl}_{3}\right.$ in wäßriger Lösung) gemischt und für $2 \mathrm{~h}$ bei $70{ }^{\circ} \mathrm{C}$ inkubiert. Anschließend wurde der Reaktionsansatz auf Raumtemperatur angekühlt und mit $40 \mu$ l Lösung B versetzt. Nach 30 min Inkubation bei Raumtemperatur wurde die Absorption bei $562 \mathrm{~nm}$ bestimmt. Die Eisenmenge im Ansatz wurde mit Hilfe einer Eichgerade kalkuliert, die mit 0,1-2 $\mu \mathrm{g} \mathrm{Fe}{ }^{3+}$ erstellt wurde.

\section{Lösung A:}

2,25 \%ige Kaliumpermanganat-Lösung in 0,6 M HCl

Frisch ansetzen.

\section{Lösung B:}

Ferrospectral (Merck, Darmstadt)

(= 3-(2-Pyridyl)-5,6-bis(4-phenylsulfonat)-1,2,4-Triazin, Dinatriumsalz) $\quad$ 6,5 mM

Neocuproin (Merck) (= 2,9-Dimethyl-1,10-Phenanthrolin) 13,1 mM

Ascorbinsäure $2 \mathrm{M}$

$\begin{array}{ll}\text { Ammoniumacetat } & 5 \mathrm{M}\end{array}$

Frisch ansetzen. 


\subsection{Photometrische Absorptionsbestimmung}

Wellenlängenspektren wurden mit einem Zweistrahlphotometer (Varian, Darmstadt, CARY 100 Conc) im Bereich von 250 bis 600 nm mit Messungen im Abstand von $1 \mathrm{~s}$ aufgenommen. Dabei wurden Quarzküvetten mit einer Schichtdicke von $1 \mathrm{~cm}$ und einem Volumen von $100 \mu \mathrm{l}$ verwendet.

\subsection{Charakterisierung der Enzymaktivität}

\subsection{1. pH-Abhängigkeit der Enzymaktivität}

Zur Ermittlung der amylolytischen Aktivität von AmyB-Tt in Abhängigkeit vom pH-Wert wurde der Standard-DNSA-Test (II.7.1) mit variablem pH-Wert im Ansatz bei $70{ }^{\circ} \mathrm{C}$ durchgeführt. Da die Aktivität des Enzyms in MacIlvaine-Puffer, der auf ein breites Spektrum an pH-Werten eingestellt werden kann, nur gering war, wurden die Messungen in zwei Puffersystemen durchgeführt. Für pH-Werte im Bereich 7,0-9,0 wurde Tris-Puffer mit einer Endkonzentration von $50 \mathrm{mM}$ verwendet, und im pH-Bereich 5,0-7,0 PIPES-Puffer, ebenfalls mit einer Enkonzentration von 50 mM. Bezogen auf die höchste gemessene Aktivität erfolgte die Angabe der Aktivitätswerte als relative Enzymaktivitäten.

\subsubsection{Temperaturabhängigkeit der Enzymaktivität}

Zur Ermittlung der amylolytischen Aktivität von AmyB-Tt in Abhängigkeit von der Temperatur wurde der Standard-DNSA-Test (II.7.1) bei Inkubationstemperaturen von $50{ }^{\circ} \mathrm{C}$ $90{ }^{\circ} \mathrm{C}$ durchgeführt. Der Tris-Puffer wurde dazu bei den jeweiligen Meßtemperaturen auf $\mathrm{pH}$ 8,0 titriert. Das Temperatur-Optimum wird durch zwei gegenläufige Faktoren bestimmt. Einerseits wird die Reaktion durch die steigende Temperatur thermodynamisch beschleunigt, andererseits wird die Umsetzung von Substraten durch die thermische Inaktivierung des Enzyms ab einer gewissen Temperatur begrenzt. Da die thermische Inaktivierung und somit die Lage des Temperatur-Optimums zeitabhängig ist, wurde die Inkubationszeit von 45 min beibehalten. Auch hier erfolgte die Angabe der Aktivität in relativen Enzymaktivitäten.

\subsubsection{Einfluß von Metallionen und Chelatoren auf die Enzymaktivität}

Der Einfluß ein- und zweiwertiger Kationen sowie von Chelatoren und potentiellen Regulatoren auf die Aktivität der rekombinanten Amylasen wurde durch den DNSA-Test (II.7.1) unter für die jeweiligen Enzyme als Standard festgelegten Bedingen ermittelt. Aufgrund der Färbung einiger Additivlösungen bzw. deren Einfluß auf die Farbreaktion des DNSA-Tests wurde die Enzymaktivität jedes Ansatzes gegen eine eigene Nullprobe mit den 
gleichen Zusätzen gemessen. Um bei Tests mit komplexierenden Zusätzen (z.B. EDTA) eine gleich lange Präinkubationszeit der Zusätze bei Testtemperaturen zu gewährleisten, wurden diese in 20 s Abständen zu den sich bereits auf den Heizblock befindenden Reaktionsansätzen hinzupipettiert. Nach entsprechender Präinkubationszeit wurden, wenn gewünscht, ebenfalls in $20 \mathrm{~s}$ Abständen reaktivierende Zusätze (z.B. $\mathrm{Ca}^{2+}$ ) dem Ansatz zugefügt. Die eigentliche Inkubation erfolgte für die für das jeweilige Enzym standardmäßig verwendetet Zeit.

\section{Charakterisierung glykosidischer Speicherstoffe}

\subsection{Isolation des Speicherpolysaccharids}

Zur Isolierung von Glykogen wurde T. maritima in $1 \mathrm{l}$ vereinfachtem Medium unter Zusatz von 0,5 \% Glukose kultiviert. Nach der Ernte durch Zentrifugation wurden die Zellen dreimal gründlich in Saline gewaschen, in $600 \mu \mathrm{l} \mathrm{KOH} \mathrm{(2} \mathrm{N)} \mathrm{pro} 100$ mg Naßgewicht resuspendiert, und auf mehrere Eppendorf-Cups mit Schraubdeckeln aufgeteilt. Die Ansätze wurden 1,5 h lang im Heizblock gekocht. Danach wurden die unlöslichen Bestandteile durch Zentrifugation (20 min, $13000 \mathrm{Upm}, 4{ }^{\circ} \mathrm{C}$ ) entfernt und die Überstände mit 2,5 Vol. eiskaltem, 90 \%igem Ethanol versetzt. Es folgte eine 20minütige Inkubation auf Eis zur Fällung des Glykogens. Nach dem Fällungsschritt wurden die Ansätze 30 min bei $13000 \mathrm{Upm}$ und $4{ }^{\circ} \mathrm{C}$ zentrifugiert, die Überstande abgenommen und die entstandenen Pellets zweimal in 70 \% Ethanol gewaschen. Nach Entfernen des Ethanols wurden die gelartigen Pellets in einer VakuumZentrifuge (Speed Vac ${ }^{\circledR}$ Plus SC110A, Savant) getrocknet, bis sie weiß waren und sich von der Wand der Eppendorf-Cups lösten. Die Pellets wurden in insgesamt $750 \mu \mathrm{H}_{2} \mathrm{O}_{\text {bidest. }}$ durch Aufkochen (20 min) gelöst. Die Lösung wurde mit Serdolit ${ }^{\circledR}$ MB-3 (Serva, Heidelberg) entsalzt, und der $\mathrm{pH}$-Wert wurde mit $\mathrm{NaOH}$ auf $\sim \mathrm{pH}$ 6,0 eingestellt.

Saline: $\quad \mathrm{NaCl} g \mathrm{~g}$

$\mathrm{H}_{2} \mathrm{O}_{\text {dest. }}$ ad $1000 \mathrm{ml}$

$\mathrm{pH} 7,0$ 


\subsection{Enzymatischer Verdau}

Das in $\mathrm{H}_{2} \mathrm{O}$ gelöste Glykogen wurde enzymatisch verdaut, um einerseits durch eine dünnschichtchromatografische Analyse Aussagen über die Zusammensetzung treffen und andererseits die freiwerdende Glukose quantifizieren zu können. Der Verdau erfolgte mit Amyloglukosidase (aus A. niger, Boehringer, Mannheim), einem Enzym, welches sowohl $\alpha$ 1,4- als auch $\alpha$-1,6-gykosidische Bindungen spaltet, und AmyA-Tm aus A. gottschalkii, einer $\alpha$-1,4-spezifischen $\alpha$-Amylase.

Verdauansatz für die Glukosebestimmung:

0,1 M Citratpuffer ( $\left.\mathrm{pH} 4,8,55^{\circ} \mathrm{C}\right) \quad 250 \mu \mathrm{l}$

Amyloglukosidase $(10 \mathrm{mg} / \mathrm{ml}) \quad 100 \mu \mathrm{l}$

Glykogenisolat $\quad 150 \mu \mathrm{l}$

\subsection{Quantitative Glukose-Bestimmung}

Die quantitative Bestimmung der durch den enzymatischen Verdau freigesetzten Glukose erfolgte mit Hilfe eines kommerziellen Kits der Firma Sigma (Glucose Kit 510-Da). Dieses basiert auf der Oxidation der durch den enzymatischen Verdau mit Amyloglukosidase aus Glykogen freigesetzten Glukose, gefolgt von einem zweiten Schritt, bei dem o-Dianisidin durch eine Peroxidase oxidiert wird. Oxidiertes o-Diansidin ist rot-braun und kann bei $450 \mathrm{~nm}$ photometrisch quantifiziert werden.

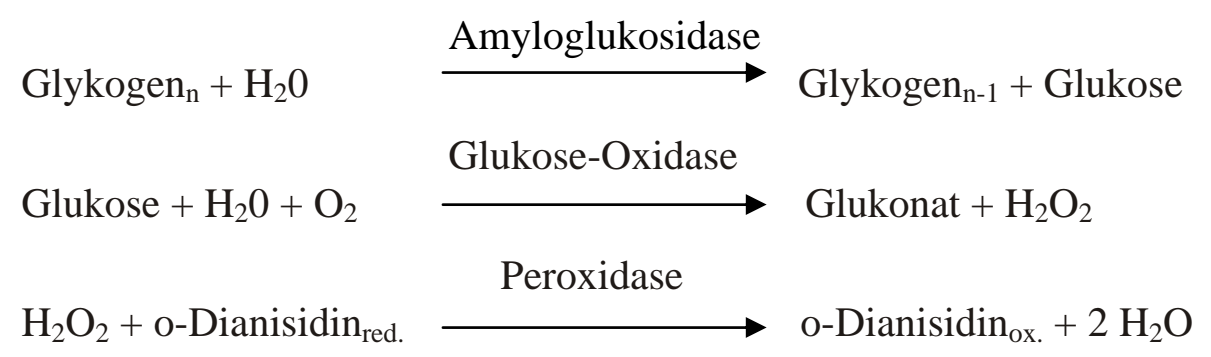

\section{Durchführung:}

Ein Aliquot des Amyloglukosidase-Verdauansatzes wurde mit Succinatpuffer und DianisidinFärbelösung nach Herstellerangaben 35 min bei $37^{\circ} \mathrm{C}$ inkubiert. Die $\mathrm{OD}_{450}$ wurde bestimmt, und die Menge an Glukose im Ansatz wurde mit Hilfe einer Eichgeraden kalkuliert, die mit 0$12 \mu \mathrm{g}$ Glukose erstellt wurde. Die Menge an Glukose und damit näherungsweise die 
Glykogenmenge wurde aus der Differenz der gemessenen Glukosemenge zwischen Proben mit und ohne vorherigen Amyloglukosidase-Verdau errechnet.

Ansatz:

Verdauansatz (II.8.2)

$120 \mu \mathrm{l}$

1 M Succinatpuffer, pH6,0

$50 \mu \mathrm{l}$

$\mathrm{H}_{2} \mathrm{O}$

$330 \mu \mathrm{l}$

Dianisidin-Färbelösung

$500 \mu \mathrm{l}$

(nach Herstelllerangabe aus o-Dianisidinlösung

und PGO-Enzymegemisch frisch hergestellt)

\section{Strukturaufklärung}

\subsection{Kristallisation biologischer Makromoleküle}

Kleine anorganische und organische Moleküle können häufig durch einfache Methoden (z.B. kontrolliertes Abkühlen einer heißen gesättigten Lösung oder langsame Präzipitation) kristallisiert werden. Das Kristallwachstum von Proteinmolekülen hingegen ist ein Prozeß, der von vielen verschiedenen Faktoren (z.B. Temperatur, Konzentration und Reinheit des Proteins, Art und Konzentration von Puffern und Fällungsmitteln) abhängig ist.

Zur anfänglichen Prüfung der Kristallisationsbedingungen gibt es Initial-Screens (SparseMatrix-Screens), deren Zusammensetzung statistisch aus bereits bekannten Kristallisationsbedingungen ermittelt wurde. Auf diese Weise erhält man in ersten Kristallisationsexperimenten Hinweise auf eine mögliche Zusammensetzung der Kristallisationslösung (Mutterlösung). Durch Variation der Komponentenkonzentrationen, dem Austausch gleichwertiger Ionen und der Konzentrationsänderung des Proteins können die Kristallisationsbedingungen optimiert werden.

Die verwendete Dampfdiffusion, durchgeführt als hängender oder sitzender Tropfen, ist die häufigste Methode zur Herstellung von Kristallen. Zu Beginn der Experimente werden die Tropfen in einem 1:1-Verhältnis von Proteinlösung zu Kristallisationslösung gemischt und in einem abgeschlossenen System durch die Plazierung auf einem Stempel oder unter dem Deckel von der Reservoirlösung räumlich getrennt. Ein Konzentrationsgradient wird aufgrund der unterschiedlichen Konzentrationen des Fällungsmittels in Tropfen und Reservoir aufgebaut. Das heißt, daß der Partialdruck des Wassers erhöht ist, da die Reservoirlösung im Tropfen durch die Proteinlösung verdünnt vorliegt. Daraufhin diffundiert das Wasser aus dem 
vergleichsweise kleinen Tropfenvolumen, und sowohl die Konzentration der Proteinlösung als auch des Fällungsmittels werden erhöht.

\section{Durchführung:}

Zur Kristallisierung des Proteins wurden Cryschem ${ }^{\mathrm{TM}}$-Platten (sitzender Tropfen; Hampton Research, Riverside, CA, USA) verwendet. Im Reservoirbehälter befand sich $1 \mathrm{ml}$ Kristallisationslösung, von der $1 \mu \mathrm{l}$ mit $1 \mu \mathrm{l}$ Protein-Lösung vermischt wurde. Die Cryschem ${ }^{\mathrm{TM}}$-Platten, die einen Stempel pro Reservoirbehälter besitzen, auf dem die Tropfen plaziert werden, wurden mit lösungsmittelbeständigem Klebeband (Crystal Clear Sealing Tape, Hampton Research) abgedichtet. Die eingesetzte Proteinlösung (AmyB-Tm, 8 mg/ml in $20 \mathrm{mM}$ Tris-Puffer, $\mathrm{pH}$ 8,0) wurde scharf abzentrifugiert, um Fremdpartikel und denaturiertes Protein zu entfernen. Für die ersten Kristallisationsversuche wurden kommerzielle Screens der Firma Hampton Research (Crystal Screen I + II) mit jeweils 50 Präzipitationslösungen verwendet, zu denen DTT (Endkonzentration $2 \mathrm{mM}$ ) hinzupipettiert wurde. Die Präzipitationslösungen wurden dem Erfolg der Kristallisation entsprechend optimiert. Für die Kristallisation von AmyB-Tm wurde ein Ansatz mit 4 M Na-Formiat, 5 \% Isopropanol und $2 \mathrm{mM}$ DTT als optimal ermittelt. Alle Ansätze wurden in einer Klimakammer bei $20^{\circ} \mathrm{C}$ aufbewahrt.

\subsection{Kontrolle der Kristallisationsansätze}

Mit Hilfe eines Leica MZ125-Stereomikroskops wurden die Ansätze in regelmäßigen Abständen kontrolliert und alle Veränderungen (Präzipitation, Kristallbildung) genauestens protokolliert. Um entstandene Proteinkristalle von Salzkristallen unterscheiden zu können, wurden die Ansätze durch einen Polfilter vor dem Binokular betrachtet. Während Salzkristalle weiterhin farblos erscheinen, glühen die Proteinkristalle geradezu in leuchtend-bunten Farben. Zusätzlich war es möglich, die Proteinkristalle mit Coomassie-Lösung anzufärben, da sie durch ihre flüssigkeitsgefüllten Kanäle, im Gegensatz zu den eng gepackten Salzkristallen, organische Farbstoffe einlagern können. Außerdem wurden einzelne Kristalle mit Hilfe einer Nylonschlaufe aus dem Kristallisationsansatz entfernt, in einem kleinen Volumen $\mathrm{H}_{2} \mathrm{O}$ gelöst und durch SDS-PAGE kontrolliert. 


\subsection{Kryo-Konservierung und Montage der Kristalle zur Datensammlung}

Die Analyse der Kristalle im Röntgenstrahl findet bei tiefen Temperaturen (100 K) statt. Dadurch wird die Diffusion freier Hydroxylradikale, die innerhalb des Kristalls durch Absorption der Strahlen entstehen, stark vermindert. Hydroxylradikale führen zu Schäden im Kristallgitter und bewirken damit eine Verschlechterung der Diffraktionseigenschaften. Um die Kristalle tiefzukühlen, ist ein Frostschutzmittel (Kryoprotektant) nötig, das das in den Kristallen vorhandene Wasser, das Kanäle und große Zwischenräume füllt, verdrängt. Ein Tiefkühlen der Kristalle ohne Frostschutzmittel würde in den meisten Fällen zur Eisbildung innerhalb des Kristalls und damit zu seiner mechanischen Zerstörung führen. Neben der Möglichkeit, größere Datenmengen eines einzelnen Kristalls durch Reduzierung der Strahlungsschäden aufnehmen zu können, und der Unterdrückung des Hintergrundrauschens durch Reduzierung der Streustrahlung, bietet das Tiefkühlen von Kristallen zusätzlich den Vorteil einer einfacheren Handhabung und Lagerung in flüssigen Stickstoff.

\section{Durchführung:}

Mit einer Nylonschlaufe (0,05-1 mm Durchmesser), die bereits für die Montage in der beamline auf einem Stab mit Magnetkappe befestigt ist, wurde ein AmyB-Tm-Kristall aus dem Kristallisationsansatz gehoben und in frischer Präzipitationslösung (4 M Na-Formiat, 5 \% Isopropanol 2 mM DTT) mit dem Zusatz von 30 \% PEG 200 als Kryoprotektant geschwenkt. Der Kristall wurde dann aus dem Kryopuffer in ein Dewargefäß mit flüssigem Stickstoff überführt, wo dieser samt dem ihn umgebenen Film von Kryopuffer gefror. Unter flüssigem Stickstoff wurde die Nylonschlaufe luftblasenfrei in ein spezielles Plastikgefäß für den Transport verpackt. Im Laufe der Messungen stellte sich heraus, daß für die AmyB-TmKristalle ein spezielles Frostschutzmittel unnötig war, so daß bei späteren Datenerhebungen auf den Zusatz von PEG 200 verzichtet wurde, und die Kristalle direkt aus dem Kristallisationsansatz tiefgefroren wurden.

\subsection{Datenerhebung}

Die Kriterien für die Streuungsqualität eines Kristalls im Röntgenstrahl sind die Auflösung, die Form der Streupunkte auf dem Detektor (spot shape) und die Mosazität, d. h. der Winkelgrad, der durchstrichen werden muß, um einen Spot komplett aufzunehmen, idealerweise 0,3-0,5 $5^{\circ}$. Für AmyB-Tm waren diese Bedingungen bei den in $4 \mathrm{M}$ Na-Formiat, 5 \% Isopropanol und 2 mM DTT gewachsenen Kristallen mit einer Auflösung von 2-2,3 $\AA$ und einer Mosazität von 0,9 erfüllt. Standardmäßig wurden pro Datensatz 100-120 Bilder mit 
einer Drehung von je $1^{\circ}$ erhoben. Die Datenerhebung erfolgte an einer PSF beamline BL2 der Berliner Elektronen-Speicherring-Gesellschaft für Synchrotronstrahlung m.b.H (BESSY) in Berlin. 


\section{Experimente und Ergebnisse}

\section{Computergestützte Analysen der Sequenz des amyB-Tm-Gens und der Aminosäure-Sequenz von AmyB-Tm}

\section{1. Überprüfung des intragenischen Stopcodons}

Thermotoga maritima war 1999 einer der ersten Organismen, dessen Genom vollständig sequenziert wurde (Nelson et al., 1999). Der ORF tm1438, der dem in dieser Arbeit untersuchten Gen amyB-Tm entspricht, wurde im Zuge dieser Genomsequenzierung als hypothetisches Protein mit einem ,authentischen frameshift' bezeichnet. Grund hierfür ist ein TAA-Stopcodon an Position 526 der Nukleotidsequenz, das den offenen Leserahmen unterbricht. Danach setzt sich die Sequenz im gleichen Leserahmen bis zu einem TGAStopcodon an Position 1585 fort. In der ERGO Datenbank (http://gl-ergo.migen.bio.unigoettingen.de/) wird amyB-Tm aufgrund dieses Stopcodons als zwei getrennte ORFs dargestellt, RTM02682 und RTM02657, wobei der zweite ORF in einem alternativen Leserahmen mit einen ATG-Codon an Position 555 beginnt. Das von Fütterer (2001) klonierte, komplette, 1587 bp große amyB-Tm-Gen führte bei der Expression in E. coli zu einem etwa $63 \mathrm{kDa}$ großen Produkt, wie es bei der Translation des vollständigen tm1438 ORFs (528 Aminosäuren) zu erwarten ist.

Aufgrund der beschriebenen Ungereimtheiten wurde das Insert des von Fütterer (2001) erstellten Plasmids pET24c::AB mit besonderem Augenmerk auf das Stopcodon sequenziert. Ebenso sequenziert wurde der amyB-Tm entsprechende Abschnitt des Plasmids pTAA31, das Teil einer T. maritima Genbank ist (W. Liebl, persönliche Mitteilung; siehe Fütterer, 2001) und aus dem das Insert von pET24c::AB amplifiziert wurde. In keiner der Sequenzen konnte das von Nelson et al. (1999) postulierte Stopcodon gefunden werden. Insgesamt wurden in der Umgebung des hypothetischen Stopcodons vier Abweichungen von der veröffentlichten Gensequenz festgestellt (Abb. 5).

$$
\begin{array}{llll}
\text { amy }-T m & 508 & \text { tac gaa aag cac atg aag aaa cac } 531 \\
\text { tm1438 } & 508 \text { tac gct aag cac atg acg taa cac } 531
\end{array}
$$

Abb. 5: Vergleich der Nukleotidsequenzen von amyB-Tm und dem veröffentlichten ORF tm1438. Die Numerierung der Basen beginnt mit der ersten Base des Startcodons. Abweichungen sind grau hinterlegt, das postulierte Stopcodon ist fett gedruckt. 
Die Abweichungen, die alle die Base Adenin betreffen, sind authentisch und wurden bei der Sequenzierung nicht durch eine Überlagerung des Fluoreszenzsignals anderer Basen durch das Adeninsignal verursacht (Abb. 6).

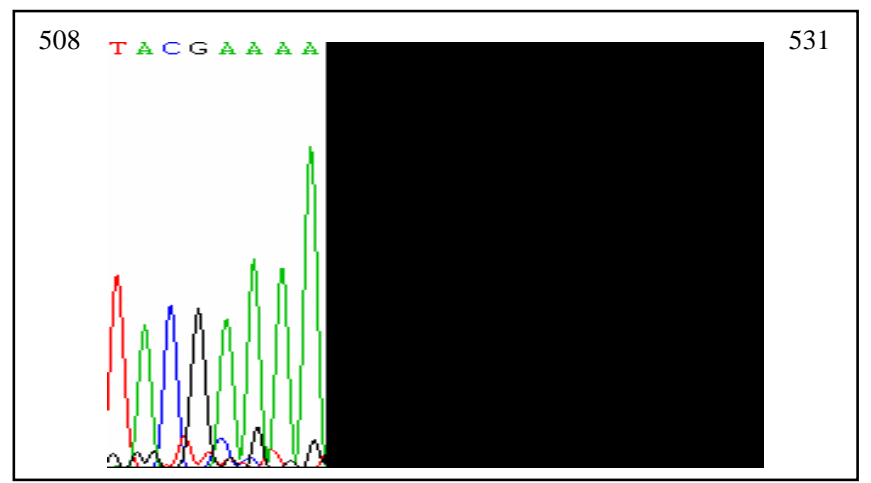

Abb. 6: Tracefile der Sequenzierung des Plasmids pTAA31 im Bereich des Stopcodons mit dem Primer amyB_ctrl_rev.

Die identifizierten Abweichungen in der Nukleotidsequenz ergeben drei Veränderungen in der abgeleiteten Aminosäuresequenz, die durch die spätere Strukturaufklärung des AmyBTm-Proteins (s. III.7) bestätigt werden konnten (Abb. 7). Alle folgenden Erwähnungen der amyB-Tm-Sequenz beziehen sich auf die korrigierte Nukleotid- bzw. Aminosäuresequenz.

$$
\begin{array}{llll}
\text { AmyB-Tm } & 170 & \text { YEKHMKKHPR } & 179 \\
\text { Tm1438 } & 170 & \text { YAKHMT }{ }^{*} \text { HPR } & 179
\end{array}
$$

Abb. 7: Vergleich der Aminosäuresequenz von AmyB-Tm und dem veröffentlichten Protein TM1438. Abweichungen sind grau unterlegt, das Stopcodon ist mit einem Platzhalter $\left(^{*}\right)$ bezeichnet. Die Numerierung der Aminosäuren beginnt mit dem durch das Startcodon kodierten Methionin.

\subsection{Datenbankabgleiche}

Mit der 528 Aminosäuren umfassenden Proteinsequenz von AmyB-Tm wurde eine Datenbanksuche mit dem BlastP Algorithmus (BLAST P 2.2.1, Altschul et al., 1997, http://www.ncbi.nlm.nih.gov/BLAST/) durchgeführt. Dabei ergab sich für große Teile der Sequenz eine signifikante Ähnlichkeit (e-value $\leq 1 \mathrm{e}-30$ ) zur Glykosidhydrolase-Familie (GHF) 57 und zur COG1543-Domäne, sowie eine geringe Ähnlichkeit zur COG1449Domäne. Die GHF 57 (= Pfam03065) ist sehr divers und umfaßt Amylasen, Pullulanasen und Glukanotransferasen, unter anderem eine $\alpha$-Glukanotransferase aus Thermococcus litoralis (Jeon et al., 1997), die sowohl biochemisch charakterisiert als auch strukturell untersucht ist. 
Die COG1449-Domäne ist als $\alpha$-Amylase/ $\alpha$-Mannosidase Domäne annotiert. Der COG1543Domäne konnte bisher keine Funktion zugewiesen werden (Abb. 8).

Neben den Aminosäuresequenzen, die in der COG1543 zusammengefaßt sind, zeigen auch andere Sequenzen signifikante Ähnlichkeit (e-value $\leq$ e-30) zu AmyB-Tm. Insgesamt sind dies 35 Aminosäuresequenzen aus diversen Bakterien und Archaeen mit einer Sequenzidentität von 54-24 \% zur Sequenz von AmyB-Tm (Tab. 6). Keines dieser Proteine wurde bisher biochemisch untersucht, und mit Ausnahme des hypothetischen Proteins aus Clostridium acetobutylicum, das als $\alpha$-Mannosidase annotiert ist (Nolling et al., 2001), und dem Protein TL2436 aus Thermococcus kodakaraensis, das als $\alpha$-Amylase der GHF 57 annotiert ist (Fukui et al., 2005), wurde bisher keinem eine Funktion zugewiesen.

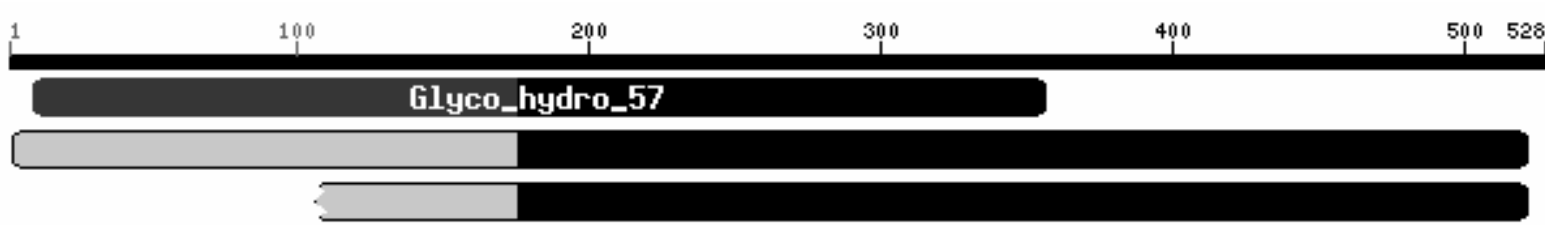

Abb. 8: Alignment der Aminosäuresequenz von AmyB-Tm zu konservierten Domänen mit dem Blast conserved domain Suchalgorithmus. Die GHF 57 Domäne ist 313 Aminosäuren lang und stimmt mit einem e-value von 6e-31 zu 97 \% mit AmyB-Tm überein. Die COG1543-Domäne (504 AS) stimmt mit einem e-value von 2e-142 zu 99,2 \% überein, die COG1449-Domäne (615 AS) mit einem e-value von 1e-6 nur zu 60,2 \%.

Tab. 6: Herkunftsorganismen der hypothetischen Proteine, die eine signifikante Ähnlichkeit (evalue $\leq \mathrm{e}-30$ ) zu AmyB-Tm aus T. maritima (Stand 1.3.05) aufweisen. Die Referenzen beziehen sich auf die GenBank-Einträge bzw. den Eintrag in der ERGO-Datenbank.

\begin{tabular}{|cccc|}
\hline Organismus & e-value & Proteinlänge & Referenz \\
\hline $\begin{array}{c}\text { Petrotoga miotherma ATCC } \\
\text { 51224 (IG) }\end{array}$ & e-148 & 526 & RPMI01414 \\
\hline Gloeobacter violaceus PCC 7421 & e-148 & 529 & gi|37523720|ref|NP_927097.1| \\
\hline $\begin{array}{c}\text { Trichodesmium erythraeum } \\
\text { IMS101 }\end{array}$ & e-147 & 527 & gi|23043733|gb|ZP_00074980.1| \\
\hline $\begin{array}{c}\text { Thermosynechococcus elongatus } \\
\text { BP-1 }\end{array}$ & e-146 & 529 & gi|22299517|ref|NP_682764.1| \\
\hline $\begin{array}{c}\text { Synechococcus elongatus PCC } \\
\text { 7942 }\end{array}$ & e-145 & 531 & gi|46130163|ref|ZP_00164915.2| \\
\hline Synechocystis sp. PCC 6803 & e-144 & 529 & gi|16332203|ref|NP_442931.1| \\
\hline Nostoc punctiforme PCC 73102 & e-143 & 529 & gi|23130149|ref|ZP_00111968.1| \\
\hline Crocosphaera watsonii WH 8501 & e-143 & 533 & gi|53735035|ref|ZP_00177036.2 \\
\hline Nostoc sp. PCC 7120 & e-142 & 529 & gi|17229942|ref|NP_486490.1| \\
\hline Anabaena variabilis ATCC 29413 & e-142 & 529 & gi|53764399|ref|ZP_00160209.2 \\
\hline $\begin{array}{c}\text { Moorella thermoacetica ATCC } \\
\text { 39073 }\end{array}$ & e-132 & 528 & gi|49236719|ref|ZP_00330776.1 \\
\hline
\end{tabular}


Fortsetzung Tab. 6

\begin{tabular}{|c|c|c|c|}
\hline $\begin{array}{l}\text { Clostridium acetobutylicum ATCC } \\
824\end{array}$ & e-129 & 527 & gi|15895680|ref|NP_349029.1| \\
\hline Heliobacillus mobilis & e-126 & 533 & RHMO03391 \\
\hline Anabaena sp. PCC7120 & $\mathrm{e}-120$ & 529 & RAN05394 \\
\hline $\begin{array}{c}\text { Moorella thermoacetica ATCC } \\
39073\end{array}$ & e-114 & 582 & gi|49235034|ref|ZP_00329111.1| \\
\hline Bacillus halodurans C-125 & e-104 & 923 & gi|15613978|ref|NP_242281.1| \\
\hline $\begin{array}{c}\text { Prochlorococcus marinus subsp. } \\
\text { pastoris str. CCMP1378 }\end{array}$ & $2 e-97$ & 527 & gi|23122900|gb|ZP_00105035.1| \\
\hline $\begin{array}{l}\text { Prochlorococcus marinus subsp. } \\
\text { pastoris str. CCMP1986 }\end{array}$ & $7 e-95$ & 527 & gi|33861621|ref|NP_893182.1| \\
\hline Exiguobacterium sp. 255-15 & $5 e-93$ & 698 & gi|46113199|ref|ZP_00182457.2| \\
\hline $\begin{array}{c}\text { Prochlorococcus marinus str. MIT } \\
9313\end{array}$ & $1 \mathrm{e}-92$ & 522 & gi|23131666|gb|ZP_00113451.1| \\
\hline Synechococcus sp. WH 8102 & $6 e-91$ & 522 & gi|33865263|ref|NP_896822.1| \\
\hline Pyrococcus horikoshii OT3 & $4 e-86$ & 560 & gi|14591189|ref|NP_143265.1| \\
\hline Pyrococcus abyssi GE5 str. Orsay & $2 \mathrm{e}-85$ & 602 & gi|14520970|ref|NP_126445.1| \\
\hline Pyrococcus furiosus DSM 3638 & $2 \mathrm{e}-85$ & 632 & gi|18977765|ref|NP_579122.1| \\
\hline Thermococcus kodakaraensis & 3e-85 & 675 & gi|57641371|ref|YP_183849.1| \\
\hline $\begin{array}{c}\text { Treponema denticola ATCC } \\
35405\end{array}$ & $2 \mathrm{e}-68$ & 525 & gi|42526604|ref|NP_971702.1| \\
\hline Thermus thermophilus HB27 & $4 \mathrm{e}-67$ & 520 & gi|46199842|ref|YP_005509.1| \\
\hline Thermus thermophilus HB8 & $9 e-66$ & 520 & gi|39654909|pdb|1UFA|A \\
\hline $\begin{array}{l}\text { Treponema pallidum subsp. } \\
\text { pallidum str. Nichols }\end{array}$ & $9 e-60$ & 526 & gi|15639349|ref|NP_218798.1| \\
\hline Nocardia farcinica IFM 10152 & $2 \mathrm{e}-40$ & 536 & gi|54026252|ref|YP_120494.1 \\
\hline Rhodococcus str. I24 (IG) & $3 e-38$ & 647 & RRK05260 \\
\hline $\begin{array}{l}\text { Mycobacterium avium subsp. } \\
\text { paratuberculosis str. k10 }\end{array}$ & $3 e-38$ & 534 & gi|41409161|ref|NP_961997.1| \\
\hline $\begin{array}{l}\text { Mycobacterium tuberculosis } \\
\text { CDC1551 }\end{array}$ & 3e-37 & 526 & gi|15842594|ref|NP_337631.1| \\
\hline Mycobacterium leprae & $1 \mathrm{e}-36$ & 522 & gi|15827918|ref|NP_302181.1| \\
\hline Chlo & 9e-31 & 485 & 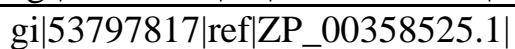 \\
\hline
\end{tabular}

\subsection{Analyse der AmyB-Tm-flankierenden Region}

In T. maritima und einigen anderen Organismen befindet sich upstream des Gens für das zu AmyB-Tm orthologe Protein ein konservierter Leserahmen, der für ein hypothetisches Protein mit unbekannter Funktion kodiert (COG3330). Dieses Protein weist laut ERGO-Annotationen Ähnlichkeiten zu Phosphat-Binde-Proteinen und Ferrochelatasen auf (Abb. 9). In dem Bakterium Thermus thermophilus HB27, das ein AmyB-Tm strukturell sehr ähnliches Protein besitzt (AmyB-Tt, s. III.9), befindet sich vor dem amyB-Tt ORF kein COG3330-ähnliches Protein, sondern eine Acetylglutamat-Kinase. 


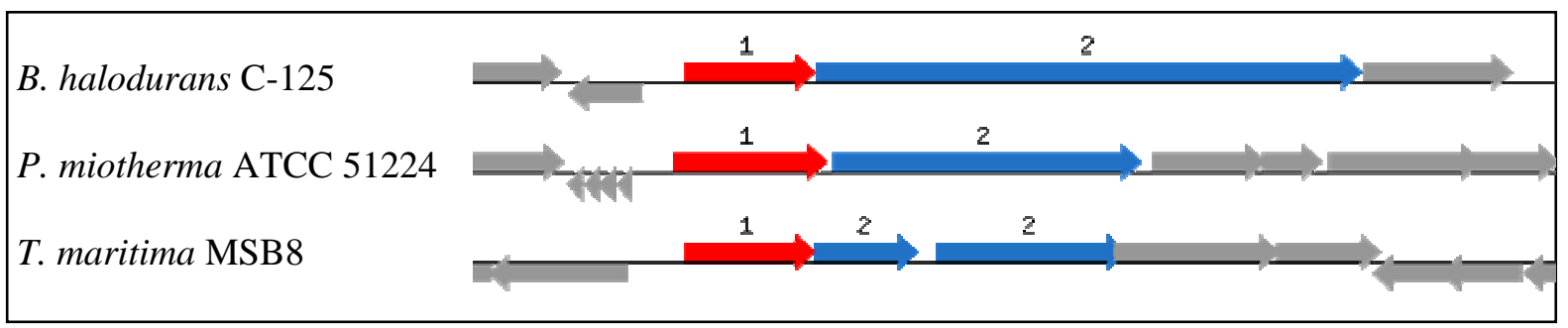

Abb. 9: ORF-Struktur der flankierenden Region um für AmyB-Tm bzw. um für AmyB-Tmhomologe Proteine kodierende Gene bei Bacillus halodurans, Petrotoga miotherma und Thermotoga maritima. ORF 1: RHD05335, RPMI01413 bzw. RTM00411 (Tm1439); ORF 2: RHD05336, RPMI01414 bzw. RTM02682/ 02657 (Tm1438, AmyB-Tm).

\section{Rekombinante Expression und Reinigung von AmyB-Tm}

\subsection{Anzucht und Aufreinigung aus E. coli BL21 (DE3)/pET24c::AB}

Zur Aufreinigung des rekombinanten Enzyms wurde eine Flüssigkultur mit einem Volumen von 2x 1,5 $\mathrm{l}$ aus einer Vorkultur von E. coli BL21 (DE3)/pET24c::AB 2 \%ig beiimpft und, wie unter II.3.2.1 beschrieben, kultiviert. Bei einer $\mathrm{OD}_{600}$ von $\sim 0,6$ wurde die Kultur mit 0,1 mM IPTG induziert und die Inkubation über Nacht fortgesetzt. Das Naßgewicht des geernteten Zellpellets betrug 4,8 g/l. Nach Resuspension in $40 \mathrm{ml} 20 \mathrm{mM}$ Tris-Puffer (pH 8,0) wurden die Zellen mit der French Pressure Cell aufgeschlossen (s. II.5.2.2). Durch eine 20minütige Hitzefällung bei $75{ }^{\circ} \mathrm{C}$ konnte ein Großteil der mesophilen E. coli-Proteine entfernt werden. Der hitzedenaturierte Rohextrakt wurde über Nacht gegen $20 \mathrm{mM}$ Tris (pH 8,0) dialysiert und anschließend einer Anionenaustausch-Chromatographie mit einer Source 30Q-Säule unterzogen. Die Fraktionen wurden auf ihren Proteingehalt und ihre amylolytische Aktivität (DNSA-Test, II.7.1) überprüft. Nach gelelektrophoretischer Kontrolle der Reinheit des Proteins wurden die Fraktionen 12-14 vereinigt und gegen $20 \mathrm{mM}$ Tris (pH 8,0) dialysiert. Abb. 10 zeigt das Chromatogramm des Säulenlaufs, die Parameter des Säulenlaufs sind in Tab. 7 aufgeführt. 
Tab. 7 : Parameter des Source 30Q-Säulenlaufs.

\begin{tabular}{ll}
\hline Parameter & \\
\hline Medium: & SOURCE 30Q \\
Säule: & HR10/10 \\
Säulenvolumnen: & $8,25 \mathrm{ml}$ \\
Probe: & $\sim 128 \mathrm{mg}$ Protein \\
Puffer A: & $20 \mathrm{mM}$ Tris (pH 8,0) \\
Puffer B: & $20 \mathrm{mM}$ Tris (pH 8,0) $+1000 \mathrm{mM} \mathrm{NaCl}$ \\
Flußrate: & $2 \mathrm{ml} / \mathrm{min}$ \\
Fraktionsgöße: & $2 \mathrm{ml}$ \\
Equilibrierung: & $3 \mathrm{SV}$ Puffer B, 10 SV Puffer A \\
Gradient: & $0-100 \%$ Puffer B (10 CV) \\
& $100 \%$ Puffer (1 CV) \\
\hline
\end{tabular}
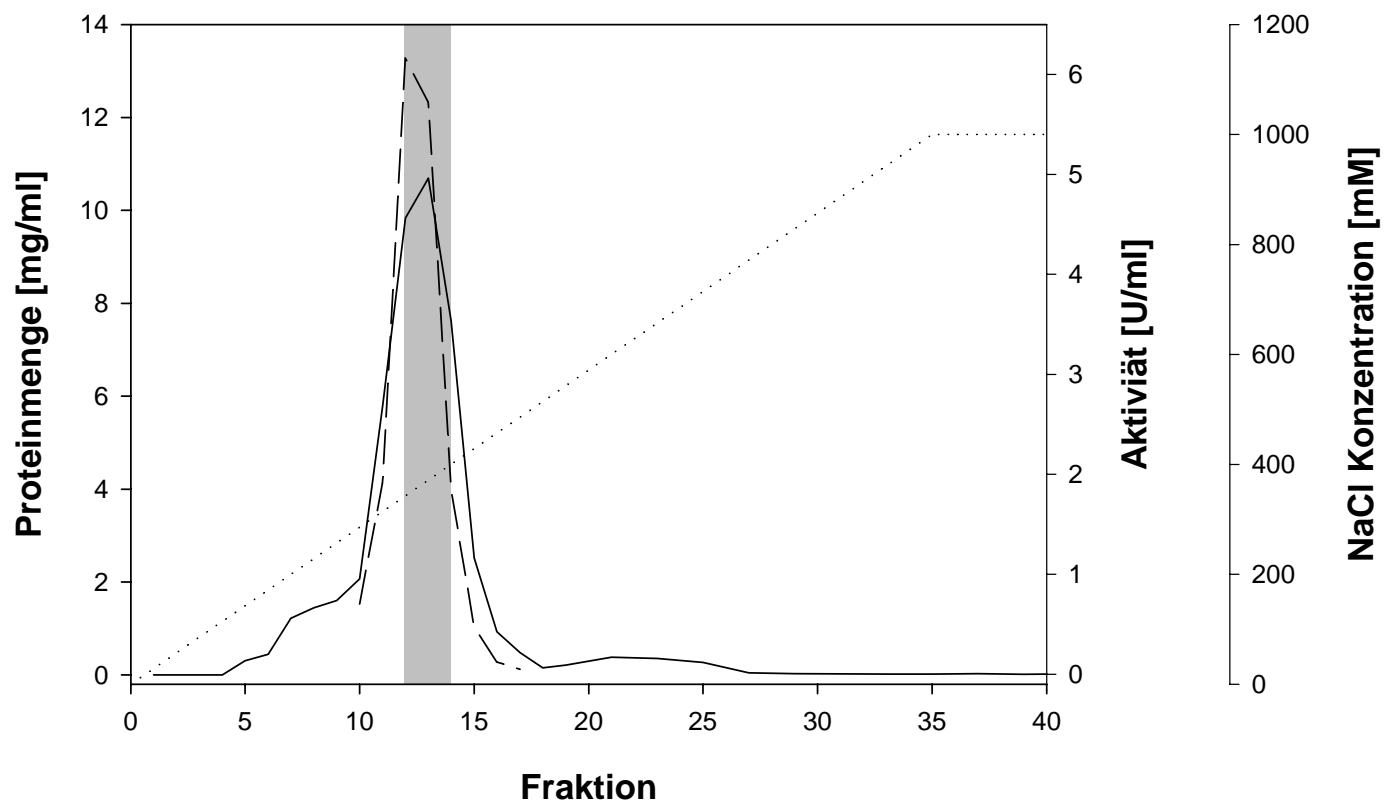

Abb. 10: Chromatogramm des Source 30Q-Säulenlaufs zur Aufreinigung des rekombinanten AmyB-Tm-Proteins. Die durchgezogene Linie stellt die Proteinkonzentration in den Fraktionen dar, die gestrichelte Linie die Aktivität und die gepunktete Linie die NaCl-Konzentration des Gradienten. Die gepoolten Fraktionen sind grau hinterlegt.

Ein Teil des über die Source 30Q gereinigten Proteins wurde einer präparativen Gelfiltration mit einer Superdex 200-Säule unterzogen, ein anderer Teil wurde einer hydrophoben Interaktionschromatographie mit einer Phenyl-Speharose Säule unterzogen. In beiden Fällen war das so gereinigte Protein inaktiv, weshalb bei weiteren Aufreinigungen von einem zweiten säulenchromatographischen Schritt abgesehen wurde. Die spezifische Aktivität des aufgereinigten AmyB-Tm-Proteins betrug 0,6 U/mg. Insgesamt wurden aus 14,3 g Zellen 72 mg reines Protein gewonnen. Die Bilanzierung der Aufreinigung erwies sich als schwierig, da offensichtlich Inhaltsstoffe des Rohextrakts, welche sich auch durch Dialyse nicht entfernen 
ließen, die Aktivität von AmyB-Tm vermindern (Tab. 8). Die Aktivität des wie oben beschrieben aufgereinigten AmyB-Tm-Proteins schwankte in späteren Aufarbeitungen zwischen 0,2 und 0,6 U/mg.

Tab. 8: Bilanz der Präparation des rekombinanten AmyB-Tm-Proteins aus E. coli BL21 (DE3)/pET24c::AB. Die Bestimmung der Aktivität erfolgte durch DNSA-Test mit löslicher Stärke für $1 \mathrm{~h}$ mit $50 \mathrm{mM}$ Tris $\mathrm{pH} 8,0$ und $10 \mathrm{mM}$ DTT bei $90^{\circ} \mathrm{C}$.

\begin{tabular}{ccccc}
\hline & $\begin{array}{c}\text { Protein } \\
{[\mathbf{m g}]}\end{array}$ & $\begin{array}{c}\text { Gesamtaktivität } \\
{[\mathbf{U}]}\end{array}$ & $\begin{array}{c}\text { spezifische } \\
\text { Aktivität } \\
{[\mathbf{U} / \mathbf{m g}]}\end{array}$ & Anreicherungsfaktor \\
\hline $\begin{array}{c}\text { Rohextrakt } \\
\text { hitzdenaturierter }\end{array}$ & 1043,2 & 6,4 & 0,01 & 1 \\
Rohextrakt & 127,7 & 17,9 & 0,14 & 14 \\
Source 30Q Pool & 72,2 & 43,3 & 0,60 & 60 \\
\hline
\end{tabular}

In Abb. 11 sind die Schritte der Aufreinigung von AmyB-Tm in einer SDS-PAGE dargestellt. Die schwache Bande oberhalb der AmyB-Tm-Bande ist authentisch. Sie ließ sich durch keinen Reinigungsversuch, d. h. auch nicht durch hydrophobe Interaktionschromatographie und Gelfiltration, von der Hauptbande trennen. Auch bei der späteren gelelektrophoretischen Kontrolle des kristallisierten Proteins trat im Gel eine Doppelbande auf (s. III.3.6).

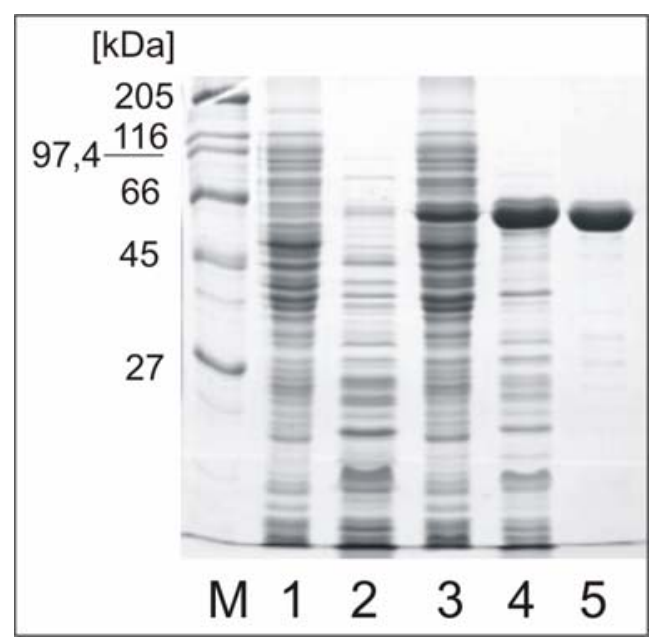

Abb. 11: SDS-PAGE-Gel der Reinigungsschritte von AmyB-Tm. M, Molekularmassenstandard; Spur 1, Rohextrakt von E. coli BL21 (DE3) (20 $\mu \mathrm{g})$; Spur 2, hitzedenaturierter Rohextrakt (12 $\mu \mathrm{g})$; Spur 3, Rohextrakt von E. coli BL21 (DE3)/pET24c::AB (26 $\mu$ l); Spur 4, hitzedenaturierter

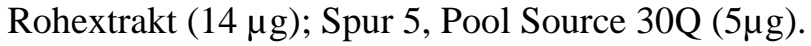




\subsection{Expressionsexperimente}

\subsubsection{Semi-anaerobe Aufreinigung von AmyB-Tm}

Die Aktivität von AmyB-Tm wurde durch Reduktionsmittel deutlich gesteigert (s. Fütterer, 2001 und III.3.2), was auf eine Empfindlichkeit des Enzyms gegenüber Sauerstoff schließen läßt. Um dies zu überprüfen, wurde in E. coli BL21/pET24c::AB exprimiertes AmyB-TmProtein anaerob aufgearbeitet. Dazu wurde eine zunächst aerobe Flüssigkultur im 1,3 l Maßstab in M1-Medium 2 \%ig angeimpft. Nach $2 \mathrm{~h}$ aeroben Wachstums bei $30{ }^{\circ} \mathrm{C}$ wurde die Kultur mit 0,1 mM IPTG induziert, und der Erlenmeyerkolben mit einem Gummistopfen luftdicht verschlossen. Die Kultur sollte sich so durch die eigene Stoffwechseltätigkeit anaerobisieren. Die Ernte erfolgte $24 \mathrm{~h}$ nach der Inokulation bei einer $\mathrm{OD}_{600}$ von 2,5. Alle Schritte der Gewinnung des hitzedenaturierten Rohextrakts wurden im Anaerobenzelt unter $\mathrm{N}_{2}$-Atmosphäre durchgeführt. Eine Ausnahme bildeten dabei die Zentrifugationen, der Zellaufschluß und die Hitzefällung. Die Kultur wurde bei 7000 Upm 15 min zentrifugiert und das Zellpellet in $20 \mathrm{mM}$ Tris-Puffer ( $\mathrm{pH}$ 8,0) mit $3 \mathrm{mM}$ DTT gewaschen. Nach einem weiteren Zentrifugationsschritt wurde das Pellet in $20 \mathrm{mM}$ Tris-Puffer (pH 8,0) mit $3 \mathrm{mM}$ DTT aufgenommen. Der Aufschluß erfolgte mittels einer einmaligen Passage durch die French Pressure Cell (s. II.5.2.2). Das Zelllysat wurde durch eine am Auslaß der Druckzelle befestigte Kanüle in eine anaerobisierte Serumflasche geleitet, ohne mit der Umgebungsluft in Berührung zu kommen. Die unlöslichen Zellbestandteile wurden bei 1100 Upm abzentrifugiert und der so gewonnene Rohextrakt einer Hitzefällung der Wirtsproteine für 15 min bei $80^{\circ} \mathrm{C}$ unterzogen. Nach einem weitern Zentrifugationsschritt wurde der Überstand in ein Hungate-Röhrchen überführt, und dieses nach dem Verlassen des Anaerobenzeltes mit Stickstoff begast. Der Rohextrakt (15 ml) hatte eine Proteinkonzentration von 25,2 mg/ml, die Proteinkonzentration des hitzedenaturierten Rohextrakts $(10 \mathrm{ml})$ betrug $1 \mathrm{mg} / \mathrm{ml}$. Abbildung 12 zeigt die Schritte der AmyB-Tm-Anreicherung. 


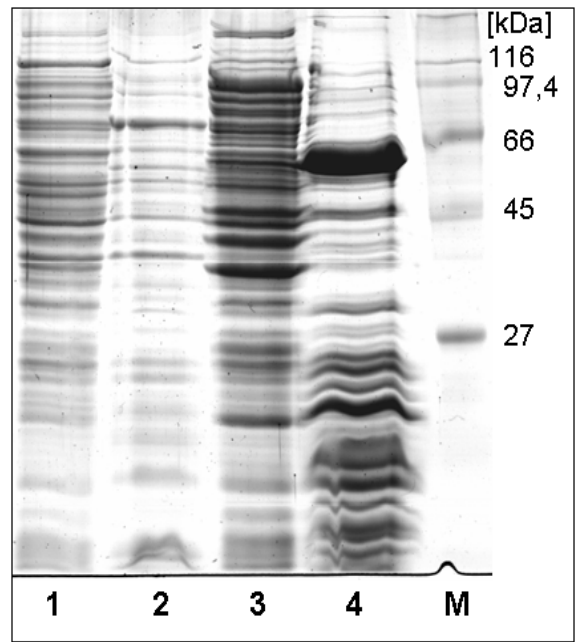

Abb. 12: SDS-PAGE Bilanz der anaeroben Aufarbeitung von AmyB-Tm. M, Molekularmassenstandard; Spur 1, E. coli BL21 (DE3) Rohextrakt; Spur, 2, hitzedenaturierter Rohextrakt (15 min, 80 ${ }^{\circ} \mathrm{C}$ ); Spur 3, E. coli BL21 (DE3)/pET24c::AB anaerob gewonnener Rohextrakt; Spur 4, hitzedenaturierter, anaerob gewonnener Rohextrakt $\left(15 \mathrm{~min}, 80^{\circ} \mathrm{C}\right)$.

Ein Teil des so gewonnen hitzedenaturierten Rohextrakts wurde durch mehrmaliges Mischen mit der Umgebungsluft in Kontakt gebracht und aerob gelagert. Nach 6 und 30 h wurden mit dem anaeroben und den aerob gelagerten Rohextrakten Aktivitätstests (DNSA-Test, s. II.7.2) durchgeführt. Dabei konnten zwischen den Enzymaufarbeitungen keine signifikanten Unterschiede in der Aktivität mit löslicher Stärke als Substrat festgestellt werden. Die Höhe der Aktivität der anaerob gewonnenen Rohextrakte unterschied sich nicht von der Aktivität aerob aus E. coli BL21 (DE)/pET24c::AB gewonnner hitzedenaturierter Rohextrakte früherer Aufreinigungen (Tab. 9). Damit konnte nachgewiesen werden, daß eine anaerobe Aufarbeitung keinen positiven Einfluß auf die Aktivität von AmyB-Tm hat. Dies deckt sich mit der Beobachtung, daß auch bei mehrmonatiger Lagerung bei $4{ }^{\circ} \mathrm{C}$ kein Aktivitätsverlust von AmyB-Tm eintritt.

Tab. 9: Spezifische Aktivität hitzedenaturierter Rohextrakte aus aeroben und anaeroben Aufarbeitungen von AmyB-Tm.

\begin{tabular}{lc}
\hline \multicolumn{1}{c}{ hitzedenaturierter Rohextrakt } & $\begin{array}{c}\text { spezifische Aktivität } \\
\text { [U/mg] }\end{array}$ \\
\hline aerobe Aufarbeitung 1 & 0,037 \\
aerobe Aufarbeitung 2 & 0,108 \\
anaerobe Aufarbeitung & 0,043 \\
anaerobe Aufarbeitung, nach $30 \mathrm{~h}$ & 0,049 \\
anaerobe Aufarbeitung, nach $6 \mathrm{~h}$ an der Luft & 0,051 \\
anaerobe Aufarbeitung, nach $30 \mathrm{~h}$ an der Luft & 0,064 \\
\hline
\end{tabular}




\subsubsection{Renaturierung von Inclusion Bodies}

Bei der heterologen Proteinexpression mit dem Vektor pET24c::AB war stets zu beobachten, daß ein Großteil des gebildeten AmyB-Tm-Proteins in unlöslicher Form als inclusion bodies vorlag. Dies traf unter allen getesteten Bedingungen zu, u. a. bei der Variation der Anzuchttemperatur sowie der Induktionszeit und -stärke. Abb. 13 zeigt ein typisches Beispiel einer solchen Expression. Die hier gelelektrophoretisch analysierten Kulturen waren kurz nach der Inokulation mit 0,1 mM IPTG induziert worden und über Nacht bei $37{ }^{\circ} \mathrm{C}$ gewachsen. Um zu testen, ob das mißgefaltete Protein in vitro in eine lösliche und möglicherweise aktive Faltungskonformation überführt werden konnte, wurde der Versuch unternommen, die inclusion bodies zu renaturieren. Dazu wurde eine $30 \mathrm{ml}$ Flüssigkultur 1 \%ig mit E. coli BL21 (DE3)/pET24c::AB angeimpft, mit 0,1 mM IPTG induziert und über Nacht kultiviert. Die Zellen wurden, wie unter II.5.2 beschrieben, geerntet, aufgeschlossen und das inclusion body-Pellet nach Waschen und Inkubation in Puffer B in $5 \mathrm{ml}$ Renaturierungspuffer mit 1 M Harnstoff aufgenommen. Im eigentlichen Rückfaltungsschritt, der Dialyse gegen Renaturierungspuffer ohne Harnstoff, fiel ein großer Teil der durch die Harnstoff-Zugabe in Lösung gebrachten Proteine wieder aus. Das Präzipitat wurde durch Zentrifugation abgetrennt. Durch SDS-PAGE-Analyse konnte gezeigt werden, daß die Mehrheit der Proteine, die zu Beginn der Renaturierung unlöslich im Pellet des Rohextrakts vorlagen, nach Entfernung des Harnstoffs aus dem Renaturierungspuffer nicht dauerhaft in Lösung blieben. Ein geringer Anteil an Protein, in erster Linie rekombinantes AmyB-Tm, konnte jedoch in eine lösliche Form überführt werden (Abb. 14). Die Proteinkonzentration des Überstands mit einem Volumen von $5 \mathrm{ml}$ betrug $0,4 \mathrm{mg} / \mathrm{ml}$. Trotz erfolgreicher Renaturierung aus inclusion bodies konnte bei diesem Protein keine amylolytische Aktivität gemessen werden. 


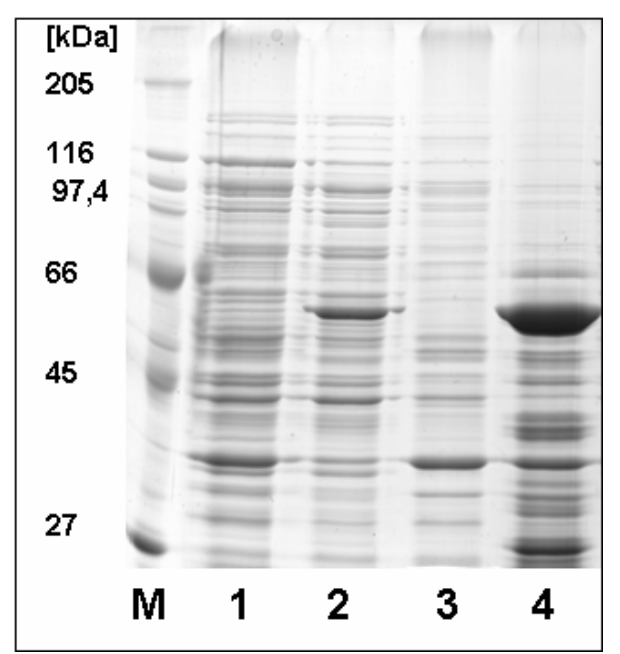

Abb. 13: SDS-PAGE-Gel der löslichen und unlöslichen Rohextrakt-Bestandteile bei heterologer Expression von AmyB-Tm. M, Molekularmassenstandard; Spur 1, E. coli BL21 (DE3) Rohextrakt, lösliche Fraktion; Spur 2, E. coli BL21 (DE3)/pET24c::AB Rohextrakt, lösliche Fraktion; Spur 3, E. coli BL21 (DE3) Rohextrakt, unlösliche Fraktion; Spur 4, E. coli BL21 (DE3)/pET24c::AB Rohextrakt, unlösliche Fraktion.

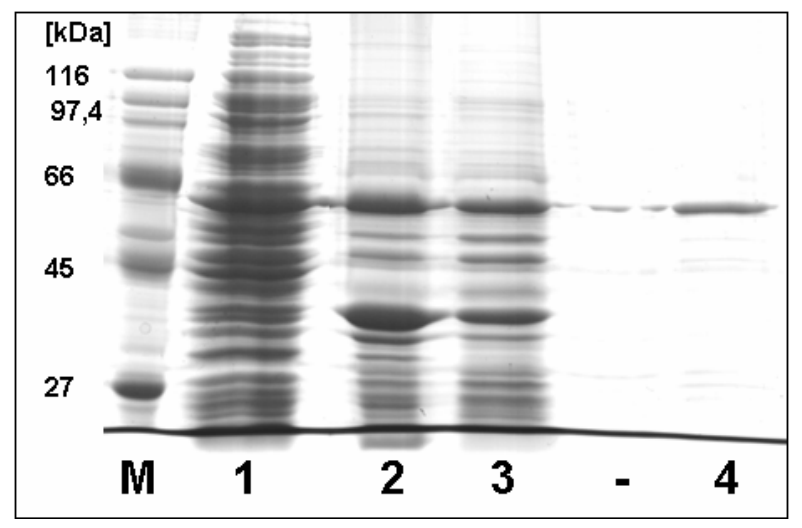

Abb. 14: SDS-PAGE Bilanz der inclusion body-Renaturierung. $M$, Molekularmassenstandard; Spur 1, löslicher Anteil des Rohextrakts der E. coli BL21 (DE3)/pET24c::AB Kultur; Spur 2, unlöslicher Anteil des Rohextrakts, Spur 3, Präzipitat nach Dialyse zur Harnstoffentfernung; Spur 4, renaturiertes Protein nach der Dialyse.

\subsubsection{AmyB-Tm-Expression in verschiedenen Medien}

Flüssigkulturen von E. coli BL21(DE3)/pET24c::AB wurden in verschiedenen Mineral- und Vollmedien angezogen. Die 20 min bei $75{ }^{\circ} \mathrm{C}$ hitzedenaturierten Rohextrakte unterschieden sich im DNSA-Test nicht signifikant in ihrer amylolytischen Aktivität bei für AmyB-Tm optimalen Testbedingungen. 


\subsubsection{Abhängigkeit von AmyB-Tm-Aktivität und Expressionszeit}

In Expressionsversuchen mit variierenden Anzuchtzeiten von E. coli BL21 (DE3)/pET24c::AB wurde ermittelt, daß die Aktivität des Proteins, das aus nach Induktion $4 \mathrm{~h}$ gewachsenen Kulturen stammte, etwa $50 \%$ höher war als bei Protein aus $8 \mathrm{~h}$ gewachsenen Kulturen. Die gewonnene Menge an sauberem Protein war bei den länger inkubierten Kulturen etwa dreimal größer (Daten nicht gezeigt). Dies läßt darauf schließen, daß die Wachstumsphase der E. coli Zellen und die Menge des produzierten rekombinanten Enzyms einen Einfluß auf die Aktivität des AmyB-Tm-Proteins haben.

\subsection{Expression in alternativen Vektorsystemen}

\subsubsection{Konstruktion des Plasmids pWLQ2::AB}

Da die Expression von AmyB-Tm mit dem Überexpressionsvektor pET24c::AB zu großen Mengen an unlöslichem rekombinanten Enzym führte, wurde das amyB-Tm-Gen in einen Vektor kloniert, in dem die Expression stärker kontrolliert werden konnte. Der Vektor pWLQ2 (Liebl et al., 1992) trägt das Gen $l a c I^{q}$, welches einen Repressor des $\mathrm{P}_{\text {tac }}$-Promotors kodiert, und die Expression eines in die multiple cloning site eingefügten Gens im nichtinduzierten Zustand verhindern soll. Der Vektor dient als Schaukel-Vektor zur Transformation von C. glutamicum. Zusätzlich zur stärker kontrollierten Expression in E. coli sollte hierbei getestet werden, ob der Wechsel des Expressionswirtes eine Aktivitätssteigerung von AmyB-Tm bewirken konnte.

Mit den spezifischen Primern $a m y B \_p W L Q 2$ for und $a m y B \_p W L Q 2 \_r e v$ wurde das amyBTm-Gen mit der davor liegenden Shine-Dalgarno-Sequenz des pET-Vektors aus dem Vektor pET24c::AB amplifiziert. Diese Strategie wurde gewählt, da im pWLQ2-Vektor keine ShineDalgarno-Sequenz vorlag. Dabei wurden eine SmaI-Schnittstelle am 3'-Ende und eine SalISchnittstelle am 5’-Ende eingefügt.

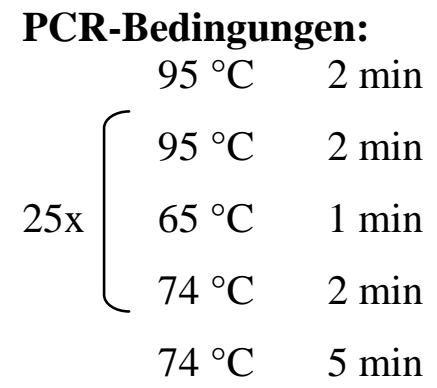

PCR Ansatz:

Pfu-Puffer (10x) $5 \mu \mathrm{l}$

template DNA (pET24c::AB) $\quad 0,2 \mu \mathrm{l}$

Primer $(100 \mathrm{pmol} / \mu \mathrm{l}) \quad$ je $0,5 \mu \mathrm{l}$

dNTP-Mix $(2 \mathrm{mM}) \quad 5 \mu \mathrm{l}$

Pfu-Polymerase $\quad 0,5 \mu \mathrm{l}$

$\mathrm{H}_{2} \mathrm{O}_{\text {bidest. }} \quad$ ad $50 \mu \mathrm{l}$ 
Das 1832 bp lange Fragment wurde mit SalI und SmaI verdaut und direkt in den ebenfalls SmaI/SalI geschnittenenVektor pWLQ2 ligiert. E. coli XL1-blue wurde mit dem Konstrukt transformiert und auf Selektionsplatten kultiviert. Die Überprüfung positiver Klone erfolgte durch PCR, Restriktionsanalyse und Sequenzierung. Abb. 15 zeigt eine Karte des konstruierten Vektors.

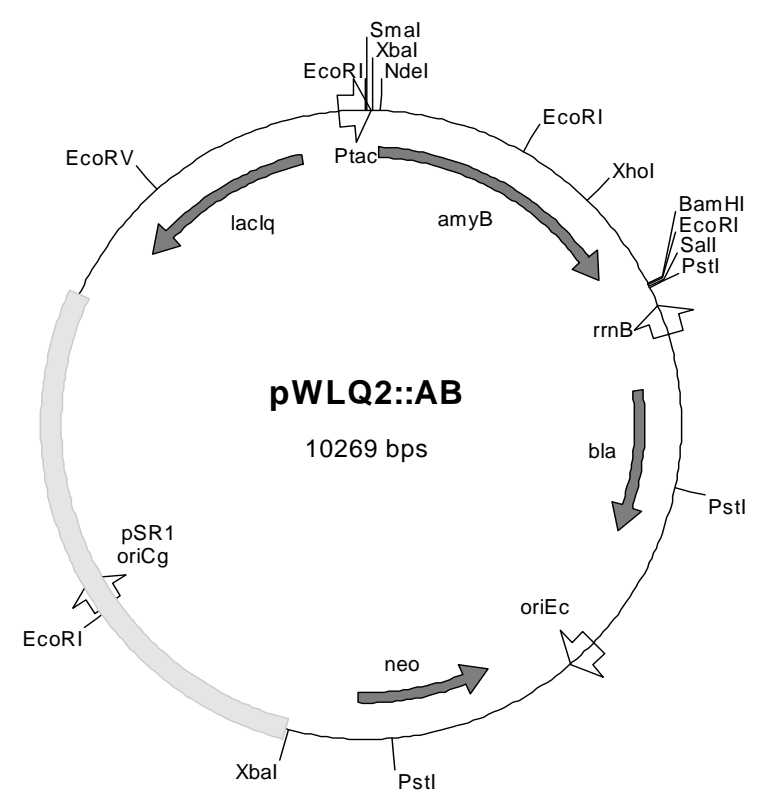

Abb. 15: Vektor pWQL2::AB

\subsubsection{AmyB-Tm-Expression in pWLQ2::AB-transformierten E. coli-Kulturen}

Zur Kontrolle der Expression wurde E. coli XL1-blue/pWLQ2::AB in einer $30 \mathrm{ml}$ Kultur mit 0,5 mM IPTG zur Induktion über Nacht angezogen. Wie schon bei der Expression mit dem Vektor pET24c::AB lag ein Großteil des exprimierten AmyB-Tm-Proteins im Pellet vor. Außerdem war zu beobachten, daß trotz starker Expressionskontrolle des Vektors AmyB-Tm in minimalen Mengen auch ohne Induktion exprimiert wurde (Abb. 16).

Um zu testen, ob diese geringfügige Expression zu AmyB-Tm-Protein führte, das eine höhere amylolytische Aktivität aufwies als das durch den Überexpressionsstamm E. coli BL21 (DE3)/pET24c::AB produzierte Enzym, wurde AmyB-Tm aus einer Flüssigkultur von E. coli XL1-blue/pWLQ2::AB aufgereinigt. Die Anzucht erfolgte $12 \mathrm{~h}$ bei $37^{\circ} \mathrm{C}$ im Maßstab von $2 \mathrm{l}$. Die Zellernte und Proteinaufreinigung erfolgten in gleicher Weise wie bei der Aufreinigung aus E. coli BL21(DE3)/pET24c::AB durch Hitzefällung $\left(20 \mathrm{~min}, 75{ }^{\circ} \mathrm{C}\right)$ und Anionenaustausch-Chromatographie mit einer Source 30Q-Säule (s. III.2.1). Das so gewonnene Protein (4 mg Protein aus 9,2 g Zellen) zeigte im Standard DNSA-Test mit löslicher Stärke (s. II. 7.1) eine Aktivität von $\sim 0,3 \mathrm{U} / \mathrm{mg}$ und wies damit keine höhere Aktivität auf als das überexprimierte Enzym aus E. coli BL21(DE3)/pET24c::AB. Von 
letzterem konnten 72 mg aus 14,3 g Zellen gewonnen werden konnten. Wie auch schon bei anderen Aufreinigungen erschien AmyB-Tm als Doppelbande. Die Aufreinigungsschritte sind in Abb. 17 dargestellt.

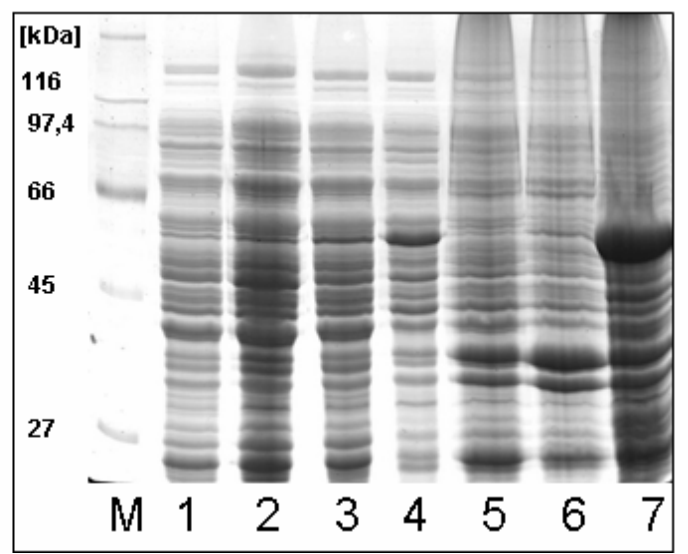

Abb. 16: SDS-PAGE-Analyse der AmyB-Tm-Expression mit dem Plasmid pWLQ2::AB bei Induktion durch 0,5 mM IPTG. M, Molekularmassenstandard; Spur 1 und 2, Rohextrakt einer E. coli XL1-blue/pWLQ2 Kultur (Negativkontrolle) -/+ Induktion; Spur 3 und 4, Rohextrakt einer E. coli XL1-blue/pWLQ2::AB Kultur -/+ Induktion; Spur 5, Pellet der Negativkontrolle ohne Induktion; Spur 6 und 7, Pellet der E. coli XL1-blue/pWLQ2::AB Kultur -/+ Induktion.

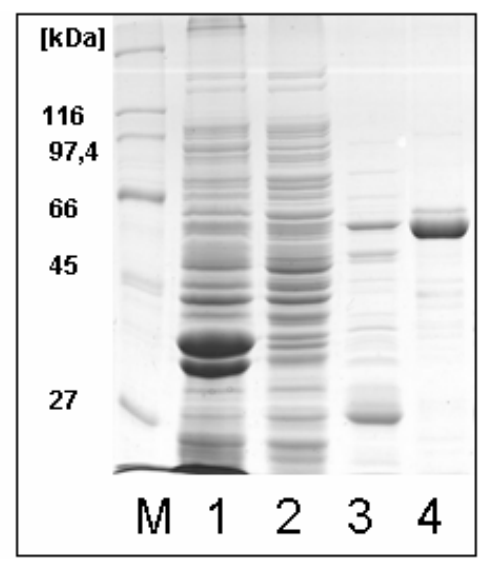

Abb. 17: SDS-PAGE-Gel der Aufreinigungsschritte von AmyB-Tm aus E. coli XL1blue/pWLQ2::AB. M, Molekularmassenstandard; Spur 1, Pellet; Spur 2, Rohextrakt (30 $\mu \mathrm{g})$; Spur 3, 20 min bei $75{ }^{\circ} \mathrm{C}$ hitzedenaturierter Rohextrakt (5 $\left.\mu \mathrm{g}\right)$; Spur 4, Source 30 Q Pool (5 $\left.\mu \mathrm{g}\right)$. 


\subsubsection{AmyB-Tm-Expression in pTAA31 transformiertem E. coli JM83}

Der Genbankvektor pTAA31 trägt die kompletten ORFs tm1438 (amyB-Tm) und tm1439 (RTM0411), sowie Teile der ORFs tm1440 und tm1437 (Abb. 18). Da das amyB-Tm-Gen sich hier im genetischen Kontext von T. maritima befindet, wird die Expression nicht wie in pET24c::AB oder pWLQ2::AB durch einen regulierbaren $P_{\text {tac }}$ bzw. T7-Promotor beeinflußt. Um zu überprüfen, ob eine eventuelle Co-Expression von AmyB-Tm mit dem Protein Tm1439 zu einer Steigerung der Aktivität führt, wurde AmyB-Tm in E. coli JM83/pTAA31 exprimiert. Wie Abb. 19 zeigt, wird AmyB-Tm in einer in der SDS-PAGE detektierbaren Menge synthetisiert. Ob es sich bei der zweiten markierten Bande um das tm1439-Produkt handelt, ist unsicher.

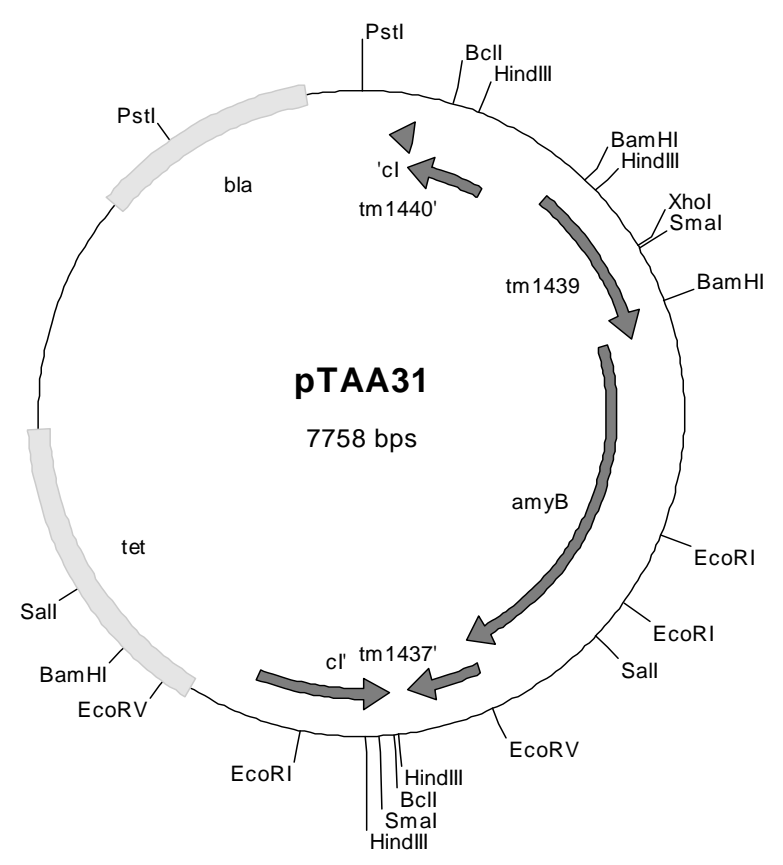

\section{Abb. 18: Vektor pTAA31}

Der hitzedenaturierte Rohextrakt von E. coli JM83/pTAA31 zeigte sowohl in der dünnschichtchromatographischen Analyse (Abb. 20) als auch im Standard DNSA-Test bei $90{ }^{\circ} \mathrm{C}$ mit löslicher Stärke als Substrat Aktivität. Da die amylolytische Aktivität des Zellextraktes aber nicht größer war, als in vergleichbaren E. coli BL21/pET24c::AB Aufarbeitungen, wurde auf eine Aufreinigung von AmyB-Tm aus E. coli JM83/pTAA31 verzichtet. 


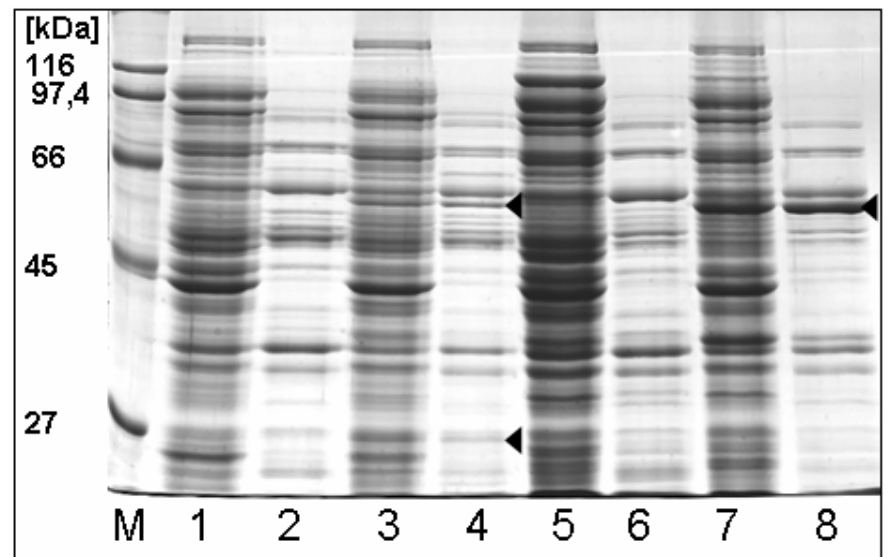

Abb. 19: SDS-PAGE-Gel der AmyB-Tm-Expression mit den Plasmiden pTAA31 und pET24c::AB. M, Molekularmassenstandard; Spur 1, E. coli JM83 Rohextrakt; Spur 2, hitzedenaturierter Rohextrakt (20 min, $75{ }^{\circ} \mathrm{C}$ ), Spur 3, E. coli JM83/pTAA31 Rohextrakt; Spur 4, hitzedenaturierter Rohextrakt (20 min, $\left.75{ }^{\circ} \mathrm{C}\right)$; Spur 5, E. coli BL21 Rohextrakt; Spur 6, hitzedenaturierter Rohextrakt (20 min, $\left.75^{\circ} \mathrm{C}\right)$; Spur 7, E. coli BL21(DE3)/pET24c::AB Rohextrakt; Spur 8, hitzdenaturierter Rohextrakt $\left(20 \mathrm{~min}, 75^{\circ} \mathrm{C}\right)$. Die Pfeile markieren die AmyB-Tm- bzw. Tm1439-Bande im hitzedenaturierten E. coli JM83/pTAA31- und E. coli BL21(DE3)/pET24c::ABRohextrakt. Die E. coli BL21 Kulturen wurden mit 0,1 mM IPTG induziert.

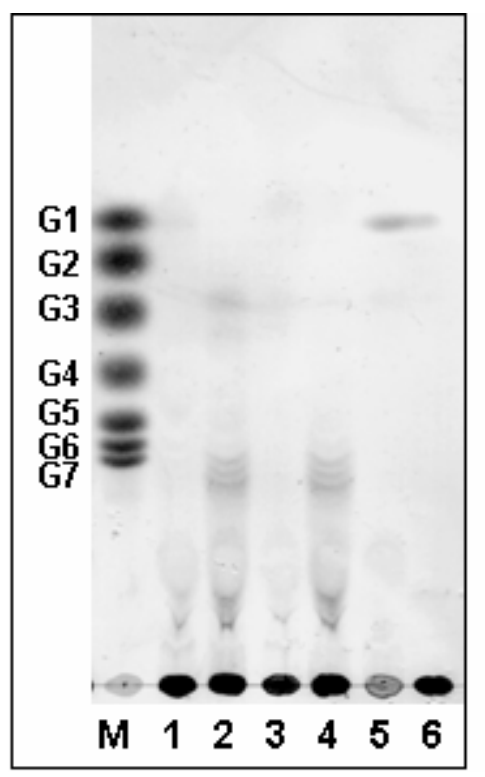

Reaktionsparameter

Ansatz:

Phosphat-Puffer (0,2 M, pH 7,0) $25 \mu \mathrm{l}$

lösl. Stärke (1 \%) $120 \mu \mathrm{l}$

Enzym

$60 \mu \mathrm{l}$

$\mathrm{H}_{2} \mathrm{O}_{\text {bidest. }} \quad 35 \mu \mathrm{l}$

Inkubation über Nacht bei $65^{\circ} \mathrm{C}$

Abb. 20: Stärkeabbau durch E. coli JM83/pTAA31 Rohextrakte. M, Maltooligosaccharidstandard; Spur 1, E. coli JM83 Rohextrakt; Spur 2, E. coli JM83/pTAA31 Rohextrakt; Spur 3, hitzedenaturierter E. coli JM83 Rohextrakt ( $\left.20 \mathrm{~min}, 75^{\circ} \mathrm{C}\right)$; Spur 4, hitzedenaturierter E. coli JM83/pTAA31 Rohextrakt (20 min, $75^{\circ} \mathrm{C}$ ); Spur 5, hitzedenaturierter E. coli JM83/pTAA31 Rohextrakt ohne Stärke; Spur 6, Stärke ohne Zellextrakt. Es wurden $9 \mu \mathrm{l}$ Probe aufgetragen. Lösungsmittel Aceton/ $\mathrm{H}_{2} \mathrm{O} /$ Laktat/Isopropanol (4:0,2:2:4). 


\subsection{Expression in Corynebacterium glutamicum}

\subsubsection{Transfer in C. glutamicum}

Um zu prüfen, ob der Wechsel des Expressionswirts einen Einfluß auf die Aktivität von AmyB-Tm hat, wurde C. glutamicum mit dem Vektor pWLQ2::AB transformiert. Zunächst wurde der restriktionsdefiziente Stamm C. glutamicum R163 mit dem Plasmid transformiert, um das Methylierungsmuster des Vektorkonstrukts dem Methylierungsmuster von $C$. glutamicum anzupassen. Der Erfolg der Transformation wurde durch PCR und Restriktionsanlyse des isolierten Plasmids kontrolliert. Die C. glutamicum R163-Klone wuchsen nur langsam und eine Expression von AmyB-Tm war nicht nachzuweisen. Daher wurde das Konstrukt aus C. glutamicum R163 isoliert und durch Elektroporation in C. glutamicum DSMZ 20300 (wt) transferiert. Wieder wurde der Erfolg der Transformation durch PCR und Restriktionsanalyse überprüft.

\subsubsection{Aufreinigung aus $C$. glutamicum}

Zur Expression von AmyB-Tm wurde eine 1,5 l Flüssigkultur 2 \%ig mit C. glutamicum (wt)/pWLQ2::AB aus einer Vorkultur angeimpft. Nach 10,5 h Wachstum wurde bei einer $\mathrm{OD}_{600}$ von 0,24 mit 0,5 mM IPTG induziert. Die Zellernte durch Zentrifugation erfolgte bei einer $\mathrm{OD}_{600}$ von 3,45 nach 26,5 h Wachstum. Das Zellpellet wurde in $30 \mathrm{ml} 20 \mathrm{mM}$ TrisPuffer (pH 8,0) aufgenommen und die Suspension nach Zugabe von $10 \mathrm{mg} / \mathrm{ml}$ Lysozym für $1 \mathrm{~h}$ bei $37{ }^{\circ} \mathrm{C}$ inkubiert, um die Zellwand der Gram-positiven Bakterien abzubauen. Die weitere Rohextraktgewinnung durch Aufschluß mit der French Pressure Cell sowie durch Hitzedenaturierung und säulenchromatographische Aufreinigung über eine Source 30Q- Säule erfolgte wie für die Aufreinigung von AmyB-Tm aus E. coli BL21 (DE3)/pET24c::AB beschrieben (s. III.2.1). Wie aus Abb. 21 ersichtlich ist, lag auch bei der Expression von AmyB-Tm in C. glutamicum ein Großteil des Proteins in unlöslicher Form im Pellet vor. Interessanterweise zeigt sich beim gereinigten AmyB-Tm-Protein eine Doppelbande in der SDS-PAGE, wie sie auch bei den Aufreinigungen aus E. coli zu beobachten war. Insgesamt konnten aus 6,35 g C. glutamicum Zellen 2,2 mg rekombinantes Enzym gewonnen werden. Die Aktivität im Standard-DNSA-Test mit löslicher Stärke (s. II.7.1) lag mit 0,2 U/mg im Bereich der Aktivität des aus E. coli aufgereinigten AmyB-Tm-Proteins. 


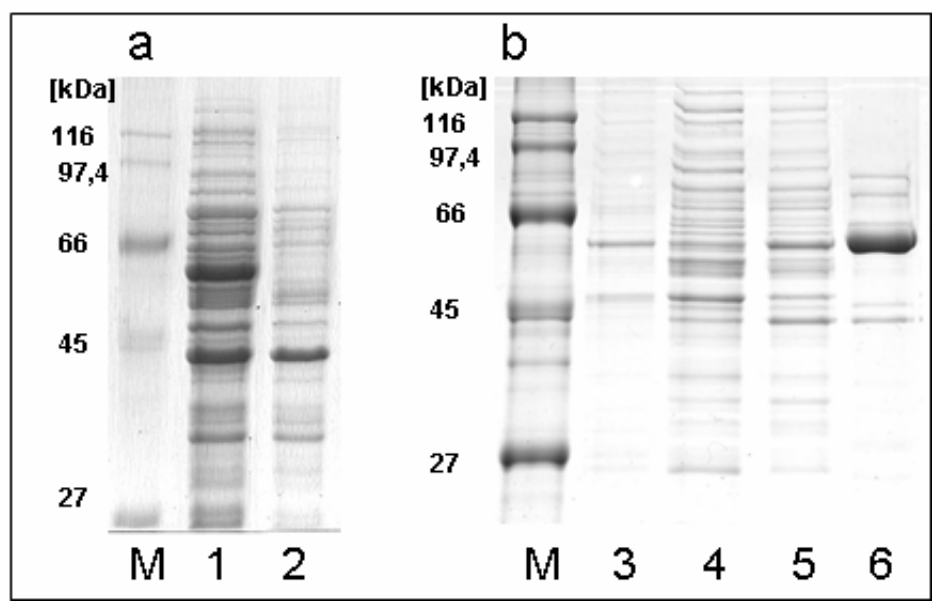

Abb. 21: Expression von AmyB-Tm in C. glutamicum a) im Vergleich zu einem Kontrollstamm und b) Bilanzierung der Aufreinigung. M, Molekularmassenstandard; Spur 1, hitzedenaturierter Rohextrakt (20 min, $75{ }^{\circ} \mathrm{C}$ ) einer C. glutamicum (wt)/pWLQ2::AB-Kultur (10 $\left.\mu \mathrm{g}\right)$; Spur 2, hitzedenaturierter Rohextrakt einer C. glutamicum (wt)/pWLQ2-Kultur (Negativkontrolle) $(10 \mu \mathrm{g})$; Spur 3, Pellet einer C. glutamicum (wt)/pWLQ2::AB Kultur; Spur 4, Rohextrakt (8 $\mu$ g); Spur 5, hitzedenaturierter Rohextrakt (5 $\mu \mathrm{g})$; Source 30Q-Fraktion (8 $\mu \mathrm{g})$.

\section{Biochemische Charakterisierung von AmyB-Tm}

\subsection{Allgemeine Untersuchungen zur enzymatischen Aktivität}

\subsubsection{Aktivität von AmyB-Tm mit pNP-Substraten}

Bei Tests mit p-Nitrophenyl(pNP)-Substraten zeigt AmyB-Tm eine niedrige Aktivität. Interessanterweise war diese im Gegensatz zu den DNSA-Tests im Phosphat-Puffer etwa dreimal höher als im Tris-Puffer. Da sich die Substrate bei längerer Erhitzung auf $90{ }^{\circ} \mathrm{C}$ als instabil erwiesen, wurde der Test über einen Zeitraum von 25 min durchgeführt. Es konnte keine klare Präferenz des Enzyms für eines der getesteten pNP-Glykoside festgestellt werden (Abb. 22). 


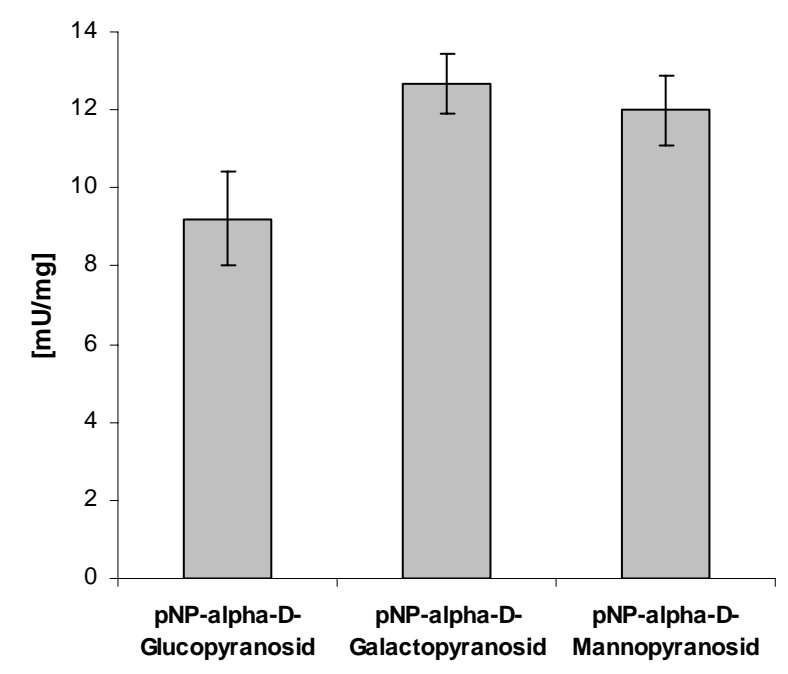

Reaktionsparameter

Ansatz:

Phosphat-Puffer (250 mM, pH 8,0) $60 \mu \mathrm{l}$

DTT (1 M)

Enzym

$5 \mu \mathrm{l}$

Nach 3 min Präinkubation bei $90^{\circ} \mathrm{C}$

0,1 M pNP-Glykosid

Inkubation 25 min bei $90{ }^{\circ} \mathrm{C}$

Abb. 22: Aktivität von AmyB-Tm mit pNP-Substraten.

\subsubsection{Enzymkinetik}

Da die Aktivität von AmyB-Tm mit den definierten pNP-Substraten nur sehr gering war, erfolgte die Ermittlung der Enzymkinetik im DNSA-Test mit löslicher Stärke als Substrat (s. II.7.1). Bei Stärke handelt es sich um ein heterogenes Polymer, bei dem sich der Polymerisierungsgrad der Moleküle, der nach Herkunft und Aufarbeitung der Stärke variiert, nur schwer abschätzen läßt. Daher beziehen sich die Substratkonzentrationsangaben nicht auf ein molares Verhältnis, sondern werden in $\mathrm{mg} / \mathrm{ml}$ angegeben. Die Hydrolyse der Stärke durch AmyB-Tm gehorcht einer Michealis-Menten Kinetik (Abb. 23). Aus der Steigung der Geraden in der doppeltreziproken Auftragung nach Lineweaver-Burk ließen sich für AmyBTm ein $K_{\mathrm{m}}$-Wert von $1,1 \mathrm{mg} / \mathrm{ml}$ und ein $V_{\max }$-Wert von 1,3 $\mathrm{U} / \mathrm{mg}$ berechnen.

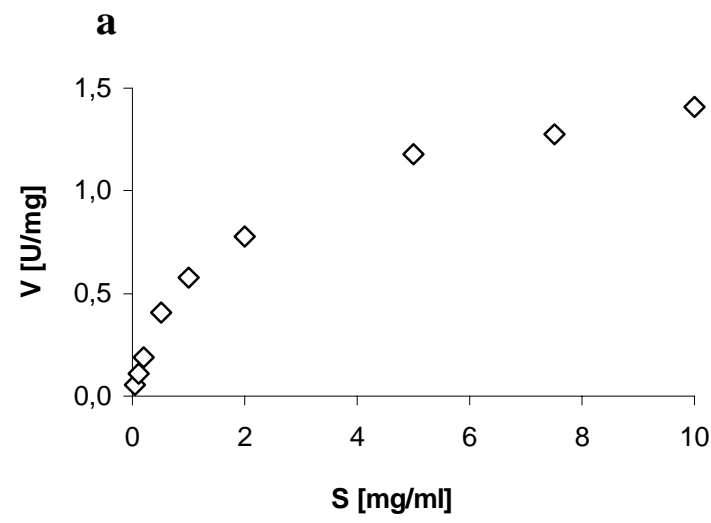

\section{b}

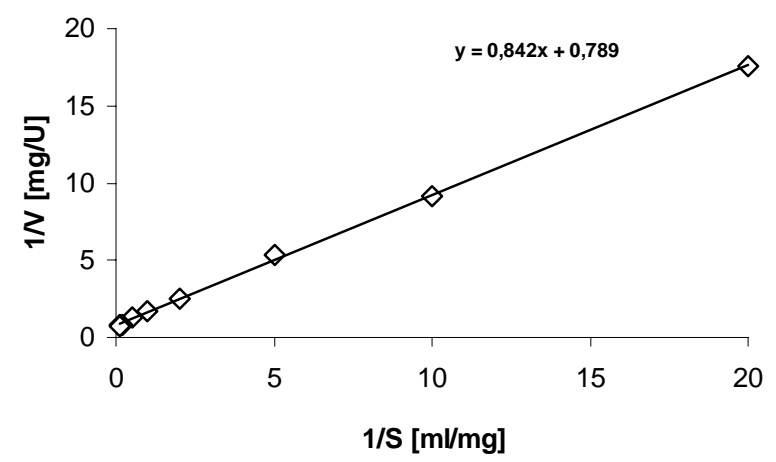

Abb. 23: Darstellung der Kinetik von AmyB-Tm nach a) Michaelis-Menten und b) LineweaverBurk. Die Ermittlung der Werte erfolgte im Standard DNSA-Ansatz mit löslicher Stärke in der Konzentration 0,05-10 mg/ml. Die Inkubationszeit betrug $30 \mathrm{~min}$, es wurden $22 \mu \mathrm{g}$ Enzym eingesetzt. 


\subsubsection{Untersuchungen zur Beteiligung von AmyB-Tm am Glykogenstoffwechsel}

Durch die cytoplasmatische Lokalisierung des Enzyms und die Aktivität mit Maltooligosacchariden und Stärke als Substraten wurde vermutet, daß AmyB-Tm am Glykogenstoffwechsel von T. maritima beteiligt ist. Das entscheidende Enzym des Glykogenabbaus ist die Glykogen-Phosphorylase, die die phosphorolytische Spaltung von Glykogen $_{\mathrm{x}} \mathrm{zu} \quad$ Glykogen $_{\mathrm{x}-1}$ und Glukose-1-Phosphat katalysiert. In dünnschichtchromatographischen Analysen konnte in Gegenwart von K-Phosphat und Pyridoxalphosphat keine Bildung von Glukose-1-Phosphat aus Maltooligosacchariden oder Stärke beobachtet werden (ohne Abbildung). Ebenso ließ sich in der Umkehrung der in vitro frei reversiblen Phosphatase-Reaktion keine gesteigerte Kettenverlängerung von Maltose oder Maltohexaose in Gegenwart von PLP und cAMP oder Glukose-1-Phosphat beobachten (ohne Abbildung). AmyB-Tm zeigte vielmehr in allen Ansätzen mit Maltohexaose als Substrat TransferaseAktivität (Abb. 24). Um zu überprüfen, ob AmyB-Tm eventuell als Glykogensynthase am Glykogenstoffwechsel beteiligt ist, wurde getestet, ob UDP-Glukose und ADP-Glukose, die bei der Reaktion von Glykogen ${ }_{\mathrm{x}} \mathrm{zu}_{\text {Glykogen }}$ Gl+ $_{\mathrm{x}}$ als Glykosyl-Donor wirken, von AmyB-Tm bei der Kettenverlängerung von Maltooligosacchariden als Substrat dienen können. In der dünnschichtchromatographischen Analyse konnte jedoch im Phosphat-Puffer weder eine Spaltung der aktivierten Zucker noch eine Kettenverlängerung von Maltopentaose festgestellt werden (ohne Abbildung).

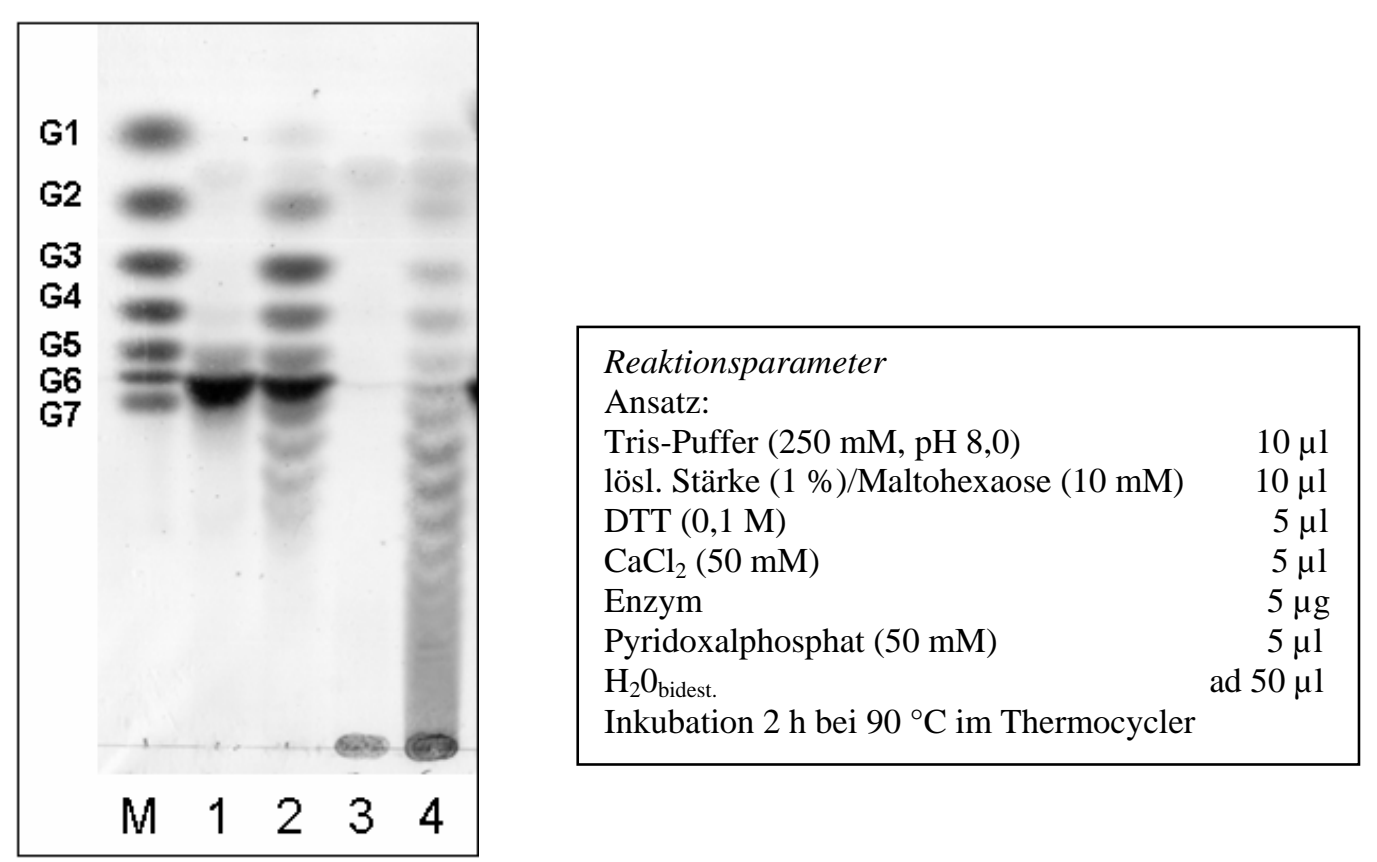

Abb. 24: Transferase-Aktivität mit Maltohexaose und Abbau von Stärke. M, Maltooligosaccharidstandard; Spur 1 und 2, Maltohexaose -/+ AmyB-Tm; Spur 3 und 4, Stärke -/+ AmyB-Tm. Es wurden $9 \mu$ l Probe auf die DC aufgetragen. Laufmittel 1-Propanol/Ethylacatat/ $\mathrm{H}_{2} \mathrm{O}$ (6:1:3). 


\subsubsection{Hemmung durch Acarbose}

Acarbose dient bei der Kristallisation vieler amylolytischer Enzyme als Substratanalogon. Das Pseudotetrasaccharid bindet im aktiven Zentrum, wird dort i. d. R. aber nicht abgebaut. Durch die Lokalisation in der Struktur können so Hinweise auf die Substratbindung im aktiven Zentrum gewonnen werden. In der dünnschichtchromatographischen Analyse konnte kein Abbau von Acarbose durch AmyB-Tm festgestellt werden. Im DNSA-Test (s. II.7.1) zeigte sich bei Anwesenheit von Acarbose eine deutliche Hemmung des Abbaus von löslicher Stärke durch das Enzym (Abb. 25). Die Inhibitorkonstante $K_{i}$ für Acarbose liegt bei geschätzten $2 \mu \mathrm{M}$. Acarbose scheint somit auch für die Co-Kristallisation mit AmyB-Tm als Substratanalogon geeignet zu sein.
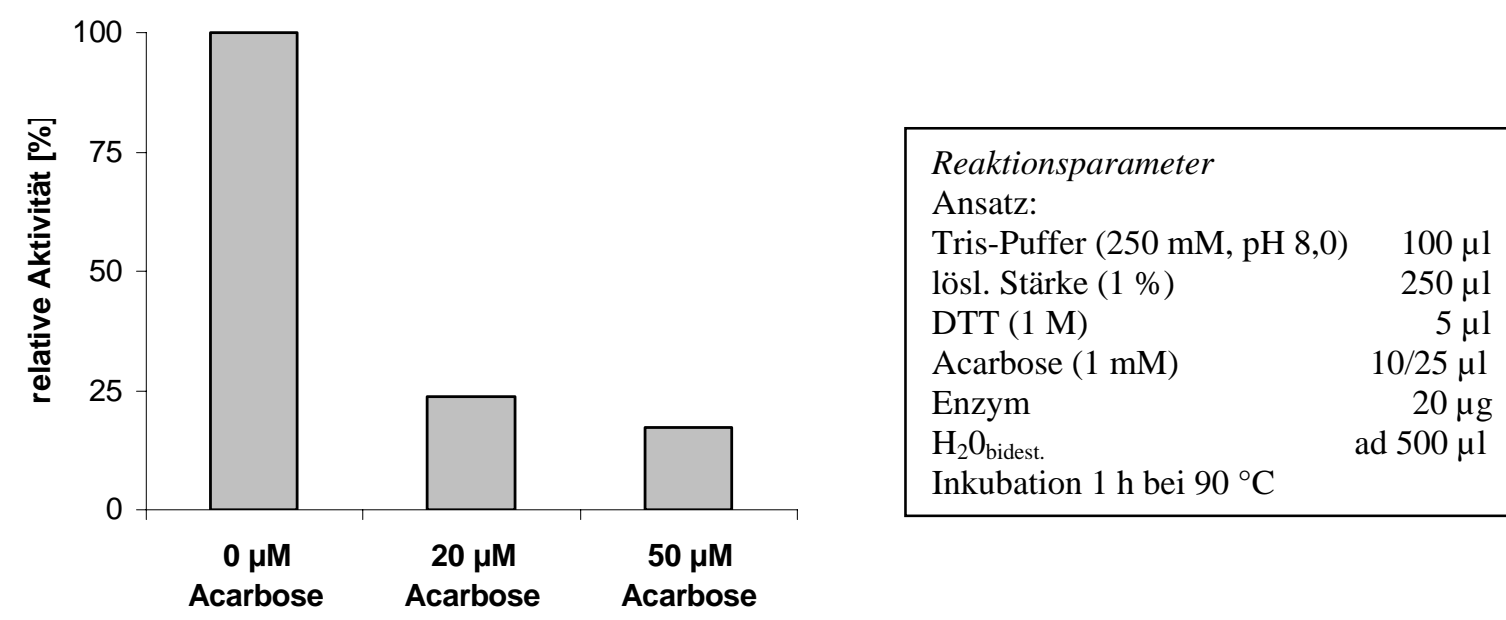

Abb. 25: Hemmung von AmyB-Tm durch Acarbose. Dargestellt sind die relativen Aktivitäten, bezogen auf den Meßwert ohne Zusatz von Acarbose. Alle Messungen wurden als Mehrfachbestimmunngen durchgeführt.

\subsection{Einfluß von reduzierenden Agenzien}

Wie bereits von Fütterer (2001) festgestellt wurde, steigert DTT die Aktivität von AmyB-Tm. Um im DNSA-Test (s. II.7.1) zu prüfen, ob die Aktivität spezifisch durch DTT oder auch durch andere reduzierende Agenzien positiv beeinflußt wird, wurden L-Cystein, DTT, und $\beta$ Mercaptoethanol in variierender Konzentration zu den Reaktionsansätzen hinzugegeben. Alle drei Reduktionsmittel bewirkten eine erhebliche Steigerung der Aktivität, was darauf schließen läßt, daß die Aktivität von AmyB-Tm allgemein vom Redoxzustand des Reaktionsansatzes abhängt (Abb. 26). Die höchste Aktivitätssteigerung auf über 300 \% war bei der Zugabe von 10 mM DTT zu beobachten. Während superoptimale Konzentrationen 
von DTT und $\beta$-Mercaptoethanol die Enzymaktivität nicht inhibierten, konnte für L-Cystein in geringen Konzentrationen eine Aktivitätssteigerung, bei Konzentrationen über $20 \mathrm{mM}$ jedoch eine Hemmung der Aktivität beobachtet werden.

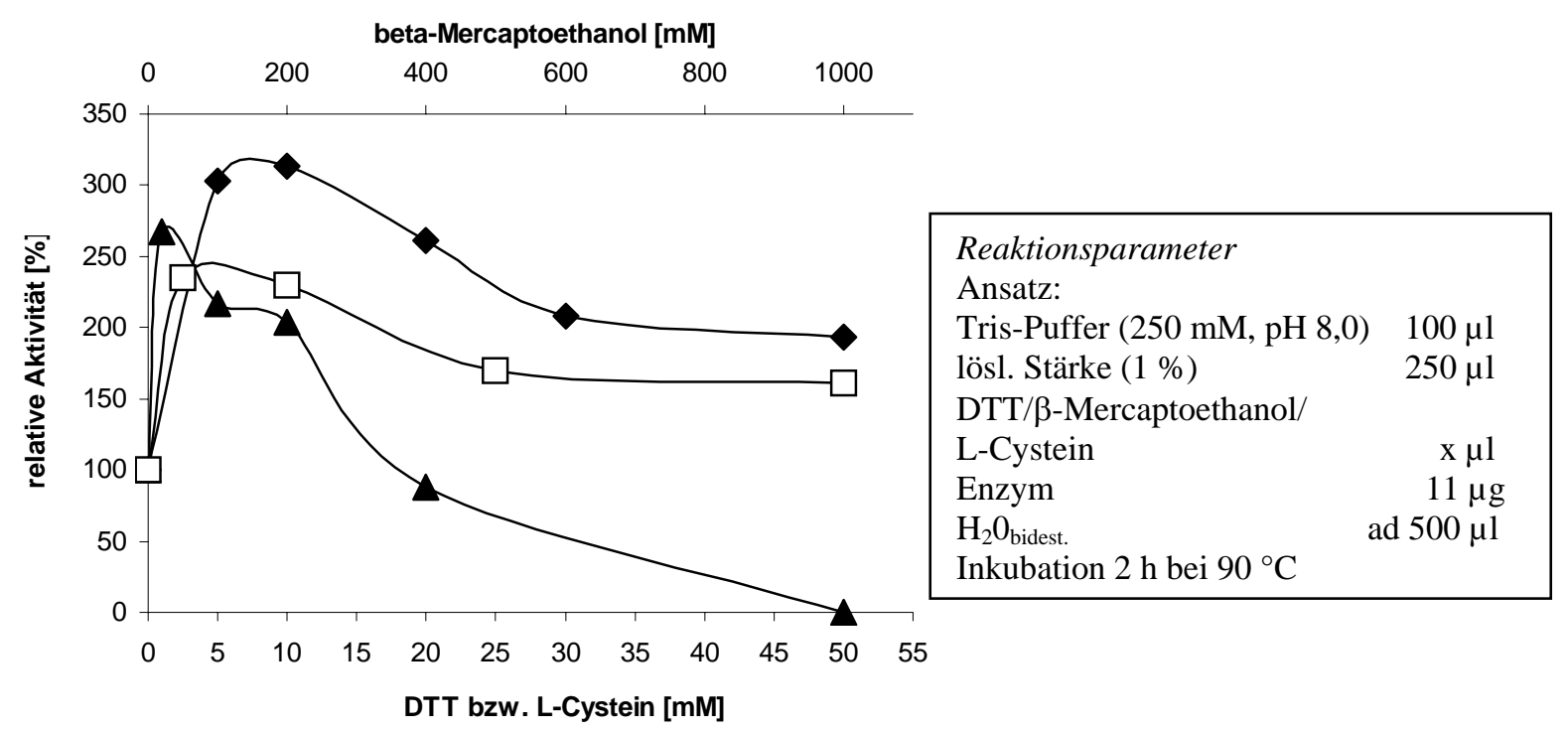

Abb. 26: Einfluß von Reduktionsmitteln auf die Aktivität von AmyB-Tm. Zum Reaktionsansatz wurden 0-50 mM DTT (schwarze Rauten), 0-1000 mM $\beta$-Mercaptoethanol (weiße Quadrate) und 0-50 $\mathrm{mM}$ L-Cystein (schwarze Dreiecke) hinzugegeben. Dargestellt sind die relativen Aktivitäten, jeweils bezogen auf den Meßwert ohne Zusatz von Reduktionsmittel. Alle Messungen wurden als Mehrfachbestimmungen durchgeführt.

Bei längerer Inkubation des Enzyms mit DTT bildete sich ein grün-schwarzer Niederschlag. Bei diesem handelte es sich jedoch nicht um denaturiertes Protein. AmyB-Tm wurde bei 90 ${ }^{\circ} \mathrm{C}$ über 4 h mit 50 mM DTT (kein Substrat, 50 mM Tris-Puffer, pH 8,0) inkubiert, ohne daß sich eine Abnahme der Proteinkonzentration mit dem Bradfordtest (s. II.5.1.1) nachweisen ließ (ohne Abbildung).

Bei der Inkubation von AmyB-Tm in 50 mM Phosphat-Puffer (pH 8,0) mit 20 mM DTT bei $90{ }^{\circ} \mathrm{C}$ entwickelte sich eine Gelbfärbung des Ansatzes, die beinahe exponentiell anstieg. Kontrollen ohne DTT sowie ohne Enzym zeigten keine Verfärbung (Abb. 27). Der gelbe Farbstoff blieb bei einer dünnschichtchromatographischen Analyse nicht an der Auftragslinie liegen, sondern wanderte mit dem Laufmittel 1-Propanol/Ethylacatat/ $\mathrm{H}_{2} \mathrm{O}$ (6:1:3) durch das Kieselgel. Dies deutet darauf hin, daß die farbige Substanz nicht fest mit dem Protein verbunden ist, welches in der Dünnschichtchromatographie nicht wandert. 


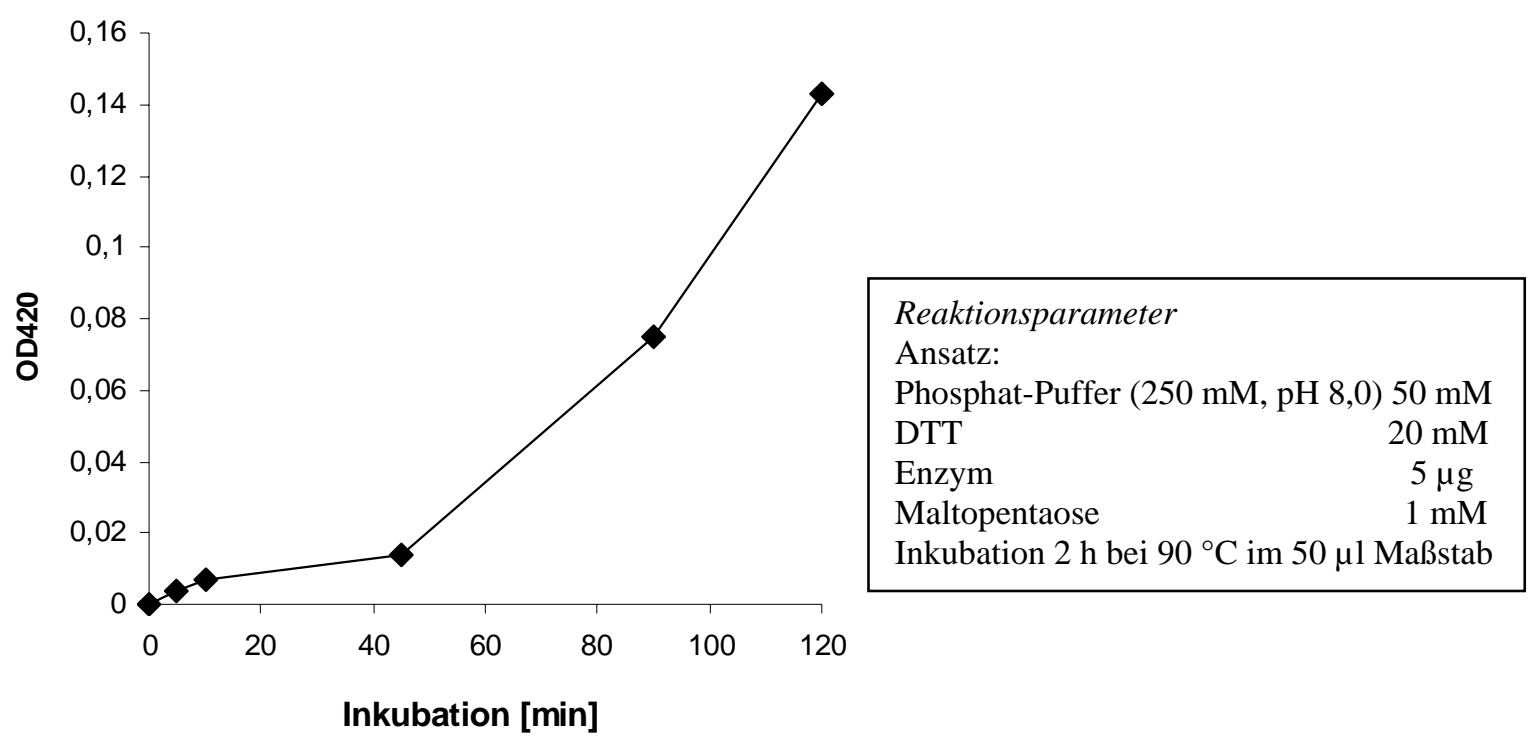

Abb. 27: Zunahme der Absorption bei 420 nm bei Inkubation von AmyB-Tm mit DTT.

Eine Verfärbung konnte auch bei der Inkubation der AmyBCys186-Mutante (s. III.8) mit DTT beobachtet werden. Beim AmyB-Tm-ähnlichen Protein aus T. thermophilus (AmyB-Tt) trat sie dagegen nicht auf (s. III.9). Abb. 28 zeigt Wellenlängenspektra der Proteine AmyBTm, AmyBCys186 und AmyB-Tt sowie BSA als Kontrolle nach Inkubation mit und ohne 20 mM DTT. Die Proteine wurden zunächst im $50 \mu \mathrm{l}$ Maßstab in einem PCR-Gerät mit $20 \mathrm{mM}$ DTT in $50 \mathrm{mM}$ Phosphat-Puffer (pH 8,0) inkubiert. Nach 2 h wurde der Ansatz mit Phosphat-Puffer, der 20 mM DTT enthielt, auf ein Volumen von $200 \mu$ gebracht und im Zweistrahlphotometer (CARY 100 conc, Varian) die Absorption der Proben im Bereich 250$600 \mathrm{~nm}$ gemessen. 


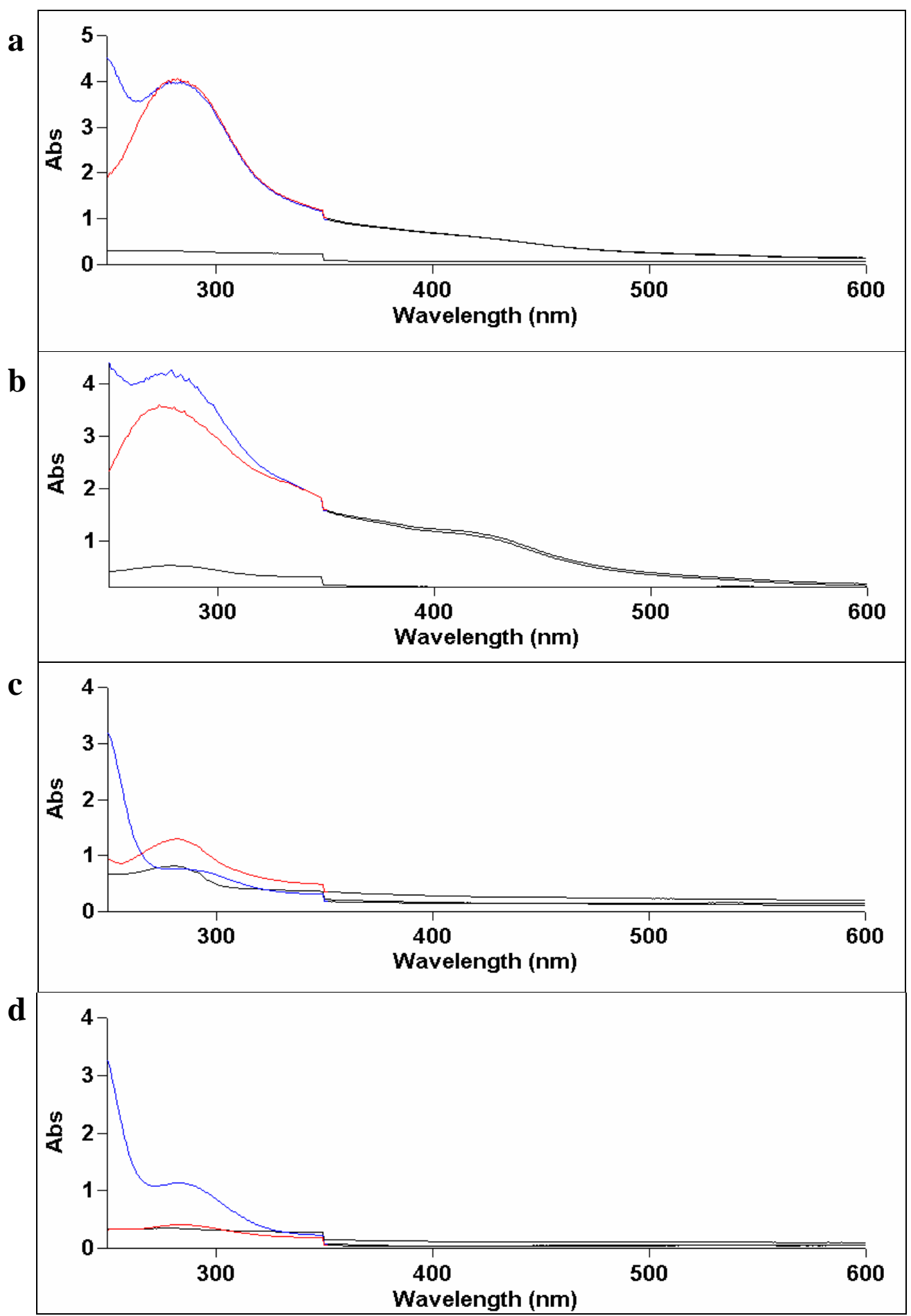

Abb. 28: Wellenlängenscans von a) AmyB-Tm (Endkonzentration $25 \mu g / m l)$, b) AmyBCys186 $(25 \mu \mathrm{g} / \mathrm{ml})$, c) AmyB-Tt $(250 \mu \mathrm{g} / \mathrm{ml})$ und d) BSA (50 $\mu \mathrm{g} / \mathrm{ml})$ nach Inkubation mit und ohne 20 mM DTT. Blaue Linie, Puffer + Enzym + DTT gemessen gegen Puffer - Enzym + DTT; rote Linie, Puffer + Enzym + DTT gemessen gegen Puffer - Enzym - DTT; schwarze Linie, Puffer + Enzym - DTT gemessen gegen Puffer - Enzym - DTT. 


\subsection{Einfluß komplexierender Agenzien und Metallionen}

Die Aktivität von AmyB-Tm mit löslicher Stärke als Substrat wird durch ATP in physiologischen Konzentrationen signifikant herabgesetzt (Fütterer, 2001). Die gleiche inhibitorische Wirkung wurde auch für GTP beobachtet (Abb. 29). Die Hemmung von AmyB-Tm durch ATP ist also nicht spezifisch, sondern ein Effekt des Zusatzes von Nukleotidtriphosphaten im Allgemeinen.

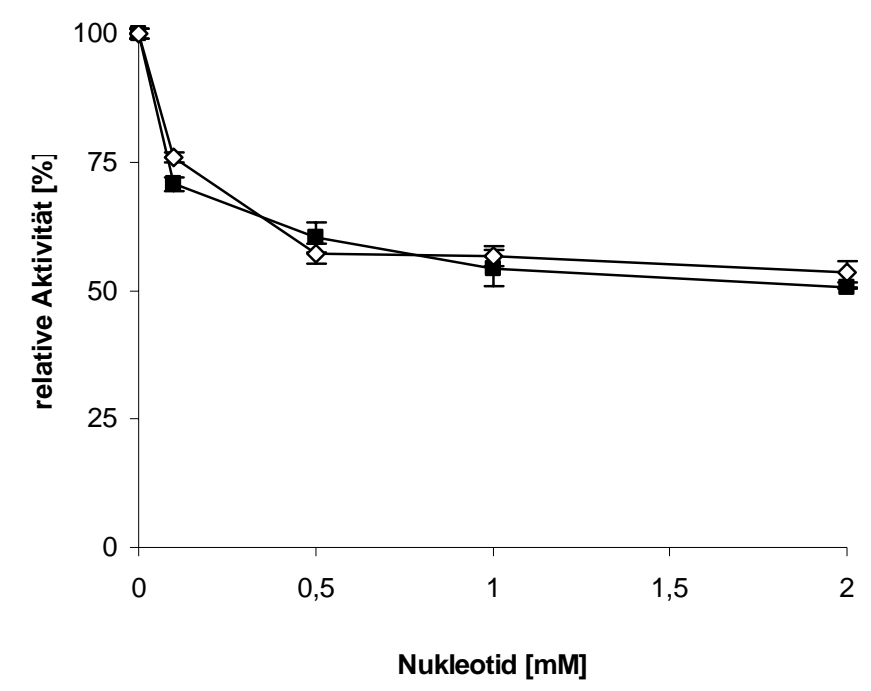

Reaktionsparameter

Ansatz:

Tris-Puffer (250 mM, pH 8,0) $100 \mu \mathrm{l}$ lösl. Stärke (1\%) $250 \mu \mathrm{l}$

$\operatorname{DTT}(1 \mathrm{M})$

ATP/GTP (50 mM)

Enzym

$\mathrm{H}_{2} \mathrm{O}_{\text {bidest. }}$

5 min Präinkubation bei $90^{\circ} \mathrm{C}$ ohne

Stärke, nach Substratzugabe Inkubation

$1 \mathrm{~h}$ bei $90^{\circ} \mathrm{C}$

Abb. 29: Einfluß von ATP (schwarze Quadrate) und GTP (weiße Rauten) auf die Aktivität von AmyB-Tm. Dargestellt ist die relative Aktivität, bezogen auf den höchsten Meßwert der Versuchsreihe. Alle Messungen wurden als Mehrfachbestimmungen durchgeführt.

Neben ATP konnte auch für ADP und AMP eine hemmende Wirkung festgestellt werden.

Diese Nukleotide haben eine schwache komplexierende Wirkung auf zweiwertige Metallionen, die abhängig ist von der Zahl ihrer Phosphatreste. Die Stärke der Aktivitätssenkung durch die Nukleotide wurde ins Verhältnis gesetzt zu ihrer Komplexierungskraft, ausgedrückt durch die Dissoziationskonstante $\mathrm{pK}_{\mathrm{d}}$ (Tab. 10). Die Abhängigkeit der Hemmung der Enzymaktivität von der Komplexierungswirkung der getesteten Substanzen deutet darauf hin, daß die beobachtete Hemmung von AmyB-Tm durch ATP, ADP und AMP auf deren komplexierender Wirkung und nicht auf einer spezifischen allosterischen Regulation beruht. Als biochemischer Nachweis des Komplexierungseffekts der Nukleotide wurde versucht, die herabgesetzte Aktivität durch Zugabe von Metall-Ionen zu rekonstituieren (Abb. 30). 
Tab. 10: Korrelation von Aktivitätshemmung und Dissoziationskonstante einiger auf AmyB-Tm hemmend wirkender Substanzen. Die $\mathrm{pK}_{\mathrm{d}}$-Werte, die sich auf die Komplexierung von $\mathrm{Ca}^{2+}$ beziehen, wurden der MaxChelator Webseite entnommen (Patton et al., 2004). (http://www.stanford.edu/ cpatton/maxc.html)

\begin{tabular}{lll}
\hline Substanz & Restaktivität von AmyB-Tm [\%] & $\mathbf{p K}_{\mathbf{d}}$ \\
\hline ATP 1 mM & 37 & 3,8 \\
ADP 1 mM & 42 & 2,9 \\
AMP 5 mM (Fütterer, 2001) & 82 & 1,8 \\
EDTA 1 mM & nicht detektierbar & 10,7 \\
EGTA 1 mM & nicht detektierbar & 11,0 \\
\hline
\end{tabular}
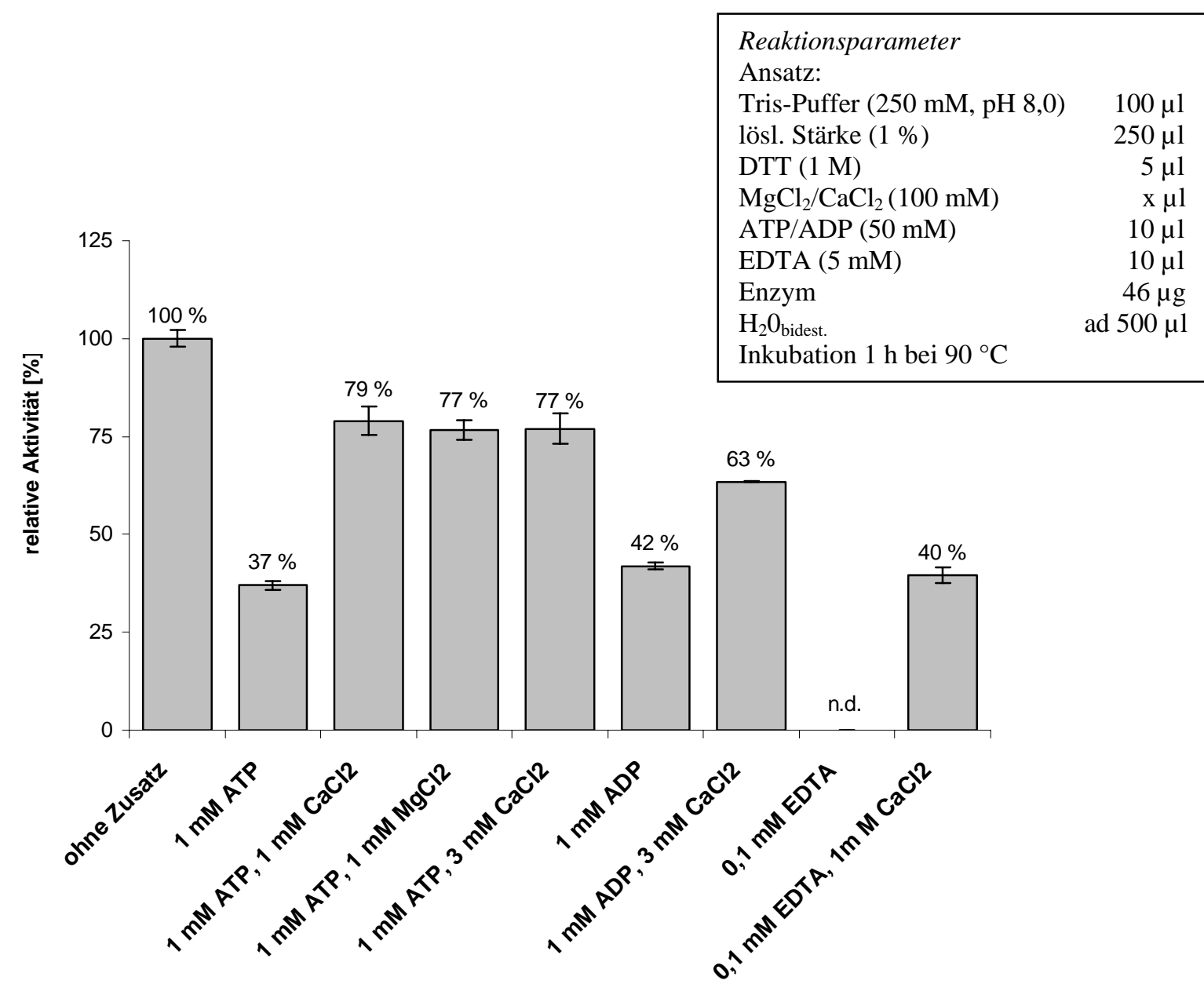

Abb. 30: Rekonstitution der Aktivität durch $\mathrm{Ca}^{2+}$ und $\mathrm{Mg}^{2+}$. Den Proben ohne Substrat wurde zunächst nur der Chelator (ATP bzw. ADP bzw. EDTA) zugesetzt. Nach einer Präinkubation von 5 min bei $90{ }^{\circ} \mathrm{C}$ erfolgte die Zugabe des Additivs $\left(\mathrm{CaCl}_{2}\right.$ oder $\left.\mathrm{MgCl}_{2}\right)$. Erst nach einer weiteren Präinkubation von 5 min bei $90{ }^{\circ} \mathrm{C}$ wurde die Reaktion durch Zugabe des vorgewärmten Substrats gestartet. Die Aktivität in Anwesenheit von 0,1 mM EDTA lag unter der Nachweisegrenze des DNSATests. Dargestellt ist die relative Aktivität, bezogen auf den höchsten Meßwert der Versuchsreihe. Alle Messungen wurden als Mehrfachbestimmungen durchgeführt. 
Die Aktivität von AmyB-Tm wurde durch ATP und ADP auf etwa $40 \%$ herabgesetzt. Bereits durch die vergleichsweise geringe Konzentration von 0,1 mM EDTA im Ansatz wurde die Aktivität vollständig inhibiert. Sowohl $\mathrm{Ca}^{2+}$ als auch $\mathrm{Mg}^{2+}$ konnten das Enzym reaktivieren. Dies deutet auf eine Abhängigkeit des Enzyms von zweiwertigen Metallionen hin. Eine vollständige Reaktivierung konnte nicht erreicht werden. Der Versuch einer Rekonstitution der Aktivität mit $\mathrm{Fe}^{2+}$-Ionen war nicht durchführbar, da diese im Reaktionsansatz ausfielen. Die Ursache für die unvollständige Wiederherstellung der Aktivität lag möglicherweise in der hemmenden Wirkung, die $\mathrm{Ca}^{2+}$ und $\mathrm{Mg}^{2+}$ auf AmyB-Tm haben. Die Halbierung der Reaktionsstärke von AmyB-Tm wurde durch eine Konzentration von $15 \mathrm{mM} \mathrm{CaCl}_{2}$ sowie von $2 \mathrm{mM} \mathrm{MgCl}_{2}$ erreicht (Abb. 31). Vermutlich beruht die rekonstitutierende Wirkung von $\mathrm{Ca}^{2+}$ und $\mathrm{Mg}^{2+}$ nicht auf einer Abhängigkeit des AmyB-Tm-Proteins von diesen Ionen. Die teilweise Rekonstitution der Aktivität ist möglicherweise ein indirekter Effekt, da der Zusatz von $\mathrm{Ca}^{2+}$ und $\mathrm{Mg}^{2+}$ das Gleichgewicht von Chelator und Metallionen im Reaktionsansatz beeinflußt. In Konzentrationen von mehr als $1 \mathrm{mM}$ verdrängen $\mathrm{Ca}^{2+}$ und $\mathrm{Mg}^{2+}$ unter Umständen ein locker im Enzym gebundenes Metallion und verursachen so die Hemmung der Aktivität von AmyB-Tm.

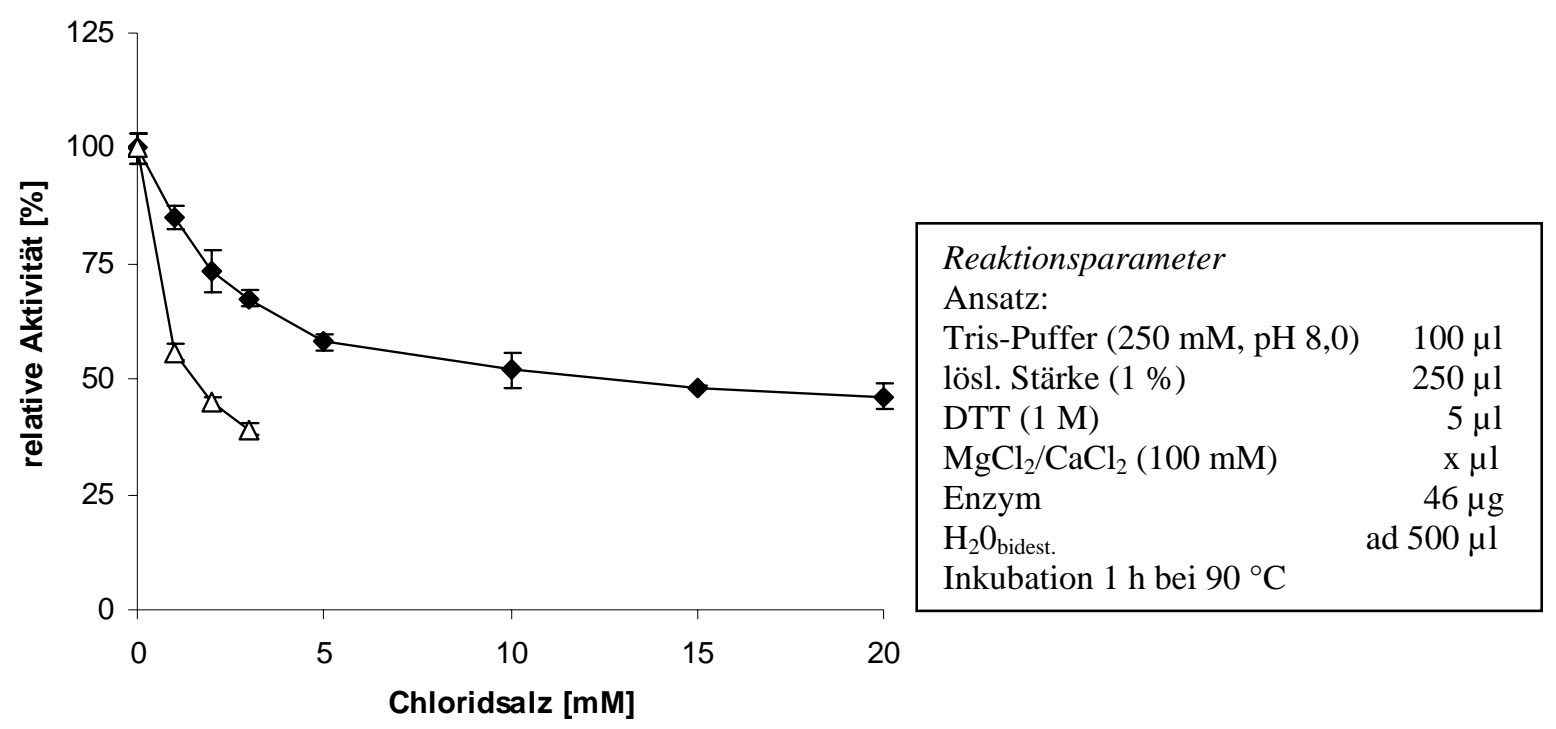

Abb. 31: Einfluß von $\mathrm{MgCl}_{2}$ (weiße Dreiecke) und $\mathrm{CaCl}_{2}$ (schwarze Rauten) auf die Aktivität von AmyB-Tm. Die Bestimmung des Einflusses von $\mathrm{MgCl}_{2}$ wurde nicht weiter fortgeführt, da die AmyB-Tm-Aktivität unter der Nachweisgrenze des DNSA-Tests fiel. Dargestellt ist die relative Aktivität, bezogen auf den höchsten Meßwert der Versuchsreihe. Alle Messungen wurden als Mehrfachbestimmungen durchgeführt. 


\subsection{Bestimmung von Nicht-Häm-Eisen}

Die Protein-Kristalle von AmyB-Tm wiesen eine rote Farbe auf (s. III.6.3, Abb. 43), was auf das Vorhandensein von Eisen im Enzym hindeutete. Dieses wurde biochemisch nachgewiesen und quantifiziert. Mit Protein aus diversen Aufreinigungen wurde eine quantitative Bestimmung von Nicht-Häm-Eisen durch einen colorimetrischen Test durchgeführt (s. II.7.4). Dabei wurden Eisenmengen von 0,4 - 1,7 mol Eisen pro mol Enzym gemessen. Eine direkte Korrelation zwischen der Enzymaktivität und der Eisenmenge konnte jedoch nicht festgestellt werden (Abb. 32). Da mit dieser Bestimmung lediglich die Menge an Eisenionen, unabhängig von deren Redoxzustand, erfaßt wurde, ist es nicht möglich eine Aussage darüber zu treffen, inwieweit ein Zusammenhang zwischen Enzymaktivität und Fe-Ionen einer bestimmten Oxidationsstufe besteht. Die Anwesenheit von Eisenionen im AmyB-Tm-Kristall konnte durch ein Fluoreszenzemissionsspektrum des Enzyms bestätigt werden (s. III.6.3). Die Aktivität des Enzyms konnte weder durch den Zusatz von $\mathrm{FeCl}_{3}$ noch $\mathrm{FeCl}_{2}$ gesteigert werden.

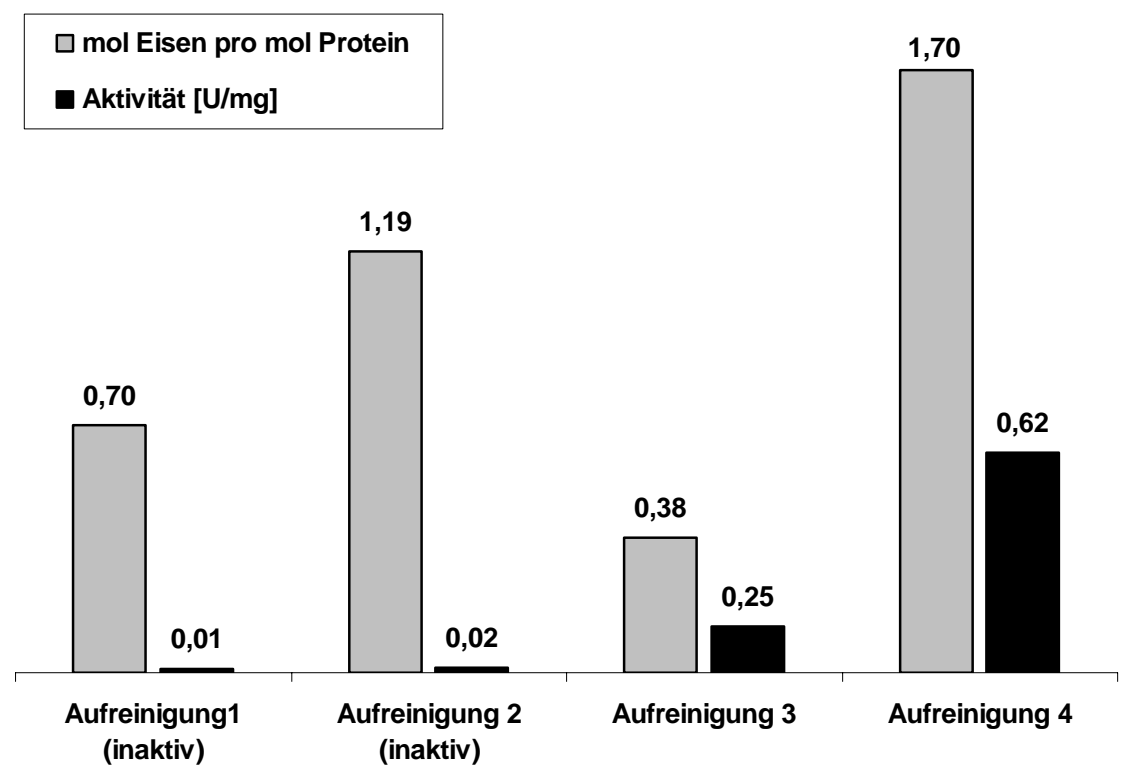

Abb. 32: Eisengehalt von aus unterschiedlichen Proteinaufreinigungen gewonnenem AmyB-TmProtein. Alle Messungen wurden als Mehrfachbestimmungen durchgeführt.

\subsection{Bestimmung des Oligomerisierungsgrades von AmyB-Tm}

\subsubsection{Analytische Gelfiltration}

Zur Aufklärung des Oligomersierungsgrades von AmyB-Tm wurden eine Gelfiltrationsstudie und Untersuchungen des Laufverhaltens des Enzyms in der Nativ-PAGE durchgeführt. Für die Gelfiltration wurde eine Superdex 200-Säule verwendet, die mit fünf Eichproteinen 
kalibiriert wurde. Alle Kalibrierungsläufe und die analytische Gelfiltration von AmyB-Tm fanden unter identischen Bedingungen statt. Das in $20 \mathrm{mM}$ Tris gelagerte Protein wurde dafür in $50 \mathrm{mM}$ Phosphatpuffer (pH 8,0) mit $300 \mathrm{mM} \mathrm{NaCl} \mathrm{umgepuffert.} \mathrm{Die} \mathrm{Parameter} \mathrm{des}$ Säulenlaufs sind in Tab. 11 aufgeführt, Abb. 33 zeigt die mit den Kalibrierungsproteinen erstellte Eichgerade.

Tab. 11: Parameter des Säulenlaufs der Gelfitration.

\begin{tabular}{ll}
\hline Parameter & \\
\hline Medium: & Superdex 200 prep grade \\
Säule: & HiLoad 16/60 \\
Säulenvolumen $\left(\mathrm{V}_{\mathrm{t}}\right):$ & $115 \mathrm{ml}$ \\
Ausschlußvolumen $\left(\mathrm{V}_{0}\right):$ & $40 \mathrm{ml}$ \\
Probe: & $0,35 \mathrm{mg}$ \\
Laufpuffer: & $50 \mathrm{mM}$ Phosphat-Puffer $(\mathrm{pH} \mathrm{8,0)}+300 \mathrm{mM} \mathrm{NaCl}$ \\
Flußrate: & $1 \mathrm{ml} / \mathrm{min}$ \\
Fraktionsgröße: & $1,5 \mathrm{ml}$ \\
Kalibrierung: & $3 \mathrm{SV}$ Laufpuffer \\
\hline
\end{tabular}

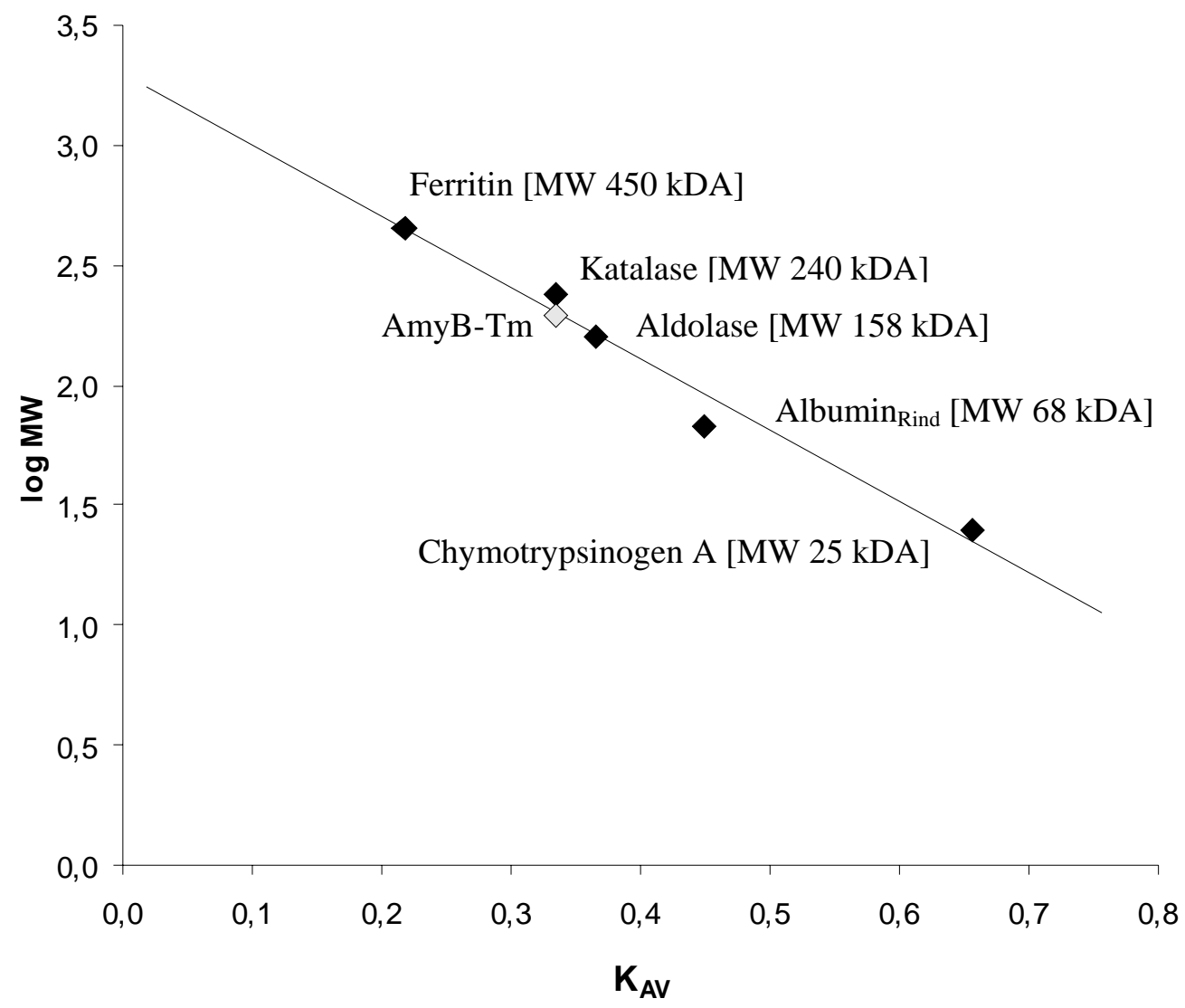

Abb. 33: Eichgerade für die analytische Gelfiltration. 
Der Verteilungskoeffizient $\left(\mathrm{K}_{\mathrm{AV}}\right)$ wurde mit folgender Formel ermittelt.

$$
K_{A V}=\frac{V_{e}-V_{0}}{V_{t}-V_{0}}
$$

Für AmyB-Tm wurde ein Elutionsvolumen $V_{\mathrm{e}}$ von 62,9 ml ermittelt. Mit der aus der Regressionsgeraden abgeleiteten Formel

$$
\log \mathrm{MW}[\mathrm{kDa}]=3,281-2,954 \mathrm{x}
$$

ergab sich für das Enzym eine Molekularmasse von 241 kDa (Abb. 33). Die für AmyB-Tm aus der Aminosäuresequenz errechnete Molekularmasse betrug 62,9 kDa. Daraus konnte geschlossen werden, daß das rekombinante AmyB-Tm-Protein im nativen Zustand als Tetramer vorliegt.

\subsubsection{Laufverhalten in der Nativ-PAGE}

Zur weitern Untersuchung der Quartärstruktur von AmyB-Tm wurde das Laufverhalten des Proteins in einer Nativ-PAGE analysiert. Zusätzlich zu dem in Nativ-Laufpuffer aufgenommenen AmyB-Tm-Protein, das aus unterschiedlichen Aufreinigungen stammte, wurde AmyB-Tm auch Nativpuffer mit 0,1 mM EDTA und in SDS-haltigem Puffer aufgenommen und aufgekocht. Das EDTA und SDS sollten die Oligomerisierung des Proteins aufheben (Abb. 34). Die Hauptbande der mit SDS-Puffer aufgekochten Proben lief deutlich unter der in Nativ-Puffer aufgenommenen. Dies deutet darauf hin, daß AmyB-Tm im nativen Zustand einen höheren Oligomerisierungsgrad hat, d.h. mindestens als Dimer vorliegt.

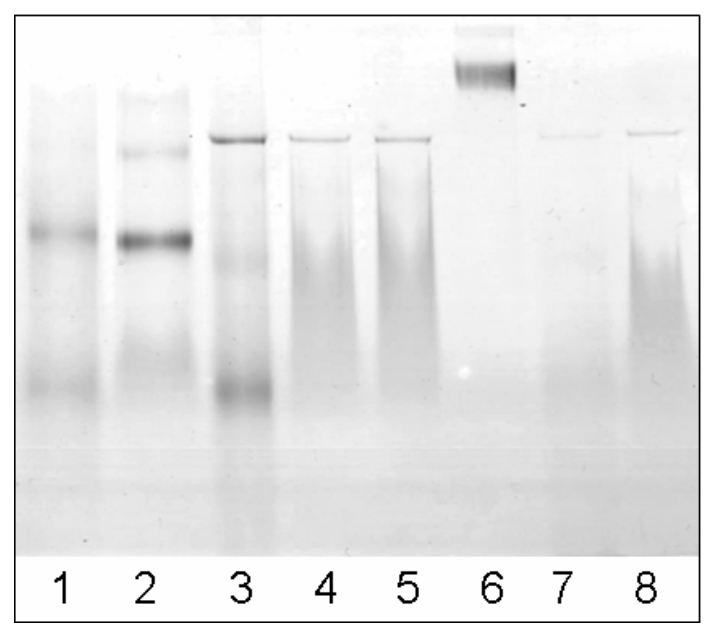

Abb. 34: Laufverhalten von AmyB-Tm in der Nativ-PAGE. Spur 1, AmyB-Tm aus Aufreinigung 1 in SDS-Auftragspuffer aufgekocht $(4 \mu \mathrm{g})$; Spur 2, AmyB-Tm aus Aufreinigung 2 in SDSAuftragspuffer aufgekocht (2,5 $\mu \mathrm{g})$; Spur 3, AmyB-Tm aus Aufreinigung 1 in Nativpuffer (4 $\mu \mathrm{g})$; Spur 4, AmyB-Tm aus Aufreinigung 2 in Nativpuffer (2,5 $\mu \mathrm{g})$; Spur 5, AmyB-Tm nach Gelfiltration in Nativpuffer (2,5 $\mu \mathrm{g})$; Spur 6, Katalase in Nativpuffer (2,4 $\mu \mathrm{g})$; Spur 7, AmyB-Tm aus Aufreinigung 1 in Nativpuffer mit 0,1 mM EDTA (4 $\mu \mathrm{g}$ ); Spur 8, AmyB-Tm aus Aufreinigung 2 in Nativpuffer mit $0,1 \mathrm{mM}$ EDTA $(2,5 \mu \mathrm{g})$. 
Die Hauptbande der in Nativpuffer aufgenommenen Proben lief wiederum unterhalb der Katalase-Bande. Die Molekularmasse der Katalase [240 kDa] ähnelt der für natives AmyBTm in der Gelfiltrationsstudie errechneten Masse, was einem AmyB-Tm-Tetramer entsprechen würde. Das Laufverhalten von AmyB-Tm in der Nativ-PAGE deutet also im Gegensatz zur Gelfiltration auf ein Dimer als Quartärstruktur hin. Im Proteinkristall liegt AmyB-Tm als Monomer vor (A. Dickmanns, persönl. Mitteilung). Die unterschiedlichen Ergebnisse der Bestimmung des Oligomerisierungsgrades hängen möglicherweise von der Reinheit der verwendeten Probe und dem Salzgehalt des Puffersystems ab. Bei der NativPage beeinflußt zusätzlich zur Proteingröße auch die Oberflächenladung das Laufverhalten der Proteine.

\subsection{Laufverhalten im SDS-PAGE-Gel}

Im SDS-PAGE-Gel erschien die Bande von AmyB-Tm als Doppelbande, wobei eine schwächere Bande oberhalb der Hauptbande lief. Eine derartige Doppelbande trat bei rekombinantem Protein aus allen Aufreinigungen, unabhängig vom Expressionssystem und vom Wirtsorganismus, auf (vergl. III.2.). Auch Protein, das eine Gelfiltration durchlaufen hatte und dort als Einzelpeak aufgetreten war, erschien in der SDS-PAGE als Doppelbande. Protein, das durch Auflösung von AmyB-Tm-Kristallen in $\mathrm{H}_{2} \mathrm{O}_{\text {bidest }}$. gewonnen wurde, erschien im SDS-PAGE-Gel ebenfalls als Doppelbande. Interessanterweise hatte sich hier das Verhältnis von Haupt- zu Nebenbande gegenüber dem zur Kristallisation eingesetzten Protein verändert. Die beiden Banden waren gleich stark (Abb. 35). Da die schwächere Bande oberhalb der Hauptbande lief, kann es sich hierbei nicht um ein Abbauprodukt von AmyB-Tm handeln. Möglicherweise liegt ein Teil des rekombinanten Proteins modifiziert vor.

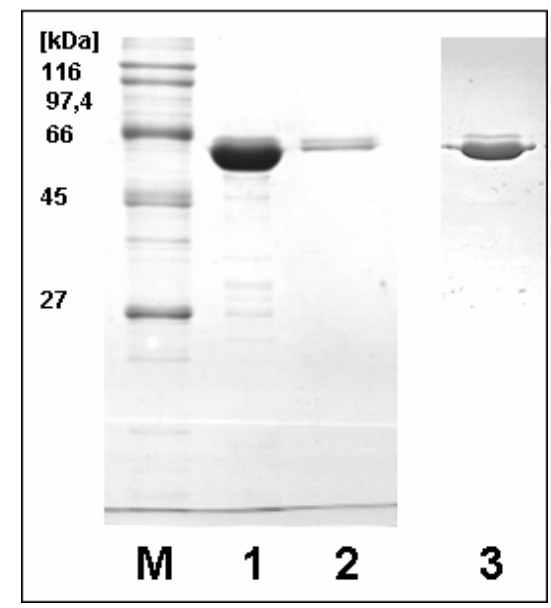

Abb. 35: Laufverhalten von AmyB-Tm in der SDS-PAGE. M, Molekularmassenstandard; Spur 1, für die Kristallisation eingesetztes Protein, über Source 30Q gereinigt (5 $\mu \mathrm{g}$ ); Spur 2, in Auftragspuffer gelöster Kristall aus 4 M Formiat; Spur 3, über Superdex 200 gereinigtes AmyB-Tm (3 $\mu \mathrm{g})$. 


\section{Untersuchung der AmyB-Expression in T. maritima}

\subsection{Immunologischer Nachweis von AmyB-Tm}

Die Anwesenheit von nativem AmyB in T. maritima wurde mittels Western-Blot überprüft. Für den immunologischen Nachweis wurden polyklonale anti-AmyB-Tm-Antikörper (aus mit rekombinantem AmyB-Tm-Protein immunisiertem Kaninchen, Endblutung; Fütterer, 2001) verwendet, deren Spezifität mittels Dot-Blot geprüft wurde (Abb. 36).

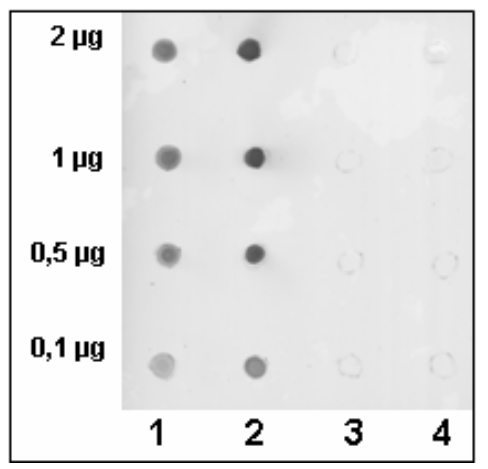

Abb. 36: Dot-Blot zur Überprüfung der anti-AmyB-Tm-Antikörper. Spur 1, AmyB-TmAufreinigung 1; Spur 2, AmyB-Tm-Aufreinigung 2; Spur 3, Amyloglukosidase aus A. niger (Boehringer, Mannheim); Spur 4, AmyA-Ag aus A. gottschalkii.

Für den Nachweis von AmyB-Tm wurden T. maritima Zellpellets in $20 \mathrm{mM}$ Tris-Puffer (pH 8,0) aufgenommen und mit Ultraschall aufgeschlossen (s. II.5.2.3). Die Rohextrakte wurden durch SDS-PAGE aufgetrennt und anschließend im Western-Blot die Anwesenheit von AmyB-Tm durch anti-AmyB-Tm-Antikörper überprüft (s. II.5.1.2, II.6). Als Kontrollen dienten rekombinant aufgereinigtes AmyB-Tm und der Rohextrakt einer E. coli AmyB-TmExpressionskultur. Im Western-Blot ließ sich AmyB-Tm als rekombinantes Protein aufgereinigt und im E. coli-Rohextrakt nachweisen. Interessanterweise ergab auch die hier im SDS-PAGE-Gel kaum sichtbare, durch säulenchromatgraphische Verfahren nicht abtrennbare Bande über der eigentlichen AmyB-Tm-Bande ein starkes immunologisches Signal. Als natives Protein konnte AmyB-Tm nur im T. maritima Rohextrakt nachgewiesen werden, der aus in vereinfachtem Vollmedium gewachsenen Zellen gewonnen wurde. Im Rohextrakt, der aus in Mineralmedium gewachsenen Zellen gewonnen wurde, ließ sich kein Signal detektieren. Beide T. maritima Medien enthielten 0,5 \% Stärke als C-Quelle (Abb. 37) 


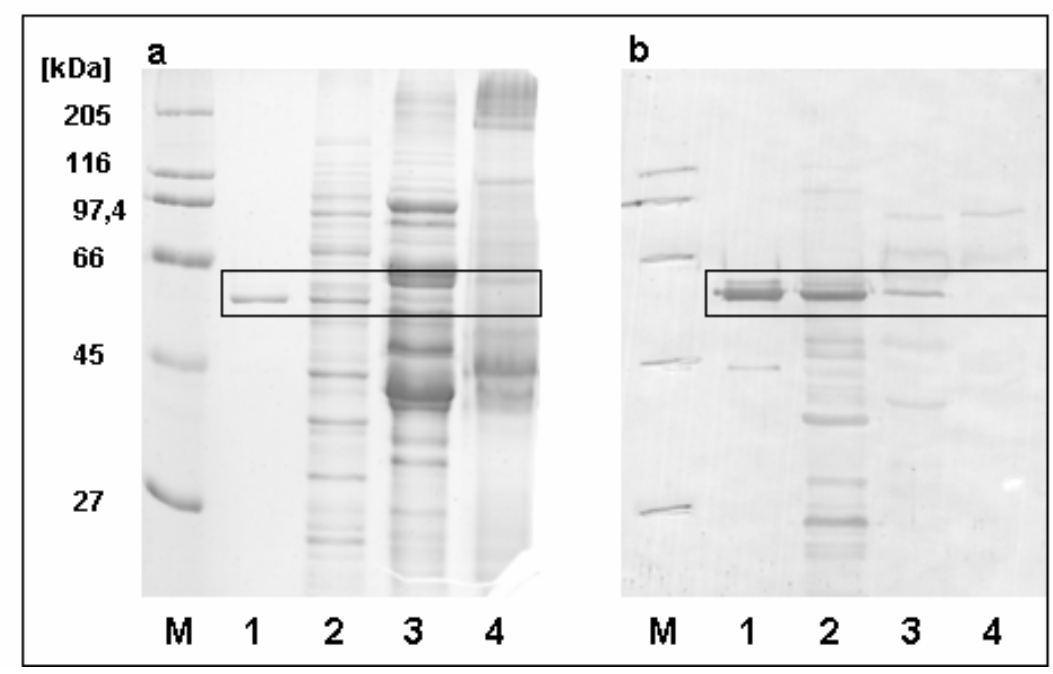

Abb. 37: a) SDS-PAGE-Gel mit T. maritima Rohextrakten und b) immunlogischer Nachweis von AmyB-Tm mittels Western-Blot. M, Molekularmassenstandard; Spur 1, rekombinant aufgereinigtes AmyB-Tm (1,3 $\mu \mathrm{g})$; Spur 2, E. coli BL21(DE3)/pET24c::AB Rohextrakt (24 $\mu \mathrm{g})$; Spur 3, T. maritima-Rohextrakt (vereinfachtes Medium + 0,5 \% Stärke) (35 $\mu \mathrm{g}$ ); Spur 4, T. maritima-Rohextrakt (Mineralmedium + 0,5 \% Stärke) (35 $\mu$ g).

\subsection{Wachstumsphasen-Abhängigkeit der AmyB-Expression in}

\section{T. maritima}

Um immunologisch zu überprüfen, ob AmyB konstitutiv in T. maritima exprimiert wird, oder ob die Anwesenheit des Enzyms von der Wachstumsphase abhängt, wurde T. maritima in vereinfachtem Vollmedium (VM, s. II.3.1.3) mit 0,5 \% Glukose kultiviert und an vier Punkten der Wachstumskurve Proben genommen (Abb. 38). Die Zeitpunkte der Probenentnahme lagen etwa in der Mitte der log-Phase (9,75 h), am Ende der log-Phase (15 h) und in der stationären Phase (26,5 h und 33,5 h). Ein Teil der zu diesen Zeitpunkten geernteten Zellen wurde in $20 \mathrm{mM}$ Tris-Puffer ( $\mathrm{pH}$ 8,0) aufgenommen, per Ultraschall aufgeschlossen und mit den Rohextrakten eine SDS-PAGE mit anschließendem Western-Blot durchgeführt. Zur Kontrolle wurde auch der Rohextrakt einer T. maritima Kultur mitgeführt, die $7 \mathrm{~h}$ in VM ohne zusätzliche C-Quelle bis zu einer $\mathrm{OD}_{600}$ von 0,08 gewachsen war. Unter den gegebenen Kulturbedingungen entsprach dies etwa dem Ende der log-Phase, wie in Vorversuchen ermittelt wurde. Wie in Abb. 39 zu erkennen ist, konnte AmyB-Tm nach 9,75 und 15 h im T. maritima Rohextrakt detektiert werden. Nach 26,5 h war das Signal nur noch sehr schwach zu erkennen. Nach 33,5 h konnte keine Anwesenheit von AmyB-Tm mehr im Rohextrakt festgestellt werden. Im Rohextrakt der in vereinfachtem Medium ohne C-Quelle gewachsenen T. maritima Zellen konnte AmyB-Tm ebenfalls immunologisch nachgewiesen werden. Interessanterweise wurde keine Kreuzreaktion des Antikörpers mit dem zu AmyBTm-ähnlichen Enzym aus T. thermophilus (AmyB-Tt, s. III.9) festgestellt. 


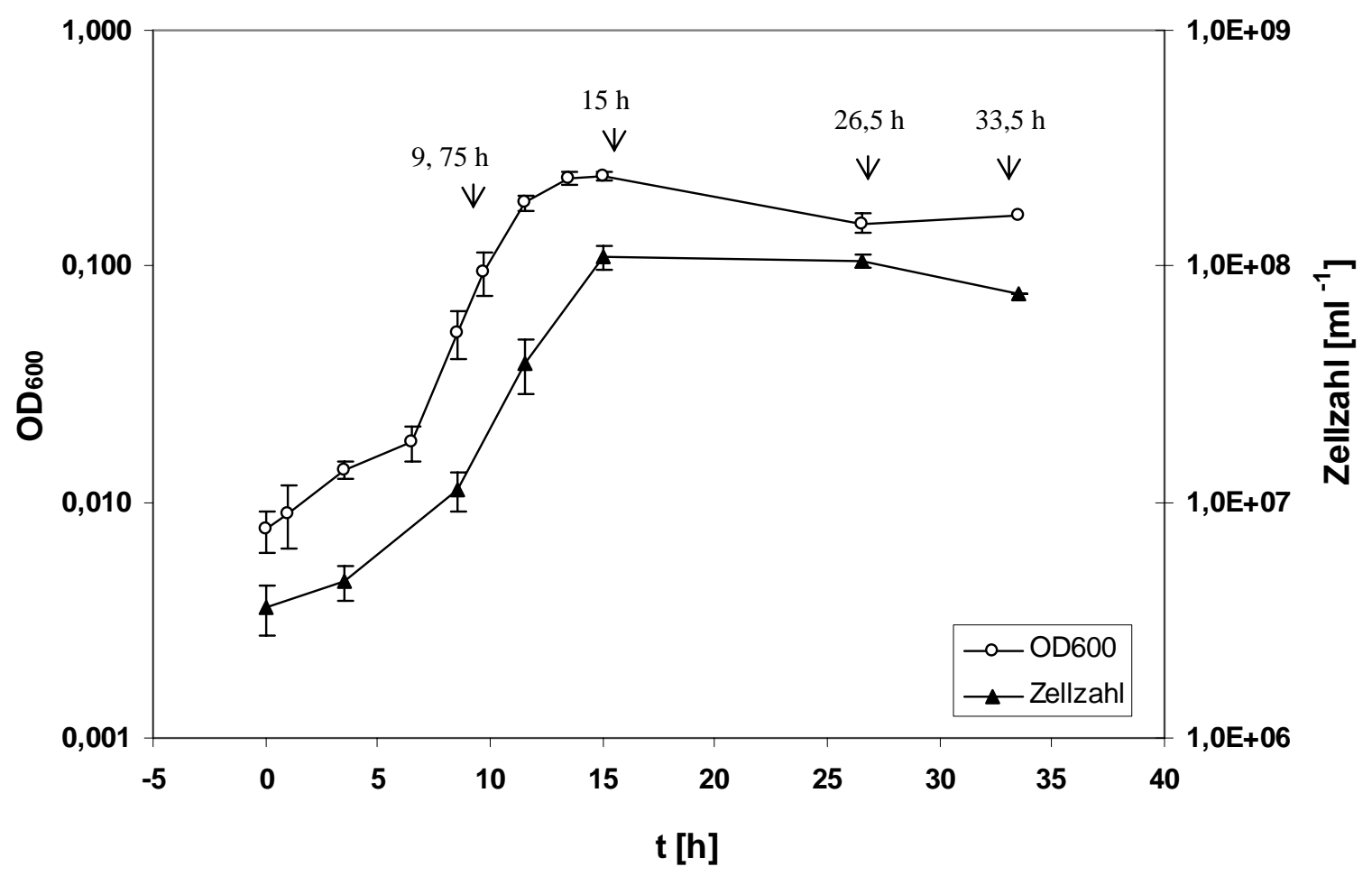

Abb. 38: Wachstumskurve von T. maritima bei Wachstum in VM mit 0,5 \% Glukose. Die Pfeile zeigen die Zeitpunkte der Probenentnahme an.

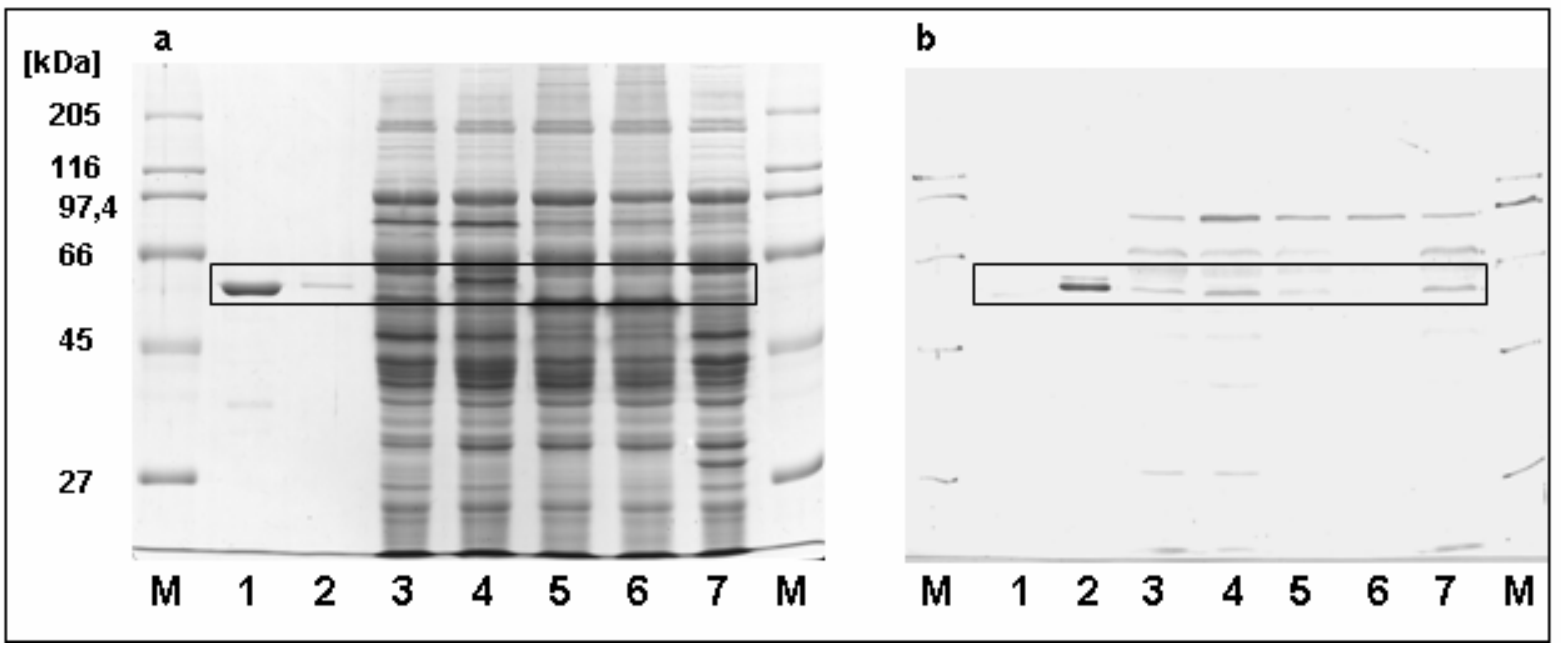

Abb. 39: a) SDS-PAGE-Gel mit T. maritima Rohextrakten und b) immunlogischer Nachweis von AmyB-Tm mittels Western-Blot. M, Molekularmassenstandard; Spur 1, rekombinant aufgereinigtes AmyB-Tm-ähnliches Protein AmyB-Tt (Negativkontrolle) (2 $\mathrm{gg}$ ); Spur 2, rekombinant aufgereinigtes AmyB-Tm (Positivkontrolle) (0,4 $\mu \mathrm{g})$; Spur 3, T. maritima-Rohextrakt (VM + 0,5 \% Glukose) nach

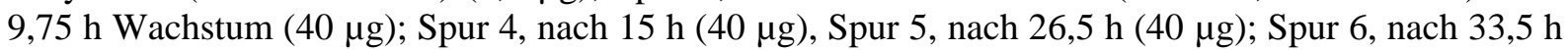
(40 $\mu \mathrm{g})$; Spur 7, T. maritima-Rohextrakt (VM ohne Glukose) nach 7 h Wachstum (40 $\mu \mathrm{g})$. 


\section{Untersuchungen des Speicherpolysaccharids von T. maritima}

\subsection{Charakterisierung des Speicherpolysaccharids}

Aus einem Teil der Zellen, die zu den unter III.4.2 genannten Zeitpunkten geerntet wurden, wurde ein Speicherpolysaccharid isoliert. Eine Ausnahme bildet dabei die 9,75 h Probe, da zu diesem Zeitpunkt nicht genug Zellmaterial zur Extraktion vorhanden war. Das isolierte Material wurde mit einer Amyloglukosidase aus A. niger und einer $\alpha$-Amylase aus A. gottschalkii verdaut (II.8). Die Amyloglukosidase spaltet $\alpha$-1,4- und $\alpha$-1,6-glykosidische Bindungen mit einem Exomechanismus, während die $\alpha$-Amylase selektiv $\alpha$-1,4-glykosidische Bindungen innerhalb eines Moleküls (Endomechanismus) hydrolysiert. Wie aus Abb. 40 ersichtlich ist, entstand beim Verdau des Speicherstoffs mit der Amyloglukosidase ausschließlich Glukose, beim Verdau mit der $\alpha$-Amylase Maltotriose, Maltose und Glukose. Diese Endprodukte der enzymatischen Hydrolysen deuten auf ein $\alpha$-Glukan als Speicherpolysaccharid von T. maritima hin. Weiterhin ist zu erkennen, daß die Abbauprodukte nur bei der nach $15 \mathrm{~h}$ Wachstum genommenen Probe auftreten. $\mathrm{Zu}$ den zwei späteren Probezeitpunkten läßt sich mit Hilfe der Dünnschichtchromatografie kein Speicherpolysaccharid detektieren. Vermutlich bildet T. maritima also während der log-Phase des Wachstums ein $\alpha$-Glukan, welches sich in der stationären Phase nicht mehr nachweisen läßt.

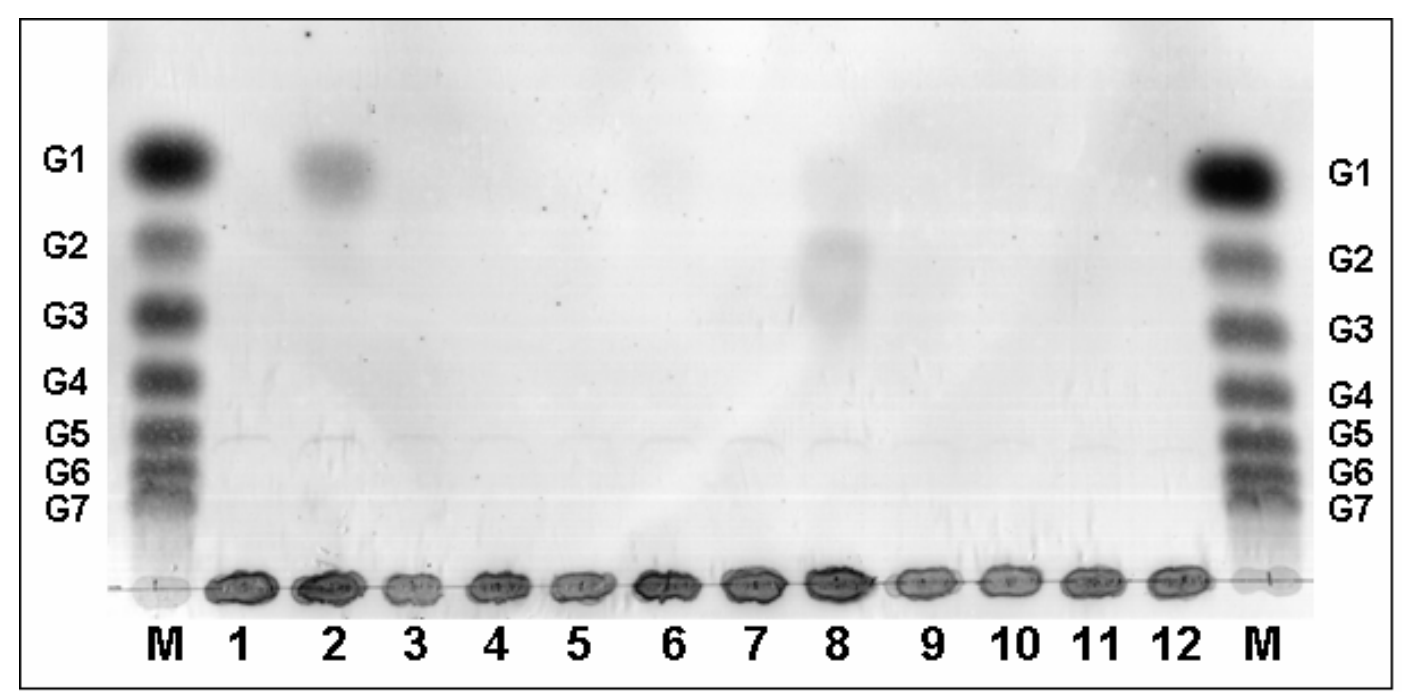

Abb. 40: Dünnschichtchromatographische Analyse des Speicherpolysaccharids aus T. maritima. M, Maltooligosaccharid-Standard; Spur 1 und 2, Speicherstoff (15 h) -/+ Amyloglukosidase-Verdau; Spur 3 und 4, Speicherstoff (26,5 h) -/+ Amyloglukosidase-Verdau; Spur 5 und 6, Speicherstoff (33,5 h) -/+ Amyloglukosidase-Verdau; Spur 7 und 8, Speicherstoff (15 h) -/+ $\alpha$-Amylase-Verdau; Spur 9 und 10, Speicherstoff (26,5 h) -/+ $\alpha$-Amylase-Verdau; Spur 11 und 12, Speicherstoff (33,5 h) $-/+\alpha$-Amylase-Verdau. Von allen Verdauansätzen wurden $21 \mu$ l aufgetragen, vom Standard $3 \mu \mathrm{l}$. Als Laufmittel wurde 1-Propanol/Nitromethan/ $\mathrm{H}_{2} \mathrm{O}$ (5:3:2) verwendet. 


\subsection{Quantifizierung des Speicherpolysaccharids}

Die Menge des von T. maritima gebildeten Speicherpolysaccharids wurde indirekt über die darin enthaltene Glukosemenge bestimmt. Dazu wurde T. maritima in vereinfachtem Medium mit 0,5 \% Glukose angezogen und die Zellen nach 16 Stunden Wachstum am Ende der logPhase bei einer $\mathrm{OD}_{600}$ von 0,207 geerntet. Das Zellnaßgewicht betrug 0,724 g/l. Die Zellen wurden mehrfach in Saline gewaschen, um eventuell anhaftende Glukose, die aus dem Medium stammt, zu entfernen. Das Speicherpolysaccharid wurde, wie unter II.8 beschrieben, isoliert und mit einer Amyloglukosidase aus A. niger verdaut. Eine sehr hohe Menge des eingesetzten Enzyms sollte eine vollständige Umsetzung des Substrats sicherstellen. Die durch die enzymatische Hydrolyse freigesetzte Glukosemenge wurde schließlich durch eine gekoppelte Glukose-Oxidase/Peroxidase-Enzymreaktion quantifiziert (s. II.3). Um zu verhindern, daß in den Zellen vorliegende Glukose, die nicht Teil des Speicherpolysaccharids ist, die Quantifizierung beeinflußt, wurde auch der Glukosegehalt von Testansätzen ohne Amyloglukosidase bestimmt und in der Berechnung berücksichtigt. Alle Messungen wurden als Dreifachbestimmungen durchgeführt.

Es ergab sich eine Glukosemenge von 37,9 $\mu \mathrm{g} / \mathrm{g}$ Zellnaßgewicht. Näherungsweise entspricht dies 37,9 $\mu$ g $\alpha$-Glukan/g Zellnaßgewicht. Um die Genauigkeit dieser Methode abschätzen zu können, wurden Proben mit eingewogener Glykogenmenge mitgeführt. Von eingewogenen $100 \mu$ g Glykogen konnten 65,1 $\mu$ g nachgewiesen werden, von eingewogenen $50 \mu \mathrm{g}$ waren es 34,3 $\mu \mathrm{g}$ und von eingewogenen $25 \mu \mathrm{g}$ konnten 17,3 $\mu \mathrm{g}$ nachgewiesen werden. Daraus ergibt sich, daß die tatsächliche Glykogenmenge mit dieser Methode um 33,5 \% unterschätzt wurde. Rechnet man aufgrund dieser Unterschätzung den für T. maritima ermittelten $\alpha$ Glukangehalt hoch, kommt man auf 56 $\mu$ g $\alpha$-Glukan pro g Zellnaßgewicht. 


\section{Aufklärung der Proteinstruktur von AmyB-Tm}

Zusätzlich zur biochemischen Charakterisierung sollte die räumliche Struktur des Enzyms aufgeklärt werden, um die Voraussetzung für eine vergleichende Analyse mit anderen glykosidischen Enzymen zu schaffen. Die Experimente zur Röntgenstrukturanalyse wurden in Kooperation mit Dr. A. Dickmanns und Prof. Dr. R. Ficner (Abteilung Molekulare Strukturbiologie, Institut für Mikrobiologie und Genetik, Göttingen) durchgeführt.

\subsection{Kristallisation und Datenerhebung}

Zur Kristallisation wurde über die Anionenaustauscher-Säule Source 30Q aufgereinigtes Protein ( 8 mg/ml in 20 mM Tris-Puffer, pH 8,0) eingesetzt. Zunächst wurden durch sparsematrix screens (Crystal Screen I+II, Hampton Research) mit der sitting drop Methode Bedingungen gesucht, unter denen AmyB-Tm kristallisiert (II.9.1). Das Protein bildete unter mehreren getesteten Bedingungen Kristalle (Abb. 41). Als beste Bedingung für die Kristallisation von AmyB-Tm stellte sich in Optimierungsversuchen ein Ansatz von $4 \mathrm{M} \mathrm{Na-}$ Formiat, $5 \%$ Isopropanol und $2 \mathrm{mM}$ DTT heraus. Hier wuchsen große, tetragonalbipyramidale Kristalle, die nach Vorversuchen zur Kryo-Konservierung ohne zusätzlichen Kryopuffer für die Datenerhebung im Röntgenstrahl eingesetzt wurden (Abb. 42).

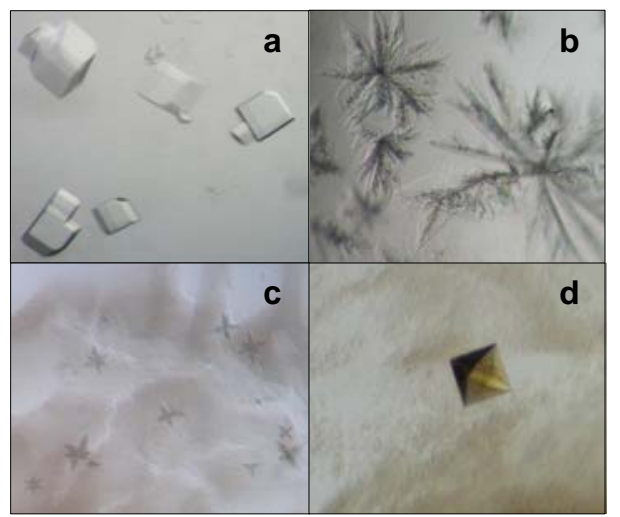

Abb. 41: Kristallbildung des AmyB-Tm-Proteins während der Initialscreens bei $20{ }^{\circ} \mathrm{C}$. Als Präzipitationslösung wurden a) $2 \%$ Polyethylenimin, 0,1 M Na-Citrat (pH 5,6), 0,5 M NaCl, b) $20 \%$ PEG 4000, 10 \% Isopropanol, 0,1 M HEPES (pH 7,5), c) 30 \% PEG 400, 0,2 M $\mathrm{MgCl}_{2}, 0,1 \mathrm{M}$ HEPES (pH 7,5) und d) $10 \%$ PEG 400, 0,3 $\mathrm{M} \mathrm{CaCl}_{2}$, 0,1 M HEPES (pH 8,5) eingesetzt. 


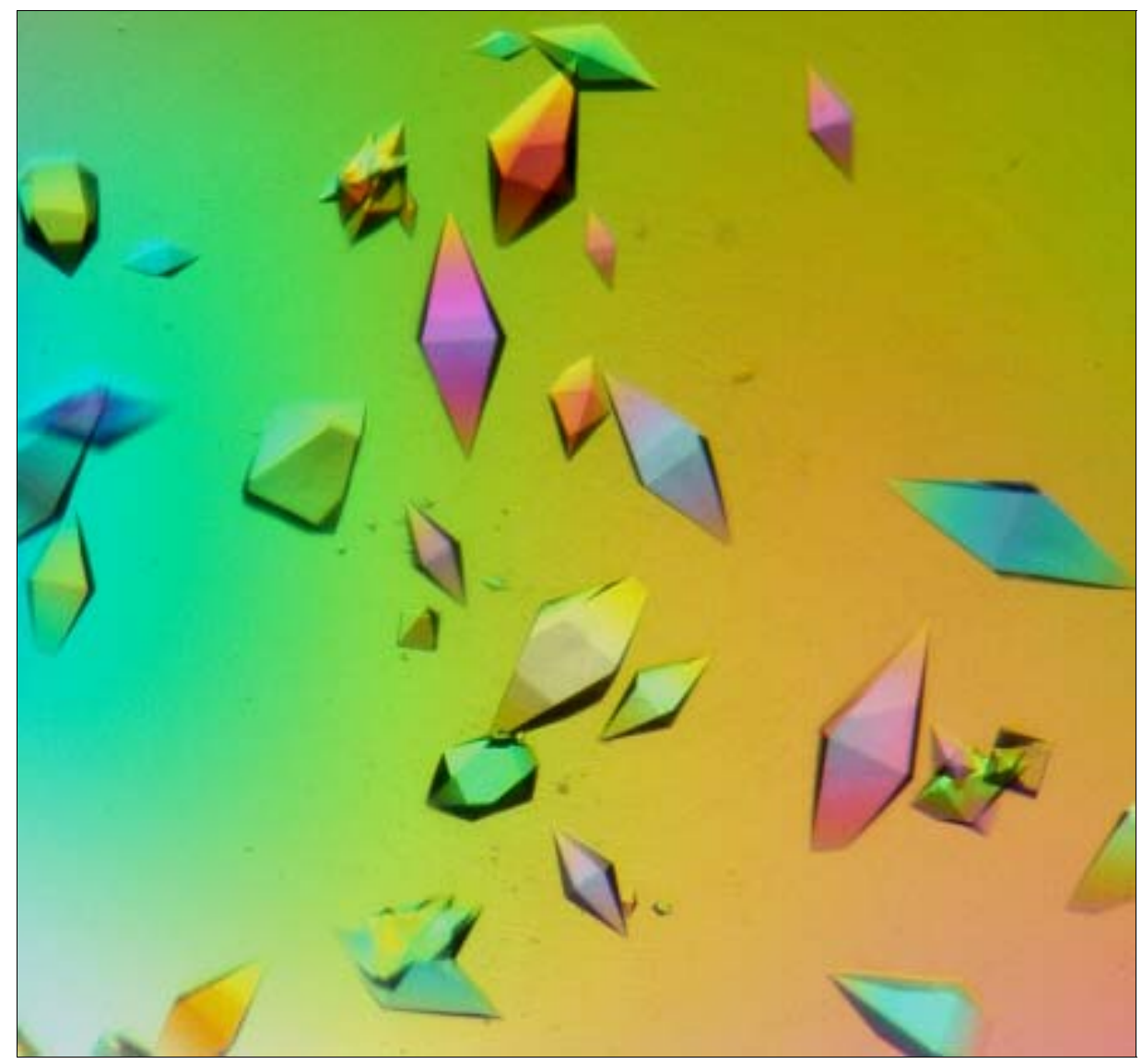

Abb. 42: AmyB-Tm-Kristalle in 4 M Na-Formiat, 5 \% Isopropanol und 2 mM DTT, betrachtet durch einen Polfilter vor dem Objektiv des Stereomikroskops.

Die Datensammlung und Auswertung wurde von Dr. A. Dickmanns durchgeführt. Die Datenerhebung erfolgte an einer PSF Beamline BL2 der Berliner Elektronen-SpeicherringGesellschaft für Synchrotronstrahlung m.b.H (BESSY). Dabei wurden standardmäßig 100120 Bilder pro Datensatz mit einer Drehung von $1^{\circ}$ und einer Belichtungszeit von $20 \mathrm{~s}$ erhoben. Die Einheitszelle des Kristalls (Raumgruppe I4) hatte die Zellkonstanten a = 47.08 $\AA, \mathrm{b}=100.75 \AA$ und $\mathrm{c}=62.70 \AA$. Alle Winkel betrugen $90^{\circ}$.

\subsection{Aufreinigung von Selenomethionin-AmyB-Tm aus E. coli B834 (DE3)}

Für die de novo Lösung der Kristallstruktur wurde ein MAD-Datensatz mit SelenomethioninAmyB-Tm aufgenommen. Um das dazu benötigte Protein, bei dem alle Methionin-Reste durch Selenomethionin substituiert waren, zu gewinnen, wurde der methioninauxotrophe Stamm E. coli B834 (DE3) mit dem Plasmid pET24c::AB transformiert und wie unter II. 3.2.2 beschrieben im 1 l-Maßstab in Selenomethionin-supplementiertem M9-Medium bei 30 ${ }^{\circ} \mathrm{C}$ angezogen. Aus $1 \mathrm{l}$ Kultur konnten dabei 1,6 g Zellen geerntet werden. Die Rohextraktgewinnung und Aufreinigung erfolgte wie für AmyB-Tm unter III.2.1 beschrieben 
durch Aufschluß der Zellen mit der French Pressure Cell, anschließender Hitzedenaturierung der E. coli Proteine (20 min, $75^{\circ} \mathrm{C}$ ) und säulenchromatographischer Aufreinigung über eine Source 30Q-Säule. Die Fraktionen der Source 30Q-Säule, die die höchste Konzentration an AmyB-Tm-Protein enthielten, wurden vereinigt, gegen $20 \mathrm{mM}$ Tris-Puffer (pH 8,0) mit $5 \mathrm{mM}$ DTT dialysiert und auf ein Volumen von $200 \mu$ l eingeengt. Es konnten insgesamt 1,4 mg sauberes Selenomethionin-AmyB-Tm gewonnen werden.

\subsection{Eisennachweis}

Die AmyB-Tm-Kristalle zeigten eine auffällige rote Farbe, die sich mit zunehmender DTTKonzentration im Ansatz verstärkte (Abb. 43). Dies deutete auf einen Redox-empfindlichen Cofaktor, vermutlich ein Metall, hin. Um das Metall zu identifizieren wurden an der PSF Beamline BL2 ein Fluoreszenzemissionsspektrum des Kristalls mit variierender Wellenlänge des Röntgenstrahls aufgenommen. Dabei wurde ein Fluoreszenzanstieg des enthaltenen Metalls bei einer Anregung mit $7,12 \mathrm{keV}$ gefunden (Abb. 44, Tab. 12). Durch diese charakteristische Anregung konnte das im AmyB-Tm-Kristall enthaltene Metall als Eisen identifiziert werden, was den biochemischen Nachweis von Eisen im AmyB-Tm-Protein bestätigte (s. III.3.4). In der gelösten Molekularstruktur von AmyB-Tm konnte kein Eisen nachgewiesen werden, was möglicherweise auf einen Eiseninkorporation in zu wenigen AmyB-Tm-Molekülen (<10 \%) zurückzuführen ist.

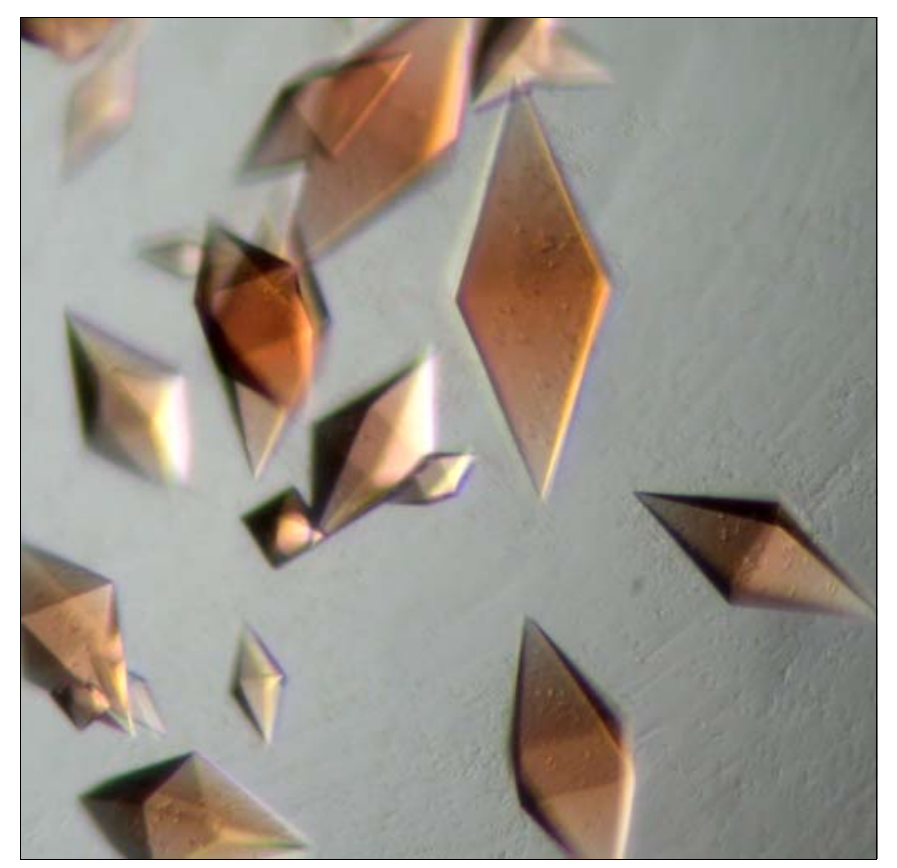

Abb. 43: Rot verfärbte AmyB-Tm-Kristalle in $4 \mathrm{M}$ Na-Formiat, $5 \%$ Isopropanol und $2 \mathrm{mM}$ DTT. 


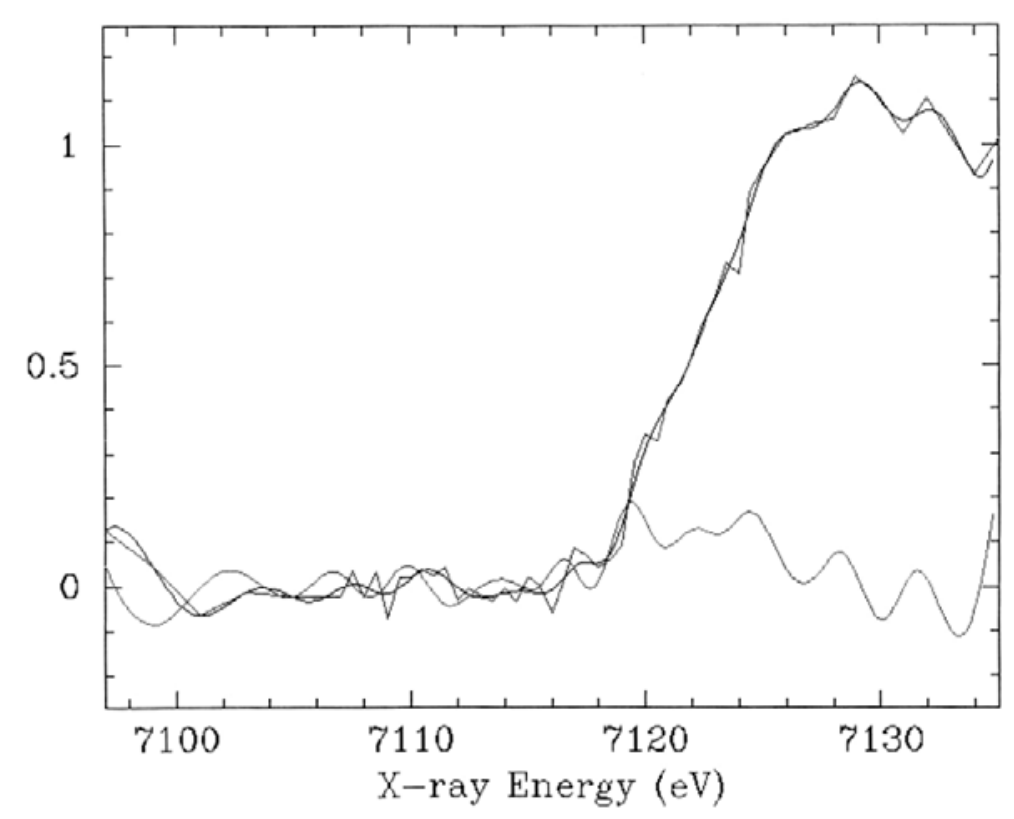

Abb. 44: Röntgen-Fluoreszenzemissionsspektrum von AmyB-Tm.

Tab. 12 :Anregungsenergien ausgewählter Metalle (K-Schale). Die Daten wurde zusammengestellt nach Informationen der Webseite des Center for Synchrotron Radiation Research and Instrumentation, Illinois Institute of Technology, Chicago (http://www.csrri.iit.edu/periodic-table.html).

\begin{tabular}{lc}
\hline Metall & Anregungsenergie (kEV) \\
\hline Magnesium & 1,3 \\
Kalzium & 4,0 \\
Chrom & 6,0 \\
Mangan & 6,5 \\
Eisen & 7,1 \\
Cobalt & 7,7 \\
Nickel & 8,3 \\
Kupfer & 9,0 \\
Zink & 9,7 \\
Ruthenium & 22,1 \\
\hline
\end{tabular}




\section{Analyse der Proteinstruktur}

\subsection{Tertiärstruktur von AmyB-Tm}

Die Proteinstruktur von AmyB-Tm wurde mit einer Genauigkeit von 2,3 Å aufgelöst. Die Molekularstruktur zeigt, daß die 528 Aminosäuren langen Polypetidkette von AmyB-Tm $9 \beta$ Stränge, $14 \alpha$-Helices und $1133_{10}$-Helices ausbildet. Die zentrale Domäne der Tertiärstruktur bildet ein aus sieben $\beta$-Strängen bestehendes, verzerrtes TIM-barrel (Abb. 45). Viele saccharolytische Enzyme, insbesondere auch die der GHF 13, besitzen ein ähnliches Faltungsmotiv, das klassischerweise jedoch aus $8 \beta$-Strängen und $8 \alpha$-Helices besteht.

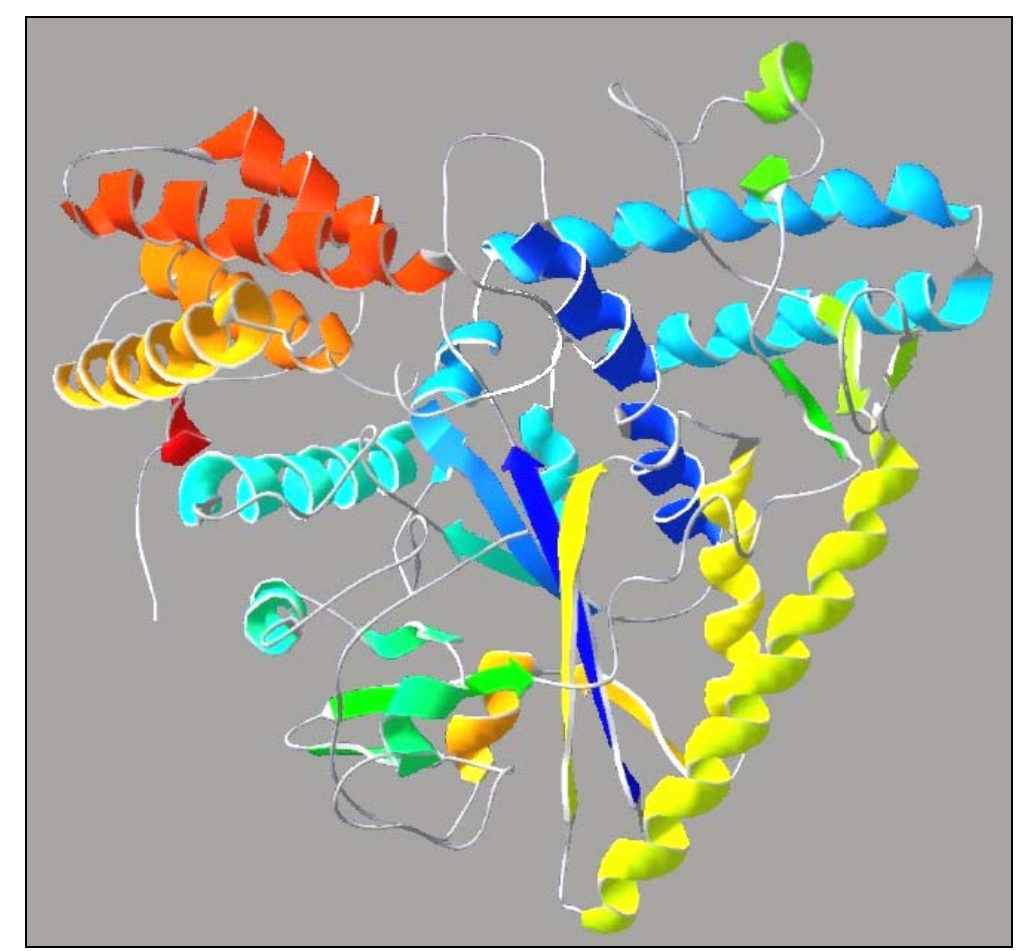

Abb. 45: Cartoon-Darstellung der AmyB-Tm-Struktur mit einem Farbverlauf vom N-Terminus (blau) zum C-Terminus (rot).

Im Topologie-Diagramm (Abb. 46) wird deutlich, daß zwischen dem 2. und 3. das $(\beta / \alpha)_{7}-\mathrm{Fa} ß$ bildenden $\alpha$-Strang eine Region inseriert ist, die aus zwei $\alpha$-Helices besteht. Zwischen dem 6 . und 7. $\beta$-Strang sind sieben $3_{10}$ Helices inseriert. Diese im Vergleich zur $\alpha$-Helix selten vorkommenden Helices sind enger gewunden und haben statt der üblichen 3,6 Aminosäuren nur 3 Aminosäuren pro Windung. Der C-terminale Abschluß des Enzyms wird von einer Domäne gebildet, die aus einem Vier-Helix-Bündel besteht. 


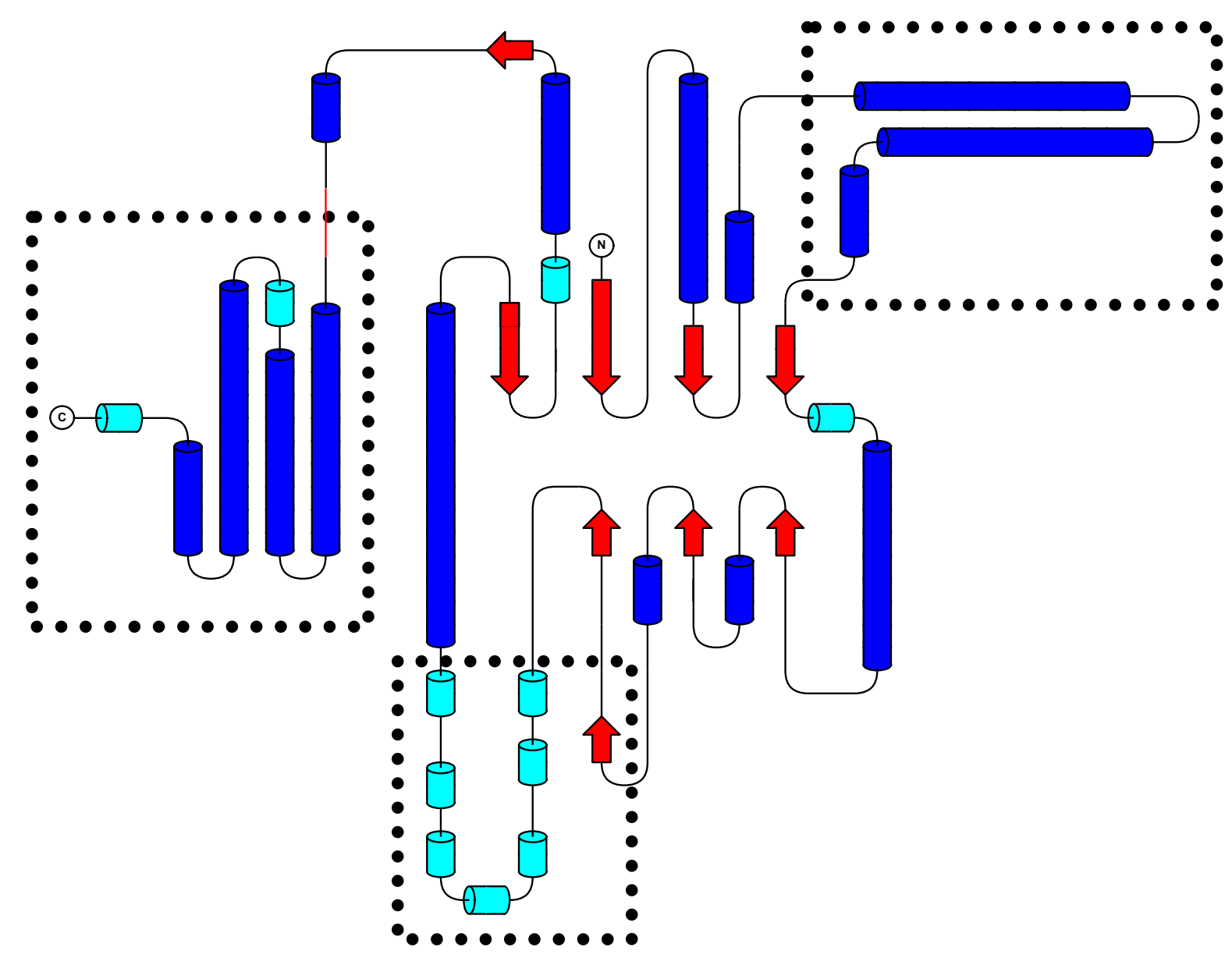

Abb. 46: Topologische Repräsentation von AmyB-Tm. Die $\beta$-Stränge durch graue Pfeile, $\alpha$-Helices durch dunkelgraue Zylinder und $3{ }_{10}$-Helices durch hellgraue Zylinder dargestellt. (Mit freundlicher Genehmigung von A. Dickmanns).

Die Struktur von AmyB-Tm zeigt außerordentliche Ähnlichkeit zu den Strukturen einer $\alpha$ Glukanotransferase (GTase) aus T. litoralis (Imamura et al., 2003) und eines hypothetischen Proteins aus T. thermophilus HB27 (Idaka et al., unveröffentlicht). Die GTase gehört zur GHF 57, einer Glykosidhydrolase Familie, zu der AmyB-Tm eine schwache Sequenzähnlichkeit hat, und ist biochemisch gut untersucht (Jeon et al., 1997; Imamura et al., 2001). Über das T. thermophilus Protein Tth1467 liegen abgesehen von der Struktur keine biochemischen Daten vor. Die Aminosäuresequenz dieses Proteins hat signifikante Ähnlichkeit (e-value $=4 \mathrm{e}-67)$ zu AmyB-Tm und taucht in der Liste der Blast Treffer an Position 27 auf (s. III.1.2, Tab. 6). Trotz der Abweichungen in der Sequenz sind die molekularen Strukturen von AmyB-Tm und Tth1467 nahezu identisch (Abb. 47). 


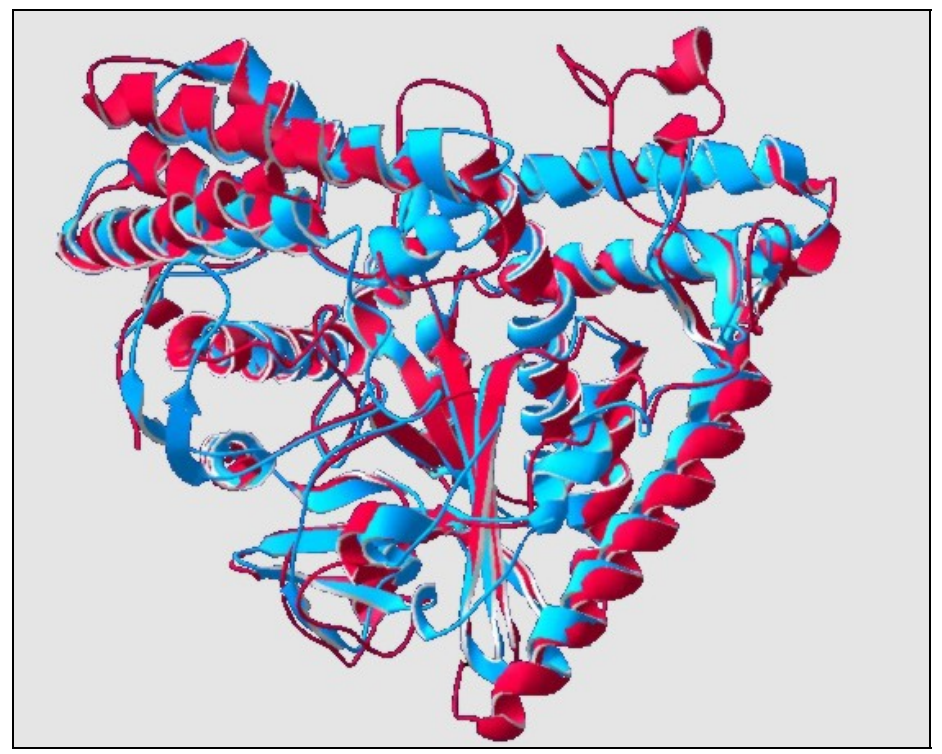

Abb. 47: Alignment der Strukturen von AmyB-Tm (rot) und des hypothetischen Proteins Tth1467aus T. thermophilus (blau).

\subsection{Identifizierung der katalytischen Aminosäuren}

Die katalytischen Aminosäurereste der GTase aus T. litoralis wurden 2001 von Imamura et al. identifiziert. Es handelt sich hierbei um Glu123 und Asp214, die C-terminal am Ende der $\beta$-Stränge $\beta 4$ bzw. $\beta 8$ liegen. Es wurde postuliert, daß der Glutamatrest bei der katalytischen Reaktion der GTase als Nukleophil fungiert und der Aspartatrest als katalytische Säure/Base. Beide Aminosäurereste sind innerhalb der GHF 57 hochkonserviert. Trotz der generellen Sequenzunterschiede zur GTase sind die Regionen um die entsprechenden Reste auch in der COG1543 konserviert. Durch Alignment der Aminosäuresequenzen von AmyB-Tm aus T. maritima, Tth1467 aus T. thermophilus und der GTase aus T. litoralis war es möglich, Glu185 und Asp349 als katalytische Reste von AmyB-Tm sowie Glu184 und Asp352 als katalytische Reste von Tth1467 zu identifizieren (Abb. 48). Wie in der Struktur der GTase ist der Glutamatrest am C-Terminus des $\beta 4$-Stranges und der Aspartatrest am C-Terminus des $\beta 8$-Stranges lokalisiert (Abb. 49).

\begin{tabular}{|c|c|c|c|c|c|c|}
\hline & & * & & & * & \\
\hline AmyB - Tm & 176 & KHPRGIWLAECGYY 189 & r. & . 342 & PVIVAPFDAELFGHWWF & 359 \\
\hline Tth_Tt1467 & 175 & KDPTGFWLPEMAYR 188 & . & . 345 & GVILSPYDAELFGHWWY & 362 \\
\hline Tli_gtra & 114 & YDAKGVWLTERVWQ 127 & . & . 207 & KVAVFHDDGEKFGVWPG & 222 \\
\hline
\end{tabular}

Abb. 48: Teilweises Alignment der Aminosäueresequenzen von AmyB-Tm aus T. maritima, Tth1467 aus T. thermophilus und der GTase aus T. litoralis. Übereinstimmungen in den Sequenzen sind grau hinterlegt, die katalytischen Aminosäurereste sind mit einem Stern gekennzeichnet. Ein vollständiges Alignment der drei Sequenzen befindet sich im Anhang. 


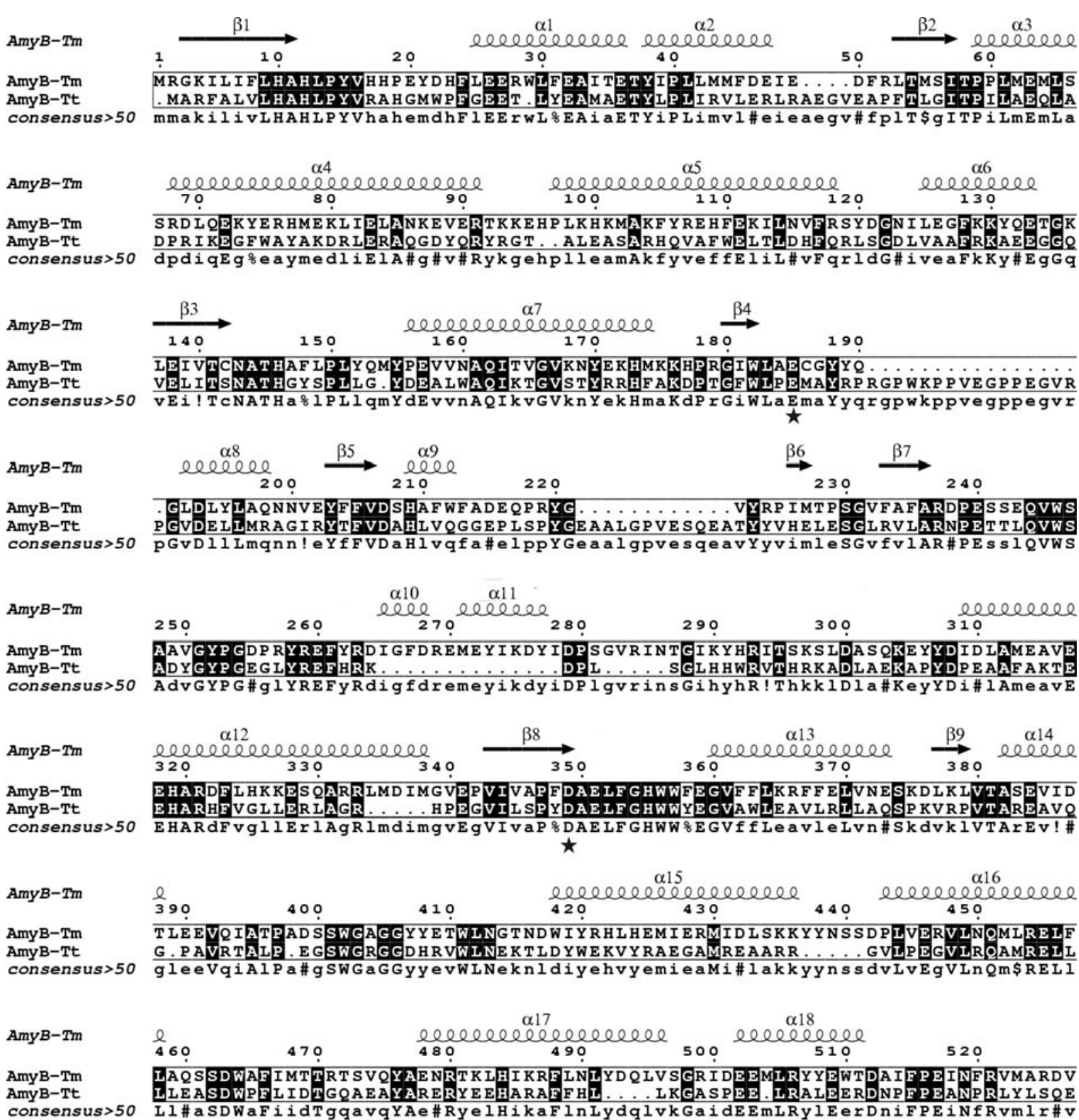

AmyB $-T m$

$\begin{array}{ll}\text { AmyB-Tm } & \mathrm{T} \\ \text { AmyB-Tt } & \mathrm{I}\end{array}$

consensus $>50$ i

Abb. 49: Alignment der Aminosäuresequenzen von AmyB-Tm und Tth1467. Die Numerierung der Aminosäuren bezieht sich auf AmyB-Tm. Identische Aminosäuren sind Schwarz hinterlegt, ähnliche sind eingerahmt. Die katalytischen Aminosäuren sind durch Sterne markiert. Die Abbildung wurde mit ESpript erstellt (Gouet et al., 1999, http://espript.ibcp.fr/ESPript/ESPript/index.php).

Durch Überlagerung der Proteinstrukturen von AmyB-Tm, Tth1467 und der GTase konnte gezeigt werden, daß die in der Primärstruktur identifizierten katalytischen Reste auch in ihrer räumlichen Anordnung in der Tertiärstruktur zur Deckung zu bringen sind (Abb. 50). 
Auffällig ist hier, daß die Lage des Asp349 aus AmyB-Tm nicht völlig identisch mit der Lage der Aspartatreste der beiden andern Enzyme ist.

Die als katalytische Aminosäuren von AmyB-Tm identifizierten Aminosäuren Glu185 und Asp349 befinden sich im Zentrum des Moleküls am C-terminalen Ende des verzerrten $(\beta / \alpha)_{7^{-}}$ Fasses. Abbildung 51 zeigt, daß das AmyB-Tm-Molekül im Bereich des hypothetischen katalytischen Zentrums eine Tasche mit einer stark negativen Oberflächenladung hat.

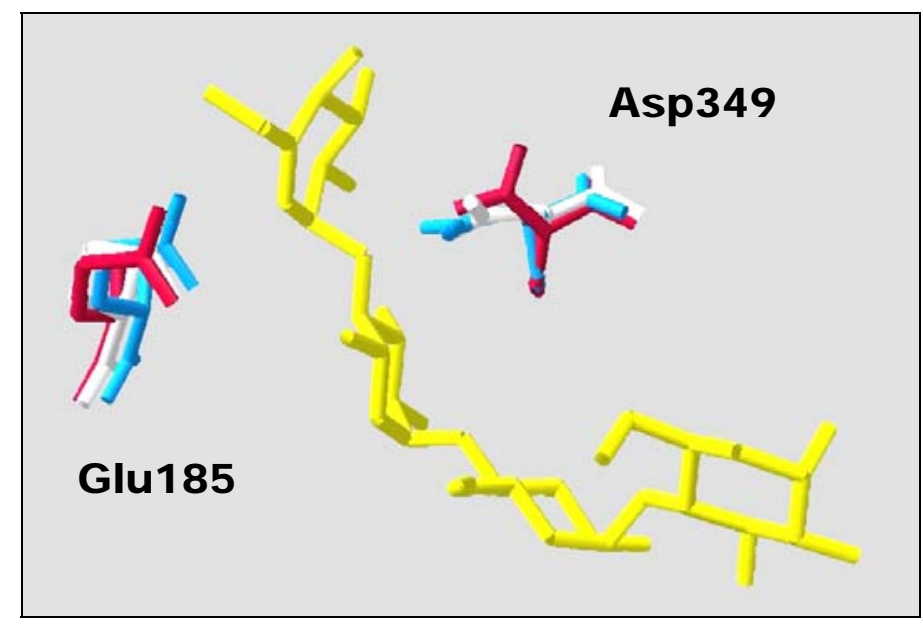

Abb. 50: Überlagerung der katalytischen Reste von AmyB-Tm aus T. maritima (rot), Tth1467 aus T. thermophilus (blau) und der GTase aus T. litoralis (weiß). Das GTase Acarbose Molekül ist gelb eingezeichnet. Die Numerierung der Aminosäuren entspricht der Position in der AmyB-Tm-Sequenz.

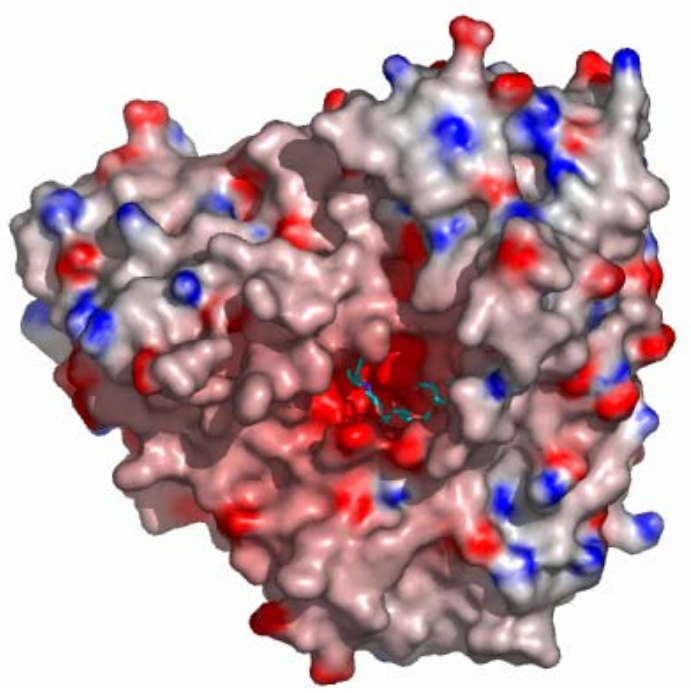

Abb. 51: Darstellung der elektrostatischen Ladungsverteilung auf der molekularen AmyB-Tm Oberfläche. In die negativ geladene Tasche des aktiven Zentrums ist ein Acarbose-Molekül hineinmodelliert (Steinke, 2004). 


\subsection{Identifizierung einer potentiellen Eisenbindestelle}

In unmittelbarer Nähe des aktiven Zentrums von AmyB-Tm konnte eine potentielle Metallbindestelle, gebildet durch His10, His12, His146 und Cys142/Cys186, identifiziert werden. Die Aminosäurereste sind tetraedrisch angeordnet und könnten Eisen koordinieren (O. Einsle, persönliche Mitteilung.) (Abb. 52). Die His10 und His12 entsprechenden Aminosäurereste der GTase (His11 und His13), die sowohl in der GHF 57 als auch im COG1543 hochkonserviert sind, wurden in der GTase Struktur als an der Substratbindung (-1 subsite) identifiziert (Imamura et al., 2003).
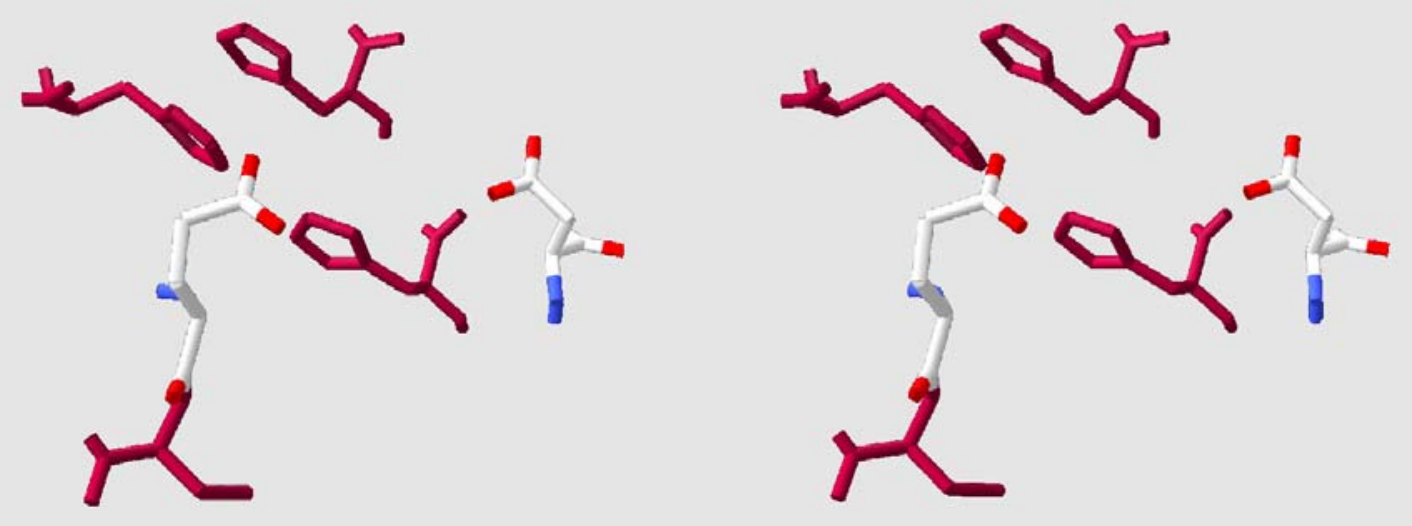

Abb. 52: Stereoansicht des potentiellen Eisenbindezentrums. Die das Zentrum bildenden Aminosäuren His11, His13, His146 und Cys186 sind rot eingefärbt. Ebenfalls eingezeichnet sind die katalytischen Reste Glu185 und Asp349. 


\section{Ortsspezifische Mutagenese von AmyB-Tm}

\subsection{Mutagenese des Cysteinrests 186}

Die computergestützte Analyse der Aminosäuresequenz von AmyB-Tm zeigte, daß das Protein zwei Cysteinreste (Cys142 und Cys186) beinhaltet. Das Cystein an Position 186 ist innerhalb der COG1543 hoch konserviert und liegt direkt neben Glu185, das als einer der katalytischen Aminosäurereste von AmyB-Tm identifiziert wurde (Abb. 53). Cysteinreste können im oxiderten Zustand Disulfid-Brücken ausbilden und so Einfluß auf die Faltungskonformation und Stabilität des Proteins haben. Da die Aktivität von AmyB-Tm im hohen Maß abhängig ist von der DTT-Konzentration und damit dem Redoxzustand des Reaktionsansatzes, wurde vermutet, daß der Redoxzustand der Cysteinreste eine Rolle bei den Aktivitätsschwankungen von AmyB-Tm spielen könnte. Zusätzlich wurde durch die Analyse der Proteinstruktur deutlich, daß eines der Cysteine an einem potentiellen Eisenzentrum beteiligt sein könnte.

\begin{tabular}{|c|c|c|c|c|c|c|}
\hline AmyB-Tm & 132 QETGKLEIVT & CNATHAFLPL YQMYPEVVNA & QITVGVKNYE & KHMKKHPRGI & WLAECGYYQG & 191 \\
\hline Pmio & 132 KDKGYIEVIT & SNGTHGYLPF YRDYPEAIKA & QIKSAVLTFK & KYFGDHPKGM & WLAECAYFKG & 191 \\
\hline Tth & 132 EEGGQVELIT & SNATHGYSPL LGY-DEALWA & QIKTGVSTYR & RHFAKDPTGF & WLPEMAYRPR & 190 \\
\hline Cac & 136 DRLGCVEIIT & CAATHALLPL ILINRQAVKA & QIATGVQSYI & NTMGHEPNGI & WLPECAYTYG & 195 \\
\hline Npu & 136 QDSNNLEIIT & CGATHGYLPL MKMYPQAVWA & QIQVACEHYE & ETFGRPPKGI & WLPECAYYEG & 195 \\
\hline Pho & 132 QDEGYVEVIT & SAATHGYLPL LGR-DEAIEA & QLLNGIKVYE & KYFGRKPRGI & WLPECAYRPD & 190 \\
\hline Pfu & 131 QEAGYLEIIT & SAATHGYLPL LGR-DEAIEG & QIANAIKTYE & KYFQRRPRGM & WLPECAYRPD & 189 \\
\hline
\end{tabular}

Abb. 53: Alignment ausgewählter Proteine der COG1543 im Bereich der Cysteine 142 und 186 (grau hinterlegt) von AmyB-Tm. Die Proteine wurden mit CLUSTAL W verglichen. Pmio, Protein aus P. miotherma; Tth, Protein aus T. thermophilus; Cac, Protein aus C. acetobutylicum; Npu, Protein aus N. punctiforme; Pho, Protein aus P. horikoshii; Pfu, Protein aus P. furiosus.

Die Rolle der Cysteine für die Aktivität von AmyB-Tm sollte experimentell überprüft werden. Dazu wurde das Cystein an Position 186 gegen ein Serin ausgetauscht. Der Basenaustausch zur Mutation des Cysteincodons erfolgte durch eine ortspezifische Mutagenese wie unter II.4.4.3 beschrieben. Dabei wurde nicht nur das Codon TGC (Cystein) in AGC (Serin) geändert, sondern auch eine BglII-Schnittstelle 18 bp von der Mutation entfernt eingefügt, ohne die Aminosäuresequenz zu verändern. Diese Schnittstelle diente zur schnellen Überprüfung der Mutanten. (Abb. 54)

Als Template für die Mutagenese wurde der Vektor pET24c::AB verwendet. Mit dem mutagenisierten Vektor pET24c::ABCys186 wurde zunächst E. coli XL1-blue transformiert (Abb. 55). Der Erfolg der Mutagenese wurde durch Restriktion mit BglII und durch 
Sequenzierung mit spezifischen Primern überprüft. Das korrekt mutagenisierte Plasmid wurde aus E. coli XL1-blue isoliert und zur Expression in E. coli BL21(DE3) transformiert.

Ausgangsequenz amyB-Tm:

5'-CTT GCG GAA TIGC GGA TAC TAT CAG GGG CTG GAT CTG TAC CTT-3'

$\begin{array}{llllllllllllll}L & A & E & C & G & Y & Y & Q & G & L & D & L & Y & L\end{array}$

amyB-Tm-Sequenz mit C186 $\rightarrow$ S186 Austausch:

5'-CTT GCG GAA AGC GGA TAC TAT CAG GGG CTA GAT CTG TAC CTT-3'

$\begin{array}{lllllllllllllll}\mathrm{L} & \mathrm{A} & \mathrm{E} & \mathrm{S} & \mathrm{G} & \mathrm{Y} & \mathrm{Y} & \mathrm{Q} & \mathrm{G} & \mathrm{L} & \mathrm{D} & \mathrm{L} & \mathrm{Y} & \mathrm{L}\end{array}$

Abb. 54 : Vergleich der Ausgangssequenz von amyB-Tm mit der mutierten Sequenz. Basenaustausche und der daraus resultierenden Aminosäurenaustausch sind grau unterlegt. Die eingefügte BglII-Schnittstelle ist unterstrichen.
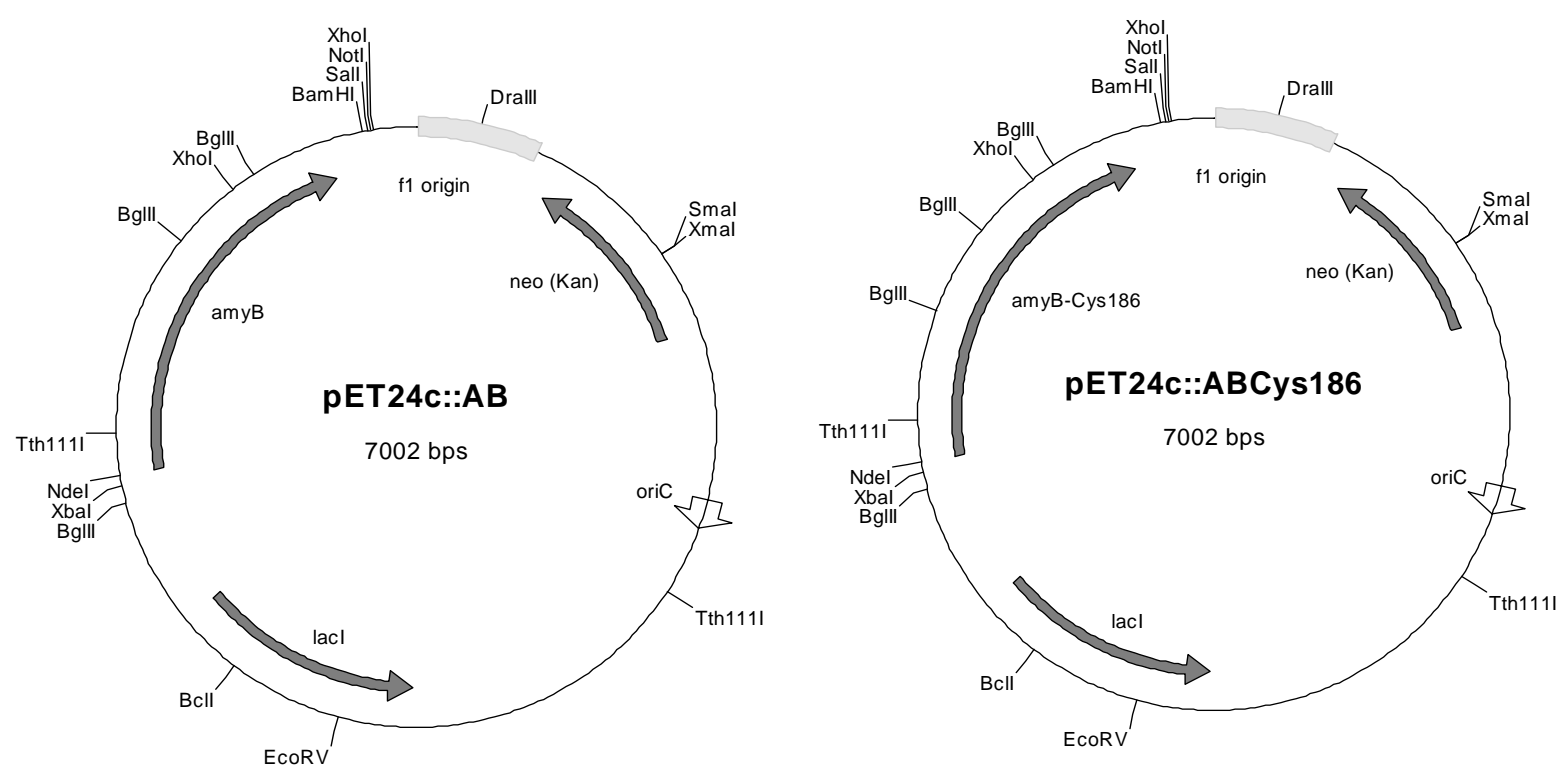

Abb. 55: Vektorkarten des Vektors pET24c:AB und des mutagenisierten pET24c::ABCys186 Vektors. 


\subsection{Expression und Aufreinigung der AmyBCys186-Mutante}

Zur Expression von AmyBCys186 wurde eine 1,5 l Flüssigkultur 2 \%ig mit E. coli BL21(DE3)/pET24c::ABCys186 aus einer Vorkultur angeimpft. Nach 4 h Wachstum ohne Induktion bei $37{ }^{\circ} \mathrm{C}$ erfolgte bei einer $\mathrm{OD}_{600}$ von 1,5 die Zellernte durch Zentrifugation. Das Zellpellet (6,7 g Naßgewicht) wurde in 25 ml 20 mM Tris-Puffer (pH 8,0) aufgenommen. Die weitere Rohextraktgewinnung durch Aufschluß mit der French Pressure Cell, Hitzedenaturierung und einer säulenchromatographische Aufreinigung über die Source 30QSäule erfolgte, wie für die Aufreinigung von AmyB-Tm aus E. coli BL21 (DE3)/pET24c::AB beschrieben (s. III.2.1). Abb. 56 zeigt eine Bilanzierung der Aufreinigung. Die Aktivität des AmyBCys186-Proteins im Standard DNSA-Test (s. II.7.1) war mit $~ 0,3$ U/mg genau so hoch wie die von aus vergleichbaren Aufreinigungen gewonnenem AmyB-Tm. Sie ließ sich durch Zugabe von 1 mM ATP auf 70 \% der Ausgangsaktivität senken und durch 0,1 mM EDTA auf 30 \%. Für AmyB-Tm waren dies unter gleichen Testbedingungen 37 \% bzw. 0 \%.

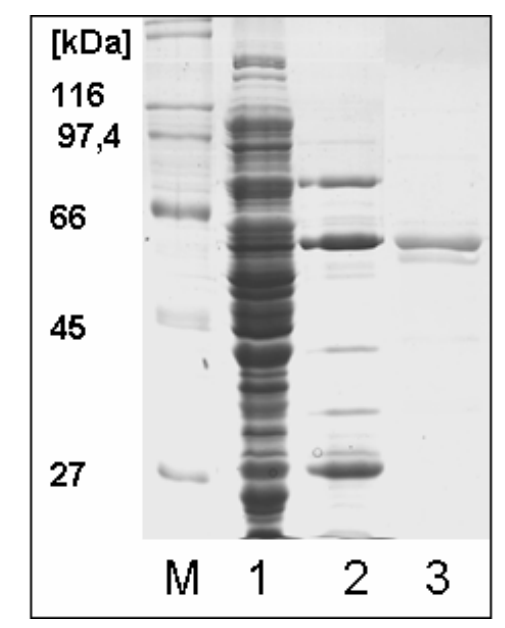

Abb. 56: SDS-PAGE Bilanz der Aufreinigung von AmyBCys186. M, Molekularmassenstandard; Spur 1, Rohextrakt von E. coli BL21 (DE3)/pET24c::ABCys186; Spur 2, bei $75{ }^{\circ} \mathrm{C} 20 \mathrm{~min}$ hitzedenaturierter Rohextrakt; Spur 3, Pool Source 30Q.

\section{Klonierung von amyB-Tt aus T. thermophilus und teilweise Charakterisierung des Genprodukts}

Thermus thermophilus ist ein aerobes, thermophiles Bakterium mit einem Temperaturoptimum des Wachstums von $75^{\circ} \mathrm{C}$, was knapp unter dem Wachstumsoptimum des anaeroben hyperthermophilen Bakteriums T. maritima liegt. Die Genprodukte von Tt1467 aus T. thermophilus HB8 (gi:39654909) und TTC1540 aus T. thermophilus HB27 (gi:46199842) gehören zu den zur COG1543-Domäne zusammengefaßten Proteinen. Ihre Aminosäuresequenzen hat eine Identität von 32 mit der von AmyB-Tm, wobei diese 
Sequenzen jedoch in der Liste der Blast Treffer erst an 27. und 28. Stelle, noch hinter der Mehrheit der Cyanobakterien und Archaeen stehen. Im Gegensatz zu AmyB-Tm enthalten diese Proteine, die sich nur durch neun Aminosäurereste unterscheiden, keine Cysteinreste. Von Tt1467 aus dem Stamm HB8 existiert eine unveröffentlichte Struktur in der RCSB Protein Data Bank (PDB, http://www.rcsb.org/pdb/), die sehr hohe Ähnlichkeit zu der in dieser Arbeit ermittelten Struktur von AmyB-Tm aufweist (1UFA.A, s. III.7.1). Um zu überprüfen, ob die nahezu identische Struktur und ähnliche Aminosäuresequenz auch eine ähnliche Funktion bedingten, sollte das amyB-Tm-ähnliche Gen aus T. thermophilus (im Folgenden amyB-Tt genannt) kloniert und das Genprodukt charakterisiert werden. Aufgrund der einfacheren Verfügbarkeit wurde hierzu das Gen TTC1540 aus T. thermophilus HB27 verwendet. Ein Alignment von TTC1540 und Tt1467 befindet sich im Anhang.

\subsection{Analyse des genetischer Kontexts}

Die flankierenden Regionen des Gens amyB-Tt aus T. thermophilus HB27 weisen keine Ähnlichkeit zu denen von amyB-Tm auf. Als einzige Gemeinsamkeit findet sich in der Nähe beider Gene ein ORF, der für ein hypothetisches Protein kodiert, das Ähnlichkeit mit Succinyl-CoA Synthetasen/ Coenzym A-bindenden Proteinen aufweist (COG1832, Pfam02629) (Abb. 57).

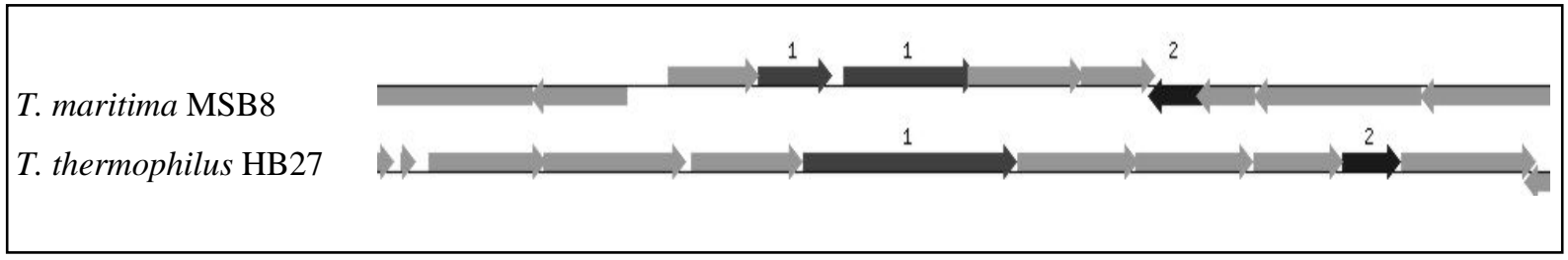

Abb. 57: Vergleich der flankierenden Region um amyB-Tm und amyB-Tt. ORF 1: amyB-Tm (RTM02682/02657, Tm1438) bzw. amyB-Tt (TTC1540); ORF 2: hypothetisches, CoA-bindendes Protein mit Ähnlichkeit zur COG1832 (TTC1536 bzw.Tm1435).

\subsection{Amplifikation und Klonierung}

Die Klonierung erfolgte durch Ligation in den Vektor pDrive und anschließender Subklonierung in den Vektor pET21c. Das amyB-Tt-Gen im Insert des Genbankplasmids tthi77, das freundlicherweise von Dr. A. Henne (Göttinger Labor für Genomanalyse) zur Verfügung gestellt wurde, wurde mit den spezifischen Primern TT_amyb_fwd und TT_amyb_rev mittels PCR amplifiziert. Die Primer wurden so gewählt, daß in das PCR Produkt am 5'-Ende eine NdeI und am 3'-Ende eine HindIII Schnittstelle eingefügt wurden. Aufgrund des sehr hohen G+C-Gehalts des zu amplifizierenden Gens von $71 \%$ wurde die 
PCR mit Pfu-Polymerase in einem Ansatz mit der ungewöhnlich hohen PrimerKonzentrationen von $10 \mathrm{pmol} / \mu \mathrm{l}$ durchgeführt.

PCR-Bedingungen:

$$
30 \mathrm{x}\left[\begin{array}{cc}
95^{\circ} \mathrm{C} & 8 \mathrm{~min} \\
95^{\circ} \mathrm{C} & 2 \mathrm{~min} \\
67^{\circ} \mathrm{C} & 1 \mathrm{~min} \\
74^{\circ} \mathrm{C} & 2 \mathrm{~min} \\
74^{\circ} \mathrm{C} & 5 \mathrm{~min}
\end{array}\right.
$$

\section{PCR Ansatz:}

Pfu-Puffer (10x)

template DNA (tthi77)

Primer $(100 \mathrm{pmol} / \mu \mathrm{l})$

DMSO

dNTP-Mix (2 mM)

$\mathrm{Pfu}$-Polymerase

$\mathrm{H}_{2} \mathrm{O}_{\text {bidest. }}$

$$
\begin{array}{r}
5 \mu \mathrm{l} \\
0,2 \mu \mathrm{l} \\
\text { je } 5 \mu \mathrm{l} \\
5 \mu \mathrm{l} \\
5 \mu \mathrm{l} \\
0,5 \mu \mathrm{l} \\
\text { ad } 50 \mu \mathrm{l}
\end{array}
$$

Das PCR-Produkt wurde gereinigt und durch PCR mit Taq-Polymerase ein A-Überhang angefügt (s. II.4.3.2 und II.4.5.3). Das so modifizierte Amplifikat wurde in den Vektor pDrive ligiert. E. coli XL1-blue wurde mit dem Ligationsprodukt transformiert, und positive Klone wurden nach Anzucht auf Selektionsmedium durch Blau-Weiß-Screening und Restriktionanalyse identifiziert. Aus einem positiven Klon wurde nach Anzucht in $5 \mathrm{ml}$ Flüssigmedium das Konstrukt pDrive::TT-AB isoliert. Das Insert wurde mit NdeI und HindIII herausgeschnitten und in den ebenfalls mit NdeI und HindIII verdauten Vektor pET21c ligiert. Eine Karte des konstruierten Vektors ist in Abb. 58 dargestellt. E. coli XL1-blue wurde mit dem Ligationskonstrukt transformiert, und positive Klone wurden nach Anzucht auf Selektionsmedium mit PCR und Restriktionsanalyse identifiziert. Das Konstrukt pET21c::TTAB wurde isoliert und zur Überexpression in E. coli BL21 (DE3) transformiert.

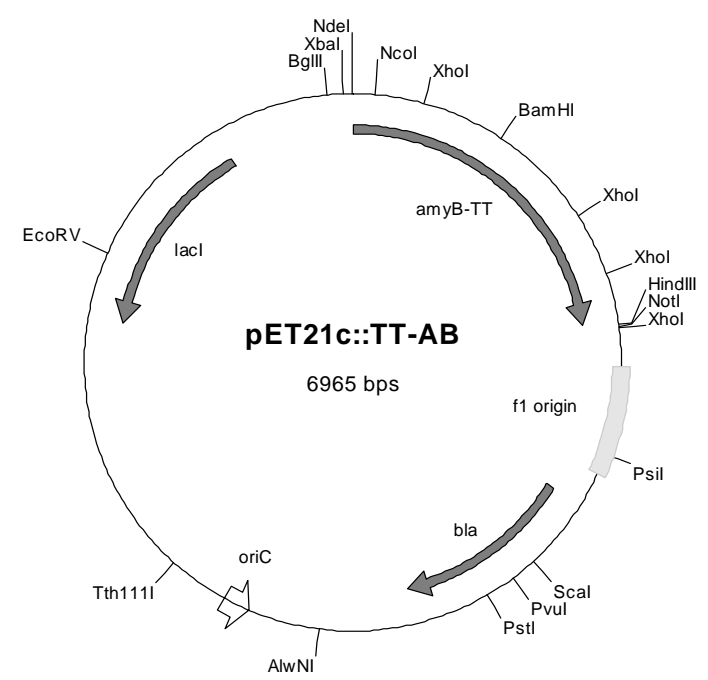

Abb. 58: Karte des konstruierten pET21c::TT-AB Vektors. 


\subsection{Expressionsvorversuch}

Die Expression von AmyB-Tt in E. coli BL21 (DE3) bei Wachstum über Nacht und Induktion mit 0,5 mM IPTG war nur schwach. Daher wurde der E. coli Stamm Rosetta2 (DE3), der sieben in E. coli selten vorkommende tRNAs auf einem zusätzlichen Plasmid (pRARE) trägt, mit dem Plasmid pET21c::TT-AB transformiert. Die Expression von AmyB-Tt war hier deutlich stärker (Abb. 59).

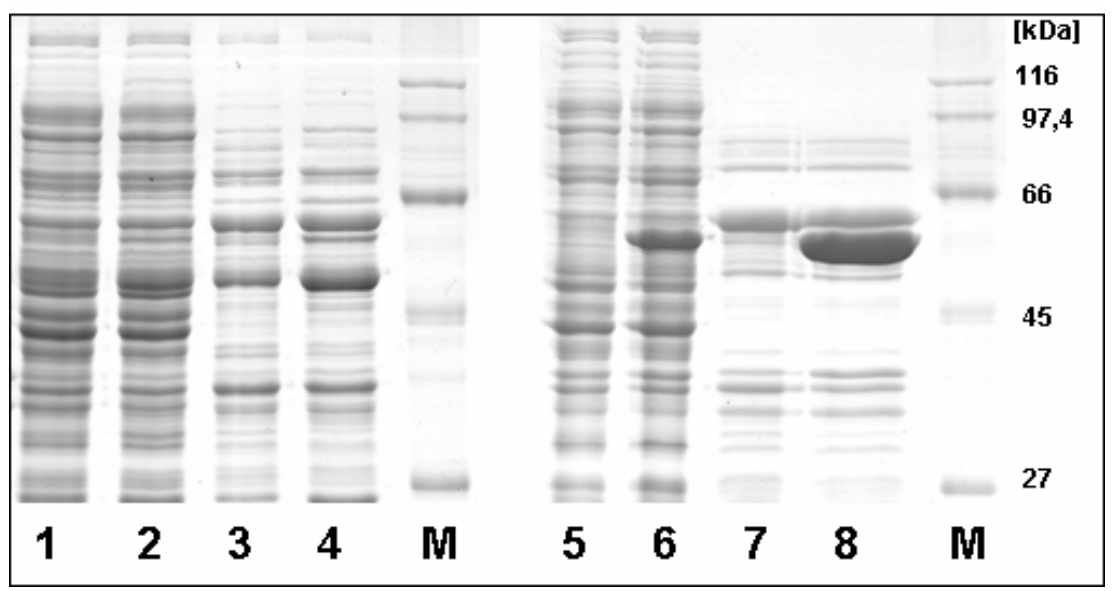

Abb. 59: SDS-PAGE Vergleich der heterologen AmyB-Tt Expression in E. coli BL21 (DE3) und Rosetta 2 (DE3). M, Molekularmassenstandard; Spur 1 und 2, Rohextrakt von E. coli BL21 (DE3)/pET21c::TT-AB -/+ 0,5 mM IPTG; Spur 3 und 4, hitzedenaturierter Rohextrakt $\left(20\right.$ min, $\left.50{ }^{\circ} \mathrm{C}\right)$ des gleichen Klons -/+ 0,5 mM IPTG; Spur 5 und 6, Rohextrakt von E. coli Rosetta2 (DE3)/pET21c::TT-AB -/+ 0,1 mM IPTG; Spur 7 und 8, hitzedenaturierter Rohextrakt (20 min, $65^{\circ} \mathrm{C}$ ) des gleichen Klons -/+ 0,1 mM IPTG.

\subsection{Anzucht und Aufreinigung}

Zur Aufreinigung des rekombinanten Enzyms wurde eine Flüssigkultur mit einem Volumen von 2x 1,5 $\mathrm{l}$ aus einer Vorkultur 2 \%ig beiimpft und, wie unter II.3.2.1 beschrieben, kultiviert. Bei einer $\mathrm{OD}_{600}$ von $\sim 0,7$ wurde die Kultur mit 0,1 mM IPTG induziert und für $4 \mathrm{~h}$ weiterinkubiert. Das Naßgewicht des geernteten Zellpellets betrug 1,2 g/l. Nach Resuspension in 20 mM Tris pH 8,0 wurden die Zellen mit der French Pressure Cell aufgeschlossen. Durch eine Hitzefällung für 20 min bei $65^{\circ} \mathrm{C}$ konnte ein Großteil der mesophilen E. coli-Proteine entfernt werden. Der hitzedenaturierte Rohextrakt wurde über Nacht gegen 20 mM Tris (pH 8,0) dialysiert und anschließend einer Anionenaustausch-Chromatographie mit einer Source 30Q-Säule unterzogen. Die Fraktionen wurden auf ihren Proteingehalt und ihre amylolytische Aktivität (DNSA-Test, II.7.1) überprüft. Nach gelelektrophoretischer Kontrolle der Reinheit des Proteins wurden die Fraktionen 7-9 vereinigt, gegen $20 \mathrm{mM}$ Tris (pH 8,0) 
dialysiert und auf ein Volumen von $1 \mathrm{ml}$ eingeengt. Tab. 13 zeigt die Parameter des Säulenlaufs, Abb. 60 das Chromatogramm.

Tab. 13: Parameter des Source 30Q-Säulenlaufs.

\begin{tabular}{ll}
\hline Parameter & \\
\hline Medium: & SOURCE 30Q \\
Säule: & HR10/10 \\
Säulenvolumnen: & $8,25 \mathrm{ml}$ \\
Probe: & $\sim 47 \mathrm{mg}$ Protein \\
Puffer A: & $20 \mathrm{mM}$ Tris $(\mathrm{pH}$ 8,0) \\
Puffer B: & $20 \mathrm{mM}$ Tris $(\mathrm{pH}$ 8,0) $+1000 \mathrm{mM} \mathrm{NaCl}$ \\
Flußrate: & $2 \mathrm{ml} / \mathrm{min}$ \\
Fraktionsgöße: & $3 \mathrm{ml}$ \\
Equilibrierung: & $3 \mathrm{SV}$ Puffer B, 10 SV Puffer A \\
Gradient: & $0-100 \%$ Puffer B (20 CV) \\
\hline
\end{tabular}

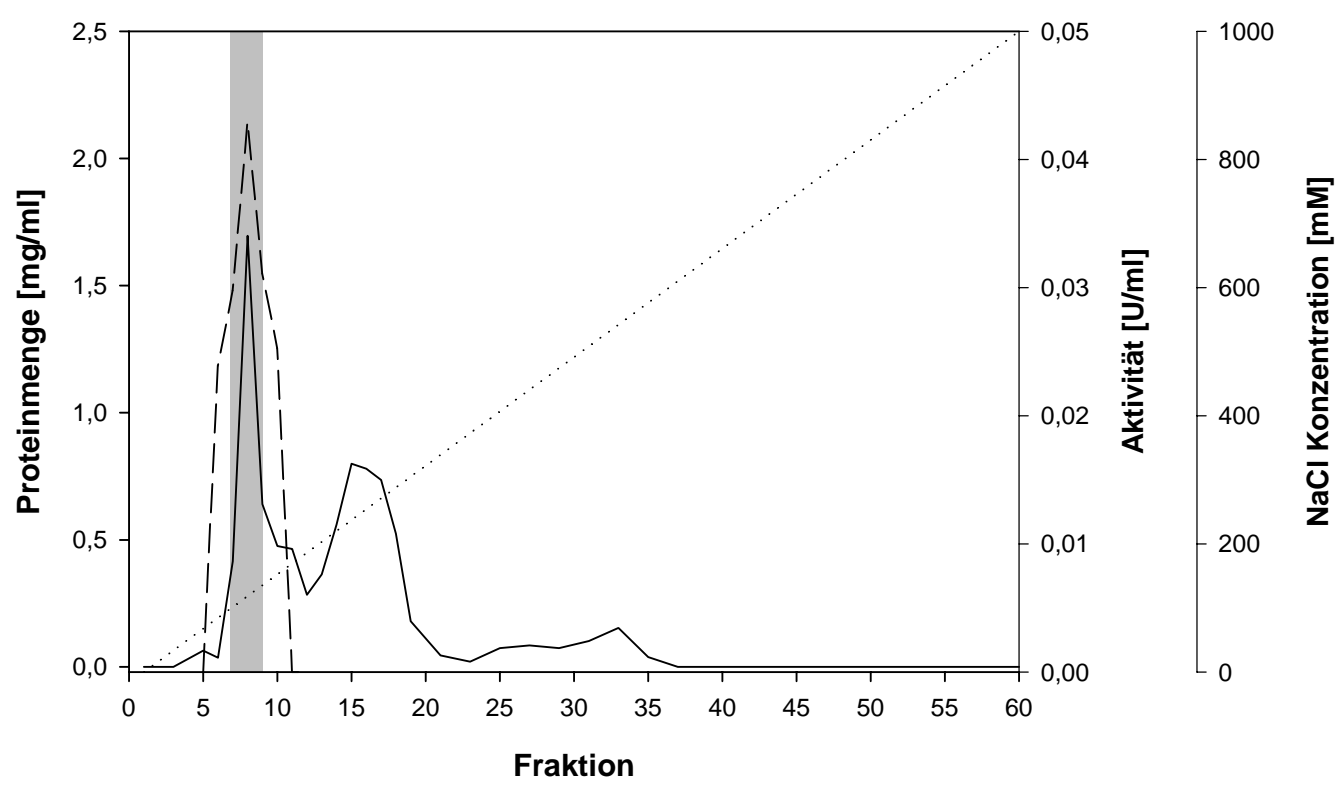

Abb. 60: Chromatogramm des Source 30Q-Säulenlaufs zur Aufreinigung des rekombinanten AmyB-Tt-Proteins. Die durchgezogene Linie stellt die Proteinkonzentration in den Fraktionen dar, die die gestrichelte Linie die Aktivität und die gepunktete Linie die NaCl-Konzentration des Gradienten. Die gepoolten Fraktionen sind grau hinterlegt.

Die spezifische Aktivität des gereinigten Enzyms betrug 0,04 U/mg, gemessen im DNSATest mit $1 \mathrm{mM}$ DTT bei $70{ }^{\circ} \mathrm{C}$ für $45 \mathrm{~min}$. Wie aus Tab. 14 ersichtlich ist, betrug die spezifische Aktivität des hitzegefällten Rohextrakts 0,06 U/mg. Beim säulenchromatographischen Reinigungsschritt ging also spezifische Aktivität verloren, obwohl die 
Reinheit des Proteins zunahm (Abb. 61). Möglicherweise wurden bei diesem Reinigungsschritt zumindest Teile eines für die Aktivität des Enzyms essentiellen Cofaktors abgetrennt. Insgesamt konnten aus 3,6 g Zellen 6,8 mg reines rekombinantes Protein mit einer spezifischen Aktivität von 40 mU/mg gewonnen werden.

Tab. 14: Bilanz der Präparation des rekombinanten AmyB-Tt aus E. coli Rosetta 2 (DE3). Die Bestimmung der Aktivität erfolgte durch DNSA-Test mit löslicher Stärke für $45 \mathrm{~min}$ mit $50 \mathrm{mM}$ Tris $\mathrm{pH} 8,0$ und $1 \mathrm{mM}$ DTT bei $70{ }^{\circ} \mathrm{C}$.

\begin{tabular}{cccccc}
\hline & $\begin{array}{c}\text { Protein } \\
\text { [mg] }\end{array}$ & $\begin{array}{c}\text { Gesamtaktivität } \\
\text { [U] }\end{array}$ & $\begin{array}{c}\text { spezifische } \\
\text { Aktivität } \\
{[\mathbf{U} / \mathbf{m g}]}\end{array}$ & $\begin{array}{c}\text { Anreiche- } \\
\text { rungsfaktor }\end{array}$ & $\begin{array}{c}\text { Ausbeute } \\
\text { [\%] }\end{array}$ \\
\hline $\begin{array}{c}\text { Rohextrakt } \\
\text { hitzdenaturierter }\end{array}$ & 282,2 & 2,54 & 0,009 & 1,0 & 100 \\
Rohextrakt & 47,5 & 2,85 & 0,060 & 6,7 & 114 \\
Source 30Q Pool & 6,8 & 0,22 & 0,038 & 4,2 & 8,5 \\
\hline
\end{tabular}

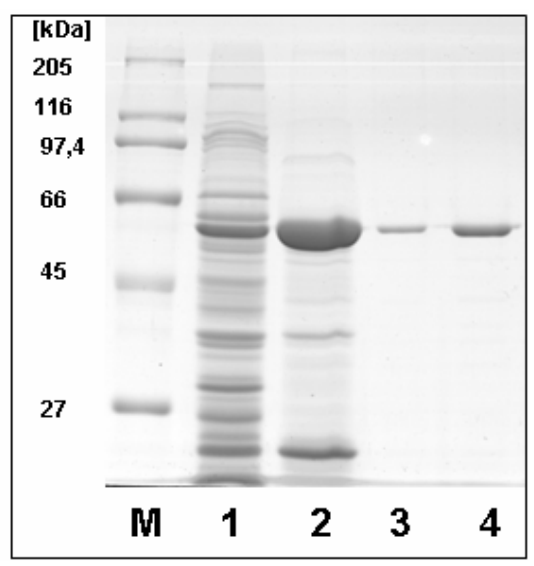

Abb. 61: SDS-PAGE Gel der Reinigungsschritte von AmyB-Tt. M, Molekularmassenstandard; Spur 1, Rohextrakt von E. coli Rosetta 2 (DE3)/pET21c::TT-AB (35 $\mu \mathrm{g})$; Spur 2, hitzedenaturierter Rohextrakt (17 $\mu \mathrm{g})$; Spur 3, Source 30Q Pool $(1 \mu \mathrm{g})$; Spur 4, Source 30Q Pool $(2,5 \mu \mathrm{g})$.

\subsection{Biochemische Charakterisierung von AmyB-Tt}

Durch Vorversuche wurde festgestellt, daß die Aktivität des rekombinanten Enzyms in TrisPuffer $\left(\mathrm{pH}\right.$ 8,0) bei $65{ }^{\circ} \mathrm{C}$ und einer Inkubationszeit von $1 \mathrm{~h}$ etwa dreimal höher war als in MacIlvaine-Puffer desselben pH-Werts. Diese Aktivität ließ sich durch Zugabe von DTT weiter steigern, weshalb der Einfluß von DTT auf die Aktivität im DNSA-Test mit löslicher Stärke genauer untersucht wurde (Abb. 62). Die höchste gemessene Aktivität wurde bei einer DTT-Konzentration von 1 mM im Reaktionsansatz erreicht. 


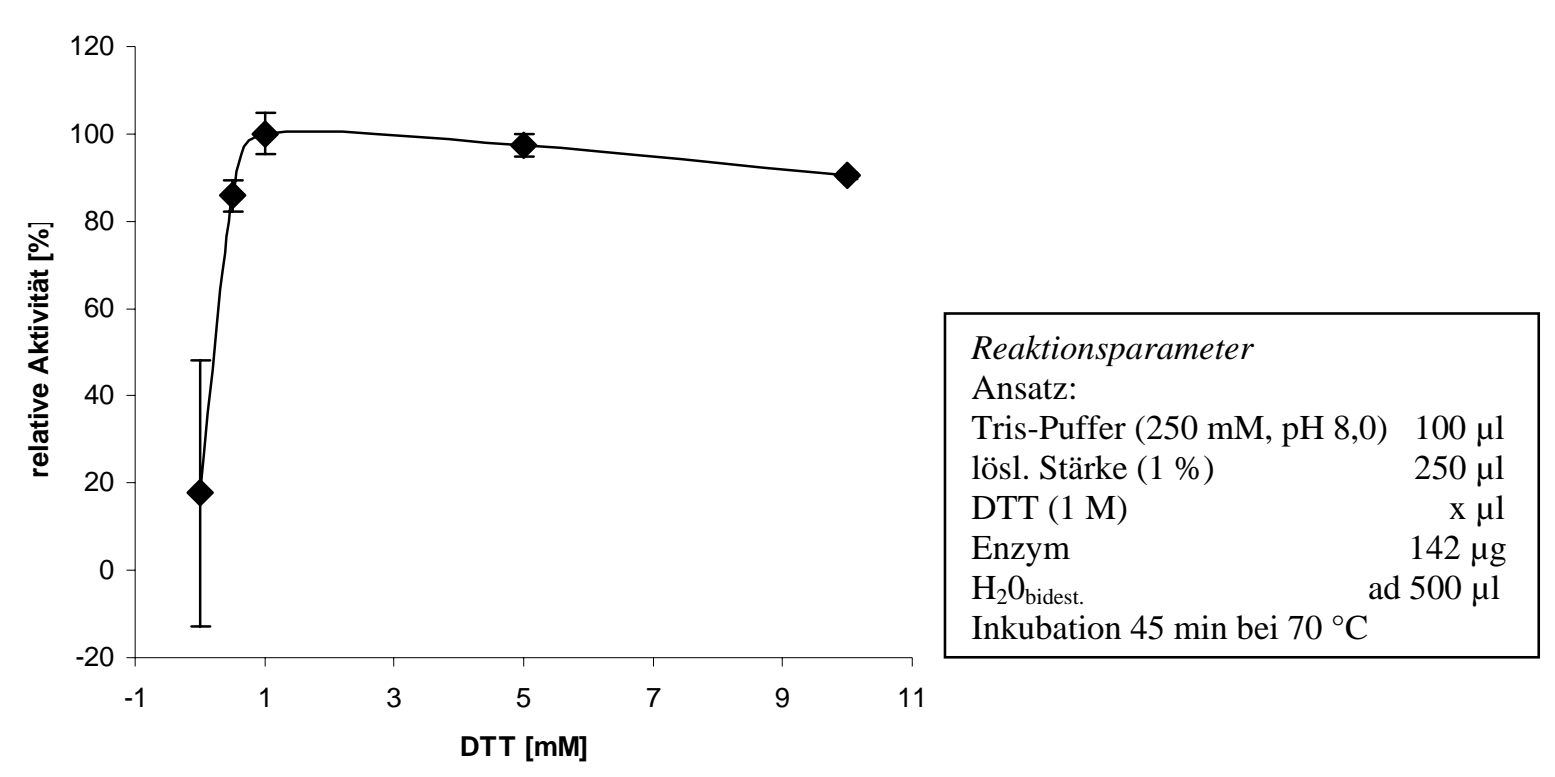

Abb. 62: Einfluß der DTT-Konzentration im Ansatz auf die Aktivität von AmyB-Tt. Dargestellt ist die relative Aktivität, bezogen auf den höchsten Wert der Meßreihe.

Der Einfluß der Temperatur auf die Aktivität von AmyB-Tt wurde im Bereich von 50 bis $90{ }^{\circ} \mathrm{C}$ ebenfalls mit löslicher Stärke im DNSA-Test ermittelt. Wie aus Abb. 63 zu entnehmen ist, erreichte AmyB-Tt ein Maximum an Aktivität zwischen 70 und $80^{\circ} \mathrm{C}$.

Die Abhängigkeit der Enzymaktivität vom pH-Wert des Reaktionsansatzes wurde von pH 5,5 bis $\mathrm{pH}$ 9,0 bestimmt. Als geeignete Puffer wurden im pH-Bereich von 5,5 bis 7,0 PIPES und im pH-Bereich von 7,0 bis 9,0 Tris gewählt. Der den gesamten pH-Bereich abdeckende MacIlvaine-Puffer wurde nicht verwendet, weil dieser die Aktivität von AmyB-Tt stark herabsetzte. Der pH-Wert aller Puffer wurde bei $70{ }^{\circ} \mathrm{C}$ titriert. Abb. 64 zeigt, daß die maximale Aktivität des rekombinanten Enzyms bei pH 6,5 in PIPES-Puffer erreicht wird. 


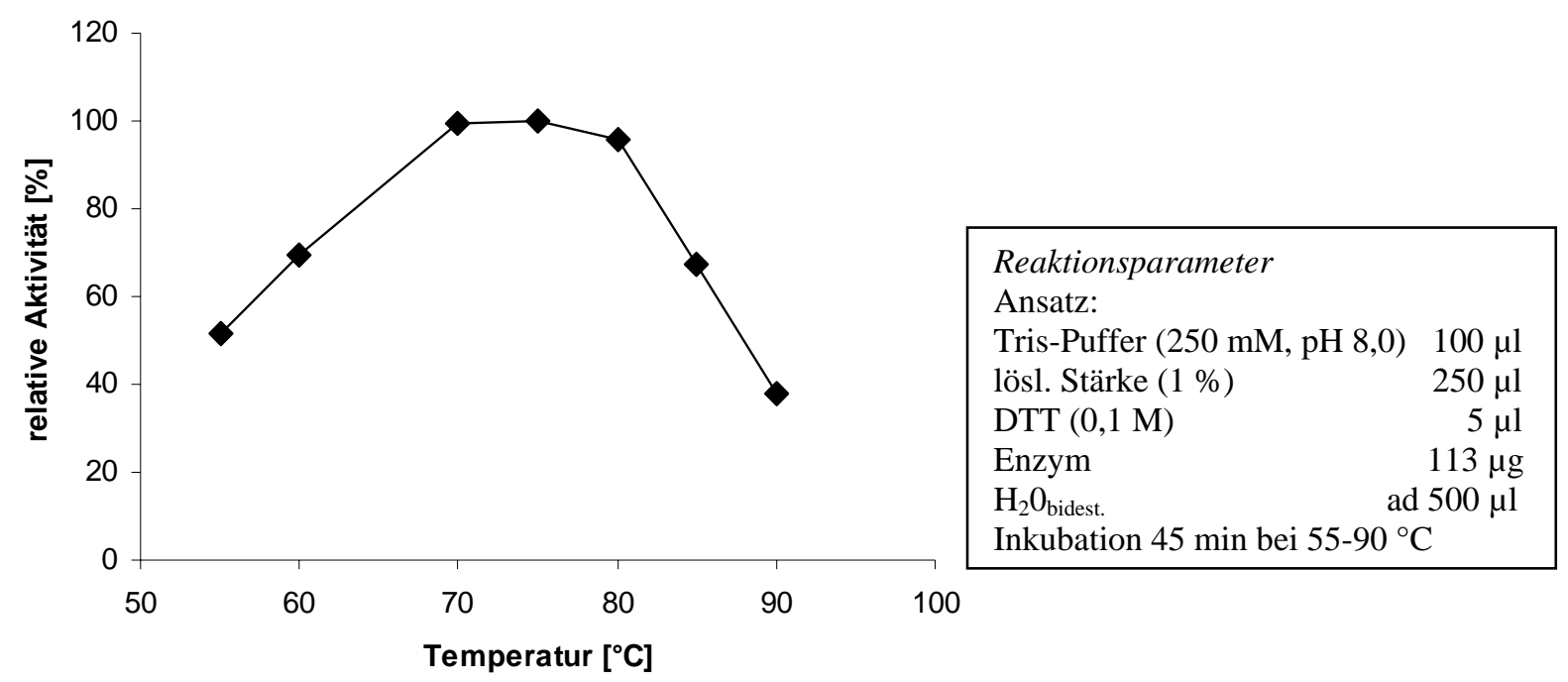

Abb. 63: Abhängigkeit der enzymatischen Aktivität von AmyB-Tt von der Reaktionstemperatur. Dargestellt ist die relative Aktivität, bezogen auf den höchsten Wert der Meßreihe.

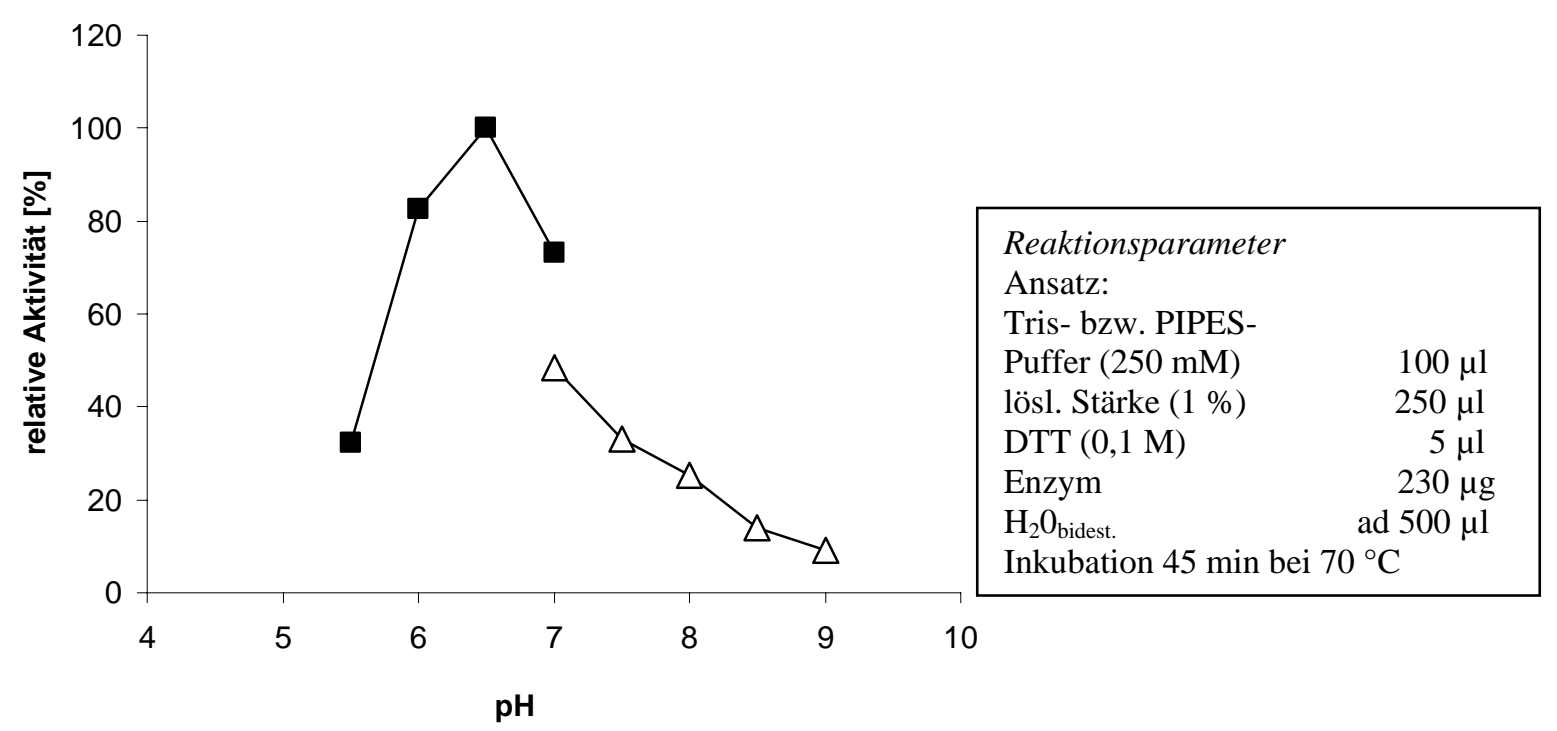

Abb. 64: Abhängigkeit der enzymatischen Aktivität von AmyB-Tt vom pH-Wert. Die ausgefüllten Quadrate stellen die Messungen mit PIPES-Puffer dar, die weißen Dreiecke die Messungen mit Tris-Puffer. Dargestellt ist die relative Aktivität, bezogen auf den höchsten Wert der Meßreihe. Alle Messungen wurden als Mehrfachbestimmungen durchgeführt. 


\section{Untersuchungen der $\alpha$-Amylasen AmyA und AmyB aus Anaerobranca gottschalkii}

Über die $\alpha$-Amylasen aus Anaerobranca gottschalkii liegen bereits Daten aus anderen Arbeiten vor (Ballschmiter, 2001; Ivanonva, mündl. Miteilung). Im Folgenden werden die im Rahmen dieser Dissertation neu hinzugewonnenen Ergebnisse dargestellt. Ältere Daten werden, wo sie dem besseren Gesamtverständnis dienen, in knapper Form wiedergegeben.

Das thermoalkaliphile Bakterium A. gottschalkii besitzt zwei $\alpha$-Amylasen, von denen eine als Lipoprotein vermutlich extrazellulär (AmyA-Ag) und eine im Cytoplasma (AmyB-Ag) lokalisiert ist. AmyA-Ag ließ sich zusammen mit der ebenfalls extrazellulären CGTase im Überstand von A. gottschalkii-Kulturen nachweisen. Im A. gottschalkii-Rohextrakt ließ sich AmyB-Ag als einziges amylolytisches Enzym nachweisen (Abb. 65).

a

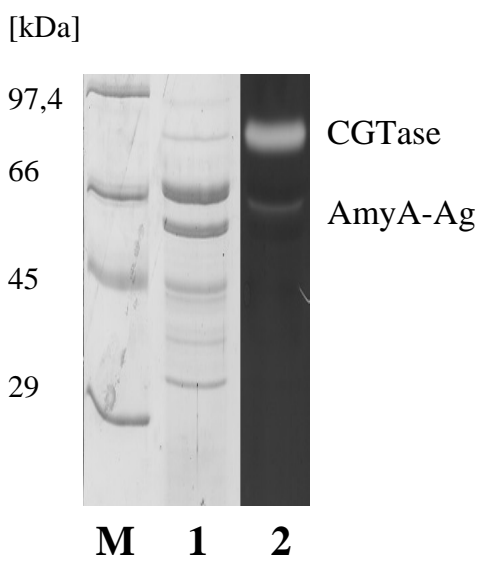

b

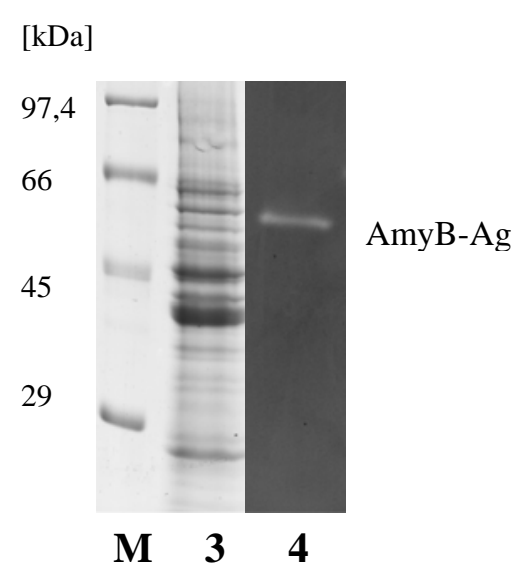

Abb. 65: SDS-PAGE-Gel und Aktivitätsfärbung mit a) dem Überstand und b) dem Rohextrakt einer A. gottschalkii-Kultur. M, Molekularmassenstandard; Spur 1, eingeengter Überstand von A. gottschalkii; Spur 3, Stärke-Aktivitätsfärbung; Spur 3, Rohextrakt von A. gottschalkii, Spur 4, StärkeAktivitätsfärbung. (a) nach Armbrecht, 2003, modifiziert.)

Die Enzyme, die beide mit einem Endomechanismus Stärke spalten, haben eine hohe Aminosäuresequenz-Ähnlichkeit zur GH-Familie 13, in der sich die meisten bekannten $\alpha$ Amylasen befinden. In ihren pH-Optima und Temperaturspektren unterscheiden sie sich jedoch (Ballschmiter et al., 2005). Die extrazelluläre $\alpha$-Amylase (AmyA-Ag) ist in einem Bereich von pH 6,0 bis 9,5 mit einem Optimum bei pH 8,0 aktiv. Das Maximum der enzymatischen Aktivität wird bei $70{ }^{\circ} \mathrm{C}$ erreicht. Die intrazelluläre Amylase dagegen ist in einem wesentlich kleinerem $\mathrm{pH}$-Bereich aktiv ( $\mathrm{pH}$ 5,5-6,5) und hat ein $\mathrm{pH}$-Optimum bei pH 6,0. AmyB-Ag zeigte auch gegenüber hohen Temperaturen eine erheblich geringere 
Toleranz. Die maximale Aktivität des Enzyms wurde bei $55^{\circ} \mathrm{C}$ erreicht (Abb. 66). Bei $70{ }^{\circ} \mathrm{C}$, der Temperatur, bei der AmyA-Ag die maximale Aktivität erreicht, trat bei AmyB-Ag bereits nach 10 min ein Aktivitätsverlust von 50 \% ein, während AmyA-Ag bei dieser Temperatur eine Halbwertszeit von 48 h hatte (ohne Abbildung).
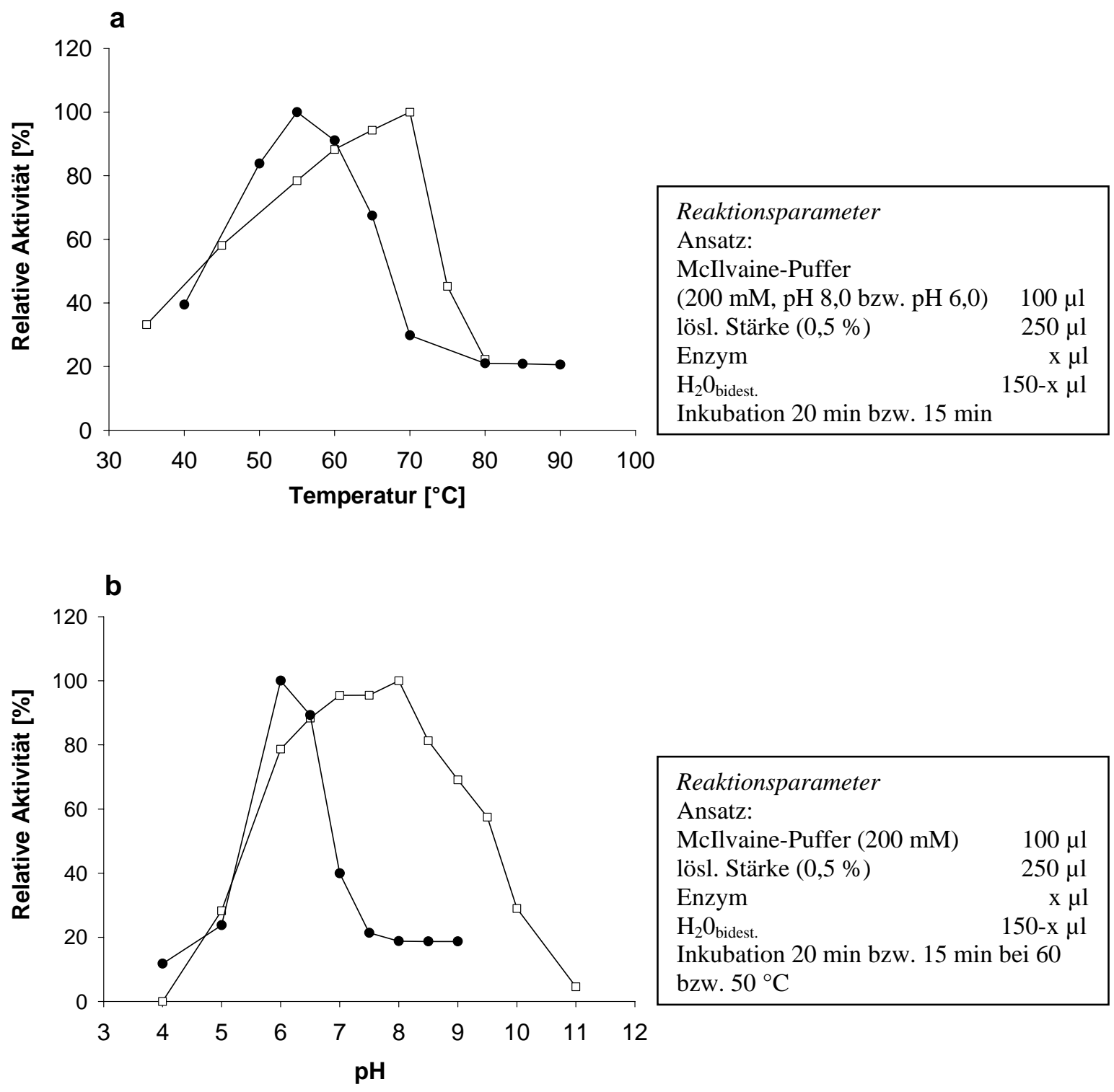

Reaktionsparameter

Ansatz:

McIlvaine-Puffer (200 mM) $\quad 100 \mu \mathrm{l}$ lösl. Stärke (0,5\%) $250 \mu \mathrm{l}$

Enzym

$\mathrm{H}_{2} \mathrm{O}_{\text {bidest. }}$

Inkubation 20 min bzw. 15 min bei 6

bzw. $50^{\circ} \mathrm{C}$

Abb. 66: a) Temperatur- und b) pH-Abhängigkeit der Aktivität von AmyA-Ag (weiße Rauten) und AmyB-Ag (schwarze Quadrate). Dargestellt ist die relative Aktivität, bezogen auf den höchsten Wert der Meßreihe. Alle Messungen wurden als Mehrfachbestimmungen durchgeführt. (Ballschmiter et al., im Druck, modifiziert)

AmyA-Ag zeigte die höchste Aktivität (52 U/mg) in Mcllvaine-Puffer. In HEPES- und TrisPuffer erreichte das Enzym nur etwa 80 \% der Aktivität. $\mathrm{Ca}^{2+}$-Ionen stimulierten die Aktivität von AmyA-Ag. Dieser Effekt konnte in McIlvaine-Puffer nicht beobachtet werden, da hier die $\mathrm{Ca}^{2+}$-Ionen von dem im Puffer enthaltenen Citrat komplexiert werden (Abb. 67). 
Im Standard-DNSA-Test (s. II.7.1) mit MacIlvaine- und HEPES-Puffer konnte keine Hemmung der AmyA-Ag-Aktivität durch EDTA festgestellt werden. In Tris-Puffer dagegen wurde die Aktivität der $\alpha$-Amylase durch Zusatz von 5 mM EDTA auf etwa $40 \%$ gesenkt. Der Zusatz von 10 mM EDTA hatte eine vollständige Hemmung der Enzymaktivität zur Folge. Dabei spielte es keine Rolle, ob der Testansatz mit EDTA präinkubiert wurde, oder ob das EDTA direkt zum Reaktionsansatz gegeben wurde (Abb. 67). Möglicherweise wird das Enzym durch Tris-Puffer destabilisiert, so daß im Protein gebundenes Kalzium für den Chelator leichter zugänglich ist. Der durch den Zusatz von 5 mM EDTA eingetretene Aktivitätsverlust konnte durch Zusatz von $10 \mathrm{mM} \mathrm{Ca}^{2+}$ vollständig aufgehoben werden (ohne

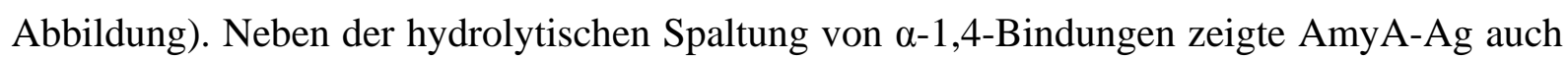
$\alpha$-4-Glukanotransferase-Aktivität, bei der außer linearen Maltodextrinen auch $\beta$-Cyclodextrin entstand. Die spezifische Aktivität der $\beta$-Cyclodextrinbildung durch AmyA-Ag lag bei 0,3 U/mg (Ballschmiter et al., 2005).

\begin{tabular}{|lr|}
\hline Reaktionsparameter & \\
Ansatz: & \\
McIlvaine- bzw. HEPES- & \\
bzw. Tris-Puffer $(250 \mathrm{mM})$ & $100 \mu \mathrm{l}$ \\
lösl. Stärke $(1 \%)$ & $250 \mu \mathrm{l}$ \\
Enzym & $1 \mu \mathrm{g}$ \\
EDTA $(50 \mathrm{mM})$ & $10 / 20 \mu \mathrm{l}$ \\
$\mathrm{CaCl}_{2}(100 \mathrm{mM})$ & $5 \mu \mathrm{l}$ \\
$\mathrm{H}_{2} 0_{\text {bidest. }}$ & ad $500 \mu \mathrm{l}$ \\
Inkubation 20 min bei $60^{\circ} \mathrm{C}$ & \\
\hline
\end{tabular}

a

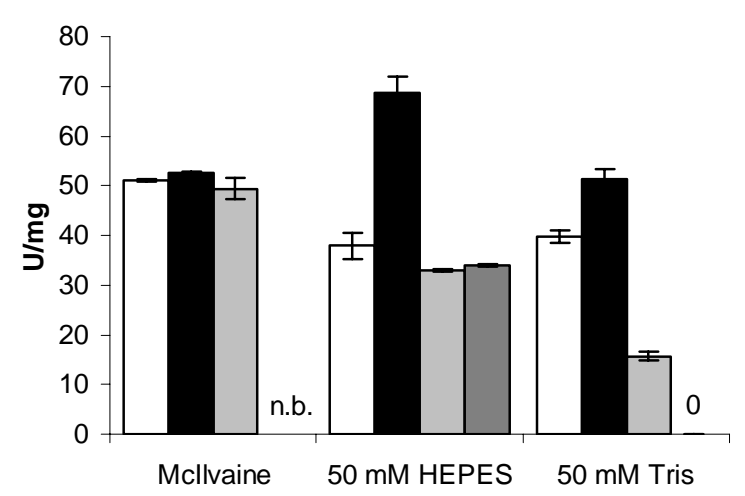

b

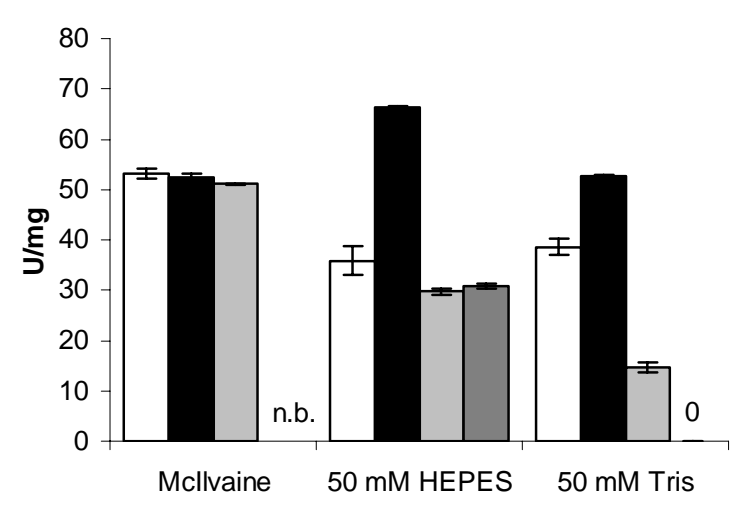

Abb. 67: Einfluß von $\mathrm{Ca}^{2+}$ und EDTA auf die Aktivität von AmyA-Ag a) ohne Präinkubation und b) nach 1 h Präinkubation bei $60{ }^{\circ} \mathbf{C}$ ohne Substrat. Weiße Balken, ohne Zusatz; schwarze Balken, mit $5 \mathrm{mM} \mathrm{CaCl}$; hellgraue Balken, mit $5 \mathrm{mM}$ EDTA; dunkelgraue Balken, mit $10 \mathrm{mM}$ EDTA; n.b.,Wert nicht bestimmt. Alle Messungen wurden als Mehrfachbestimmungen durchgeführt. 


\section{Diskussion}

Das Bakterium Thermotoga maritima weist in seinem Genom den höchsten bisher bekannten prozentualen Anteil an Genen auf, die für Kohlenhydrat-modifizierenden und -abbauenden Enzyme kodieren. Allein der Prozentsatz der für diese Arbeit relevanten Glykosid-Hydrolasen übersteigt den anderer Prokaryoten bei weitem. Die biochemischen Charakteristika vieler dieser Enzyme wurden in den letzten Jahren aufgeklärt, aber die physiologische Rolle der überwiegenden Mehrheit der Proteine liegt noch immer im Dunkeln. T. maritima besitzt mit AmyA-Tm (extrazellulär), AmyB-Tm (intrazellulär) und AmyC-Tm (intrazellulär) drei Enzyme, die zu den mechanistisch gut untersuchten $\alpha$-Amylasen gehören (Liebl et al., 1997; Fütterer, 2001). Die Enzymklasse der $\alpha$-Amylasen (EC 3.2.1.1) greift $\alpha$-1,4-glykosidische Bindungen in aus Glukose-Einheiten bestehenden Poly- und Oligosacchariden ( $\alpha$-Glukanen) mit einem Endo-Mechanismus, d.h. an einer beliebigen Stelle des Moleküls, an. So werden Maltodextrine von variierender Länge hydrolytisch vom Substrat abgespalten. Anaerobranca gottschalkii besitzt zwei $\alpha$-Amylasen, AmyA-Ag (extrazellulär) und AmyB-Ag (intrazellulär) (Prowe, 1996). In Thermus thermophilus konnte dagegen noch kein einziges für eine $\alpha$ Amylase kodierendes Gen gefunden werden (Henne et al., 2004).

\section{Die intrazelluläre $\alpha$-Amylase AmyB-Tm aus Thermotoga maritima}

\subsection{Biochemische Untersuchungen von AmyB-Tm und AmyB-Tt}

Das rekombinante AmyB-Tm-Enzym hydrolysiert als bevorzugte Substrate Amylose und lösliche Stärke, aber auch Amylopektin und $\beta$-Grenzdextrin werden abgebaut. Die Abbauprodukte sind Glukose, Maltose und Maltooligosaccharide. Maltodextrine mit einer Länge von drei und mehr Glukoseeinheiten werden ebenfalls hydolysiert, während Glykogen und $\beta$-Cyclodextrin nur mit geringer Effizienz abgebaut werden. Als Hauptprodukt bei der Hydrolyse gradzahliger Maltooligosaccharide entsteht Maltose, die von diesem Enzym nicht weiter gespalten wird. Somit kann eine $\alpha$-Glukosidase-Aktivität des Enzyms ausgeschlossen werden. Weiterhin stellen Panose und Isomaltose keine Substrate für AmyB-Tm dar. Dies belegt, in Übereinstimmung mit der Unfähigkeit Pullulan abzubauen, daß $\alpha$-1,6-glykosidische Bindungen nicht von AmyB-Tm gespalten werden können. Aufgrund der spezifischen Spaltung von intramolekularen $\alpha$-1,4-glykosidischen Bindungen wurde AmyB-Tm als $\alpha$ Amylase charakterisiert. Die höchste Aktivität des Enzyms wurde mit löslicher Stärke als Substrat bei $90^{\circ} \mathrm{C}$, pH 8,5 und einem Zusatz von 10 mM DTT ermittelt (Fütterer, 2001). 
Das rekombinant aus E. coli BL21(DE3)/pET21c::TT-AB aufgereinigte AmyB-Tt-Protein, dessen Aminosäuresequenz 32 \% Identität mit der von AmyB-Tm aufweist, erreichte sein Aktivitätsmaximum mit löslicher Stärke als Substrat bei $70{ }^{\circ} \mathrm{C}, \mathrm{pH}$ 6,5 und dem Zusatz von $1 \mathrm{mM}$ DTT (s. III.9.5). Das Maximum an Aktivität von AmyB-Tt liegt damit etwa im Temperaturbereich des Wachstumsoptimums von T. thermophilus, der aerob bei $75{ }^{\circ} \mathrm{C}$ und pH 7,0 wächst (Oshima und Imahori, 1974). AmyB-Tm dagegen erreicht sein Maximum an Aktivität bei $90{ }^{\circ} \mathrm{C}$, und liegt damit ebenfalls im Wachstumsbereich von T. maritima (Huber et al., 1986). Trotz ihrer Struktur- und Sequenzähnlichkeit unterscheiden sich die Enzyme demnach in ihren physikochemischen Charakteristika, was als evolutionäre Anpassung der Enzyme an die Lebensumstände der Organismen gedeutet werden kann.

In kinetischen Experimenten mit löslicher Stärke als Substrat wurde für AmyB-Tm eine maximale Geschwindigkeit ( $V_{\max }$ ) von 1,3 U/mg und ein $K_{\mathrm{m}}$-Wert von 1,1 mg/ml bestimmt (s. III.3.1.2). Im Kontrast dazu stehen von Fütterer (2001) ermittelte Werte für $V_{\max }$ von $25 \mathrm{U} / \mathrm{mg}$ und $K_{\mathrm{m}}$ von $8,7 \mathrm{mg} / \mathrm{ml}$. Im Verlauf dieser Arbeit zeigte die Aktivität des aufgereinigten Enzyms je nach Charge starke Schwankungen; es wurden spezifische Aktivitäten von 0,2 bis 0,6 U/mg gemessen. Fütterer erzielte spezifische Aktivitäten von bis zu 5 U/mg.

Offenbar liegt AmyB-Tm nach der Aufreinigung in einem nicht optimalen Zustand vor. SDSPAGE-Analysen von Zellfraktionen nach dem Aufschluß zeigten, daß ein ungewöhnlich hoher Anteil an unlöslichem Protein im Zellpellet vorlag (s. III.2.1. und III.2.2). Dies deutet auf Schwierigkeiten bei der Faltung des rekombinanten Proteins hin. Möglicherweise liegt auch ein Teil des löslichen Proteins in einer falschen Konformation vor. Für gewöhnlich werden thermophile Proteine in mesophilen Bakterien korrekt gefaltet, was diese zu geeigneten, weil einfach zu handhabenden, heterologen Wirten macht (Bertoldo und Antranikian, 2001). Auch das mesophile, AmyB-homologe Protein aus Anabaena sp., das von Arthur (2003) in E. coli exprimiert wurde, lag vollständig in unlöslicher Form vor. Dies spricht dafür, daß die Ursache für die Instabilität von AmyB-Tm nicht in der Thermophilie des Proteins, sondern im heterologen Expressionssystem zu suchen ist. Ein Wechsel des Expressionswirtes von E. coli zu C. glutamicum konnte jedoch die Aktivität von AmyB-Tm nicht erhöhen (s. III.2.4). Eine Ursache für die große Empfindlichkeit von AmyB-Tm gegenüber hohen Expressionsraten könnte sein, daß das Protein in T. maritima auf besondere Faltungshelfer angewiesen ist, die es in heterologen Wirtsystemen nicht vorfindet.

Möglicherweise fehlt dem Protein auch ein für die Aktivität nötiger Cofaktor, der entweder im heterologen Wirt gar nicht oder nur in zu geringem Umfang bereitgestellt wird, oder der während der Aufreinigung des Proteins verloren geht. Die Aktivität von sauberem AmyB-Tm 
ließ sich nicht mit E. coli-Rohextrakt steigern, wie dies z.B. bei der $\alpha$-Glukosidase AglA aus T. maritima möglich war. Bei der Aufreinigung von AglA waren für die Enzym-Aktivität wichtige Cofaktoren verloren gegangen, die jedoch durch Zugabe von E. coli-Zellextrakt komplementiert werden konnten (Raasch, 2001). Sollte AmyB-Tm ein Cofaktor für die Aktivität fehlen, wird dieser entweder im Expressionswirt nur unter bestimmten Wachstumsbedingungen in ausreichender Menge hergestellt, oder er kann, einmal aus dem Protein entfernt, nicht wieder zugeführt werden.

Gleiches gilt für AmyB-Tt. Die gemessene Aktivität ist mit $40 \mathrm{mU} / \mathrm{mg}$ ist im Vergleich mit anderen intrazellulären $\alpha$-Amylasen sehr gering, so daß auch hier ein nicht optimaler Zustand des Proteins nach der Aufreinigung nahe liegt (vergl. IV.1.7, Tab. 15). Da beide Enzyme intrazellulär lokalisiert sind, ist eine Aktivität, wie sie bei extrazellulären $\alpha$-Amylasen beobachtet wurde, nicht zu erwarten. Solche Aktivitäten können durchaus im Bereich von 5600 U/mg liegen, wie für die native AmyA aus T. maritima gezeigt wurde (Liebl et al., 1997). Während der Zweck extrazellulärer Amylasen darin liegt, Stärke als Nahrungsquelle möglichst schnell durch Abbau zu erschließen, ist bei einem intrazellulären Enzym eine schnelle, schwer zu steuernde Reaktion nicht von Vorteil. Die je nach Aufreinigung stark schwankende Aktivität von AmyB-Tm deutet jedoch auf Probleme während der Expression oder der Aufreinigung hin.

Im SDS-PAGE-Gel des gereinigten AmyB-Proteins ist neben der AmyB-Hauptbande eine zweite, schwächere Bande zu sehen, unabhängig vom Expressionssystem oder Wirtsorganismus (s. III.2.1 und III.2.4). Da sie oberhalb der Hauptbande läuft, kann es sich nicht um ein Abbauprodukt des Enzyms handeln. Auch Protein, das eine Gelfiltration durchlaufen hatte und dort als Einzelpeak detektiert worden war, erschien in der SDS-PAGE als Doppelbande. Es könnte sich hierbei um vom Expressionswirt modifiziertes Protein handeln. Da jedoch in der Aminosäuresequenz durch Datenbankvergleiche keine Modifikationsstelle gefunden wurde, und die Struktur von AmyB-Tm keine Elektronendichte aufweist, die einer Proteinmodifikation entsprechen würde, erscheint dies unwahrscheinlich. Posttranslational modifizierte Amylasen sind nur aus Eukaryoten bekannt. So liegen z.B. alle drei in Aspergillus awamori identifizierten $\alpha$-Amylasen glykosyliert vor (Anindyawati et al., 1998). Modifizierte, bakterielle Amylasen sind nicht bekannt.

Das Auftreten der Doppelbande beruht möglicherweise auf einer unvollständigen Denaturierung des AmyB-Proteins im SDS-Auftragspuffer. Interessanterweise verändert sich das Verhältnis von Neben- und Hauptbande im Gel dramatisch, wenn AmyB-Tm kristallisiert. Wird der AmyB-Tm Kristall in $\mathrm{H}_{2} \mathrm{O}_{\text {bidest }}$ gelöst und einer SDS-PAGE unterworfen, sind beide 
Banden etwa gleich stark (s. III.3.6, Abb. 35). Dies spricht dagegen, daß es sich bei der Doppelbande um ein reines Denaturierungsartefakt handelt.

Es konnte gezeigt werden, daß sich die Aktivität von AmyB-Tm durch Reduktionsmittel erheblich steigern ließ. Dabei spielte es eine untergeordnete Rolle, ob es sich um das Reduktionsmittel DTT, L-Cystein oder $\beta$-Mercaptoethanol handelte. Entscheidend war offenbar der Redoxzustand des Reaktionsansatzes. Als optimal wurde ein Zusatz von $10 \mathrm{mM}$ DTT ermittelt (s. III.3.2). Eine Abhängigkeit der Aktivität von DTT ist auch von der $\alpha$ Glukosidase AglA aus T. maritima und T. neapolitana bekannt. Beide Enzyme sind Manganabhängig und benötigen eine DTT-Konzentration von 50 mM (Bibel et al., 1998; Raasch, 2001). Auch die Aktivität der $\alpha$-Glukosidase MalA aus T. neapolitana läßt sich durch eine DTT-Konzentration von $10 \mathrm{mM}$ steigern (Veith, 2001). Die Funktion des Reduktionsmittels ist in diesem Fall noch nicht geklärt. Die $\beta$-Glukosidasen aus Bacillus polymyxa und der Nierenrinde der Ratte hingegen werden durch DTT in einer Konzentration von 5 bzw. 10 mM gehemmt (Painbeni et al., 1992; Glew et al., 1976). Auf Enzyme, deren Stabilität auf der Ausbildung von Disulfidbindungen beruht, wirkt DTT durch seine reduzierende Wirkung auf die Cysteinreste destabilisierend und deaktivierend, was z.B. für die Phytase PhyA aus Aspergillus niger nachgewiesen werden konnte (Wang et al., 2004). Da AmyB-Tm zwei Cysteinreste in den Positionen 142 und 186 besitzt, die auch in der COG1543 weitestgehend konserviert sind, wurde vermutet, daß DTT die reaktiven Thiolgruppen vor dem Angriff von Sauerstoff schützt. Beide Cysteine liegen nahe am aktiven Zentrum und könnten eine Rolle bei der Katalyse spielen. Alternativ könnte ihre Oxidation sich negativ auf die Polypeptidstruktur in dieser wichtigen Region auswirken.

Auch die Aktivität von AmyB-Tt ließ sich durch DTT steigern. Allerdings erwies sich hier eine weit geringere Menge von 1 mM DTT als optimal (s. III.9.5). Im Gegensatz zu AmyBTm enthält das Protein aus T. thermophilus keine Cysteinreste. Damit wird die ursprüngliche Annahme, AmyB-Tm brauche DTT, um die beiden im Protein enthaltenen Cysteine in einem reduzierten Zustand zu halten, zumindest teilweise entkräftet. Möglicherweise spielt DTT eine Rolle für den Redoxzustand des im Protein nachgewiesenen Eisen-Cofaktors (vergl. IV.1.6)

\subsection{Abhängigkeit der AmyB-Tm-Aktivität von Metallionen}

AmyB-Tm erwies sich als ungewöhnlich empfindlich gegenüber komplexierenden Agenzien. So wurde bereits durch den Zusatz von 0,1 mM EDTA die Aktivität komplett inhibiert. Die Aktivität konnte durch die Zugabe von $1 \mathrm{mM}$ Kalzium teilweise rekonstituiert werden. 
Generell jedoch hemmte die Anwesenheit von Kalzium oder Magnesium die Aktivität von AmyB-Tm (s. III.9.3). Diese Beobachtung und der Hinweis auf eine oft bei Amylasen beobachtete Kalzium-Abhängigkeit des Enzyms, der sich aus der Rekonstitution der inhibierten Aktivität ergab, scheinen sich zu widersprechen. Offenbar wird durch das EDTA ein anderes, zweiwertiges Metallion aus dem Enzym gelöst, was die Inhibierung des Enzyms zur Folge hat. Es ist vorstellbar, daß durch die Zugabe eines Kalziumüberschusses dieses Metallion zumindest teilweise aus dem Komplex mit EDTA verdrängt wird, und somit wieder für AmyB-Tm verfügbar ist, was zu einer Erhöhung der Aktivität führt. Fütterer (2001) konnte mit Thermoinaktivierungskinetiken zeigen, daß Kalzium langfristig einen destabilisierenden Einfluß auf AmyB-Tm hat. Nach 6 h Präinkubation des Enzyms bei $90{ }^{\circ} \mathrm{C}$ lag die Aktivität ohne Zusatz bei ungefähren $80 \%$ und mit $10 \mathrm{mM} \mathrm{Ca}^{2+}$ bei etwa $60 \%$. Auch hier scheint es möglich zu sein, daß Kalzium im Verlauf der Präinkubationszeit einen essentiellen Cofaktor des Enzyms verdrängt. Neben $\mathrm{Ca}^{2+}$ und $\mathrm{Mg}^{2+}$ hatten auch $\mathrm{Co}^{2+}, \mathrm{Cu}^{2+}$, $\mathrm{Ni}^{2+}, \mathrm{Mn}^{2+}$ und $\mathrm{Ba}^{2+}$ in der jeweiligen Konzentration von $5 \mathrm{mM}$ einen hemmenden Effekt auf AmyB-Tm. Hierbei könnte es sich ebenfalls um den Effekt der Verdrängung eines vom Enzym benötigten Kations handeln. Die Hemmwirkung des Anions der eingesetzten Metallsalze spielt eine untergeordnete Rolle, wie Fütterer (2001) in Versuchen mit Sulfat- und Chloridionen zeigen konnte. Im Verlauf der vorliegenden Arbeit gelang es durch biochemische und spektrometrische Methoden, den im AmyB-Protein gebundenen MetallCofaktor zweifelsfrei als Eisen zu identifizieren und zu quantifizieren (s. III.3.4, III.6.3).

Metallionen in Enzymen dienen verschiedenen Zwecken. So können sie stabilisierend auf das Enzym einwirken, eine Oligomerisierung vermitteln, oder an der Substratbindung bzw. der Katalyse beteiligt sein. Ein stabilisierender Effekt von $\mathrm{Ca}^{2+}$ und $\mathrm{Zn}^{2+}$ wurde von Savchenko et al. (2002) für eine $\alpha$-Amlyase aus $P$. furiosus beobachtet. Eine $\mathrm{Zn}^{2+}$-vermittelte Trimerisierung konnte für die Arginase aus Saccharomyces cerevisiae festgestellt werden (Green at al., 1991). Anhand einer Gelfiltrationsstudie und des Laufverhaltens in der NativPAGE wurde nachgewiesen, daß AmyB-Tm als Dimer oder als Tetramer vorliegt (s. III.3.5). Da die Zugabe von 0,1 mM EDTA zum Probenauftragspuffer das Laufverhalten von AmyBTm in der Nativ-PAGE nicht beeinflussen konnte (s. III.3.5.2, Abb. 35), erscheint eine Rolle des Eisenatoms bei der Oligomerisierung des Enzyms unwahrscheinlich.

Die potentielle Bindestelle für Eisen in der Molekularstruktur von AmyB-Tm wurde in unmittelbarer Nähe (ca. $8 \AA$ ) zum katalytischen Zentrum lokalisiert, was eine Rolle bei der Substratbindung oder Katalyse plausibel erscheinen läßt (vergl. IV.1.6). 


\subsection{Inhibitorischer Effekt von Nukleotiden auf AmyB-Tm}

Eine Aktivitätshemmung von AmyB-Tm wurde nicht nur durch EDTA, sondern auch durch ATP, GTP und ADP festgestellt (s. III.3.3). Auch diese Hemmung konnte durch Zugabe von $\mathrm{Ca}^{2+}$ teilweise aufgehoben werden. Dies deutet darauf hin, daß es sich bei der Inhibition des Enzyms durch Nukleotide um einen unspezifischer Effekt handelt, der auf die Komplexierung eines Metallions zurückzuführen ist. Weiterhin spricht die Tatsache, daß die Inhibition durch ATP oder GTP etwa gleich stark ist, sowie das Fehlen eines ATP-Bindemotivs in der AmyBSequenz gegen eine allosterische Regulation durch ATP.

Eine durch $\mathrm{Ca}^{2+}$ aufhebbare Hemmung der Enzymaktivität durch ATP und ADP wurde auch für die extrazelluläre Trehalase des Pilzes Humicola grisea beschrieben (Zimmermann et al., 1990). Dieses Enzym ist ebenso wie AmyB-Tm gegenüber EDTA empfindlich, was vermutlich ebenfalls für einen unspezifischen Komplexierungseffekt spricht. Im Gegensatz dazu sind Enzyme, die mutmaßlich durch ATP allosterisch gehemmt werden, gegenüber EDTA unempfindlich, wie bei der Phospho- $\beta$-Galaktosidase aus Streptococcus mutans gezeigt wurde (Calmes und Brown, 1979). Das bislang einzige amylolytische Enzym, für das eine Inhibition durch ATP beschrieben wurde, ist ein Glykogen-Entzweigungsenzym ( $\alpha$-1,6Glukosidase) aus dem Rinderhirn (Narahara et al., 2001) Ob es sich hier allerdings um einen echten allosterischen Effekt handelt, ist fraglich, da der Einfluß von EDTA auf das Enzym nicht geprüft wurde.

Neben der beschriebenen Hemmung durch Nukleotide beobachtete Fütterer (2001) auch eine Aktivitätssteigerung von AmyB-Tm auf etwa 140 \% durch 5 mM cAMP. Der Effekt konnte in dieser Arbeit nicht reproduziert werden. In Gram-negativen Bakterien spielt cAMP eine essentielle Rolle bei der transkriptionellen Kontrolle vieler Gene. Es steht in einem komplexen regulatorischen Zusammenhang mit der Aufnahme von Sacchariden durch das Phosphoenolpyruvat-abhängige Phosphotransferase-System (PEP-PTS). Beim spezifischen PTS-Transport in die Zelle wird z. B. Glukose phosphoryliert, und durch die folgende Phosphorylierungs-Kaskade hat der Typ der aufgenommenen Zucker Einfluß auf die cAMPBildung durch die Adenylat-Cyclase. In Abwesenheit von Glukose ist der cAMP-Spiegel hoch, in Anwesenheit von Glukose niedrig. Durch das System der Katabolitrepression (Crp) hat die cAMP-Konzentration einen indirekten regulatorischen Einfluß auf die Transkription unter anderem einer ganzen Reihe von Genen des Zuckerstoffwechsels. Das nahe mit T. maritima verwandte Bakterium T. neapolitana besitzt, obwohl Gram-negativ, kein PEPPT-System (Galperin et al., 1996). Für T. neapolitana konnte ebenfalls gezeigt werden, daß der Organismus eine cAMP-unabhängige Katabolitrepression besitzt und unabhängig von der 
C-Quelle im Medium stets die gleichen niedrigen cAMP-Konzentrationen vorliegen (Vargas und Noll, 1996). Diese Daten lassen sich uneingeschränkt auf T. maritima übertragen. Aufgrund der für T. maritima fehlenden Bedeutung von cAMP bei der der transkriptionellen Regulation der Zuckerverwertung erscheint es unwahrscheinlich, daß gerade cAMP eine Rolle in der allosterischen Regulation des Zuckermetabolismus spielen sollte. Auch entsprechen die von Fütterer bei der Aktivitätssteigerung von AmyB-Tm eingesetzten Mengen von $5 \mathrm{mM}$ nicht physiologischen Bedingungen. Die von Vargas und Noll (1996) gemessenen cAMP-Mengen in T. neapolitana Zellen lagen zwischen 44 und 280 fmol pro mg Zellprotein. Bei der von Fütterer gezeigten Aktivitätssteigerung handelt es sich also vermutlich um einen unspezifischen Effekt.

\subsection{AmyB-Tm als Protein der GHF 57}

Thermotoga maritima besitzt, obwohl auf Basis der phylogenetischen Einordnung eher als primitiv anzusehen, ein großes Repertoire an Glykosidhydrolasen. Die Klassifizierung von Glykosidhydrolasen erfolgt einerseits aufgrund ihrer Substratspezifität und andererseits aufgrund der Ähnlichkeit der Aminosäuresequenz der Enzyme. Eine Gliederung nach ersterem Kriterium, bei der strukturelle Aspekte nicht berücksichtigt werden, erfolgt durch die IUB-MB (International Union of Biochemistry and Molecular Biology). Oft mangelt es jedoch an einer eindeutigen Substratpräferenz der Enzyme, da häufig Nebenaktivitäten vorhanden sind. Unter in vitro Bedingungen können die Parameter des Versuchsaufbaus einen nicht unerheblichen Einfluß auf die Substratpräferenz der Enzyme haben. Die Klassifizierung nach Aminosäuresequenz-Ähnlichkeit in der Carbohydrate-Active Enzymes (CAZY)Datenbank umgeht diese Problematik (http://afmb.cnrs-mrs.fr/CAZY/; Henrissat, 1991; Henrissat und Bairoch, 1996). Mit dieser Zuordnung wird den strukturellen Eigenschaften der Enzyme, die in direkter Beziehung zur Aminosäuresequenz stehen, Rechnung getragen. Zusätzlich wird die evolutionäre Beziehung zwischen Enzymen unterschiedlicher Substratspezifität deutlich.

Zur Zeit umfaßt die CAZY-Datenbank 99 Glykosid-Hydrolase-Familien (GHF). Proteine, die wie die in dieser Arbeit untersuchten Enzyme als $\alpha$-Amylasen (EC 3.2.1.1) klassifiziert wurden, sind in den Familien 13 und 57 zu finden. Während Familie 57 momentan 52 Proteine umfaßt, wird die gut untersuchte GHF 13 von 2014 zum Großteil putativen Proteinen gebildet und stellt damit die größte Glykosid-Hydrolase-Familie dar. Die A. gottschalkii Amylasen AmyA-Ag und AmyB-Ag sind aufgrund ihrer Aminosäuresequenz beide in die GHF 13 einzuordnen. 
Die $\alpha$-Amylasen AmyB-Tm aus T. maritima und AmyB-Tt aus T. thermophilus haben keinerlei Ähnlichkeit zur , $\alpha$-Amylase-Familie’ GHF 13. Sie weisen große strukturelle Analogien zur 4- $\alpha$-Glukanotransferase aus T. litoralis (Imamura et al., 2003) auf, welche ein Vertreter der GHF 57 ist. In dieser Familie sind neben $\alpha$-Amylasen und 4- $\alpha$ Glukanotransferasen (EC 2.4.1.25) auch $\alpha$-Galaktosidasen (EC 3.2.1.22) und Amylopullulanasen (3.2.1.41) zu finden. Bislang jedoch wurden nur sieben Vertreter der Familie biochemisch charakterisiert.

Die Übereinstimmung von AmyB-Tm und der GHF 57 ist auf Aminosäuresequenz-Ebene nur gering. Der Versuch, die Enzyme der COG1543 in die GHF 57 einzugliedern zeigt, daß diese innerhalb der GHF 57 eine distinkte Unterfamilie bilden (Abb. 68). Ebenso ist aus dem Phylogramm ersichtlich, daß die GHF 57 in drei Unterfamilien zerfällt, die von jeweils einer Gruppe von Enzymen mit gleichem Reaktionstypus gebildet werden. Aufgrund der insgesamt niedrigen Homologie der COG1543-Proteine zu denen der GHF 57 ist es möglich, daß die COG1543 eine eigene, zweifellos nahe mit der GHF 57 verwandte GHF darstellt.

Die meisten Glykosidasen enthalten ein $(\beta / \alpha)_{8}-\mathrm{Fa}$, eine der am weitesten verbreiteten Supersekundärstrukturen überhaupt, als gemeinsames Faltungsmotiv (Orengo et al., 1997; Nagano et al., 2001). Dieses besteht aus je acht alternierenden $\beta$-Strängen und $\alpha$-Helices. Die $\beta$-Stränge bilden, ähnlich den Dauben eines Fasses, ein paralleles $\beta$-Faltblatt um einen Hohlraum in der Mitte. Die $\alpha$-Helices umgeben das so gebildete Faß an der Außenseite. Diese charakteristische Form war namensgebend für das $(\beta / \alpha)_{8}$-Faß oder TIM-barrel, wie es nach der Triosephosphat-Isomerase, bei der es zuerst beobachtet wurde, auch genannt wird. Die große Mehrheit der Glykosid-Hydrolase-Familien, deren Molekularstruktur bekannt ist, besteht aus Proteinen mit einem solchen Faltungsmotiv, darunter auch die , $\alpha$-Amylase Familie’ GHF 13. 


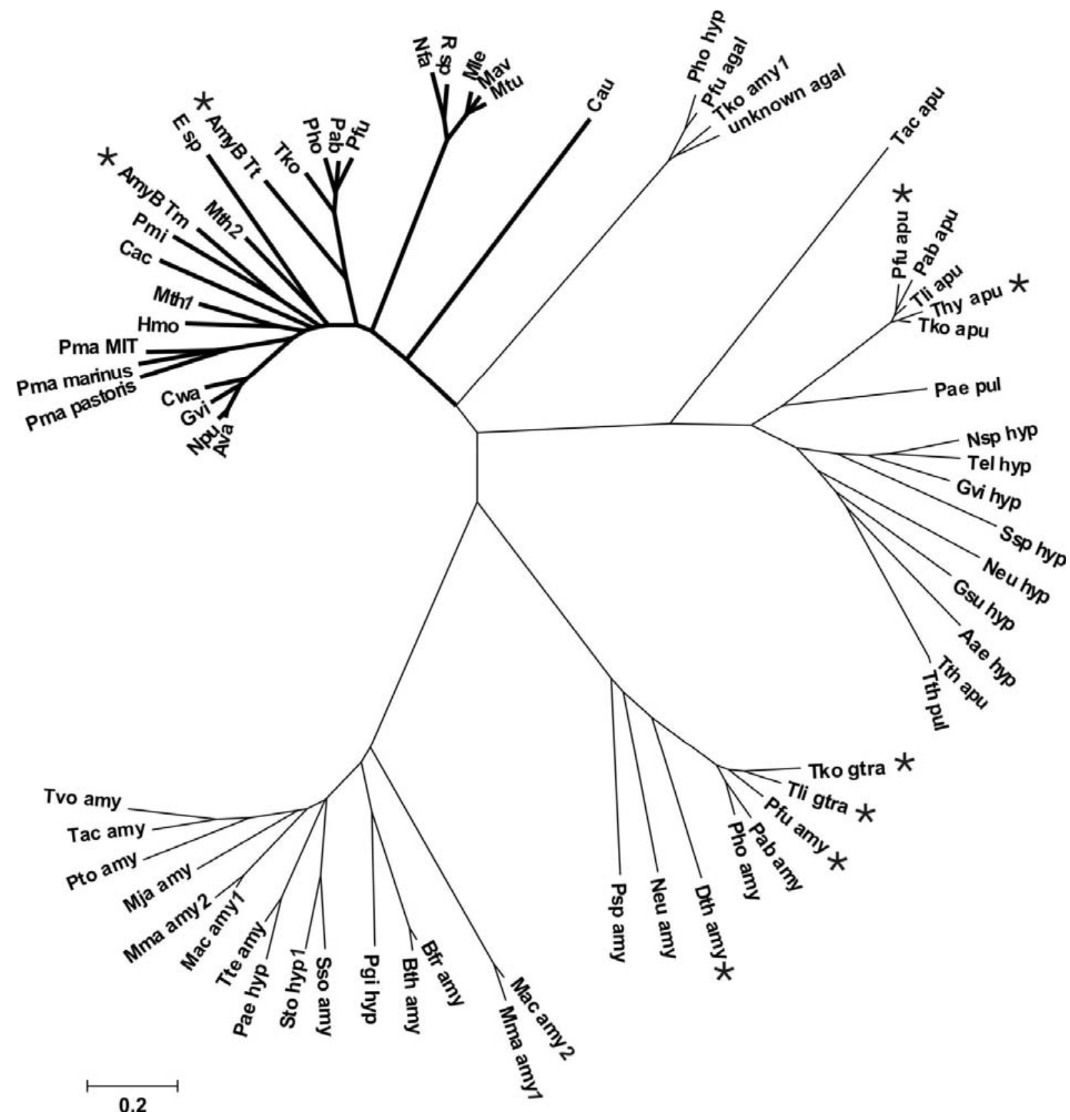

Abb. 68: Phylogenetische Analyse der GHF 57 und der COG1543 Proteine auf Basis der Aminosäuresequenzen. Das Phylogramm wurde mit dem Programm Mega 2.1 (Kumar et al., 2001) aus einem ClustalW- Alignment mit der Neighbor Joining-Methode erstellt. Der aus den AmyB-ähnlichen Proteinen der COG1543 gebildete Zweig ist durch dicke Linien gekennzeichnet. Biochemisch charakterisierte Enzyme sind mit einem Sternchen gekennzeichnet. Die Beschriftung der GHF 57 Proteine bezieht sich auf den Herkunftsorganismus und ihre Funktion, die Beschriftung der COG1543 Proteine bezieht sich nur auf ihren Herkunftsorganismus. Amy, $\alpha$-Amylase; apu, Amylopullulanase; gtra, 4- $\alpha$-Glukanotransferase; agal, $\alpha$-Galaktosidase; hyp, hypothetisches Protein. Die Bezeichnungen der Organismen können Tab. 3 (COG1543, s. III.1.2) bzw. der Auflistung der GHF 57-Proteine im Anhang entnommen werden. 
Die Strukturaufklärung von AmyB-Tm zeigte, daß das Enzym ein verzerrtes, siebensträngiges $(\beta / \alpha)$-Faß besitzt. Im Gegensatz zum $(\beta / \alpha)_{8}$-Faß ist dieses Motiv sehr selten. Bisher konnte laut SCOP-Datenbank (Structural Classification of Proteins, http://scop.berkeley.edu) eine solche Supersekundärstruktur erst in elf Proteinstrukturen gefunden werden (Murzin et al., 1995; Andreeva et al., 2004). Dabei handelt es sich neben AmyB-Tm um vier eukaryotische Cellulasen, eine putative Phosphoesterase-Domäne (YcdX) aus E. coli, eine putative Polysaccharid-Deacetylase (PdaA) aus B. subtilis, zwei $\alpha$-Mannosidasen aus Bos taurus und Drosophila melanogaster, die der GHF 38 angehören, eine Hyaluronidase aus Apis mellifera, die der GHF 56 angehört, und die 4- $\alpha$-Glukanotransferase aus T. litoralis, die zur GHF 57 gehört (Spezio et al., 1993; Zou et al., 1999; Varrot et al., 2003; Davies et al., 2000; Teplyakov et al., 2003; van den Elsen et al., 2001; Heikinheimo et al., 2003; Forouhar et al., nicht publ.; Markovic-Housley et al., 2000; Imamura et al., 2003). Interessanterweise handelt es sich hierbei mit Ausnahme der Phosphoesterase um Polysaccharid-abbauende oder -modifizierende Enzyme. Auch das Protein AmyB-Tt, dessen Molekularstruktur in der RCSB Protein Datenbank (PDB, http://www.rcsb.org/pdb/) hinterlegt ist, enthält ein solches $(\beta / \alpha)_{7^{-}}$ Faß (1ufa, Idaka et al., nicht publ.). Aufgrund der sehr hohen Sequenzähnlichkeit der anderen COG1543-Proteine mit AmyB-Tm und AmyB-Tt kann man davon ausgehen, daß sich das Faltungsmotiv des $(\beta / \alpha)_{7}$-Fasses auf die gesamte COG1543 übertragen läßt. Es kann darüber spekuliert werden, ob das $(\beta / \alpha)_{7}$-Motiv eine Variation des $(\beta / \alpha)_{8}$-Fasses darstellt und aus dieser weit verbreiteten Struktur evolutionär hervorgegangen ist. Abb. 69 zeigt die Faßstrukturen der TAKA-Amylase (GHF 13), der GTase aus T. thermophilus (GHF 57) und von AmyB-Tm im Vergleich.

Bisher ist neben der GHF 57 nur von den Glykosid-Hydrolase-Familien 38 und 56 ein $(\beta / \alpha)_{7^{-}}$ Faß bekannt. Die GHF 56 umfaßt 48 ausschließlich eukaryotische Hyaluronidasen (EC 3.2.1.35). Die GHF 38 wird von 136 Proteinen gebildet, bei denen es sich, sofern ihre Funktion bekannt ist, ausschließlich um $\alpha$-Mannosidasen (EC 3.2.1.24, EC 3.2.1.114) handelt. Imamura et al. (2003) vermuten aufgrund der strukturellen Ähnlichkeit, daß die GH-Familien 57 und 38 einen gemeinsamen evolutionären Ursprung haben. Diese Verwandtschaft wird dadurch untermauert, daß sich die katalytischen Reste der $\alpha$-Mannosidase aus dem GolgiApparat von Drosophila melanogaster mit denen der Glukanotransferase aus T. litoralis in ihrer räumlichen Lage im Enzym decken.

Aufgrund der vergleichsweise hohen Zahl an archaeellen und eukaryotischen Proteinen wurden die GHF 57 und GHF 38 von Imamura et al. (2003) als archaelle bzw. eukaryotische Glykosid-Hydrolase Familien bezeichnet. Mit der steigenden Anzahl sequenzierter 
bakterieller Genome und dem damit verbundenen Anstieg an bekannten Proteinsequenzen ist jedoch der Anteil an prokaryotischen Proteinen in diesen Familien gestiegen, so daß bei den GHFs 38 und 57 von exklusiv eukaryotischen oder archaeellen Glykosid-Hydrolase-Familien keine Rede mehr sein kann. Weitere Strukturaufklärungen werden zeigen, ob das $(\beta / \alpha)_{7}$-Faß als gemeinsame Struktur der GHFs 38, 56 und 57 bestätigt werden kann.

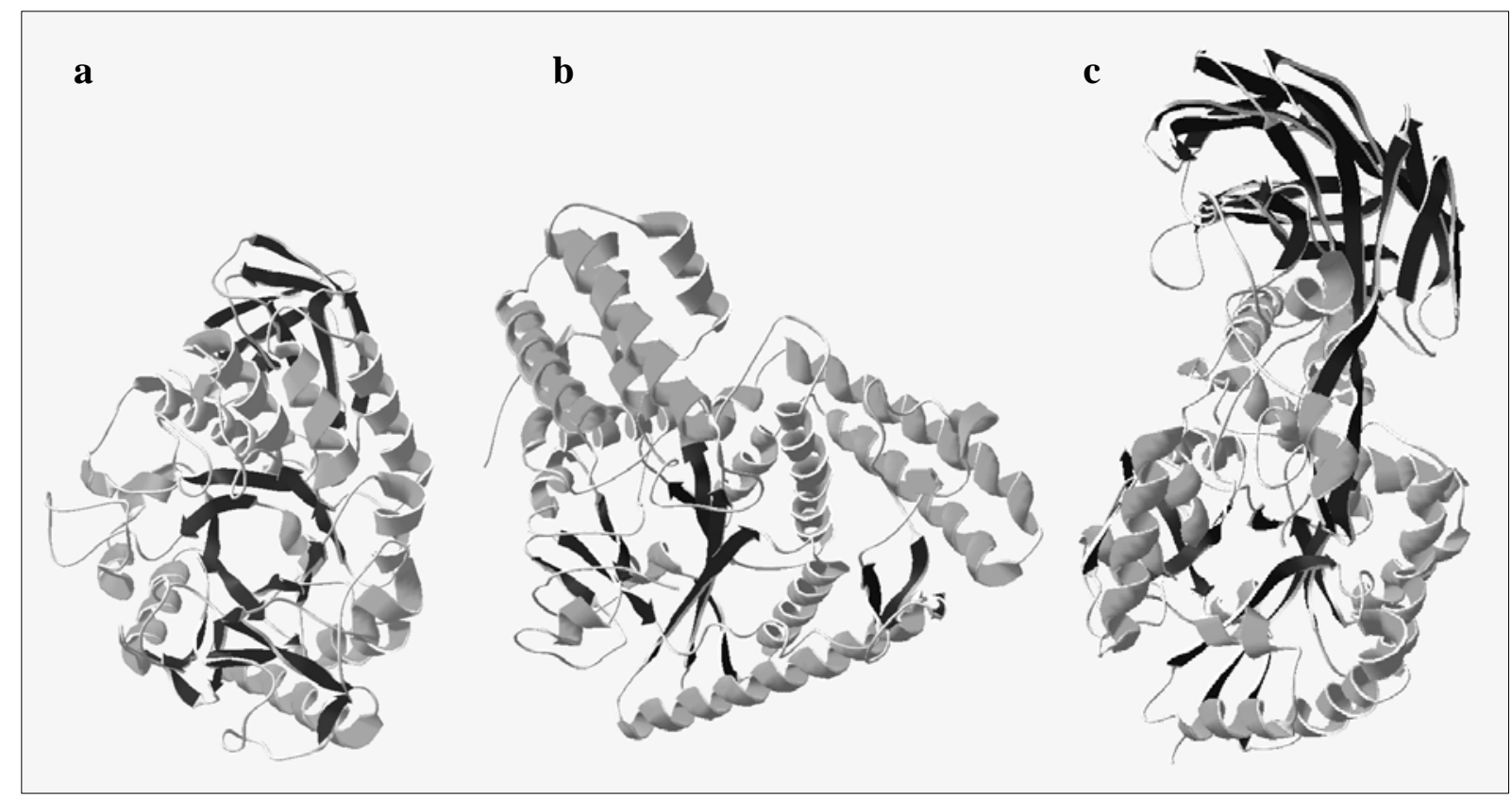

Abb. 69: Proteinstrukturen a) der TAKA-Amylase, GHF 13 (Brzozowski et al., 1997), b) des AmyB-Tm-Proteins und c) der 4- $\alpha$-Glukanotransferase aus T. litoralis, GHF 57 (Imamura et al., 2003).

\subsection{Das katalytische Zentrum von AmyB-Tm}

Die enzymatische Hydrolyse von Glykosidbindungen basiert, von Sonderfällen (GHF 4) abgesehen, auf zwei möglichen Mechanismen. Entweder wird durch einen einstufigen Katalysemechanismus (single displacement) die Konformation des anomeren Kohlenstoffatoms beibehalten (Retention) oder durch einen zweistufigen Mechanismus (double displacement) umgekehrt (Inversion). In beiden Fällen haben die katalytischen Aminosäurereste endständige Carboxylgruppen, d.h. es handelt sich um Aspartat oder Glutamat. Die für diese Arbeit relevanten Enzymklassen der $\alpha$-Amylasen und 4- $\alpha$ Glukanotransferasen haben einen Katalysemachanismus, der eine Retention der Konformation des anomeren C-Atoms zur Folge hat.

Bei retendierenden Glykosid-Hydrolasen läuft folgender Zweischrittmechanismus ab. Die als Säure/Base-Katalyst fungierende Carboxylgruppe protoniert im ersten Schritt das 
Sauerstoffatom der glykosidischen Bindung. Die als Nukleophil agierende Carboxylgruppe greift dann das anomere Zentrum des Zuckersubstrats an und bildet ein Glykosyl-Intermediat. Im zweiten Schritt wird das Akzeptor-Molekül durch die Säure/Base-Funktion deprotoniert und der Aglykonrest darauf übertragen, d.h. der Rest, der über eine glykosidische Bindung mit der reaktiven Gruppe des Zuckers (Glykon), von dem die glykosidische Bindung ausgeht, verknüpft ist. Als Akzeptor kann ein Wassermolekül (Hydrolyse), ein anderes Zuckermolekül (Transglykosylierung) oder ein Phosphatmolekül (Phosphorolyse) fungieren (Sinnot, 1990; McCarter und Withers, 1994; Davies und Henrissat, 1995).

Für die 4- $\alpha$-Glukanotransferase aus T. litoralis wurden Glu123 und Asp214 als katalytische Reste identifiziert (Imamura et al., 2001; Imamura et al., 2003), wobei Glu123 als Nukleophil agiert und Asp214 die Säure/Base-Funktion darstellt. Durch Vergleich der Primär- und Tertiärstruktur von AmyB-Tm mit der der Glukanotransferase konnten in AmyB-Tm Glu185 und Asp349 als Nukleophil bzw. Säure/Base-Funktion identifiziert werden (s. III.7.2). Daher läßt sich ein retendierender Mechanismus der Katalyse unter Beteiligung von Glu185 und Asp349 postulieren. Im Unterschied zur Glukanotransferase, die eine Transglykosylierung katalysiert, dient bei der $\alpha$-Amylase AmyB-Tm, die die glykosidische Bindung hydrolysiert, $\mathrm{H}_{2} \mathrm{O}$ als Akzeptor des Aglykonrests (Abb. 70).
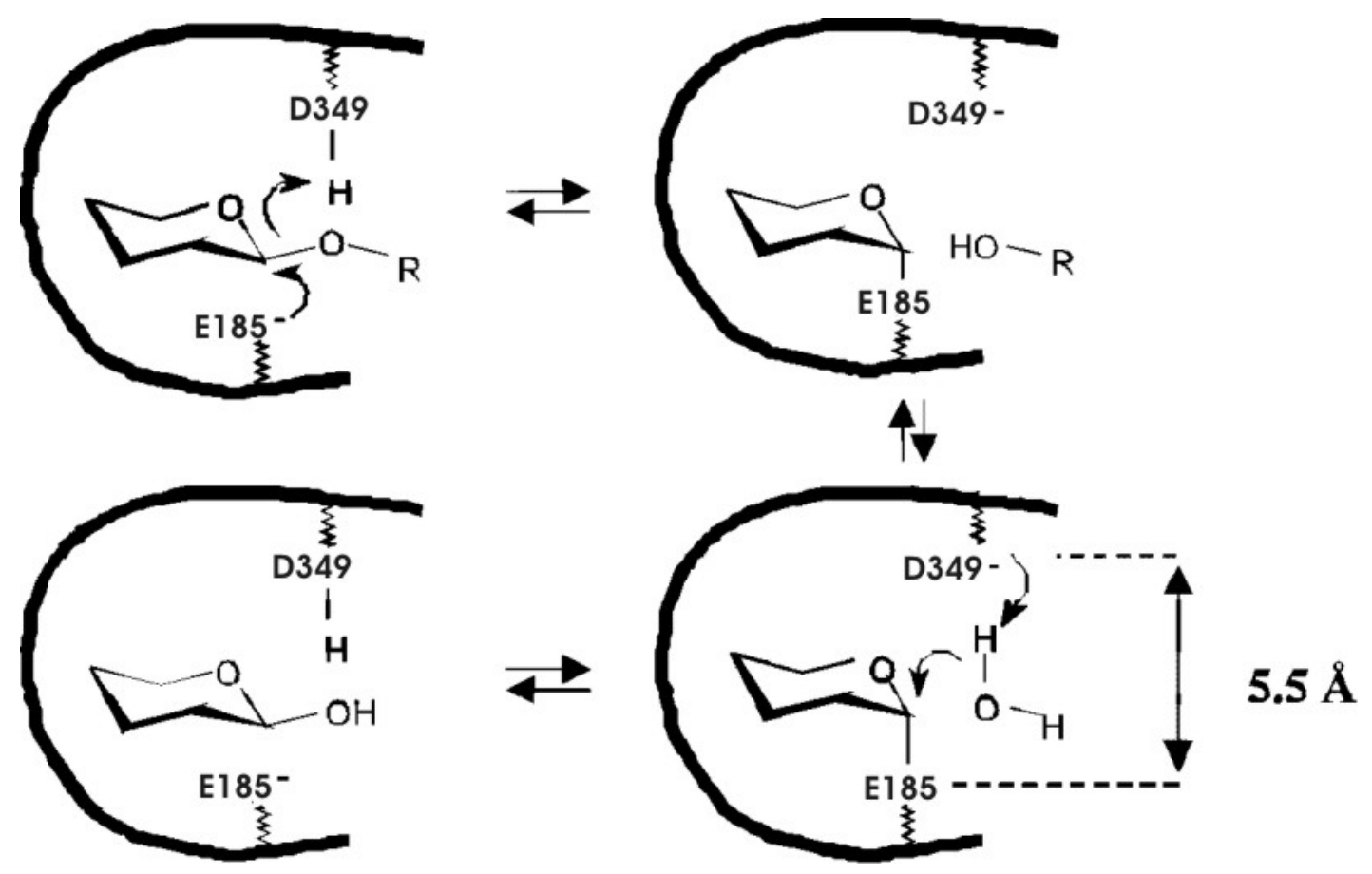

Abb. 70: Mutmaßlicher Mechanismus der Katalyse im katalytischen Zentrum von AmyB-Tm. R steht als Platzhalter für einen $\alpha$-Glukanrest (nach Davies und Henrissat, 1995, modifiziert). 
Analog zu AmyB-Tm lassen sich für AmyB-Tt Glu184 und Asp352 als katalytische Reste identifizieren (s. III.7.2). Sowohl der Glutamat- als auch der Aspartatrest sind in der GHF 57 hoch konserviert. Das Gleiche gilt für beide Aminosäuren und ihre Umgebung innerhalb der COG1543. Interessanterweise ist in der COG1543 auch das direkt auf das Glutamat folgende Cystein (Cys186) hochkonserviert, was für eine wichtige Rolle dieser Aminosäure im katalytischen Zentrum spricht. Das aktive Zentrum liegt bei TIM-barrel Enzymen immer am C-terminalen Ende des $(\beta / \alpha)_{8}$-Fasses. Für $\alpha$-Amylasen der GHF 13 bedeutet dies, daß der als Nukleophil fungierende Aminosäurerest immer am C-Terminus des $\beta 4$-Stranges lokalisiert ist. Auch bei AmyB-Tm und der Glukanotransferase aus T. litoralis liegt das Nukleophil am C-Terminus des $(\beta / \alpha)_{7}$-Fasses (Imamura et al., 2003).

In der COG1543 sind unter anderem drei Histidinreste (His10, His12 und His146 in AmyB$\mathrm{Tm}$ ) hochkonserviert. Diese liegen ebenfalls in vielen GHF 57-Proteinen vor. Imamura et al. (2003) postulieren, daß zwei der entsprechenden Histidinreste der 4- $\alpha$-Glukanotransferase (His11 und His13) mit der -1 subsite des Substrats interagieren und so an der Substratbindung während der Katalyse beteiligt sind. His11 formt dabei eine H-Brücke mit dem Substrat, während His13 indirekt über ein Wassermolekül mit dem Substrat interagiert. Auch für $\alpha-$ Amylasen der GHF 13 wird postuliert, daß zwei Histidinreste den Übergangszustand während der Katalyse an der subsite -1 stabilisieren (MacGregor et al., 2001). Dies ist zumindest für die Amylase aus Gerste belegt (Sögaard et al., 1993). In der Terminologie der TAKAAmylase, der Modell-Amylase der GHF 13, sind dies die Histidinreste 122 und 296, die in den konservierten Regionen I und IV liegen. In der räumlichen Struktur ähneln sie in ihrer Lage zueinander und zum Substrat den Resten His12 und His146 aus AmyB-Tm. Im Widerspruch hierzu läßt die Lage der Histidinreste 10 und 12 in der AmyB-Tm-Struktur vermuten, daß diese Reste zusammen mit Cys146 und His142 ein Eisenzentrum bilden.

\subsection{Eisen als Metallcofaktor von AmyB-Tm}

Nachdem durch Komplexierungsexperimente bereits Hinweise auf die Gegenwart eines Metallions im AmyB-Tm Enzym vorlagen, konnte die Präsenz von Eisen im Protein sowohl biochemisch (s. III.3.4) als auch spektroskopisch (s. III.6.3) nachgewiesen werden. Es konnte jedoch keine Abhängigkeit der enzymatischen Aktivität von der Menge des im Enzym gebundenen Eisens festgestellt werden. Die zur Quantifizierung des Eisengehalts angewendete Methode erfaßt $\mathrm{Fe}^{2+}$ - und $\mathrm{Fe}^{3+}$-Ionen gleichermaßen. Der ebenfalls beobachtete, positive Effekt von Reduktionsmitteln auf die Aktivität von AmyB-Tm läßt den Schluß zu, daß nicht nur die Anwesenheit von Eisen, sondern auch dessen Oxidationstufe von Bedeutung 
für AmyB-Tm sein könnte. Unter den gegebenen Umständen würde das bedeuten, daß das im Enzym gebundene Eisenion in seiner reduzierten Form als $\mathrm{Fe}^{2+}$ vorliegen muß, um einen positiven Einfluß auf die Aktivität von AmyB-Tm zu haben.

Eisen ist ein unerwarteter Cofaktor der $\alpha$-Amylase AmyB-Tm, da eine Bindung dieses Metalls bisher vor allem von Enzymen, die einen Elektronenfluß vermitteln, z.B. Oxidoreduktasen, bekannt ist. Als Cofaktor glykosidischer Enzyme ist Eisen bisher nicht in Erscheinung getreten. Viele $\alpha$-Amylasen der GHF 13 sind $\mathrm{Ca}^{2+}$-abhängig, wobei $\mathrm{Ca}^{2+}$ hier zur Stabilisierung der Enzyme beiträgt (Vihinen und Mäntsälä, 1989). So wird etwa die Thermostabilität der zweiten intrazellulären $\alpha$-Amylase von T. maritima (AmyC) durch $\mathrm{Ca}^{2+}$ erhöht (Lim et al., 2003). Auch die 4- $\alpha$-Glukanotransferase aus T. litoralis bindet ein $\mathrm{Ca}^{2+}$-Ion pro Untereinheit (Imamura et al., 2003).

Von den $\alpha$-Glukosidasen der GHF 4 ist bekannt, daß sie manganabhängig sind. So benötigt die $\alpha$-Glukosidase AglA aus T. maritima $1 \mathrm{mM} \mathrm{Mn}^{2+}$ für maximale enzymatische Aktivität (Raasch et al,. 2000). Mit dem kürzlich aufgeklärten Mechanismus des Enzyms BglT (6Phospho- $\beta$-Glukosidase) aus T. maritima konnten Varrot et al. (2005) zeigen, daß das Mangan bei diesem Enzym aus der GHF 4 sowohl an der Substratbindung, in diesem Fall pNP- $\beta$-Glukose-6-Phosphat, als auch im Zusammenspiel mit $\mathrm{NAD}^{+}$am katalytischen Mechanismus beteiligt ist. Diese Ergebnisse lassen sich vermutlich auf AglA übertragen.

In AmyB-Tm konnte eine potentielle Bindestelle für Eisen identifiziert werden, die in unmittelbarer Nähe zum katalytischen Zentrum des Enzyms liegt. Diese wird aus His10, His12, His146 und Cys142 oder Cys186 gebildet. Die Aminosäurereste His10 und His12 sind sowohl in den Proteinen der GHF 57 als auch der COG1543 durchgehend konserviert. Auch Cys186 und His146 sind in der COG1543 stark konserviert, während Cys142 häufig durch ein Serin substituiert ist. Ein Vergleich der räumlichen Struktur von AmyB-Tm mit der LigandenBindestellen-Datenbank des (Patterns in Non-homologous Tertiary Structures) PINTSServers zeigte, daß die räumliche Lage der Reste His10, His12, His146 und Cys142 MetallBindestellen aus diversen Oxidoreduktasen gleicht (http://www.russell.embl.de/pints, Stark et al., 2003). Die so gefundenen ähnlichen Bindestellen koordinieren die Metalle Eisen, Kupfer, Kobalt oder Zink (Abb. 71).

Sollte das Eisenion in AmyB-Tm tatsächlich durch die genannten Aminosäurereste koordiniert werden, wäre es in unmittelbarer Nähe zu den katalytischen Seitenketten des Enzyms lokalisiert. Diese Lage würde eine Beteiligung an der Katalyse oder der Substratbindung implizieren. Eine Beteiligung an der Katalyse erscheint jedoch fraglich, da bei AmyB-Tm alle nötigen Funktionen für einen retendierenden Glykosid-Hydrolyse- 
Mechanismus von den Resten Glu185 und Asp349 übernommen werden können. Sollten die Histidinreste His10 und His12 an der Substratbindung an der -1 subsite beteiligt sein (vergl. IV.1.5), könnte die potentielle Bindung von Eisen einer bestimmten Oxidationsstufe die Substratbindung stören. Linden et al. (2003) konnten für die $\alpha$-Amylase PWA aus Pyrococcus wosei zeigen, daß die Bindung von $\mathrm{Zn}^{2+}$ an die -1 subsite die Aktivität des Enzyms inhibiert. Das gleiche konnten Boel et al. (1990) für $\mathrm{Ca}^{2+}$ bei einer $\alpha$-Amylase von Aspergillus niger beobachten. Eine Behinderung der Substratbindung in der -1 subsite durch ein Eisenion, welches mit den die Bindung vermittelnden Histidin-Resten interagiert, könnte eine Erklärung für die schwankende Aktivität der AmyB-Aufreinigungen darstellen.
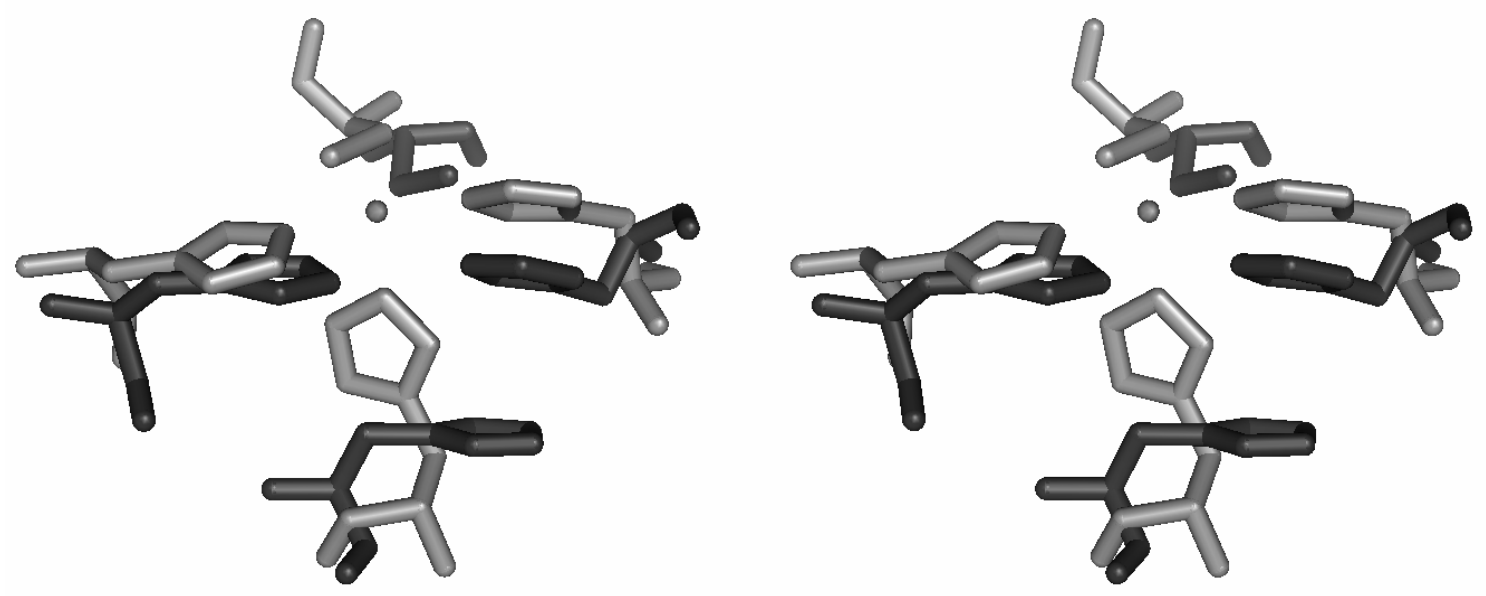

Abb. 71: Stereobild der Überlagerung der Aminosäurereste der potentiellen Eisenbindestelle von AmyB-Tm mit denen der Eisenbindestelle der Superoxid-Reduktase aus $P$. furiosus (1dqi) (Yeh et al., 2000). Die Reste His10, His12, His146 und Cys142 von AmyB-Tm (dunkelgrau) entsprechen dabei den Eisen koordinierenden Resten His47, His41, His16 und Cys111 der SuperoxidReduktase (hellgrau).

\subsection{Die Rolle von AmyB-Tm im T. maritima Stoffwechsel}

Da in der Sequenz von AmyB kein Signalpeptid gefunden wurde, und es keine Hinweise auf einen Export des Enzyms gibt, wird davon ausgegangen, daß es sich bei AmyB um eine cytoplasmatische $\alpha$-Amylase von $T$. maritima handelt. Während die Funktion von extrazellulären Amylasen eindeutig im möglichst schnellen Abbau von Maltodextrinen und Stärke zur Erschließung als C-Quelle liegt, ist die Rolle von Amylasen im Zusammenspiel der intrazellulären Enzyme weniger eindeutig. Die biochemisch charakterisierten intrazellulären $\alpha$-Amylasen unterscheiden sich in ihren Eigenschaften oft erheblich. Unterschiedliche in vitro Testmethoden und -bedingungen zur Charakterisierung der Aktivität machen die Eigenschaften der Amylasen schwer vergleichbar, und Schlüsse auf potentielle in vivo Funktionen fast unmöglich (Tab. 15). 
Tab. 15: Eigenschaften ausgewählter intrazellulärer $\alpha$-Amylasen.

\begin{tabular}{|c|c|c|c|c|c|c|c|c|c|c|c|c|c|c|}
\hline$\sum^{\Xi}$ & 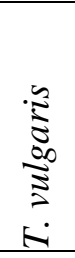 & $\begin{array}{l}2 \\
\infty \\
1 \\
1 \\
\end{array}$ & I & $\begin{array}{l}u \\
0 \\
0 \\
\dot{\gamma} \\
\end{array}$ & $\begin{array}{l}0 \\
6\end{array}$ & 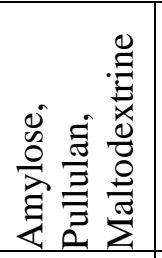 & 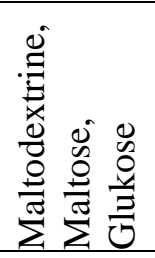 & 1 & 1 & 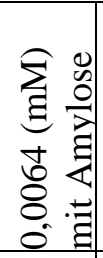 & 1 & $\stackrel{m}{\sim}$ & 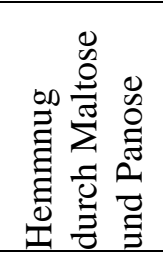 & 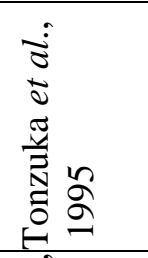 \\
\hline$\underset{S}{\mathbb{T}}$ & 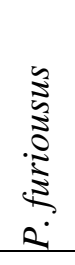 & 1 & है & $\underset{-1}{8}$ & $\begin{array}{l}0 \\
0\end{array}$ & 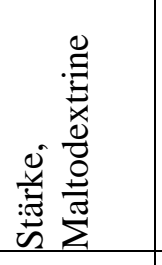 & 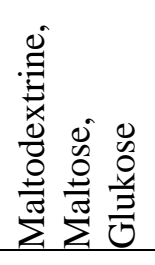 & 1 & 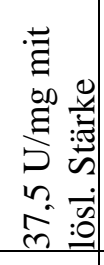 & 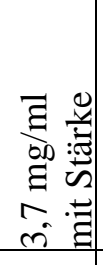 & 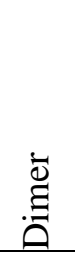 & 슨 & 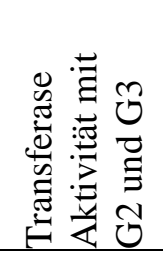 & 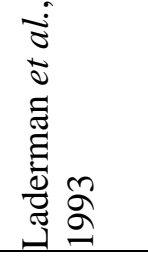 \\
\hline 起 & $\begin{array}{l}: \overline{0} \\
\text { 퍼 }\end{array}$ & $\stackrel{\stackrel{\sim}{\sigma}}{\stackrel{\sigma}{\sigma}}$ & ம) & 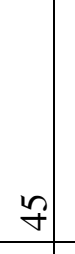 & $N$ & 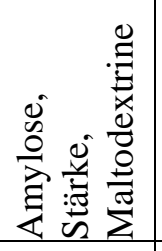 & 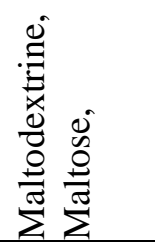 & 1 & 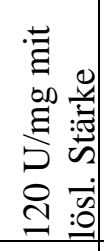 & 1 & I & $\stackrel{m}{\rightarrow}$ & 1 & 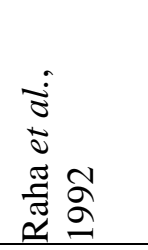 \\
\hline 主 & 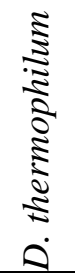 & $\begin{array}{l}0 \\
8 \\
0 \\
\end{array}$ & $\infty$ & ৪ & $\begin{array}{c}\llcorner 0 \\
\llcorner \\
\wedge \\
\wedge\end{array}$ & 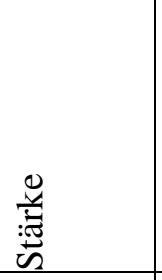 & 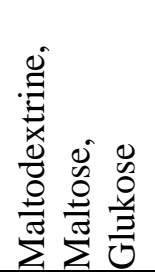 & 1 & 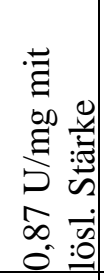 & 1 & 1 & $\stackrel{m}{\rightarrow}$ & I & 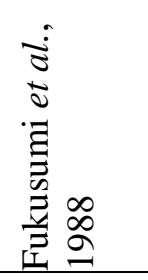 \\
\hline 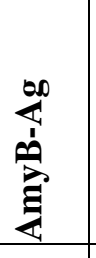 & 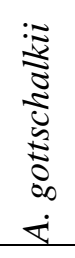 & $\stackrel{\vartheta}{f}$ & กิ & 능 & $\begin{array}{l}0 \\
6\end{array}$ & 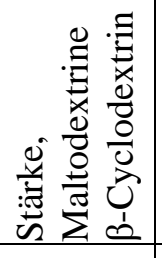 & 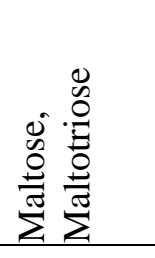 & 1 & 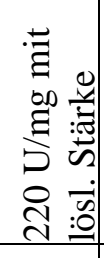 & 1 & 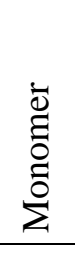 & $\stackrel{m}{\sim}$ & 1 & 莃 \\
\hline 至 & 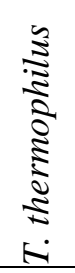 & $\stackrel{\text { N }}{\text { กิ }}$ & คి & $\stackrel{R}{R}$ & $\begin{array}{c}10 \\
6 \\
6\end{array}$ & 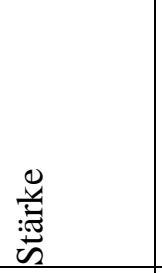 & I & 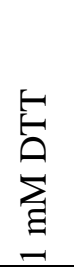 & 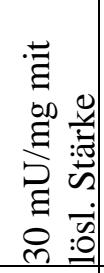 & 1 & 1 & ถิ) & I & 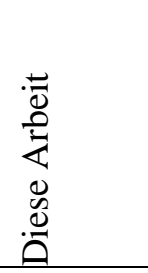 \\
\hline 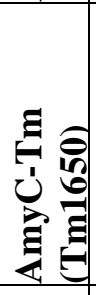 & 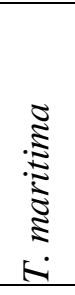 & $\underset{\mathcal{T}}{\mathcal{7}}$ & 이 & $\begin{array}{l}\text { 尺 } \\
0 \\
0\end{array}$ & $\begin{array}{l}0 \\
0 \\
0 \\
0\end{array}$ & 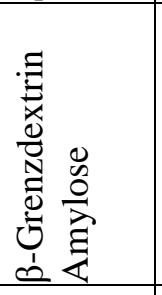 & 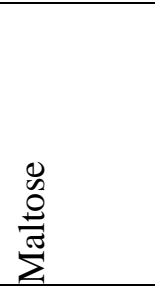 & 1 & 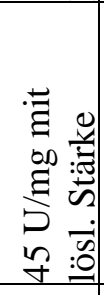 & 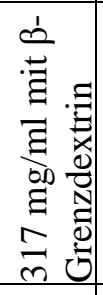 & 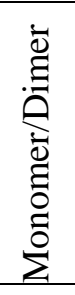 & $\stackrel{m}{-1}$ & 1 & 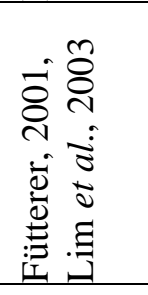 \\
\hline 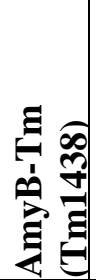 & 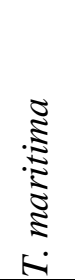 & 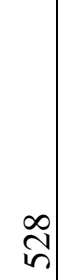 & 8 & ৪) & $\begin{array}{l}10 \\
\infty\end{array}$ & 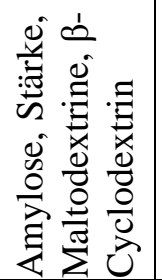 & 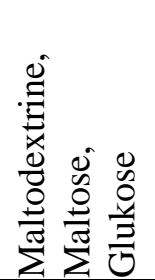 & 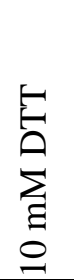 & $\begin{array}{l}\infty \\
E \\
\vdots \\
0 \\
0 \\
0\end{array}$ & 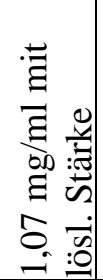 & 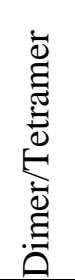 & ถิ & 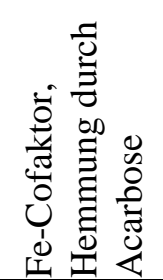 & 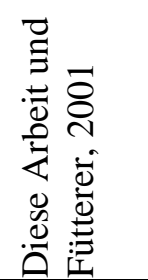 \\
\hline & 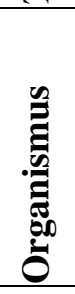 & 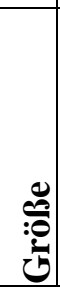 & 至 & 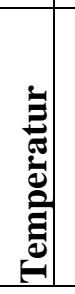 & 琣 & 节 & 产 & 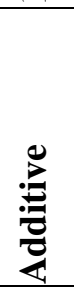 & : & 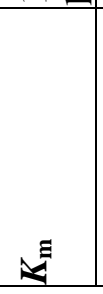 & 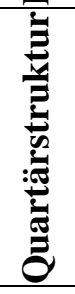 & 至 & D: & 苞 \\
\hline
\end{tabular}


Als Substrate für intrazelluläre Amylasen sind prinzipiell Maltodextrine und Glykogen denkbar. Maltodextrine werden im Zuge des extrazellulären Polysaccharidabbaus gebildet und durch das MalEFGK 2 -Transportsystem in die Zelle geschleust. Glykogen dagegen ist ein von den Zellen gebildetes Speicherpolymer. Grundsätzlich wäre die Beteiligung von AmyBTm an beiden Stoffwechselwegen denkbar. Die Organismen, in denen AmyB-ähnliche Enzyme vorkommen (s. Tab. 6, III.1.2) sind in ihrer phylogenetischen Herkunft über das ganze Spektrum der Eubakterien verteilt, es finden sich darunter Cyanobakterien sowie Grampositive Bakterien und Spirochaeten. Hinzu kommen mit mehreren Pyrococcus-Arten auch Archaeen. Eine Gemeinsamkeit aller Organismen ist die bewiesene oder durch Anwesenheit des Glykogensynthase-Gens vermutete Bildung von Glykogen als Speicherstoff, so daß aufgrund der Physiologie der Organismen, die ein AmyB-Tm-ähnliches Protein haben, weder eine Rolle im Glykogen- noch im Maltose-Stoffwechsel ausgeschlossen werden kann.

\section{Glykogenmetabolismus}

Im Genom von T. maritima liegen die für den Glykogenstoffwechsel nötigen Gene der Glykogensynthase (tm0895), der $\alpha$-Glukan-Phosphorylase (agpA) und zweier Glukose-1-P Adenylyltransferasen (tm0239, tm0240) vor, was darauf schließen läßt, daß der Organismus zur Bildung von Glykogen befähigt ist. Die $\alpha$-Glukan-Phosphorylase AgpA (Bibel et al., 1998) weist eine nahezu identische Aminosäuresequenz zu dem Protein Tm1168 auf. Interessanterweise wurde Tm1168 wie AmyB-Tm im Zuge der Genomsequenzierung als Protein mit einem ,authentischen frameshift' bezeichnet und wird in der ERGO-Datenbank als zwei ORFs dargestellt (RTM02667/02666).

In T. maritima liegen im Gegensatz zu E. coli die Gene für Glykogensynthese und -abbau nicht in einem Cluster vor. Ein Verzweigungsenzym (,branching enzyme') konnte in T. maritima noch nicht gefunden werden. Armbrecht (2003) spekulierte, daß der ORF tm1844, der Ähnlichkeit zu Genen von Isoamylasen und Verzweigungsenzymen aufweist, für das Verzweigungsenzym kodieren könnte. Das vorhergesagte Protein Tm1844 besitzt ein Nterminales Signalpeptid, was eine periplasmatische Lokalisierung des Genprodukts vermuten läßt. Die dadurch implizierte Lokalisierung des Glykogens im Periplasma ist jedoch fraglich, da weder die Glykogensynthase noch AgpA ein Signalpeptid für den Export ins Periplasma haben. Die Rolle des Verzweigungsenzyms scheint daher einem andern, bisher nicht charakterisierten Enzyme von T. maritima zuzufallen. Auch in T. thermophilus konnten die Gene für die Glykogensynthese und den Abbau gefunden werden. Bemerkenswert ist auch 
hier, daß die Glykogen-Phosphorylase (TTC808) außerhalb des Glykogen-Synthese-Clusters (TTC1976-1981) liegt.

Die Bildung eines Speicherglukans durch T. maritima wurde in dieser Arbeit erstmalig biochemisch nachgewiesen. Es konnten etwa 56 mg $\alpha$-Glukan /g Zellen (Naßgewicht) aus einer Kultur in der späten logarithmischen Wachstumsphase isoliert werden (s. III.5.2). Boeck und Schinzel (1998) konnten aus T. thermophilus in der gleichen Wachstumsphase $28 \mathrm{mg}$ Glykogen /g Zellen isolieren.

Neben den essentiellen Enzymen des Glykogenabbaus, der Glykogen-Phosphorylase und der a-1,6-Glukosidase (Entzweigungsenzym), sind vermutlich weitere Enzyme an der Degradation von Glykogen und deren Regulation beteiligt. So können zum Beispiel $\alpha$ Amylasen den Abbau des Polymers beschleunigen, indem sie $\alpha$-1,4-Bindungen innerhalb des Moleküls hydrolysieren und so mehr reduzierende C4-Enden, d.h. Angriffspunkte für die Glykogen-Phosphorylase schaffen. Das genaue Zusammenspiel von Glykogendegradierenden Enzymen liegt auch bei gut untersuchten Glykogenabbau-Systemen noch teilweise im Dunkeln. So spekuliert Pallen (2003) auf Basis von AminosäuresequenzVergleichen, daß die $\alpha$ - und $\beta$-Untereinheiten der menschlichen Phosphorylase-Kinase (Phk) und die Phosphorylase-Kinase (PkgA) aus E. coli neben ihrer regulatorischen Funktion eine bislang übersehene glukoamylolytische Funktion haben könnten.

Wie die Genomsequenzierung zeigte, besitzt T. maritima viele intrazelluläre, amylolytische Enzyme, für die eine Beteiligung am Glykogenmetabolismus denkbar wäre (Nelson et al., 1999). Man kann davon ausgehen, daß Gene, deren Transkription durch Stärke induziert wird, Genprodukte kodieren, die am Abbau von Stärke bzw. der darauf folgenden Verstoffwechselung von Maltodextrinen beteiligt sind. Im Umkehrschluß könnten Gene, die in Anwesenheit von Stärke und Glukose keine oder nur geringe Änderungen in der Expressionsstärke zeigen, eine Rolle bei im Glykogenstoffwechsel spielen. Zu den intrazellulären Proteinen von T. maritima, deren Gene in Anwesenheit von Stärke oder Glukose keinen Expressionsunterschied zeigen und damit möglicherweise am Glykogenstoffwechsel beteiligt sind, gehören die MTase (Tm0767), AmyC (Tm1650), eine putative $\alpha$-Glukosidase (Tm0752), zwei putative Typ I-Glykosyltransferasen (Tm0392, Tm0744), die Gykogensynthase (Tm0895) und überraschenderweise AglA (Tm1834), obwohl das Gen für letzteres mit diversen Genen des Stärkeabbaus in einem Cluster vorliegt. Die Expression anderer Gene dieses Clusters, AmyA (tm1840), PulA (tm1845) und aglB (tm1835), wird erwartungsgemäß in Anwesenheit von Stärke induziert (Chhabra et al., 2003). Über die Expression des amyB-Tm(Tm1438)-Gens liegen bisher keine Erkenntnisse vor. 
Es kann vermutet werden, daß sich die gesamte Kontrolle des Zuckerstoffwechsels von T. maritima von der des Modellorganismus E. coli unterscheidet. Indizien dafür sind die ungewöhnlich hohe Zahl an Kohlenhydrat-aktiven Enzymen, die hohe Zahl an spezifischen Zuckertransportern, das Fehlen eines PEP-PT-Systems und die dadurch cAMP-unabhängige Regulation der Katabolitrepression (Nelson et al., 1999; Galperin et al., 1996; Vargas und Noll, 1996). Auch bei T. thermophilus konnten bisher keine Gene gefunden werden, die für Komponenten des PEP-PT-Systems kodieren (Henne et al., 2004).

Für T. thermophilus konnten Boeck und Schinzel (1998) zeigen, daß die Regulation des Glykogenmetabolismus von der von E. coli abweicht. So ist die Bildung von Glykogen in E. coli abhängig vom Stickstoffhaushalt der Zellen und der Art der C-Quelle. Stickstofflimitiertes Wachstum induziert die Glykogenbildung (Preiss, 1984, Preiss und Romeo, 1989). Bei T. thermophilus ist dies nicht der Fall. Dort wird Glykogen sowohl im Vollmedium als auch unter N-limitierten Bedingungen gebildet. Die Glykogen-Akkumulation beginnt bereits in der logarithmischen Wachstumsphase und die Glykogen-Phosphorylase wird nicht durch Glukose gehemmt (Boeck und Schinzel, 1998). Auch König et al. (1982) beobachteten beim Archaeon Sulfolobus acidocaldaricus zwar eine Abhängigkeit der Glykogen-Bildung von der C-Quelle, jedoch keine Steigerung durch niedrige N-Konzentrationen. Beim Wachstum in Medium mit Hefeextrakt ohne zusätzliche C-Quelle produzierte S. acidocaldarius 0,45 mg Glykogen/mg Zellprotein, was die gebildete Glykogenmenge beim Wachstum unter Nlimitierten Bedingungen mit Maltose oder Laktose als C-Quelle um ein dreifaches übertraf. Die Erkenntnisse über den Glykogenstoffwechsel von S. acidocaldaricus und T. thermophilus sind auch für T. maritima von Bedeutung, da der Organismus als den Archaeen sehr nahestehender Vertreter der Bakterien gilt. Das thermophile Bakterium T. thermophilus stammt ebenfalls aus einem recht ursprünglichen Zweig der Bakterien. Ferner kodiert das Gen TTC1540 aus T. thermophilus das AmyB-Tm-homologe Protein AmyB-Tt, welches möglicherweise am Glykogenmetabolismus beteiligt ist.

In dieser Arbeit konnte für in Vollmedium mit Glukose als C-Quelle kultivierte T. maritimaZellen die Präsenz eines Speicherglukans in der späten log-Phase gezeigt werden, welches in der stationären Phase nicht mehr nachweisbar war. Die Anwesenheit von AmyB-Tm in den Zellen konnte durch Western-Blots ebenfalls nur für die logarithmische Phase nachgewiesen werden, was zusätzlich zur Substratspezifität von AmyB-Tm für eine Beteiligung des Enzyms am Glykogenstoffwechsel spricht (s. III.4.2).

AmyB-Tm konnte auch in T. maritima-Zellen nachgewiesen werden, die in Vollmedium ohne zusätzliche C-Quelle gewachsen waren und in Zellen, die in Vollmedium mit Stärke als C- 
Quelle gewachsen waren. In Zellen, die in Mineralmedium mit Stärke als C-Quelle abgezogen wurden, ließ sich AmyB-Tm dagegen nicht nachweisen (s. III.4.1). Sollte die Anwesenheit von AmyB-Tm tatsächlich mit der Anwesenheit von Glykogen verknüpft sein, wären die Western-Blots ein Hinweis darauf, daß Glykogen auch in T. maritima unabhängig von einer $\mathrm{N}$-Limitierung, wie sie in E. coli Voraussetzung für die Glykogensynthese ist, gebildet wird.

\section{Maltose-Metabolismus}

Neben einer Rolle im Glykogenmetabolismus ist für AmyB-Tm auch eine Rolle beim intrazellulären Abbau von Maltooligosacchariden denkbar. Maltodextrine einer Größe von bis zu 7-8 Glukoseeinheiten, die durch den extrazellulären Abbau von Polysacchariden entstanden sind, werden durch den Maltosetransporter MalEFGK 2 in die Zelle geschleust. Dort werden sie von $\alpha$-Glukosidasen abgebaut. Für AgpA stellen die Maltodextrine vermutlich neben Glykogen ein weiteres Substrat dar, und werden so zumindest teilweise zu Glukose-1-Phosphat abgebaut. Der Abbau von Maltodextrinen durch AgpA liegt nahe, da AgpA die einzige $\alpha$-Glukan-Phosphorylase von T. maritima zu sein scheint. In E. coli dagegen liegen zwei Phosphorylasen vor, die spezifisch entweder Maltodextrine (MalP) oder Glykogen (glgP) abbauen (Boos und Shuman, 1998).

Es ist möglich, daß es zwischen Glykogenstoffwechsel und Maltoseabbau eine Verbindung besteht. Im Zusammenspiel von MalP, MalQ und MalZ beim Maltoseabbau in E. coli ist die Anwesenheit eines endogenen Maltodextrin-Primers von mindestens drei Glukoseeinheiten nötig. Beim Wachstum auf Maltose, bei dem keine Maltodextrine in die Zelle eintreten, muß dieser Primer im Zellinneren zu Verfügung gestellt werden. Möglicherweise fällt diese Aufgabe einer intrazellulären $\alpha$-Amylase zu, die Maltotriose aus Glykogen freisetzt (Boos und Shuman, 1998). In T. maritima wäre diese Rolle für AmyB-Tm möglich.

Neben Glykogen stellen auch kurzkettige Maltodextrine mit einer Kettenlänge von mehr als drei Glukoseeinheiten ein Substrat für AmyB-Tm dar. Dies macht eine Beteiligung von AmyB-Tm, zusätzlich zu den $\alpha$-Glukosidasen, am hydrolytischen Abbau der in die Zelle geschleusten Maltodextrine denkbar. Auch eine Beteiligung des Enzyms am Abbau von verzweigten Maltodextrinen, die zur Regulation des osmotischen Drucks im Cytoplasma von gebildet werden könnten, ist möglich.

Überraschend fanden Nguyen et al. (2004) in T. maritima Hinweise auf einen regulatorischen Zusammenhang zwischen der für die Zellen verfügbaren C-Quelle und intrazellulären RedoxProzessen bzw. der Expression von Eisen-Schwefel-Cluster enthaltenden Enzymen und Eisen-Transportern. Ob dies von Bedeutung für die einen Eisen-Cofaktor bindende und in ihrer Aktivität stark durch DTT beeinflußbare Amylase AmyB-Tm sein könnte, ist beim 
jetzigen Stand der noch in den Anfängen steckenden Transkriptionsanalyse von T. maritima noch nicht abzusehen.

\section{Vergleich zweier $\alpha$-Amylasen aus Anaerobranca gottschalkii}

Das anearobe thermoalkaliphile Bakterium A. gottschalkii besitzt zwei $\alpha$-Amylasen, AmyAAg und AmyB-Ag, von denen eine extrazelluär und eine im Cytoplasma lokalisiert ist. Für die extrazelluläre Amylase (AmyA-Ag) wird ein Lipoprotein-Signalpeptid vorhergesagt. Sie kann, obwohl wahrscheinlich membranassoziiert, im Überstand von A. gottschalkii-Kulturen nachgewiesen werden. AmyB-Ag besitzt kein Signalpeptid und ist als einziges amylolytisches Enzym im A. gottschalkii-Rohextrakt nachweisbar (s. III.10). Beide Enzyme zeigen die für $\alpha$ Amylasen typische Präferenz für intramolekulare $\alpha$-1,4-Bindungen von $\alpha$-Glukanen, und aufgrund ihrer Aminosäuresequenz sind beide Proteine, anders als AmyB-Tm und AmyB-Tt, der Glykosid-Hydrolase-Familie 13 zuzuordnen. Die Aminosäuresequenzen beider Enzyme, deren Identität bei 33 \% liegt, besitzen die für $\alpha$-Amylasen dieser Familie typischen vier konservierten Regionen. Weiterhin ist allen Proteinen der GHF 13 das $(\beta / \alpha)_{8}$-Faß als Faltungsmotiv gemeinsam. Im Gegensatz zur GHF 57 umfaßt die GHF 13 eine ausreichende Zahl biochemisch charakterisierter Proteine, um statistische Aussagen über den Zusammenhang von bestimmten Sequenzabschnitten und der Enzymaktivität treffen zu können. So sind die beiden letzten Aminosäurereste in der konservierten Region II von GHF 13-Proteinen laut MacGregor et al. (2001) ausschlaggebend für die Substratspezifität. Sowohl bei AmyA-Ag als auch bei AmyB-Ag befinden sich an dieser Stelle ein Lysin und ein Histidin, was die Beobachtung bestätigt, daß diese beiden Reste an der genannten Position

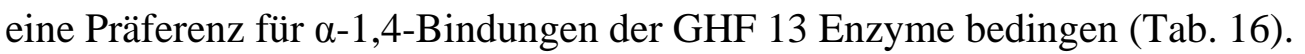

Tab. 16: Vergleich der vier hochkonservierten GHF $13 \alpha$-Amylase-Regionen von AmyA-Ag und AmyB-Ag mit denen der TAKA-Amylase aus Aspergillus oryzae, dem Modellenzym der GHF 13 (Toda et al., 1982). Die drei katalytischen Aminosäuren sind schwarz unterlegt, die die $\alpha-1,4,-$ Spezifität vermittelnden Reste sind grau hinterlegt. Die Numerierung der Aminosäuresequenzen beginnt am Amino-Terminus des jeweiligen (prozessierten) Enzyms.

\begin{tabular}{|c|c|c|c|c|}
\hline Enzym & Region I & Region II & Region III & Region IV \\
\hline TAKA-Amylase & 117 DVVANH & 202 GLRIDTVKH & 229 GEVLD & 292 FVENHD \\
\hline AmyA-Ag & 150 DLVVNH & 238 GFRLDAAKH & 276 GEIWD & 339 FLSNHD \\
\hline AmyB-Ag & 108 DIVVNH & 180 GFRIDTVKH & 212 GEVWH & 274 FIDNHD \\
\hline
\end{tabular}


Auf die beschriebenen biochemischen und katalytischen Eigenschaften der Enzyme, z.B. die $\beta$-Cyclodextrinbildung durch AmyA-Ag (Ballschmiter et al., 2005), wird an dieser Stelle nicht weiter eingegangen. Statt dessen soll der Blick auf die physikochemischen Unterschiede der $\alpha$-Amylasen gelenkt werden. In diesen spiegelt sich deutlich die unterschiedliche zelluläre Lokalisierung von AmyA-Ag und AmyB-Ag in A. gottschalkii wider. Insbesondere das $\mathrm{pH}-$ Optimum und der pH-Bereich der jeweiligen enzymatischen Aktivität zeigen die Anpassung der Amylasen an ihre Umgebung (s. III.10). AmyA-Ag zeigt Aktivität im Bereich von pH 6,0 - 9,5 mit einem Optimum bei pH 8,0. Als Lipoprotein ist das Enzym direkt dem alkalischen Milieu der Umgebung ausgesetzt, in der A. gottschalkii lebt. Das Bakterium selbst wächst zwischen pH 6,0 und 10,5, was etwa dem Aktivitätsbereich von AmyA-Ag entspricht (Prowe und Antranikian, 2001). Auch die zwei anderen bisher untersuchten extrazellulären Enzyme von A. gottschalkii, eine Pullulanase und eine CGTase, zeigen eine solche Anpassung an den pH-Bereich des Ursprungsorganismus (Bertoldo et al., 2004; Thiemann et al., 2004).

Die intrazelluläre $\alpha$-Amylase AmyB-Ag hat ein $\mathrm{pH}$-Optimum von $\mathrm{pH}$ 6,0 und ist insgesamt in einem viel engeren $\mathrm{pH}$-Bereich als AmyA-Ag aktiv (s. III.10). Das niedrigere pH-Optimum stellt eine Anpassung an die intrazellulären Bedingungen dar, denn der intrazelluläre pH-Wert alkaliphiler Bakterien liegt für gewöhnlich 1-2 pH-Einheiten unter dem $\mathrm{pH}$-Wert des sie umgebenden Mediums. Auch sind Schwankungen des internen pH-Werts aufgrund der zellulären $\mathrm{pH}$-Homeostasis gering, wodurch sich die geringere Toleranz der intrazellulären $\alpha$ Amylase gegenüber pH-Änderungen erklärt. Im Umgebungsmedium ist dies anders. Das thermoalkaliphile Bakterium A. gottschalkii stammt aus einer Heißwasserquelle im Natron See Lake Bogoria, Kenia (Prowe und Antranikian, 2001). Hier dringt heißes Süßwasser in den See ein und vermischt sich mit dessem alkalischen Wasser. Es ist also zu erwarten, daß der Organismus, und damit auch seine extrazellulären Enzyme, pH-Schwankungen in seinem Habitat ausgesetzt sind. Die extrazelluläre $\alpha$-Amylase mit ihrem größeren $\mathrm{pH}$-Spektrum ist in der Lage, ihre Aktivität auch unter wechselnden Bedingungen aufrechtzuerhalten.

Die Temperatur, bei der AmyA-Ag und AmyB-Ag maximale Aktivität zeigen, unterscheidet sich mit $70{ }^{\circ} \mathrm{C}$ bzw. $55{ }^{\circ} \mathrm{C}$ (s. III.10). Bemerkenswerter noch ist der Unterschied in der Thermostabilität der Enzyme. Während die Aktivität von AmyA-Ag bei $70{ }^{\circ} \mathrm{C}$ eine Halbwertszeit von $48 \mathrm{~h}$ hat, sinkt die Aktivität von AmyB-Ag bei dieser Temperatur bereits nach 10 min auf $50 \%$. Auch hier spiegelt sich offenbar die unterschiedliche Lokalisierung wider. AmyB-Ag könnte durch die intrazelluläre Umgebung (hohe Polymerkonzentration, Anwesenheit von Chaperonen) in gewissem Ausmaß geschützt werden. Aber auch im Falle einer raschen Denaturierungsrate in vivo ist vorstellbar, daß AmyB-Ag schnell in 
ausreichender Konzentration neu synthetisiert werden kann, während die Neusynthese und nachfolgende Sekretion von AmyA-Ag ungleich energieaufwendiger wäre.

Im Gegensatz zu den Beobachtungen bei AmyB-Tm aus T. maritima hatte Kalzium auf die Aktivität von AmyA-Ag einen positiven Effekt. EDTA kann jedoch die Aktivität unter bestimmten Bedingungen, namentlich in Tris-Puffer, senken. In MacIlvaine- und HEPESPuffer hat EDTA keinen Effekt auf die Aktivität. Dabei spielte es keine Rolle, ob das Enzym bei der Reaktionstemperatur $\left(60^{\circ} \mathrm{C}\right)$ mit EDTA präinkubiert wurde oder ob auf diesen Schritt verzichtet wurde (s. III.10.). Dies deutet darauf hin, daß die Temperatur und damit die hitzebedingte höhere Flexibilität der Peptidketten im Enzym keinen Einfluß auf die Empfindlichkeit gegenüber EDTA hat. Vielmehr scheint es sich hier um einen reinen Puffereffekt zu handeln. Möglicherweise wird ein im Enzym sehr fest gebundenes KalziumIon nur dann freigesetzt, wenn das Enzym durch Tris destabilisiert wird. Dieser durch Tris ausgelöste Effekt wurde bisher noch nicht beobachtet, aber bei mehreren $\alpha$-Amylasen wurde eine Wirkung von Tris als kompetitiver Inhibitor beschrieben (Linden et al., 2003; Aghajari et al., 1998). Mit Ausnahme der Testansätze mit Tris-Puffer hat sich die Amylase Amy-Ag als Chelator-resistent erwiesen, was sie zusammen mit ihrer hohen Temperaturtoleranz und ihrem alkalischen pH-Optimum zu einem geeigneten Enzym für industrielle Anwendungen macht. Die pH- und Temperaturspektren von AmyA-Ag und AmyB-Ag demonstrieren die evolutionäre Anpassung der $\alpha$-Amylasen aus A.gottschalkii an die verschiedenartigen Erfordernisse ihrer jeweiligen Umgebung. Die unterschiedlichen physikochemischen Eigenschaften zeigen, daß trotz gemeinsamen Faltungsmotivs (TIM-barrel) und gemeinsamer invariabler Regionen, trotz 33 \% Identität der Aminosäuresequenz und einem gemeinsamen Herkunftsorganismus durch kleine Variationen große Veränderungen der Enzymeigenschaften möglich sind. 


\section{Zusammenfassung}

Im Rahmen dieser Arbeit wurden die $\alpha$-Amlyasen AmyB aus T. maritima (AmyB-Tm), AmyB aus T. thermophilus (AmyB-Tt) und AmyA sowie AmyB aus A. gottschalkii (AmyAAg und AmyB-Ag) untersucht. Der Schwerpunkt lag dabei auf dem Enzym aus T. maritima. Nach Überexpression in E. coli und Aufreinigung durch Hitzedenaturierung der Wirtsproteine und Anionenaustauschchromatographie betrug die spezifische Aktivität des rekombinanten AmyB-Tm-Proteins 0,6 U/mg, gemessen bei $90{ }^{\circ} \mathrm{C}$ in $50 \mathrm{mM}$ Tris-Puffer ( $\mathrm{pH} \mathrm{8,0}{ }^{90^{\circ} \mathrm{C}}$ ) mit löslicher Stärke als Substrat. Die Aktivität von AmyB-Tm ließ sich durch Reduktionsmittel (L-Cystein, $\beta$-Mercaptoethanol, DTT) steigern, wobei die maximale Aktivität in Anwesenheit von $10 \mathrm{mM}$ DTT erreicht wurde. Durch kinetische Studien konnte der $V_{\max }$-Wert mit 1,3 U/mg und der $K_{\mathrm{m}}$-Wert mit $1,1 \mathrm{mg} / \mathrm{ml}$ bestimmt werden. AmyB-Tm ist außergewöhnlich empfindlich gegenüber komplexierenden Agenzien und wurde bereits von 0,1 mM EDTA vollständig gehemmt. Auch $\mathrm{Mg}^{2+}$ und $\mathrm{Ca}^{2+}$ haben ebenso wie Acarbose eine hemmende Wirkung auf das Enzym. Es konnte nachgewiesen werden, daß die in einer früheren Arbeit beobachtete Hemmung von AmyB-Tm durch ATP und ADP ein unspezifischer Effekt ist, der auf der komplexierenden Wirkung der Nukleotide beruht. Eisen konnte biochemisch und röntgenspektroskopisch als Cofaktor von AmyB-Tm nachgewiesen werden. Die Abhängigkeit des Enzyms von Reduktionsmitteln spricht dafür, daß Eisen als $\mathrm{Fe}^{2+}$ vorliegen muß, um einen positiven Effekt auf AmyB-Tm zu haben.

Ein Großteil von AmyB-Tm liegt bei der heterologen Expression in unlöslicher Form vor. Weder durch einen Wechsel des Expressionsvektors noch durch einen Wechsel des Expressionswirts hin zu C. glutamicum gelang es, den Anteil an unlöslichem Protein zu senken, bzw. die je nach Aufreinigung schwankende spezifische Aktivität des rekombinanten Proteins zu steigern. Auch durch die anaerobe Aufarbeitung des AmyB-Tm-Proteins konnte keine Steigerung der Aktivität erzielt werden. Es gibt Hinweise darauf, daß die Wachstumsphase des Expressionswirtes und die Menge des produzierten rekombinanten Proteins Einfluß auf die Aktivität haben.

Durch immunologische Methoden wurde die Anwesenheit von nativem AmyB-Tm in T. maritima in der logarithmischen Wachstumsphase nachgewiesen. In der stationären Phase des Wachstums ließ sich AmyB-Tm nicht nachweisen.

T. maritima besitzt mehrere vorhergesagte Enzyme des Glykogenmetabolismus. In dieser Arbeit konnte erstmalig aus T. maritima ein Speicherpolysaccharid isoliert (56 $\mu \mathrm{g} / \mathrm{g}$ Zellen nach Wachstum auf Vollmedium mit 0,5 \% Glukose) und als $\alpha$-Glukan charakterisiert werden. In Wachstumsversuchen konnte die Präsenz des $\alpha$-Glukans unabhängig von einer 
Stickstoff-Limitierung in der späten logarithmischen Phase nachgewiesen werden. Das gleichzeitige, wachstumsabhängige Auftreten des nativen AmyB-Tm-Proteins und des $\alpha$ Glukans in T. maritima spricht dafür, daß AmyB-Tm am Glykogenmetabolismus beteiligt ist. In Kooperation mit der Arbeitsgruppe von Prof. Ficner (Molekulare Strukturbiologie, Göttingen) gelang die Kristallisation und Röntgenstrukturaufklärung von AmyB-Tm mit einer Auflösung von 2,3 Å. Durch die Strukturanalyse zeigte sich, daß das Enzym ein verzerrtes, siebensträngiges $(\beta / \alpha)$-Faß-Faltungsmotiv besitzt. Eine solche Supersekundärstruktur ist im Gegensatz zu dem weit verbreiteten $(\beta / \alpha)_{8}$-Faß erst in wenigen Proteinen gefunden worden. Als katalytische Aminosäuren von AmyB-Tm konnten Glu185 und Asp349, die am CTerminus des $(\beta / \alpha)_{7}$-Fasses liegen, identifiziert werden. In unmittelbarer Nähe zum katalytischen Zentrum wurde eine potentielle Eisenbindestelle gefunden, gebildet aus den Seitenketten der Aminosäuren His10, His12, Cys142 und His146. Durch gezielte ortsspezifische Mutagenese wurde das in der Nähe des katalytischen Zentrums liegende Cys186 in ein Serin überführt. Dadurch konnte jedoch keine signifikante Veränderung der biochemischen Eigenschaften von AmyB-Tm herbeigeführt werden.

Das zu AmyB-Tm ähnliche Protein AmyB-Tt aus T. thermophilus wurde in E. coli überexprimiert und aufgereinigt. Die spezifische Aktivität des rekombinanten Proteins betrug $40 \mathrm{mU} / \mathrm{mg}$. Die höchste katalytische Aktivität des Enzyms wurde im Aktivitätstest mit löslicher Stärke bei $70{ }^{\circ} \mathrm{C}$ und pH 6,5 (50 mM PIPES-Puffer) in Anwesenheit von $1 \mathrm{mM}$ DTT gemessen.

Die Enzyme AmyB-Tm und AmyB-Tt gehören zu den in der COG1543 zusammengefassten Proteinen. Durch die biochemische Charakterisierung von AmyB-Tm und AmyB-Tt als $\alpha-$ Amylasen konnte der COG1543 erstmals eine Funktion zugewiesen werden. Gleichzeitig konnte die COG1543 als Unterfamilie der GHF 57 identifiziert werden.

Ein weiterer Teil der Arbeit befaßte sich mit mit zwei zur GHF 13 gehörenden $\alpha$-Amylasen von A. gottschalkii, einem thermoalkaliphilen Bakterium. Im Rohextrakt von A. gottschalkii konnte die $\alpha$-Amylase AmyB-Ag nachgewiesen und damit die vermutete intrazelluläre Lokalisierung des Enzyms bestätigt werden. Für die extrazelluläre $\alpha$-Amylase AmyA-Ag konnte gezeigt werden, daß die Zugänglichkeit des vermutlich im Enzym gebundenen Kalziums für Chelatoren vom Puffersystem abhängig ist. In MacIlvaine- und HEPES-Puffer konnte kein Effekt von EDTA auf AmyA-Ag beobachtet werden, während Tris-Puffer das Enzym offenbar soweit destabilisiert, daß das $\mathrm{Ca}^{2+}$ für EDTA zugänglich wird. Die Eigenschaften von AmyA-Ag und AmyB-Ag spiegelten ihre zelluläre Lokalisation (extrazellulär bzw. intrazellulär) wider. 


\section{Literaturverzeichnis}

Achenbach-Richter, L., R. Gupta, K. O. Stetter und C. R. Woese. 1987. Were the original eubacteria thermophiles? Syst Appl Microbiol 9:34-9.

Aghajari, N., G. Feller, C. Gerday und R. Haser. 1998. Crystal structures of the psychrophilic alpha-amylase from Alteromonas haloplanctis in its native form and complexed with an inhibitor. Protein Sci 7:564-72.

Altschul, S. F., T. L. Madden, A. A. Schaffer, J. Zhang, Z. Zhang, W. Miller und D. J. Lipman. 1997. Gapped BLAST and PSI-BLAST: a new generation of protein database search programs. Nucleic Acids Res 25:3389-402.

Andreeva, A., D. Howorth, S. E. Brenner, T. J. Hubbard, C. Chothia und A. G. Murzin. 2004. SCOP database in 2004: refinements integrate structure and sequence family data. Nucleic Acids Res 32:D226-9.

Anindyawati, T., R. Melliawati, K. Ito, M. Iizuka und N. Minamiura. 1998. Three different types of alpha-amylases from Aspergillus awamori KT-11: their purifications, properties and specificities. Biosci. Biotechnol. Biochem. 62:1351-1357.

Armbrecht, M. 2003. Lokalisierung und Charakterisierung amylolytischer Enzyme aus Thermotoga maritima MSB8 und Anaerobranca gottschalkii. Dissertation zur Erlangung des Doktorgrades der Mathematisch-Naturwissenschaftlichen Fakultäten der Georg-August-Universität Göttingen.

Arthur, P. K. 2003. Analysis of novel amylase genes. Master's Thesis am Institut für Mikrobiologie und Genetik, Universität Göttingen, unveröffentlicht.

Bachmann, B. J. 1987. Linkage map of Escherichia coli K12, p. 807-876. In F. C. Neidhardt, J. L. Ingraham, K. B. Low, B. Magasanik, M. Schaechter, and U. H. E. (Hrsg.), Escherichia coli and Salomonella typhimurium: Cellular and molecular biology, 7. Ausg. ASM, Washington, D.C.

Ballschmiter, M. 2001. Klonierung, Expression und Charakterisierung einer alpha-Amylase aus Anaerobranca gottschalkii. Diplomarbeit am Institut für Mikrobiologie und Genetik, Universität Göttingen, unveröffentlicht.

Ballschmiter, M., M. Armbrecht, K. Ivanova, G. Antranikian und W. Liebl. 2005. AmyA, an alpha-Amylase with beta-cyclodextrin-forming activity, and AmyB from the thermoalkaliphilic Anaerobranca gottschalkii: two alpha-Amylases adapted to their different cellular localization. Appl Environ Microbiol. Im Druck.

Belkin, S., C. O. Wirsen und H. W. Jannasch. 1986. A new sulfur-reducing, extremely thermophilic eubacterium from a submarine thermal vent. Appl Environ Microbiol 51:1180-1185.

Bertoldo, C. und G. Antranikian. 2001. Amylolytic enzymes from hyperthermophiles. Methods Enzymol 330:269-89. 
Bertoldo, C., M. Armbrecht, F. Becker, T. Schafer, G. Antranikian und W. Liebl. 2004. Cloning, sequencing, and characterization of a heat- and alkali-stable type I pullulanase from Anaerobranca gottschalkii. Appl Environ Microbiol 70:3407-16.

Bibel, M., C. Brettl, U. Gosslar, G. Kriegshauser und W. Liebl. 1998. Isolation and analysis of genes for amylolytic enzymes of the hyperthermophilic bacterium Thermotoga maritima. FEMS Microbiol Lett 158:9-15.

Birnboim, H. C. und J. Doly. 1979. A rapid alkaline extraction procedure for screening recombinant plasmid DNA. Nucleic Acids Res 7:1513-23.

Blochl, E., R. Rachel, S. Burggraf, D. Hafenbradl, H. W. Jannasch und K. O. Stetter. 1997. Pyrolobus fumarii, gen. and sp. nov., represents a novel group of archaea, extending the upper temperature limit for life to 113 degrees C. Extremophiles 1:1421.

Boeck, B. und R. Schinzel. 1998. Growth dependence of alpha-glucan phosphorylase activity in Thermus thermophilus. Res Microbiol 149:171-6.

Boel, E., L. Brady, A. M. Brzozowski, Z. Derewenda, G. G. Dodson, V. J. Jensen, S. B. Petersen, H. Swift, L. Thim und H. F. Woldike. 1990. Calcium binding in alphaamylases: an X-ray diffraction study at 2.1-A resolution of two enzymes from Aspergillus. Biochemistry 29:6244-9.

Boos, W. und H. Shuman. 1998. Maltose/maltodextrin system of Escherichia coli: transport, metabolism, and regulation. Microbiol Mol Biol Rev 62:204-29.

Bradford, M. M. 1976. A rapid and sensitive method for the quantitation of microgram quantities of protein utilizing the principle of protein-dye binding. Anal Biochem 72:248-54.

Brzozowski, A. M. und G. J. Davies. 1997. Structure of the Aspergillus oryzae alphaamylase complexed with the inhibitor acarbose at 2.0 A resolution. Biochemistry 36:10837-45.

Bullock, W., J. Fernandez und J. Short. 1987. XL1-blue: A high efficiency plasmid transforming recA Escherichia coli strain with beta-galactosidase selection. Bio Techniques 5:376-378.

Calmes, R. und A. T. Brown. 1979. Regulation of lactose catabolism in Streptococcus mutans: purification and regulatory properties of phospho-beta-galactosidase. Infect Immun 23:68-79.

Chhabra, S. R., K. R. Shockley, S. B. Conners, K. L. Scott, R. D. Wolfinger und R. M. Kelly. 2003. Carbohydrate-induced differential gene expression patterns in the hyperthermophilic bacterium Thermotoga maritima. J Biol Chem 278:7540-52.

Davies, G. und B. Henrissat. 1995. Structures and mechanisms of glycosyl hydrolases. Structure 3:853-9. 
Davies, G. J., A. M. Brzozowski, M. Dauter, A. Varrot und M. Schulein. 2000. Structure and function of Humicola insolens family 6 cellulases: structure of the endoglucanase, Cel6B, at 1.6 A resolution. Biochem J 348 Pt 1:201-7.

DeLong, E. F. 2001. A phylogenetic perspective on hyperthermophilic microorganisms. Methods Enzymol 330:3-11.

Di Giulio, M. 2003. The universal ancestor was a thermophile or a hyperthermophile: tests and further evidence. J Theor Biol 221:425-36.

Engel, A. M., Z. Cejka, A. Lupas, F. Lottspeich und W. Baumeister. 1992. Isolation and cloning of Omp alpha, a coiled-coil protein spanning the periplasmic space of the ancestral eubacterium Thermotoga maritima. Embo J 11:4369-78.

Fish, W. W. 1988. Rapid colorimetric micromethod for the quantitation of complexed iron in biological samples. Methods Enzymol 158:357-64.

Forouhar, F., W. Edstrom, J. Khan, L. Ma, Y. Chiang, T. B. Acton, G. T. Montelione, J. F. Hunt und L. Tong. Crystal Structure of Polysaccharide Deacetylase (Pdaa_Bacsu) from B. subtilis (Pdaa_Bacsu) Northeast Structural Genomics Research Consortium (Nesg) Target Sr127. Nicht publiziert.

Fukui, T., H. Atomi, T. Kanai, R. Matsumi, S. Fujiwara und T. Imanaka. 2005. Complete genome sequence of the hyperthermophilic archaeon Thermococcus kodakaraensis KOD1 and comparison with Pyrococcus genomes. Genome Res 15:352-63.

Fukusumi, S., A. Kamizono, S. Horinouchi und T. Beppu. 1988. Cloning and nucleotide sequence of a heat stable amylase gene from an anaerobic thermophile, Dictyoglomus thermophilum. Eur J Biochem 174:15-21.

Fütterer, O. 2001. Vergleichende Untersuchung von drei Amylasen des hyperthermophilen Bakteriums Thermotoga maritima MSB8. Dissertation zur Erlangung des Doktorgrades der Mathematisch-Naturwissenschaftlichen Fakultäten der GeorgAugust-Universität zu Göttingen.

Galperin, M. Y., K. M. Noll und A. H. Romano. 1996. The glucose transport system of the hyperthermophilic anaerobic bacterium Thermotoga neapolitana. Appl Environ Microbiol 62:2915-8.

Glew, R. H., S. P. Peters und A. R. Christopher. 1976. Isolation and characterization of beta-glucosidase from the cytosol of rat kidney cortex. Biochim Biophys Acta 422:179-99.

Gouet, P., E. Courcelle, D. I. Stuart und F. Metoz. 1999. ESPript: analysis of multiple sequence alignments in PostScript. Bioinformatics 15:305-8.

Green, S. M., A. Ginsburg, M. S. Lewis und P. Hensley. 1991. Roles of metal ions in the maintenance of the tertiary and quaternary structure of arginase from Saccharomyces cerevisiae. J Biol Chem 266:21474-81. 
Hanahan, D. 1983. Studies on transformation of Escherichia coli with plasmids. J Mol Biol 166:557-80.

Heikinheimo, P., R. Helland, H. K. Leiros, I. Leiros, S. Karlsen, G. Evjen, R. Ravelli, G. Schoehn, R. Ruigrok, O. K. Tollersrud, S. McSweeney und E. Hough. 2003. The structure of bovine lysosomal alpha-mannosidase suggests a novel mechanism for low-pH activation. J Mol Biol 327:631-44.

Henne, A., H. Bruggemann, C. Raasch, A. Wiezer, T. Hartsch, H. Liesegang, A. Johann, T. Lienard, O. Gohl, R. Martinez-Arias, C. Jacobi, V. Starkuviene, S. Schlenczeck, S. Dencker, R. Huber, H. P. Klenk, W. Kramer, R. Merkl, G. Gottschalk und H. J. Fritz. 2004. The genome sequence of the extreme thermophile Thermus thermophilus. Nat Biotechnol 22:547-53.

Henrissat, B. 1991. A classification of glycosyl hydrolases based on amino acid sequence similarities. Biochem J 280 ( Pt 2):309-16.

Henrissat, B. und A. Bairoch. 1996. Updating the sequence-based classification of glycosyl hydrolases. Biochem J 316 ( Pt 2):695-6.

Huber, R., T. A. Langworthy, H. Köning, M. Thomm, C. R. Woese, U. B. Sleytr und K. O. Stetter. 1986. Thermotoga maritima sp. nov. represents a new genus of unique extremely thermophilic eubacteria growing up to $90^{\circ} \mathrm{C}$. Arch Microbiol 144:324-333.

Huber, R. und K. O. Stetter. 1992. The order Thermotogales, p. 3809-3815. In A. Balows, H. G. Trüper, M. Dworkin, W. Harder und K. H. Schleifer (Hrsg.), The Prokaryotes. Springer Verlag, New York.

Idaka, M., T. Terada, K. Murayama, H. Yamaguchi, O. Nureki, R. Ishitani, S. Kuramitsu, M. Shirouzu und S. Yokoyama. Crystal Structure of Tt1467 from Thermus Thermophilus HB8. Nicht publiziert.

Illingworth, B., J. Larner und G. T. Cori. 1952. Structure of glycogens and amylopectins. I. Enzymatic determination of chain length. J Biol Chem 199:631-40.

Imamura, H., S. Fushinobu, B. S. Jeon, T. Wakagi und H. Matsuzawa. 2001. Identification of the catalytic residue of Thermococcus litoralis 4-alphaglucanotransferase through mechanism-based labeling. Biochemistry 40:12400-6.

Imamura, H., S. Fushinobu, M. Yamamoto, T. Kumasaka, B. S. Jeon, T. Wakagi und H. Matsuzawa. 2003. Crystal structures of 4-alpha-glucanotransferase from Thermococcus litoralis and its complex with an inhibitor. J Biol Chem 278:19378-86.

Jeon, B. S., H. Taguchi, H. Sakai, T. Ohshima, T. Wakagi und H. Matsuzawa. 1997. 4alpha-glucanotransferase from the hyperthermophilic archaeon Thermococcus litoralis: enzyme purification and characterization, and gene cloning, sequencing and expression in Escherichia coli. Eur J Biochem 248:171-8.

König, H., R. Skorko, W. Zillig und W. D. Reiter. 1982. Glycogen in thermoacidophilic Archaebacteria of the genera Sulfolobus, Thermoproteus, Desulfurococcus and Thermococcus. Arch Microbiol 132:297-303. 
Koyama, Y., T. Hoshino, N. Tomizuka und K. Furukawa. 1986. Genetic transformation of the extreme thermophile Thermus thermophilus and of other Thermus spp. J Bacteriol 166:338-40.

Kumar, S., K. Tamura, I. B. Jakobsen und M. Nei. 2001. MEGA2: molecular evolutionary genetics analysis software. Bioinformatics 17:1244-5.

Laderman, K. A., B. R. Davis, H. C. Krutzsch, M. S. Lewis, Y. V. Griko, P. L. Privalov und C. B. Anfinsen. 1993. The purification and characterization of an extremely thermostable alpha-amylase from the hyperthermophilic archaebacterium Pyrococcus furiosus. J Biol Chem 268:24394-401.

Laemmli, U. K. 1970. Cleavage of structural proteins during the assembly of the head of bacteriophage T4. Nature 227:680-5.

Lengeler, J. W., G. Drews und H. G. Schlegel. 1999. Biology of the Prokaryotes, 1. Aufl. Thieme Verlag, Stuttgart.

Liebl, W., A. Bayerl, B. Schein, U. Stillner und K. H. Schleifer. 1989. High efficiency electroporation of intact Corynebacterium glutamicum cells. FEMS Microbiol Lett 53:299-303.

Liebl, W., A. J. Sinskey und K. H. Schleifer. 1992. Expression, secretion, and processing of staphylococcal nuclease by Corynebacterium glutamicum. J Bacteriol 174:1854-61.

Liebl, W., I. Stemplinger und P. Ruile. 1997. Properties and gene structure of the Thermotoga maritima alpha-amylase AmyA, a putative lipoprotein of a hyperthermophilic bacterium. J Bacteriol 179:941-8.

Lim, W. J., S. R. Park, C. L. An, J. Y. Lee, S. Y. Hong, E. C. Shin, E. J. Kim, J. O. Kim, H. Kim und H. D. Yun. 2003. Cloning and characterization of a thermostable intracellular alpha-amylase gene from the hyperthermophilic bacterium Thermotoga maritima MSB8. Res Microbiol 154:681-7.

Linden, A., O. Mayans, W. Meyer-Klaucke, G. Antranikian und M. Wilmanns. 2003. Differential regulation of a hyperthermophilic alpha-amylase with a novel (Ca,Zn) two-metal center by zinc. J Biol Chem 278:9875-84.

MacGregor, E. A., S. Janecek und B. Svensson. 2001. Relationship of sequence and structure to specificity in the alpha-amylase family of enzymes. Biochim Biophys Acta 1546:1-20.

Markovic-Housley, Z., G. Miglierini, L. Soldatova, P. J. Rizkallah, U. Müller und T. Schirmer. 2000. Crystal structure of hyaluronidase, a major allergen of bee venom. Structure Fold Des 8:1025-35.

McCarter, J. D. und S. G. Withers. 1994. Mechanisms of enzymatic glycoside hydrolysis. Curr Opin Struct Biol 4:885-92. 
Murzin, A. G., S. E. Brenner, T. Hubbard und C. Chothia. 1995. SCOP: a structural classification of proteins database for the investigation of sequences and structures. $\mathrm{J}$ Mol Biol 247:536-40.

Nagano, N., C. T. Porter und J. M. Thornton. 2001. The $(\beta / \alpha)_{8}$ glycosidases: sequence and structure analyses suggest distant evolutionary relationships. Protein Eng 14:845-55.

Narahara, E., Y. Makino und K. Omichi. 2001. Glycogen debranching enzyme in bovine brain. J Biochem (Tokyo) 130:465-70.

Nelson, K. E., R. A. Clayton, S. R. Gill, M. L. Gwinn, R. J. Dodson, D. H. Haft, E. K. Hickey, J. D. Peterson, W. C. Nelson, K. A. Ketchum, L. McDonald, T. R. Utterback, J. A. Malek, K. D. Linher, M. M. Garrett, A. M. Stewart, M. D. Cotton, M. S. Pratt, C. A. Phillips, D. Richardson, J. Heidelberg, G. G. Sutton, R. D. Fleischmann, J. A. Eisen, O. White, S. L. Salzberg, H. O. Smith, J. C. Venter und C. M. Fraser. 1999. Evidence for lateral gene transfer between Archaea and bacteria from genome sequence of Thermotoga maritima. Nature 399:323-9.

Nguyen, T. N., A. D. Ejaz, M. A. Brancieri, A. M. Mikula, K. E. Nelson, S. R. Gill und K. M. Noll. 2004. Whole-genome expression profiling of Thermotoga maritima in response to growth on sugars in a chemostat. J Bacteriol 186:4824-8.

Nisbet, E. G. und N. H. Sleep. 2001. The habitat and nature of early life. Nature 409:108391.

Nolling, J., G. Breton, M. V. Omelchenko, K. S. Makarova, Q. Zeng, R. Gibson, H. M. Lee, J. Dubois, D. Qiu, J. Hitti, Y. I. Wolf, R. L. Tatusov, F. Sabathe, L. DoucetteStamm, P. Soucaille, M. J. Daly, G. N. Bennett, E. V. Koonin, und D. R. Smith. 2001. Genome sequence and comparative analysis of the solvent-producing bacterium Clostridium acetobutylicum. J Bacteriol 183:4823-38.

Orengo, C. A., A. D. Michie, S. Jones, D. T. Jones, M. B. Swindells und J. M. Thornton. 1997. CATH: a hierarchic classification of protein domain structures. Structure 5:1093-108.

Oshima, T. und K. Imahori. 1974. Physiochemical properties of deoxyribonucleic acid from an extreme thermophile. J Biochem (Tokyo) 75:179-83.

Painbeni, E., S. Valles, J. Polaina und A. Flors. 1992. Purification and characterization of a Bacillus polymyxa beta-glucosidase expressed in Escherichia coli. J Bacteriol 174:3087-91.

Pallen, M. J. 2003. Glucoamylase-like domains in the alpha- and beta-subunits of phosphorylase kinase. Protein Sci 12:1804-7.

Patton, C., S. Thompson und D. Epel. 2004. Some precautions in using chelators to buffer metals in biological solutions. Cell Calcium 35:427-431.

Preiss, J. 1984. Bacterial glycogen synthesis and its regulation. Annu Rev Microbiol 38:41958. 
Preiss, J. und T. Romeo. 1989. Physiology, biochemistry and genetics of bacterial glycogen synthesis. Adv Microb Physiol 30:183-238.

Prowe, S. 1996. Characterization of extracellular amylolytic enzymes and sodium coupled energy transduction of a newly isolated thermoalkaliphilic bacterium Thermoalcalibacter bogoriae. Dissertation zur Erlangung des Doktorgrades am Lehrstuhl für Technische Mikrobiologie der Technischen Universität HamburgHarburg.

Prowe, S. G. und G. Antranikian. 2001. Anaerobranca gottschalkii sp. nov., a novel thermoalkaliphilic bacterium that grows anaerobically at high $\mathrm{pH}$ and temperature. Int J Syst Evol Microbiol 51:457-65.

Raasch, C., W. Streit, J. Schanzer, M. Bibel, U. Gosslar und W. Liebl. 2000. Thermotoga maritima AglA, an extremely thermostable NAD+-, Mn2+-, and thiol-dependent alpha-glucosidase. Extremophiles 4:189-200.

Raasch, C. 2001. Molekulare, biochemische und strukturelle Untersuchungen an amylolytischen Enzymen von Thermotoga maritima MSB8. Dissertation zur Erlangung des Doktorgrades der Mathematisch-Naturwissenschaftlichen Fakultäten der Georg-August-Universität zu Göttingen.

Raha, M., I. Kawagishi, V. Muller, M. Kihara und R. M. Macnab. 1992. Escherichia coli produces a cytoplasmic alpha-amylase, AmyA. J Bacteriol 174:6644-52.

Savchenko, A., C. Vieille, S. Kang und J. G. Zeikus. 2002. Pyrococcus furiosus alphaamylase is stabilized by calcium and zinc. Biochemistry 41:6193-201.

Schröder, C., M. Selig und P. Schönheit. 1994. Glucose fermentation to acetate, $\mathrm{CO}_{2}$ and $\mathrm{H}_{2}$ in the anaerobic hyperthermophilic eubacterium Thermotoga maritima: involvement of the Embden-Meyerhof pathway. Arch Microbiol 161:460-470.

Selig, M., K. B. Xavier, H. Santos und P. Schönheit. 1997. Comparative analysis of Embden-Meyerhof and Entner-Doudoroff glycolytic pathways in hyperthermophilic archaea and the bacterium Thermotoga. Arch Microbiol 167:217-32.

Sinnot, M. L. 1990. Catalytic mechanisms of enzymatic glycosyl transfer. Chem. Rev. 90:1171-1202.

Sögaard, M., A. Kadziola, R. Haser und B. Svensson. 1993. Site-directed mutagenesis of histidine 93, aspartic acid 180, glutamic acid 205, histidine 290, and aspartic acid 291 at the active site and tryptophan 279 at the raw starch binding site in barley alphaamylase 1. J Biol Chem 268:22480-4.

Spezio, M., D. B. Wilson und P. A. Karplus. 1993. Crystal structure of the catalytic domain of a thermophilic endocellulase. Biochemistry 32:9906-16.

Stark, A. und R. B. Russell. 2003. Annotation in three dimensions. PINTS: Patterns in Nonhomologous Tertiary Structures. Nucleic Acids Res 31:3341-4. 
Steinke, C. 2004. Präparation und röngenkristallographische Untersuchungen an archaebakteriellen Box C/D sRNPs und einer neuartigen Glukosyltransferase aus Thermotoga maritima MSB8. Dissertation zur Erlangung des Doktorgrades der Mathematisch-Naturwissenschaftlichen Fakultäten der Georg-August-Universität Göttingen.

Stetter, K. O. 1999. Extremophiles and their adaptation to hot environments. FEBS Lett 452:22-5.

Stryer, L. 1995. Biochemie, 4. Aufl. Spektrum Akademischer Verlag, Heidelberg.

Teplyakov, A., G. Obmolova, P. P. Khil, A. J. Howard, R. D. Camerini-Otero und G. L. Gilliland. 2003. Crystal structure of the Escherichia coli YcdX protein reveals a trinuclear zinc active site. Proteins 51:315-8.

Thiemann, V., C. Donges, S. G. Prowe, R. Sterner und G. Antranikian. 2004. Characterisation of a thermoalkali-stable cyclodextrin glycosyltransferase from the anaerobic thermoalkaliphilic bacterium Anaerobranca gottschalkii. Arch Microbiol 182:226-35.

Toda, H., K. Kondo und K. Narita. 1982. The Complete Amino Acid Sequence of TakaAmylase A. Proc. Jpn. Acad. 58:208-212.

Tonozuka, T., S. Mogi, Y. Shimura, A. Ibuka, H. Sakai, H. Matsuzawa, Y. Sakano und T. Ohta. 1995. Comparison of primary structures and substrate specificities of two pullulan-hydrolyzing alpha-amylases, TVA I and TVA II, from Thermoactinomyces vulgaris R-47. Biochim Biophys Acta 1252:35-42.

Towbin, H., T. Staehelin und J. Gordon. 1979. Electrophoretic transfer of proteins from polyacrylamide gels to nitrocellulose sheets: procedure and some applications. Proc Natl Acad Sci U S A 76:4350-4.

van den Elsen, J. M., D. A. Kuntz und D. R. Rose. 2001. Structure of Golgi alphamannosidase II: a target for inhibition of growth and metastasis of cancer cells. Embo J 20:3008-17.

van der Rest, M. E., C. Lange und D. Molenaar. 1999. A heat shock following electroporation induces highly efficient transformation of Corynebacterium glutamicum with xenogeneic plasmid DNA. Appl Microbiol Biotechnol 52:541-5.

Vargas, M. und K. M. Noll. 1996. Catabolite repression in the hyperthermophilic bacterium Thermotoga neapolitana is independent of cAMP. Microbiology 142 (Pt 1):139-44.

Varrot, A., T. P. Frandsen, I. von Ossowski, V. Boyer, S. Cottaz, H. Driguez, M. Schulein und G. J. Davies. 2003. Structural basis for ligand binding and processivity in cellobiohydrolase Cel6A from Humicola insolens. Structure (Camb) 11:855-64.

Varrot, A., V. L. Yip, Y. Li, S. S. Rajan, X. Yang, W. F. Anderson, J. Thompson, S. G. Withers und G. J. Davies. 2005. NAD $(+)$ and Metal-ion Dependent Hydrolysis by Family 4 Glycosidases: Structural Insight into Specificity for Phospho-beta-dglucosides. J Mol Biol 346:423-35. 
Veith, B. 2001. Die thermostabilen alpha-Glucosidasen AglB aus Thermotoga maritima MSB8 und MalA aus Thermotoga neapolitana NS-E:Expression, Reinigung und biochemische Charakterisierung der rekombinanten Enzyme. Diplomarbeit am Institut für Mikrobiologie und Genetik, Universität Göttingen, unveröffentlicht.

Vihinen, M. und P. Mäntsälä. 1989. Microbial amylolytic enzymes. Crit Rev Biochem Mol Biol 24:329-418.

Wang, X. Y., F. G. Meng und H. M. Zhou. 2004. The role of disulfide bonds in the conformational stability and catalytic activity of phytase. Biochem Cell Biol 82:329334.

Wiegel, J. 1998. Anaerobic alkalithermophiles, a novel group of extremophiles. Extremophiles 2:257-67.

Winterhalter, C., P. Heinrich, A. Candussio, G. Wich und W. Liebl. 1995. Identification of a novel cellulose-binding domain within the multidomain $120 \mathrm{kDa}$ xylanase XynA of the hyperthermophilic bacterium Thermotoga maritima. Mol Microbiol 15:431-44.

Yanish-Perron, C., J. Vieira und J. Messing. 1985. Improved M13 phage cloning vectors and host strains: nucleotide sequences of M13mp18 and pUC19 vectors. Gene 33:103109.

Yeh, A. P., Y. Hu, F. E. J. Jenney, M. W. Adams, and D. C. Rees. 2000. Structures of the superoxide reductase from Pyrococcus furiosus in the oxidized and reduced states. Biochemistry 39:2499-2508.

Zehnder, A. J. und K. Wuhrmann. 1976. Titanium (III) citrate as a nontoxic oxidationreduction buffering system for the culture of obligate anaerobes. Science 194:1165-6.

Zimmermann, A. L., H. F. Terenzi und J. A. Jorge. 1990. Purification and properties of an extracellular conidial trehalase from Humicola grisea var. thermoidea. Biochim Biophys Acta 1036:41-6.

Zou, J., G. J. Kleywegt, J. Stahlberg, H. Driguez, W. Nerinckx, M. Claeyssens, A. Koivula, T. T. Teeri und T. A. Jones. 1999. Crystallographic evidence for substrate ring distortion and protein conformational changes during catalysis in cellobiohydrolase Ce16A from Trichoderma reesei. Structure Fold Des 7:1035-45. 


\section{Anhang}

Anhang A: Alignment der Aminosäuresequenzen von AmyB-Tm, AmyB-Tt und der GTase aus T. litoralis.

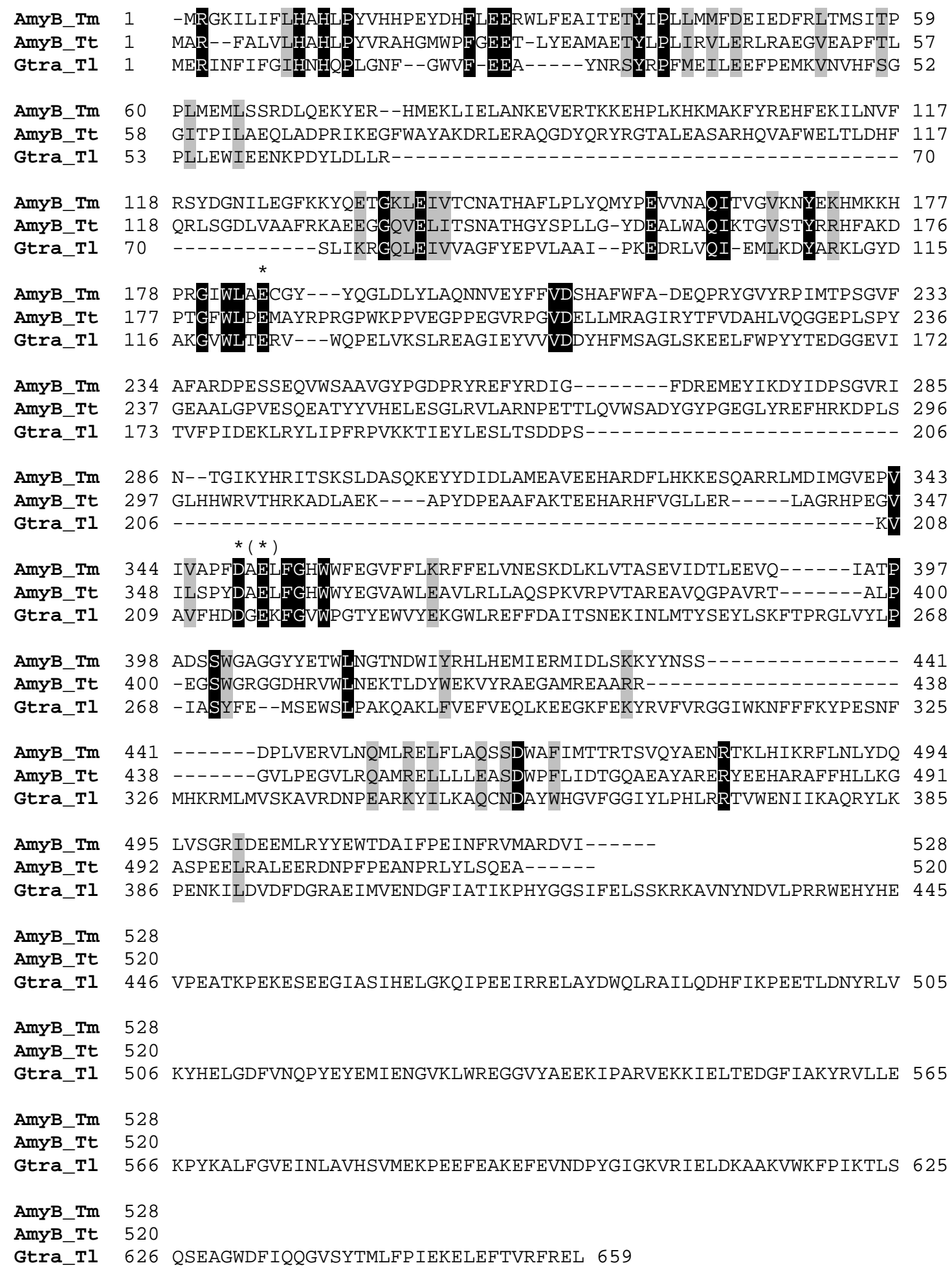


Anhang B: Alignment der Aminosäuresequenzen von TTC1540 (T. thermophilus HB27) und Tt1467 (T. thermophilus HB8).

Tth_HB27

Tth_HB8

Tth HB27

Tth_HB8

Tth HB27

Tth HB8

Tth_HB27

Tth_HB8

Tth_HB27

Tth_HB8

Tth HB27

Tth_HB8

Tth

Tth_HB8

Tth_HB27

Tth HB8

Tth_HB27

Tth_HB8
MARFALVLHAHLPYVRAHGMWPFGEETLYEAMAETYLPLIRVLERLRAEGVEAPFTLGIT 60 MARFALVLHAHLPYVRAHGMWPFGEETLYEAMAETYLPLIRVLERLRAEGVEAPFTLGIT 60

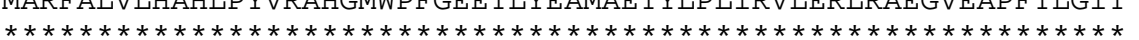

PILAEQLADPRIKEGFWAYAKDRLERAQGDYQRYRGTALEASARHQVAFWELTLDHFQRL 120 PILAEQLADARIKEGFWAYAKDRLERAQGDYQRYRGTALEASARHQVAFWELTLDHFQRL 120 $* * * * * * * * * . * * * * * * * * * * * * * * * * * * * * * * * * * * * * * * * * * * * * * * * * * * * * * * * * * *$

SGDLVAAFRKAEEGGQVELITSNATHGYSPLLGYDEALWAQIKTGVSTYRRHFAKDPTGF 180 SGDLVAAFRKAEEGGQVELITSNATHGYSPLLGYDEALWAQIKTGVSTYRRHFAKDPTGF 180

WLPEMAYRPRGPWKPPVEGPPEGVRPGVDELLMRAGIRYTFVDAHLVQGGEPLSPYGEAA 240 WLPEMAYRPKGPWKPPVEGPPEGVRPGVDELLMRAGIRYTFVDAHLVQGGEPLSPYGEAA 240

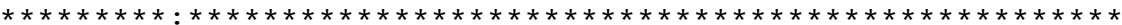

LGPVESQEATYYVHELESGLRVLARNPETTLQVWSADYGYPGEGLYREFHRKDPLSGLHH 300 LGPVESOEATYHVHELESGLRVLARNPETTLOVWSADYGYPGEGLYREFHRKDPLSGLHH 300

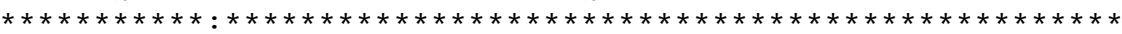

WRVTHRKADLAEKAPYDPEAAFAKTEEHARHFVGLLERLAGRHPEGVILSPYDAELFGHW 360 WRVTHRKADLAEKAPYDPEAAFAKTEEHARHFVGLLERLAGRHPEGVILSPYDAELFGHW 360

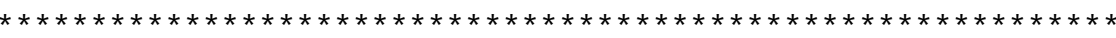

WYEGVAWLEAVLRLLAQSPKVRPVTAREAVQGPAVRTALPEGSWGRGGDHRVWLNEKTLD 420 WYEGVAWLEAVLRLLAQNPKVRPVTAREAVQGPAVRTALPEGSWGRGGDHRVWLNEKTLD 420

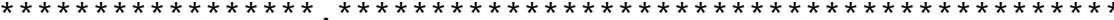

YWEKVYRAEGAMREAARRGVLPEGVLRQAMRELLLLEASDWPFLIDTGQAEAYARERYEE 480 YWEKVYRAEGAMREAARRGVLPEGVLRQAMRELLLLEASDWPFLMETGQAEAYARERYEE 480

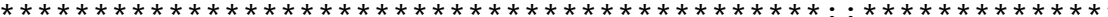

HARAFFHLLKGASPEELRALEERDNPFPEANPRLYLSQEA 520 HARAFFHLLKGASPEELRALEERDNPFPEADPRLYLFREA 520 $\star * * * * * * * * * * * * * * * * * * * * * * * * * * * * *: * * * * *::^{* *}$ 
Anhang C: Proteine der GHF 57, Stand 1.3.05

\begin{tabular}{|c|c|}
\hline Protein & Organismus \\
\hline Aq_720 & Aquifex aeolicus VF5 \\
\hline BF1000 & Bacteroides fragilis $\mathrm{YCH} 46$ \\
\hline BT4305 & Bacteroides thetaiotaomicron VPI-5482 \\
\hline$\alpha$-amylase 1 (AmyA) & Dictyoglomus thermophilum \\
\hline GSU3255 & Geobacter sulfurreducens PCA \\
\hline Gll1326 & Gloeobacter violaceus PCC 7421 \\
\hline$\alpha$-amylase (MJ1611) & Methanococcus jannaschii \\
\hline MMP1291 & Methanococcus maripaludis S2 \\
\hline MA4052 & Methanosarcina acetivorans str. C2A \\
\hline MA4053 & Methanosarcina acetivorans str. C2A \\
\hline MM0861 & Methanosarcina mazei Goe1 \\
\hline MM0862 & Methanosarcina mazei Goe1 \\
\hline MCA2118 & Methylococcus capsulatus str. Bath \\
\hline MCA2119 & Methylococcus capsulatus str. Bath \\
\hline NE2031 & Nitrosomonas europaea ATCC 19718 \\
\hline NE2032 (AmyA) & Nitrosomonas europaea ATCC 19718 \\
\hline Alr1310 & Nostoc sp. PCC 7120 \\
\hline PTO1240 & Picrophilus torridus DSM 9790 \\
\hline RB2160 & Pirellula sp. 1 \\
\hline PG1683 & Porphyromonas gingivalis W83 \\
\hline PAE3428 & Pyrobaculum aerophilum IM2 \\
\hline PAE3454 & Pyrobaculum aerophilum IM2 \\
\hline PAB0118 (amyA) & Pyrococcus abyssi \\
\hline PAB0122 (apu) & Pyrococcus abyssi \\
\hline$\alpha$-amylase (AmyA;PF0272) & Pyrococcus furiosus DSM 3638 \\
\hline a-galaktosidase (GalA, PF0444) & Pyrococcus furiosus DSM 3638 \\
\hline amylopullulanase (PF1935) & Pyrococcus furiosus DSM 3638 \\
\hline PH0193 ( $\alpha$-amylase) & Pyrococcus horikoshii OT3 \\
\hline PH0368 & Pyrococcus horikoshii OT3 \\
\hline a-amylase (AmyA;SSO1172) & Sulfolobus solfataricus P2 \\
\hline
\end{tabular}

$\begin{array}{lr}\text { EC\# } & \text { GenBank } \\ \text { n.d. } & \text { AE000704 } \\ & \text { NC_000918 } \\ \text { n.d. } & \text { AP006841 }\end{array}$

n.d. AE016944

3.2.1.1 X07896

n.d. AE017218

NC_002939

n.d. AP006572

3.2.1.1 $\quad$ NC_005125

NC_000909

n.d. BX957222

n.d. AE011117

NC_003552

n.d. AE011117

NC_003552

n.d. AE013311

NC_003901

n.d. AE013311

NC_003901

n.d. AE017282

n.d. AE017282

n.d. BX321863

NC_004757

n.d. BX321863

NC_004757

n.d. AP003585

NC_003272

n.d. AE017261

n.d. BX294136

NC_005027

n.d. AE017177

NC_002950

n.d. AE009930

NC_003364

n.d. AE009932

NC_003364

n.d. AJ248283

NC_000868

n.d. AJ248283

NP_125873

3.2.1.1 L22346

AE010151

NC_003413

3.2.1.22 AF195244

AE010167

NC_003413

3.2.1.41 AF016588

AE010287

NC_003413

3.2.1.1 AP000001

NC_000961

n.d. $\quad \mathrm{AP} 000002$

NC_000961

3.2.1.1 AE006733

NC_002754 
SSO0988

ST0817

ST1102

slr0337

amylopullulanase

4- $\alpha$-glukanotransferase (TK1809)

TK1436

TK1774

TK1830

4- $\alpha$-glukanotransferase

amylopullulanase (Apu)

Ta0129

Ta0339

$\alpha$-amylase (TVG0421416)

AmyA

Tll1277

TTC1828

TTHA0158

TDE1395

TP0147

Sequence 4 Patent US 5958751

( $\alpha$-Galaktosidase)

Sequence 4 Patent US 6644756
Sulfolobus solfataricus P2

Sulfolobus tokodaii 7

Sulfolobus tokodaii 7

Synechocystis sp. PCC 6803

Thermococcus hydrothermalis

Thermococcus kodakaraensis KOD1

Thermococcus kodakaraensis KOD1

Thermococcus kodakaraensis KOD1

Thermococcus kodakaraensis KOD1

Thermococcus litoralis

Thermococcus litoralis

Thermoplasma acidophilum DSM1728

Thermoplasma acidophilum DSM1728

Thermoplasma volcanium GSS1

Thermoproteus tenax

Thermosynechococcus elongatus BP-1

Thermus thermophilus HB27

Thermus thermophilus HB8

Treponema denticola ATCC 35405

Treponema pallidum subsp. pallidum str. Nichols

Unknown

Unknown.
3.2.1.1 AE006718 NC 002754

n.d. AP000983

NC_003106

n.d. AP000985

NC 003106

n.d. D63999

NC_000911

3.2.1.41 AF113969

2.4.1.- $\quad$ D87907

AP006878

n.d. AP006878

n.d. AP006878

n.d. AP006878

2.4.1.- D88253

3.2.1.1 AB054186

3.2.1.41

n.d. AL445063

NC 002578

n.d. AL445064

NC_002578

n.d. AP000992

NC_002689

n.d. AJ621296

n.d. AP005373

NC_004113

n.d. AE 017307

NC_005835

n.d. AP008226

n.d. AE017250

NC_002967

n.d. AE001199

NC_000919

n.d.

n.d. 


\section{Danksagung}

Ich danke Prof. Dr. W. Liebl für die Betreuung dieser Arbeit, insbesondere für die Bereitschaft, sich wenn nötig die Zeit zu nehmen, über auftauchende Probleme ausführlich nachzudenken.

Prof. Dr. G. Gottschalk danke ich für die Übernahme des Korreferats.

Prof. Dr. R. Ficner und Dr. A. Dickmanns danke ich für die nette Zusammenarbeit bei der Kristallisation von AmyB-Tm.

Mein besonderer Dank gilt allen derzeitigen und ehemaligen Mitgliedern der Arbeitsgruppe Angel Angelov, Anika Apelles, Patrique Arthur, Mechthild Bömeke, Susan Brandenburg, Marta Brewinska, Julia Busse, Christian Elend, Elke Heinz, Volker Hoffmann, Krassimira Ivanova, Jessica Jabin, Jörg Kleine, Steve Klopfleisch, Sabrina Koßmehl, Susanne Keese, Monika Nöller, Christina Schipper, Christel Schmeißer, Inga Schulte, Wolfgang Streit, Andzelika Solczyk, Andrea Thürmer, Mladen Tzevtkov, Alexandra Uesbeck, Sonja Voget, Anne Vor, Jörn Voß und Silja Wittenberg - für die einzigartig freundschaftliche Atmosphäre im Labor und ihre zuverlässige Unterstützung.

Vor allem möchte ich mich bei Carsten Raasch, Ole Fütterer, Ute Ludwig und Martin Armbrecht bedanken, von denen ich im Labor, über das Labor und außerhalb des Labors unsagbar viel gelernt habe.

Heike, Sonja, Christel, Christian und Angel danke ich für das Korrekturlesen dieser Arbeit.

Nicht zuletzt danke ich meinen Eltern für ihre fortwährende Unterstützung während meines Studiums und meiner Doktorarbeit. 


\section{$\underline{\text { Lebenslauf }}$}

1. Juli 1975

1982-1986

1986-1992

1992-1995

Mai 1995

Oktober 1995

Juli 1997

September 1997-

Juli 1998

Februar 2001

Mai 2001-

November 2001

Januar 2002
Geburt in Göttingen

Besuch der Grundschule in Witzenhausen

Besuch der Gesamtschule in Witzenhausen

Besuch der Gymnasialen Oberstufe der Rhenanus-Schule in Bad Sooden-Allendorf

Abitur

Immatrikulation an der Georg-August-Universität zu Göttingen im Fach Biologie

Vordiplom in den Fächern Mikrobiologie, Botanik, Anorganische- und Physikalische Chemie

Studium an der University of California, Santa Cruz, mit einem Stipendium des Kalifornischen Studienzentrums der Georg-AugustUniversität

Diplomprüfung in den Fächern Mikrobiologie, Genetik und Organische Chemie

Experimentelle Diplomarbeit unter Anleitung von Prof. Dr. W. Liebl mit dem Titel ,Klonierung, Expression und Charakterisierung einer $\alpha$ Amylase aus Anaerobranca gottschalkii’

Beginn der experimentellen Arbeit zur vorliegenden Dissertation 